\title{
Physiotherapy and sick leave in patients with chroniclow back pain
}

Citation for published version (APA):

Kool, J. P. (2005). Physiotherapy and sick leave in patients with chroniclow back pain. [Doctoral Thesis, Maastricht University]. https://doi.org/10.26481/dis.20051213jk

Document status and date:

Published: 01/01/2005

DOI:

10.26481/dis.20051213jk

Document Version:

Publisher's PDF, also known as Version of record

\section{Please check the document version of this publication:}

- A submitted manuscript is the version of the article upon submission and before peer-review. There can be important differences between the submitted version and the official published version of record.

People interested in the research are advised to contact the author for the final version of the publication, or visit the DOI to the publisher's website.

- The final author version and the galley proof are versions of the publication after peer review.

- The final published version features the final layout of the paper including the volume, issue and page numbers.

Link to publication

\footnotetext{
General rights rights.

- You may freely distribute the URL identifying the publication in the public portal. please follow below link for the End User Agreement:

www.umlib.nl/taverne-license

Take down policy

If you believe that this document breaches copyright please contact us at:

repository@maastrichtuniversity.nl

providing details and we will investigate your claim.
}

Copyright and moral rights for the publications made accessible in the public portal are retained by the authors and/or other copyright owners and it is a condition of accessing publications that users recognise and abide by the legal requirements associated with these

- Users may download and print one copy of any publication from the public portal for the purpose of private study or research.

- You may not further distribute the material or use it for any profit-making activity or commercial gain

If the publication is distributed under the terms of Article $25 \mathrm{fa}$ of the Dutch Copyright Act, indicated by the "Taverne" license above, 


\section{Physiotherapy and sick leave in patients with chronic low back pain}


ISBN 9052785058

Lay-out: Conny de Zwart, UM Epidemiologie, Maastricht Cover photo: Andrea Reissner

Cover design: Datawyse

Printing: Datawyse, Universitaire Pers Maastricht

by Jan P. Kool

All rights reserved. No part of this thesis may be reproduced or transmitted in any form by any means, electronic or mechanical, including photocopying, recording or any information storage or retrieval system, without the permission of the author, or, when appropriate, from the publishers of the publications. 


\section{Physiotherapy and sick leave in patients with chronic low back pain}

\section{PROEFSCHRIFT}

Ter verkrijging van de graad van doctor

aan de Universiteit Maastricht,

op gezag van de Rector Magnificus,

Prof, mr. G.P.M.F. Mols

volgens het besluit van het College van Decanen,

in het openbaar te verdedigen,

op dinsdag 13 december 2005 om 14.00 uur

door

Jan Pieter Kool

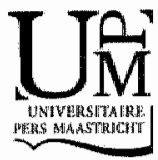




\section{Promotores:}

Profdr. R.A. de Bie

Prof dr.ir. P.A. van den Brandt

\section{Beoordelingscommissie:}

Prof. dr. S. van der Linden (voorzitter)

Prof. dr. W. van den Heuvel iRv Kenniscentrum voor Revalidatie en Handicap Hoensbroek

Prof. dr. H. van Mameren

Dr. M.F. Reneman

Academisch Centrum voor Arbeid en Gezondheid Haren

Prof. dr. M. van Tulder

EMGO Instituat VU Amsterdam

The randomised controlled trial presented in this thesis was supported by a grant from the Swiss Federal Office of Health. Financial support for the printing of this thesis has been kindly provided by the Rehabilitation Centre Valens 


\section{Content}

1. Introduction.

2. Predictive tests for non-return to work in patients with chronic low back pain

3. Exercise reduces sick days in patients with nonacute nonspecific low back pain: a meta-analysis

4. Increasing days at work using function-centred rehabilitation in nonacute nonspecific low back pain: three-month results from a randomized controlled trial.

5. Function-centered rehabilitation increases days at work in patients with non-acute nonspecific low back pain: one year results of a randomised controlled trial.

6. Inconsistency of test performance during functional capacity testing and medico-legal consequences.

7. The influence of a functional capacity evaluation on fitness for work certificates in patients with nonspecific chronic low back pain

8. Reconditioning of patients with chronic low back pain: the influence of the symptom magnification syndrome

9. General discussion

10. Summary 165 Samenvatting - Zusarnmenfassung - Dankwoord - About the author. 



\section{Chapter 1}

\section{Introduction}

After graduating in physiotherapy in 1980 in the Netherlands, I went to Switzerland where 1 specialized in the rehabilitation of patients with nieurological disorders. At that time almost no results from clinical research existed and treatment was either theory or expert based. Slowly, rehabilitation research developed and I was very interested in the results. Although I could read the publications, my methodical knowledge was insufficient and I was unable to critically assess the information. A special topic of personal interest was the repeated application of casts to increase muscle length. I used this method with neurological patients with contractures in the presence of spasticity. My first publication summarized the available information about the theoretical background of muscle length adaptation. Most experiments were conducted with rabbits and other animals. It took me more than two years to write this non-systematic review.

The first and probably most important milestone of my scientific career was the decision to study research methodology at Maastricht University. The two-year curriculum was planned and organized by the Department of Epidemiology. I remember talking to a young Dutch physiotherapist at a party of our physiotherapy department in December 1991. He had studied movement sciences at Maastricht University and told me that a two-year course in research in physiotherapy was planned to start in 1992. I immediately thought I wanted to do this, despite the fact that, at that time, no jobs were 
available for research in physiotherapy. The time in Maastricht with my wife and our three children would not have been possible without the financial support of my employer, the Rehabilitation Centre in Valens, Switzerland.

After two inspiring years in Maastricht I returned to Valens. It was far from clear whether I would ever have the opportunity to conduct a large research project. An important field with possibilities for clinical research was the rehabilitation of patients with nonspecific chronic low back pain (LBP). Until a few years ago, the majority of patients in our Rehabilitation Centre had specific or 'mechanical' nusculoskeletal disorders. Our focus, therefore, was biomedical, and manual therapists were the key experts in the physiotherapy department. However, over the years, we saw an increasing number of patients with nonspecific chronic LBP. There had been complaints we could not explain with the biomedical model. Many of us felt that passive treatments, including manual therapy, were ineffective for these patients. As a consequence, we developed a more active, function centred treatment (FCT).

For quite a number of patients pain increased with FCT. The complaints of several patients reached Otto Knilisel, Head of the Rheumatology Department. 1 remember that he discussed one of these patients with Peter Oesch. I consider this discussion to be the second milestone, initiating our research. Otto Knüsel asked Peter Oesch to treat this patient with manual therapy twice a day in order to reduce pain. Peter explained why he thought the complaints were not primarily mechanical. He suggested not focusing the treatment on the patient's pain, treat hands-off instead of hands-on and increase activity in spite of the pain. Otto agreed but he was not satisfied with Peter's assessment method and asked him to look for an assessment instrument to support fiuture similar observations. We started using the assessment of abnormal behavioural responses to examination, described by Gordon Waddell.' We made several unsystematic observations suggesting that our treatment was only minimally effective with patients who had a high pain intensity and preliminary cessation of two active tests. To assess the predictive value of these tests for non-return to work, we planned a prospective cohort study about patients with non-acute LBP, presented in Chapter 2.

After conducting the cohort study, we wanted to evaluate the effectiveness of our FCT by means of a randomised controlled trial (RCT). Although we thought that our shift from a pain centred treatment $(\mathrm{PCT})$ towards an $\mathrm{FCT}$ would improve the results, no studies were available showing whether one treatment was more effective than the other. Even though the guidelines advocated return to work and normal activities as primary goals of treatment since 1987, there was no clear evidence that exercise actually leads to an increase in work days ${ }^{2}$ Another question was which work related outcome was most appropriate for the use in an RCT. Measuring time until the return to work had the disadvantage that subsequent sick leave was disregarded. Sick days had been used in several previous studies but we could not find a proper solution for the 
classification of patients who lost their job during the year following the study, which occurred quite frequently and was probably associated with their previous sick leave. Therefore, we conducted a meta-analysis of the effect of exercise or activity on work related outcomes in patients with non-acute nonspecific LBP, presented in Chapter 3.

In 1999, I spent two hard-working but extremely valuable days in a restaurant in Maienfeld with Peter Oesch and Stefan Bachmann. We developed the research protocol for the RCT. My responsibility was the methodology of the study while Peter Oesch further developed the treatments and Stefan Bachmann focussed on medicall exclusion criteria, the use of medication, and patient recruitment. After a long discussion about the power of an RCT I could convince Peter and Stefan to exclude patients with two or more positive predictive tests for non-return to work. In the RCT we analysed patients with non-acute non-specific LBP and compared the number of days they at work after three weeks of FCT or PCT. Secondary outcomes were pain, disability and functional capacity. We also wanted to know whether the treatment had a larger effect in certain subgroups of patients, and which factors determined the result. Our effort was rewarded by the Swiss Federal Office of Health who supported our RCT (grant 00.00437). This third milestone enabled me to plan my PhD thesis. I contacted Rob de Bie and Piet van den Brandt. The results of the RCT after three months and one year are described in chapters 4 and 5 .

Functional Capacity Evaluations (FCEs) are frequently mentioned in this thesis. They take a central place in work related rehabilitation. We use Isernhagen Work Systems FCEs and assess work related physical demands by observing 23 tasks in a standardized manner. ${ }^{3}$ Several of these tasks concern lifting and carrying loads. The Disability Insurance company refers patients with musculoskeletal disorders to our rehabilitation centre to assess their remaining work-related physical capacity. During an FCE, the patient's full effort within safety limits is needed in order to determine his or her capacity. Multiple inconsistencies in tasks are considered to indicate submaximal effort and performance. In this case, the patient's remaining physical capacity is set at a higher level. If the FCE report shows inconsistent results, the Disability Insurance will decide on a lower level of disability, resulting in a smaller disability allowance. Patients frequently disagree with the decision of the Disability Insurance and go to court. As a consequence, the FCE-reports are increasingly used as evidence in medico-legal issues. It is therefore important to record any inconsistencies systematically in the FCE-report. I was interested in the psychometric properties of the checklist for the consistency of FCE results. Consequently, we investigated the internal consistency of the FCE'S checklist for test consistency. The results are presented in Chapter 6.

We used FCE results in our RCT for several purposes: In FCT, work related treatment is based on the results of the FCE. Secondly, lifting capacity was an important secondary outcome. Thirdly, the final FCE results of the FCT group were used to determine fitness for work after rehabilitation. The question arose whether the FCE results could improve 
the quality of fitness for work certificates and infuence the physicians" restrictions to working capacity. We analysed this issue and I present the results in Chapter 7.

An important question was whether endurance and strength training is possible for all patients with nonspecific LBP. As I have already mentioned, we decided to exclude patients from our RCT if they had wo or more positive predictive tests for non-return to work. Two of these tests assessed if a patient was capable to perform light physical activity for two minutes. This can be regarded a minimal requirement for rehabilitation using activity and exercise. Other experts, however, regretted that we excluded these patients. Therefore, we conducted a study in which we compared the effect of three weeks of intensive training on two groups of patients; one group with severe, the other with low level of symptoms and activity. The results of this study are described in Chapter 8.

In Chapter 9, I discuss the main results, the limitations, and the impact of this research on physiotherapy and on the rehabilitation of patients with LBP in Switzerland. This thesis ends with personal reconmendations for future research and developments.

\section{References}

1. Waddell G, MeCulloch JA, Kummel E, Venner RM. Nonorganic physical signs in low-back pain. Spine $1980 ; 5(2), 117-125$

2. Spitzer. Quebec Task Jorce Report. Spine 1987;12(7):S10-S53

3. Isernhagen \$J. Functional capacity evaluation. Work Injury: Management and Prevention. Oaithersburg: Aspen Publishers Inc, 1988: 139-174 


\section{Chapter 2}

\section{Predictive tests for non-return to work in patients with chronic low back pain}

Jan P. Kool ', Peter R. Oesch ${ }^{2}$, Rob A. de Bie ${ }^{3}$

Affiliations of the authors

${ }^{1}$ Research Dpt., Rehabilitation Centre Valens, Switzerland

${ }^{2}$ Dpt. of Work Rehabilitation, Rehabilitation Centre Valens, Switzerland ${ }^{3}$ Dpt. of Epidemiology, Maastricht University, The Netherlands.

European Spine Journal 2002;11:258-266 


\section{Abstract}

Introduction: Return to work (RTW) is the primary goal in the rehabilitation of patients with chronic low back pain. In spite of expensive rehabilitative efforts, many patients do not RTW. To increase cost effectiveness, predictive tests for non-RTW are needed to select patients for rehabilitation. The reliability of these tests must be high, to prevent exclusion of patients who might improve. This study evaluates the reliability and predictive validity of four tests and the following psychosocial factors for non-RTW: nationality, off-work duration, unemployment and work load.

Methods: Prospective cohort study of 99 patients with chronic low back pain. Upon entry, physical work load, time off work, unemployment and nationality were recorded. The study investigated four tests with an anticipated prognostic value for non-RTW: the Numeric Pain Rating Scale (NRS, 9-10 of a maximum of 10), the Step Test and Pseudo Strength Test (precipitous cessation) and Behavioural Signs. After 12 months, the RTW rate was obtained from the physicians responsible for sick-listing by postal survey.

Results: The response rate regarding RTW was $91 \%$ at 1 year. The RTW rate at 1 year Was $20 \%$. All investigated tests significantly correlated with non-RTW. Regression analysis showed that the best prediction of non-RTW was obtained when at least two out of the four tests were positive (positive predictive value 0.97 , sensitivity $0.45 \%$. Unemployment, time off work, nationality and physical work load were less predictive.

Conclusion: The results show that the combination of the four prognostic tests allows a very reliable prognosis of non-RTW. The cost effectiveness of rehabilitation aiming at RTW will, therefore, be increased by excluding patients with two or more positive tests. 


\section{Introduction}

\section{EPIDEMIOLOGY}

Chronic low back pain (CLBP), with its associated disabilities and compensations, is a common problem in western societies that has reached 'epidenic proportions"." Between 1986 and 1996, Switzerland showed a $4.7 \%$ annual increase in the number of persons receiving a disability pension due to musculoskeletal problems (personal communication, F. Donini). Regions with a higher unemployment rate showed a greater increase in disability. ${ }^{4}$

Non-medical factors such as unemployment apparently influence medical opinion. regarding an individual's working capacity, with the consequence that the unemployed are more frequently diagnosed as being disabled.? Patients medically diagnosed as unable to perform their present work have the right to receive help from the Swiss Disability Insurance Corporation. All possible vocational measures are considered before a disability pension is granted. Vocational measures are usually coordinated by a social worker and may consist of advisory consultations, adaptive training, workplace visits and assistance in finding a job adapted to the functional capacity of the patient.

\section{ILLNESS BEHAVIOUR.}

CLBP disability is mostly attributed to non-specific low back pain (NSLBP) ${ }^{6,33}$, occurring without identifiable specific anatomical or neurophysiological causative factors. Known causes for specific back pain are vertebral fracture, tumour, infection, inflammatory diseases, nerve root compression, spondylolisthesis, spinal stenosis and definite instabillity. Evidence suggests that fewer than $15 \%$ of individuals with back pain can be assigned to one of these specific back pain categories, ${ }^{25}$ The patient witlin NSLBP cannot be viewed as suffering solely from a nociceptive stimulation, but rather as having a problem involving biological, psychological and social aspects, all of which must be analysed from the perspective of a biopsychosocial model. ${ }^{6,32}$

Increased behavioural responses during the clinical examination are often observed in patients with CLBP. ${ }^{33}$ Pain drawings may show a spreading in the painful areas, and patients may report a very high pain intensity, even at rest. Many patients tend to catastrophise, they are afraid that activity might lead to further spinal damage. Fear avoidance behaviour is the consequence, causing a decrease in activity. Positive Behavioural Signs ${ }^{34}$ should be understood as a response to examiination affected by fear in the context of recovery from injury and the development of chronic incapacity. ${ }^{17}$ 
This study investigates the performance of the Step Test and the Pseudo Strength Test (see Methods; Fig. 1, Fig. 2). The inability to perform these tests cannot be explained by musculoskeletal pathology and may be regarded as behavioural signs. The reduction of physical activity resulting from illness behaviour causes a reduction in physical capacity due to disuse.

\section{"Two out of Four"}

Single tests may have a greater risk of giving false-positive results, causing a decreased positive predictive value and specificity. Sensitivity of one test may also be limited. Therefore the Behavioural Signs, the Step Test, the Pseudo Strength Test and a pain score of 9 or 10 were combined into the "Two out of Four' test, which was considered positive when two or more of these four tests were positive.

\section{PSYCHOSOCIAL FACTORS WTH AN EXPECTED PROGNOSTIC VALUE FOR OUTCOME}

The main purpose of this study was the investigation of the previously described predictive tests. Because psychosocial factors are known to be important predictors for RTW, we also investigated the influence of work load, off-work duration, unemployment and nationality for RTW.

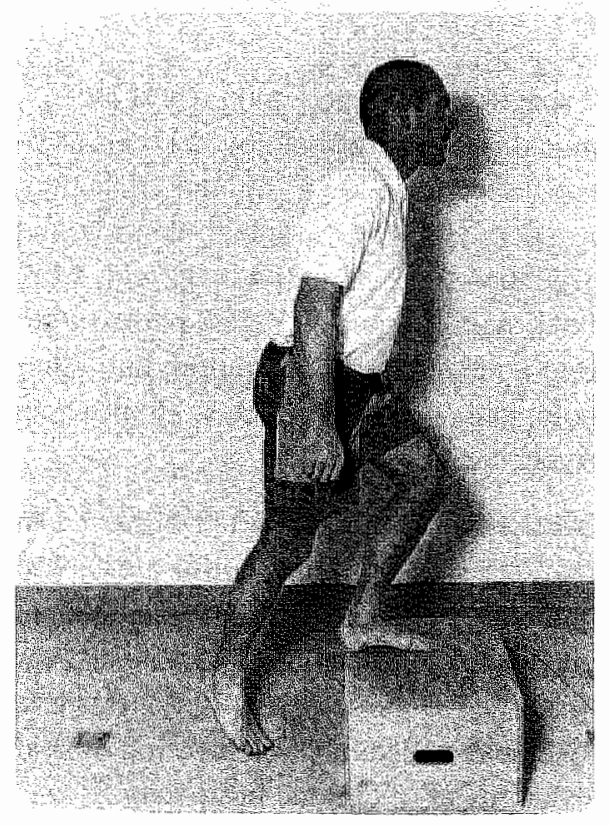

Fig. 1: The Step Test. The patient is asked to step up and down a 30 -cm-high step for 3 minutes Precipitous cessation of the test is counted as a pasitive test 


\section{STATISTICAL ANALYSIS}

Logistic regression analyses were performed to evaluate which of the previously mentioned tests and psychosocial factors were significantly associated with non-RTW. The prior probability (PP) of RTW and non-RTW was determined. The absolute risk increase (ARI) measures the gain in predictive knowledge obtained from the test result. The maximum value for the ARI depends on the PP (ARI $\leq 1-P P)$.

For each factor showing a significant association with non-RTW we determined the positive predictive value (PPV), the probability of non-RTW in patients with a positive factor. In a perfect test the $P P V=1$.

A positive predictive test for non-RTW indicates an increased probability of non-RTW. The negative predictive value expresses the ability of the test to predict RTW. Predictive tests must at least be able to predict either RTW or non-RTW in a reliable manner. Only a very good test fulfils both aims.

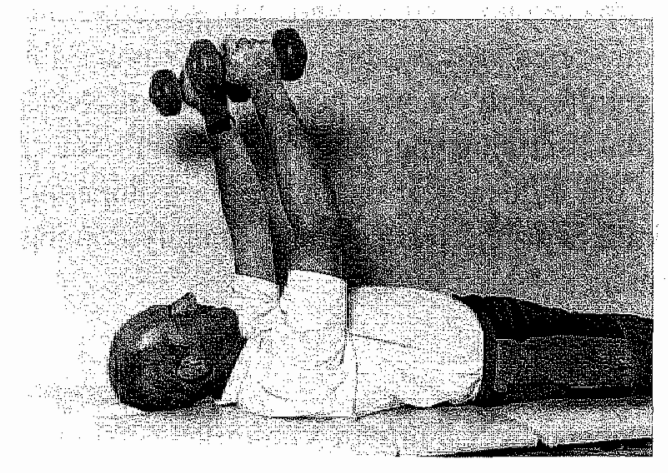

Figl. 2: Pseudo Strength Test. The patient is in a supine position and holds two $3 \mathrm{~kg}$ weights against gravily with straight elbows and a 90 : shoulder flexion for 2 min. Precipitous cessation of the trist is counted as a posiliwe terst

\section{RETURN TO WORK: THE PRIMARY GOAL OF TREATMENT}

In terms of lost work days and the failure of modern medicine to diagnose the causative anatomical structure and to relieve the pain and disability in chronic pain patients, nonspecific disability constitutes a continuing challenge. These problems have occasioned a change in the approach to treatment over the past few decades. Return to work (RTW), and not pain relief, has become the primary goal in the treatment of patients with CLBP. ${ }^{25}$ To achieve this goal, an interdisciplinary evaluation and an intensive treatment, including work assessment, ergonomic intervention, postural information and strengthening exercises, is recommended. ${ }^{1,25}$ Research results are inconclusive as to the effectiveness of rehabilitation programmes to improve RTW in patients with CLBP. ${ }^{27}$ RTW rates vary between 23 and $85 \% .^{19.23}$ Different selection procedures, unknown 
predictive factors for RTW and varying definitions of RTW may have influenced the results. For example, in a randomized clinical trial on 542 patients, Mitchell reported an impressive rate of $79 \%$ 'full return to previous work". If, however, the average of more than 400 sick days during the 2-year follow-up period ${ }^{20}$ is taken into account, the investigated patients appear to be considerably more disabled than the classification as 'full return to work' might imply. In our study, RTW is defined as an improvement in actual work activity after one year, and patients on vocational measures were regarded as non-RTW.

\section{PREDICTION OF NON-RETURN TO WORK}

This study investigates factors predicting non-RTW. Positive Behavioural Signs ${ }^{34}$ are a reliable predictor for non-RTW after an intensive rehabilitation programme. ${ }^{12,35}$ A pilot study has shown that the Step Test, the Pseudo Strength Test and the reported pain intensity at initial examination also have the potential of being predictive for nonRTW. ${ }^{22}$ Known psychosocial predictors for non-RTW after conservative treatment in patients with CLBP are: time off work, low social status, poor job security and nationality. $2,10,18,28,32$ The outcome of a somatic-orientated rehabilitation programme for patients from the former Yugoslavia was significantly poorer than for that of Swiss patients. $^{28}$ We find it important to offer non-discriminating, objective tests to select patients for rehabilitation, and will evaluate the influence of nationality by comparing patients from the region of former Yugoslavia with the other patients mainly coming from Switzerland and its neighbouring countries.

\section{PuRpose}

The purpose of this study is to determine the predictive vallidity of a modified version of the Step Test, the Pseudo Strength Test and a pain intensity of 9 or 10 (Numeric Rating Scale) for non-RTW in patients with CLBP. The second aim is to determine whether the prediction of non- RTW can be improved by combining these tests with the Behavioural Signs. We also evaluated the predictive value of work load, nationality, time off work and employment status.

\section{MATERIALS AND METHODS}

\section{Design}

The investigated predictive tests were analysed in a longitudinal prospective cohort study. Assessment and treatment of the patients were not altered for this study. Informed consent was obtained from all patients. The study design was approved by the ethical committee of the clinic. 
The patients were referred to the clinic by their treating physicians without pre-selection by an insurance company of the clinic. Patients generally had suffered a long history of LBP. In most of these "end of the line" patients, a variety of diagnostic procedures and many treatments had been performed.

All patients fulfilling the following admission requirements were consecutively included in the study.

1. To enable RTW at follow-up, the age range was limited to 20 -60 years.

2. Only patients willing to go back to full time work were included.

Therefore, housewives and part-time employees were excluded.

And all included patients had:

3. Taken more than 6 weeks off work during the preceding 6 months because of CLBP

4. No comorbidity contributing to disability and sickness leave, and

5. Sufficient understanding of either German, Serbo-Croatian, Spanish or Italian needed to fill out the questionnaires

Follow-up questionnaires were sent to the patients and the treating physicians 12 months after treatment (Table 1). Non-responders received a reminder and a phone call. The physicians were not informed about the results of the predictive tests.

Table 1: Measurements (NRS Numeric Rating Scale)

\begin{tabular}{|c|c|c|}
\hline Measurements. & Entry & $12 \mathrm{months}$ \\
\hline Bahavioural Signins & $x$ & \\
\hline Pain Intensity NRS 0-10 & $x$ & $x$ \\
\hline Step Test & $x$ & \\
\hline Pseudo Strangth Test $x$ & $x$ & \\
\hline Disability (Roland and Morris Questionnaire? & $x$ & $x$ \\
\hline Vocational measures & $x$ & $x$ \\
\hline Work activity & $x$ & $x$ \\
\hline
\end{tabular}

\section{POPULATION, TREATMENT AND WORK STATUS}

The diagnosis was described according to the guidelines of the Quebec Task Force Report $^{25}$ (see Results and Table 4). According to the definition of Fordyce, the following four diagnostic codes are regarded as representative of a specific diagnosis: 
1. Pain with radiation to the lower limb in combination with neurological signs

2. Confrimed compression of a spinal nerve root

\section{Spinal stemosis}

\section{Low back pain less than 6 months following surgery}

Work activity at the time of I-year follow-up was recorded as a percentage of full-time activity. RTW was defined as an improvement in work activity. Patients were considered as non-RTW if their work activity was unimproved. Patients on vocational measures were regarded as non-RTW. Unemployed patients were also considered as non-RTW, because most patients lose their job as a consequence of LBP.

The physical work load was registered according to the classification of the US Department of Labour (max. load that has to be lifted at work: $1=0-5 \mathrm{~kg}, 2=5-10 \mathrm{~kg}$, $3=10-25 \mathrm{~kg}, 4=25-45 \mathrm{~kg}, 5>45 \mathrm{~kg}$ ). ${ }^{20}$ Disability was measured with the Roland and Morris Disability Questionnaire ${ }^{24}$ in order to describe the research population at entry and to investigate whether an improvement in disability correlates with an increased work activity.

\section{TESTS WITH AN RXXPECTED PROGNOSTIC VALUE FOR OUTCOME}

Pain intensity

Before the physical examination, the patient rated the current pain intensity on a Numeric Rating Scale (NRS 0-10). A pain intensity 260 of 9 or 10 was counted as a positive test. The guidelines for the assessment of psychosocial "Yellow Flags"13 describe risk factors for the early identification of chronicity in patients with CLBP, and interpret a pain intensity of 9 or 10 as "pain behaviour".

Step Test

The Step Test was originally designed to evaluate aerobic capacity. ${ }^{30}$ The patient is asked to step up and down a 30 -cm-high step for $3 \mathrm{~min}$, which requires four steps per cycle (Fig. 1). The initial stepping frequency is 96 (24 cycles per min). Patients were allowed to reduce speed to a comfortable level. The test does not increase the stress on the lumbar spine more then going up stairs. Precipitous cessation is counted as a positive test.

Pseudo Strength Test

In the Pseudo Strength Test, the patient lies in a supine position and is asked to hold two $3-\mathrm{kg}$ weights with straight arms against gravity for 2 min (Fig. 2). ${ }^{21}$ This test does not give any significant load to the lumbar spine or the spinal muscles, and can be 
performed by patients with acute radicular pain. Precipitous cessation is cotunted as a positive test.

Behavioural responses to examination

Waddell et al. first described behavioural or "nonorganic" signs as clinical signs that have a "predominantly nonorganic basis' in patients with L.BP. ${ }^{34}$ They described eight items and grouped them into five categories (Table 2). Waddell's definition was used to interpret the test as positive if at least three out of the five categories scored positive.

Table 2: Behravioural Signs

\begin{tabular}{|c|c|c|}
\hline Type of test & & Clinical signs \\
\hline \multicolumn{3}{|l|}{ Tenderness } \\
\hline Superficial & & $\begin{array}{l}\text { The skin is tender to light pinch over a wide lumbar area, A localised band in a } \\
\text { posterior primary ramus distribution may be caused by nerve irritation and should be } \\
\text { discounted. }\end{array}$ \\
\hline Deep & & $\begin{array}{l}\text { Tenderness is felt over a wide area. It is not localised to one structure, and often } \\
\text { extends to the thoracic spine, sacrum, or pelvis. }\end{array}$ \\
\hline \multicolumn{3}{|l|}{ Simulation tests } \\
\hline Axiall loading & & $\begin{array}{l}\text { Low-back pain is reported on vertical loading over the standing subject's skull by the } \\
\text { examiner's hands. Neck pain is common and should be discountted. }\end{array}$ \\
\hline Rotation & & $\begin{array}{l}\text { Back pain is reported when shoulders and pelvis are passively rotated in the same } \\
\text { plane, as the subject stands relaxed with the feet together. In the presence of root } \\
\text { irmitation, leg pain may be produced and should be discounted. }\end{array}$ \\
\hline \multicolumn{3}{|l|}{ Distraction Test } \\
\hline Straight leg raising & & $\begin{array}{l}\text { Straight leg raising is the most useful distraction test. The subjed whose back pain } \\
\text { has a non-organic component shows marked improwement in straight leg raising on } \\
\text { distraction as compared with formal lesting. }\end{array}$ \\
\hline \multicolumn{3}{|l|}{ Regional disturbances } \\
\hline Sensory & & $\begin{array}{l}\text { Sensory disturbances include diminished sensation to light touch, pinprick, and } \\
\text { somelimes other modalities, fitting a "stocking" rather than a dematomal pathern. }\end{array}$ \\
\hline Weakness & & $\begin{array}{l}\text { Weakmess is demonstrated on formal tesling by a partial cagwhed 'giwing way" of } \\
\text { many muscle groups that cannot be explained on a localised neurological basis. }\end{array}$ \\
\hline \multicolumn{3}{|l|}{ Overreaction } \\
\hline & 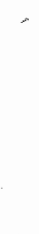 & $\begin{array}{l}\text { Overreaction during examination may take the form of disproportionate werbalisation, } \\
\text { facial expressions, muscle tension and lremor, collapsing, or sweating. The response } \\
\text { to procedures such as venipuncture or myelography provides additional intomation. } \\
\text { Judgements should, however, be made with caution, minimising the examiner's own } \\
\text { emotional reaction; there are considerable cutfural warialions, and it is wery easy to } \\
\text { introduce observer bias or to provoke this type of response unconsciousty. }\end{array}$ \\
\hline
\end{tabular}


To select prognostic tests for the future exclusion of patients from treatment, a limit for fallse-positive results was set at 0.05 . Therefore, the first requirement for the test is that the positive predictive value be $>0.95$. Optimal sensitivity is the second criterion for test selection. The significance level of the non-parametric correlation is displayed by the $x^{2}$ value.

Table 3 shows the formulas for the computation of the prior probability of non-RTW, the absolute risk increase, the positive and negative predictive value, the sensitivity and the specificity. Statistical analysis was performed using SPSS software.

Table 3: Predictive tests for non-retum to work (non RTW)

\begin{tabular}{lccc}
\hline NonRTW & RTW & \\
Posilive predictive test & $a$ & $b$ & $a+b$ \\
Negrative predictive test & $a$ & false positive & \\
& false negative & $d$ & $c+d$ \\
\hline & $a+c$ & $b+d$ & $a+b+c+d$ \\
\hline
\end{tabular}

$P P=$ Prior Probability $($ non-RTW $)=(a+c)(a+b+c+d)$

$A R I=$ Absiolute Risk increase $=a /(a+b)-(a+c) /(a+b+c+d)$

PPV $=$ Positive Predictwe Vallue $=a /(a+b)$

NPV = Negative Predictive Value $=\mathrm{d} /(\mathrm{c}+\mathrm{d})$

Se $=$ Sensilivity $=a /(a+c)$

$S p=S p e c i f i c i t y=d /(d+b)$

\section{Results}

\section{SUBIECTS}

Patients entered the study between January 1996 and December 1998. The average age of the 99 patients ( 84 male) was 41.8 years (SD 8.9 years). The median time off work because of LBP before rehabilitation was 26 weeks (range 6-349 weeks), including sick leave, time on a disability pension because of LBP and time out of work. Twenty-six percent of the patients were unemployed, $5 \%$ were unemployed and received a disability pension. The following nationalities were represented." region of former Yugoslavia $41 \%$, Switzerland $35 \%$, Italy $10 \%$, Portugal $5 \%$ and other countries $9 \%$. The physical work load was rated as 5 for $45 \%, 4$ for $25 \%, 3$ for $21 \%$ and 1 for $8 \%$ of the 
patients. Fifteen percent of the test population had been given a specific diagnosis. Table 4 shows the frequency of the different diagnostic categories. The 7 patients with symptomatic post-surgical status were classified as nonspecific because they had shown negative results on specific imaging techniques conceming compression of a spinal nerve root, instability or spinal stenosis.

Table 4: The incidence of the different diagnostic categonies

\begin{tabular}{|c|c|}
\hline $\begin{array}{l}\text { No, of patients } \\
(N=99)\end{array}$ & Diagnosis according to the Quebec Iask Force \\
\hline 7 & Pain without radialion \\
\hline 6 & Pain + radiation to extremily, proximally \\
\hline 30 & Pain + radiation to extremity, distally \\
\hline 7 & Pain + radiation to lower limb, neurologiccal signs \\
\hline 0 & Presumptive compression of aspinal nerve root \\
\hline 6 & Compression of a spinal nerve root \\
\hline 0 & Spinal stemosis \\
\hline 2 & Post-surgical stalus, $1-6$ months postoperative \\
\hline 17 & Symptomatic post-surgical stalus, $>6$ months postoperative \\
\hline 24 & Chronic pain syndrome \\
\hline
\end{tabular}

\section{RETURN TO WORK}

The response rate at follow-up regarding RTW was $91 \%$ at 12 months. We obtained the data regarding $\mathbb{R T W}$ from the treating physicians who, in Switzerland, are responsible for the determination of work activity. Among physicians, the reason for non-response at 12 months was the withdrawal of informed consent by one patient and an untraceable new address in eight patients.

Before rehabilitation, $96 \%$ of the patients had been off work. Four percent of the patients were on a partially reduced work activity because of low back pain. The rate of persons at work increased from $4 \%$ at entry to $26 \%$ at 3 months $(P<0.05)$, and then slightly decreased to $24 \%$ after 1 year. The RTW rate, the difference between the work rate before rehabilitation and after 1 year, was $20 \%$. Thirteen patients returned to full work activity, five worked $50 \%$ and three worked $25 \%$. 
At entry, $25 \%$ of the patients were in contact with the Swiss Disability Insurance Corporation for vocational measures. This percentage increased to $47 \%$ at 3 months and $53 \%$ at 1 year (Fig. 3 ). The number of patients receiving a disability pension increased from $10 \%$ at entry to $28 \%$ after 1 year. Approximately $50 \%$ of the patients with a disability pension received a full pension. The $25-75 \%$ pensions of the other patients were supplemented either by working at a reduced level (time or work load), or being sick-listed or receiwing unemployment benefit.

The correlation of improvement in the Roland Disability Questionnaire with RTW was positive, weak and not significant (Spearman $\rho=0.20, P=0.124$ ).

Fig. 3. Work status

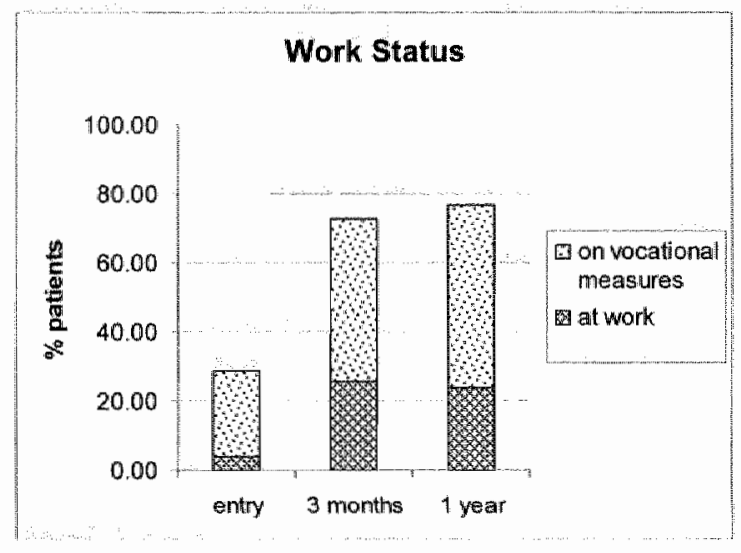

\section{PREDICTIVE TESTS AND PSYCHOSOCIAL FACTORS}

Table 5 shows the main results of this study: the reliability of the investigated tests in predicting non-RTW after 1 year. The results of all predictive tests were available from all patients. None of the patients showed comorbidity limiting the performance and interpretation of the Step Test and the Pseudo Strength Test. In all patients with precipitous cessation of the Pseudo Strength Test or the Step Test, the reason for discontinuation of the activity was an increase in back pain. None of the patients mentioned tiredness as the reason for stopping. The outcome concerning RTW at 1 year was obtained for $91 \%$ of the patients. 
Table 5: Positwe results in the Behavioural Signs and the three investigated tests significantly correlate with non-RTW. When two or more of these four tests ("Two out of Four") are positive, the prognosis of non-RTW shows optimal sensitivity: and a PPV greater than 0.95 (positive patients with positive resultpatients followed up, ARI Absolute Risk Increase, Se Sensitivity, Sp Specificity, PPV Positive Predictive Value, NPV Negative Predictive Value, $x^{2}$ $P$-walue for $X^{2}$ test of non-parametric comrelation)

\begin{tabular}{lcccccccc}
\hline & & & & & & & & \\
\hline & Positive & ARI & Se & Sp & PPV & NPV & $X^{2}$ P.value \\
\hline Two out of Four positive & $31 / 90$ & 0.19 & 0.45 & 0.95 & 0.97 & 0.31 & 0.0015 \\
Step Test posifive & $36 / 90$ & 0.14 & 0.49 & 0.88 & 0.95 & 0.30 & 0.0050 \\
Behavioural Signs positive & $36 / 90$ & 0.18 & 0.38 & 0.94 & 0.96 & 0.30 & 0.0073 \\
Pain NRS 9 or 10 & 18190 & 0.20 & 0.26 & 1.00 & 1.00 & 0.28 & 0.0159 \\
Pseudo Strength Test positive & $26 / 90$ & 0.13 & 0.37 & 0.88 & 0.93 & 0.27 & 0.0470 \\
Unemployed & $27 / 90$ & 0.17 & 0.35 & 0.88 & 0.88 & 0.35 & 0.0597 \\
Off work >52 weeks & $25 / 90$ & 0.12 & 0.32 & 0.89 & 0.92 & 0.25 & 0.0727 \\
Nationality (former Yugoslavia) & $39 / 90$ & 0.06 & 0.48 & 0.72 & 0.87 & 0.26 & 0.1246 \\
Work load 4-5 & $63 / 90$ & 0.00 & 0.71 & 0.30 & 0.77 & 0.24 & 0.9474 \\
\hline
\end{tabular}

Logistic regression analysis showed that the Behavioural Signs, the Step Test, pain (NRS 9 or 10), the Pseudo Strength Test and the combination of these four tests "Two out of Four' were significantly associated with non-RTW. The contribution of the psychosocial factors: unemployment, off-work duration, nationality and workload was not significant. Using a stepwise regression, the only factor taken into the model was 'Two out of Four'.

The negative predictive value was below 0.50 for all tests (Table 5), which means that none of the investigated tests is clinically useful for the identification of a patient who wil RTW.

The prior probability for the outcome non-RTW was 0.80 . The maximum absolute risk increase (ARI) for non- RTW was 0.20 . The ARI was greater than 0.10 in seven out of nine investigated factors. Four tests ('Two out of Four', Step Test, Behavioural Signs and 'pain 9 or 10') had a positive predictive value greater than 0.95 and reached the first criterion for screening tests used to exclude patients from treatment. The second criterion, an optimal sensitivity, was best met by the Step Test $(0.49)$ followed by "Two out of Four' $(0.45)$.

The Behavioural Signs, a recognised test to assess the behavioural response to examination, with a well-known predictive value for non-RTW, showed good results 
regarding sensitivity, specificity and positive predictive value. A pain intensity of 9 or 10 had the best positive predictive value and specificity for non-RTW after 1 year. There were no false-positiwe results. The sensitivity of a pain intensity of 9 or 10 proved relatively poor. Of the four investigated tests, the Step Test had the best sensitivity, but the specificity was relatively poor.

The frequency of positive predictive tests was the same in patients with $(91 \%)$ and without (9\%) 1-year RTW data.

\section{PAIN AND DISABILITY}

The following description of the results regarding pain and disability are meant to further describe the population and are based on the $63 \%$ response rate of patients at 12 months. Pain was initially rated at 6.2 and increased to $7.0(P=0.015)$ over the following year. The score on the Roland Disability Questionnaire deteriorated insignificantly, from 16.2 to 16.5 out of a maximum score of 24 points. In individual patients, a change is considered significant and clinically relevant when the difference exceeds four points. ${ }^{26}$ Using this criterion, disability remained unchanged over the follow-up year in $61 \%$ of the patients. Twenty-five percent of the patients showed an improvement, whereas $14 \%$ had a deterioration of four or more points.

\section{TREATMENT}

This study does not investigate the effectiveness of treatment. Nevertheless the treatment may influence the prognosis of RTW and will therefore be briefly described here.

The average length of stay in the rehabilitation centre was 28.2 days (SD 7.4 days). The treatment duration was $16.2 \mathrm{~h} /$ week, with an emphasis on active treatment $(11.2 \mathrm{~h} /$ week) such as strength and endurance training ( $4 \mathrm{~h} /$ week), exercise therapy $(2.3$ $\mathrm{h} /$ week), back school $(1.9 \mathrm{~h} /$ week) and swimming with fins to increase endurance. Psychological interventions were offered to approximately $10 \%$ of the patients, depending on their personal needs. Relaxation techniques and passive treatment completed the interdisciplinary rehabilitation.

\section{Discussion}

To increase cost effectiveness in the rehabilitation of patients with CLBP, screening tests are needed to either include patients with a good prognosis for RTW or exclude patients who will almost certainly not RTW. The results of this study indicate that it is much easier to predict non- RTW than RTW. This may be because many prerequisites 
must be fulfilled for successful RTW. It is impossible to detect all relevant psychosocial factors and to judge their relevance and interactions. Moreover RTW depends to an important degree on factors that are unknown in advance, stuch as the availability of lighter work and the state of the job market. Some people ready to RTW might therefore not be at work after 1 year. Non-RTW is easier to predict, as negative factors apparently constitute significant barriers to RTW independent of other factors. Therefore, tests can be developed to predict non-RTW and exclude those patients from rehabilitation who have an extremelly small probability of RTW. Cost effectiveness can be increased using these tests.

An important question is whether the results of this study can be generalized to other populations of patients with CLBP. It is important that, in this study, no pre-selection by the clinic or insurance companies took place. Patients were referred to the clinic by their treating physicians. Therefore, we think that the results of this study can be applied to other patients with CLBP.

The investigated group consisted mainly of men $(84 \%)$ doing heavy or very heavy work. Sex did not correlate with RTW or with the number of predictive tests. "The results remained the same when women were excluded from the analysis. Patients from other countries than Switzerland $(65 \%)$ were over-represented in this study. This can be explained by the fact that heavy work is frequently done by persons from other countries. The off-work duration was long (median 26 weeks) and the unemployment rate was high (31\%). Most patients reported that they had lost their job and had found it difficult to find a new job because of their LBP.

The incidence of a specific diagnosis may seem small, raising the question of whether diagnostic procedures are sufficient. Non-specific LBP was diagnosed in $85 \%$ of the patients. The medical records of the patients showed that diagnostic procedures had been exhaustively applied and that the rate of specific diagnosis correlates very well with the findings of other studies. 825

The validity of the translated versions of the Roland and Morris Disability Questionnaire requires some analysis. The risk of a change in meaning after translation is considered small, as the items concern straightforward activities of daily life, such as climbing stairs, sleeping, walking and sitting. It is, however, possible that cultural differences lead to variations in scoting. Comparisons between groups of different nationalities might therefore not be valid. In this study, a comparison within a group of persons between entry -and follow-up was performed. As expected ${ }^{25}$, there was no change in symptoms or disability.

Loss to follow-up among patients was $37 \%$ at 12 months. As the follow-up data were not used for the prediction model, the incomplete follow-up did not bias the results. Responders and non-responders were the same at entry with regard to pain, disability, 
nationality and "Two out of Four" positive tests. The improvement by more than four points on the disability level in $25 \%$ of the patients can be viewed as an illustration of the fact that LBP can get better. Further efforts to increase this percentage should be made.

The $91 \%$ response rate among the physicians at 12 months conceming $R T W$ enables a reliable analysis of the predictive tests. Information about RTW was obtained from the physicians.

The $20 \%$ RTW rate after 12 months in the present study may seem very low compared to other studies. A possible explanation is that RTW is defined differently in different studies, contributing to the wide variations in results, which range from $23 \%{ }^{23}$ to $81 \%^{9}$ and $85 \%$. ${ }^{19}$ Some authors use the first day of RTW ${ }^{16}$; in other studies patients ready to work, or looking for work ${ }^{5}$ are included in the group of persons who have RTW. In this study RTW was defined as being at work at the time of follow-up. Patients ready to work or on vocational measures were not considered as RTW. If patients on vocational measures $(53 \%)$ had been included in the present study, the RTW rate would increase to $73 \%$. There is also some doubt as to the internal validity of the studies of Mayer et al. ${ }^{19}$ and Hazard et al.", reporting RTW rates of $81 \%$ and $85 \%$. In both studies, the experimental group was pre-selected by a medical insurance corporation, which agreed to finance the treatment. In addition, by including the drop-outs in Mayer's study $(17 \%)$, the RTW is reduced to $70 \%$. Lack of compliance with treatment was not clearly defined, and may have been one of the reasons for the drop-outs in Mayer's study. ${ }^{27}$ In the present study, $37 \%$ of the patients can be regarded as showing a lack of compliance, as they were unable to perform the Step Test and $28 \%$ were unable to hold two weights of $3 \mathrm{~kg}$ from a supine position against gravity. The inability to perform these tests cannot be explained by a physical problem, and suggest that behavioural or psychosocial factors may play an important role. The RTW rate in our study has also been negatively influenced by the $31 \%$ unemployment rate. The fact however, that two unemployed patients were working at the follow-up, indicates that unemployment alone does not justify exclusion from treatment. If patients with "Two out of Four" positive predictive tests had been excluded from treatment, the RTW rate would have been $32 \%$ instead of $20 \%$, comparable with Oland and Tveiten ${ }^{23}$, who reported a RTW rate of $32 \%$ at 6 months and $23 \%$ after 18 montlis.

Non-RTW can be predicted with excellent reliability by means of the Step Test, the Pseudo Strength Test, and a Pain Rating of 9 or 10 (positive predictive value $=0.93-$ 1.00, specificity $0.88-1.00)$. A positive Step Test and Pseudo Strength Test cannot be explained by mechanical pathology and suggest illness behaviour. This hypothesis is supported by the fact that $80 \%$ of the patients with a specific diagnosis were able to perform these two tasks. A pain intensity of 9 or 10 is interpreted as exaggerated pain behaviour and not primarily related to a somatic disorder. This explains the comparable 
predictive value of these tests with the Behavioural Signs $(0.96)$. Maximal sensitivity with a concomitant positive predictive value of more than 0.95 is achieved by the combination of four tests, interpreted positive when two or more of the four tests are positive. Kummel improved prediction of RTW by adding two "new non-organic physical signs' to the Behavioural Signs. ${ }^{15}$ In the present study, the evaluation of activity-associated illness behaviour in combination with the Behavioural Signs improves the prediction of RTW.

The decision to compare non-RTW in persons from former Yugoslavia with all other persons was based on the specific psychosocial factors among these patients. The constitution of groups can be debated and the results of this study argue strongly against the use of nationality as a predictive factor. In an analysis of non-RTW limited to persons with less than "Two out of Four" positive tests, nationality no longer influenced RTW.

An unexpected result in this study is that work load is not predictive for non-RTW. This finding can be explained by the small number of patients with a low work load, and the fact that persons with a low work load are not white-collar workers, but employees with a llow education, low responsibility and a very limited possibility of finding more attractive work.

Although nationality, unemployment and off-work duration are related to RTW (Table 5), using these factors to select patients for treatment would result in an unacceptable number of wrong decisions. ${ }^{14}$ It is not ethical to apply nationality as a reason to exclude patients from treatment.

\section{Conclusion}

The validity to predict non-RTW in patients with CLBP was established for three of the four investigated tests (Step Test, Pseudo Strength Test, Pain Rating of 9 or 10). Positive results in these tests reliably indicate that the patient will not $R T$ T after an extensive active rehabilitation programme.

A very good positive predictive value of 0.97 with a sensitivity of 0.45 is achieved by the combination of these three tests with the Behavioural Signs. These are interpreted as positive when two or more of these four tests are positive.

The investigated tests are based on objective criteria. Using these criteria, patients are evaluated based on their behaviour and not on potentially discriminating and less predictive factors such as nationality, work load, unemployment or time off work. 
Cost effectiveness in rehabilitation of patients with CLBP can be improved by selecting patients accordingly.

\section{Acknowledgements}

The authors wish to thank all physicians and physical therapists involved in the acquisition of data at entry and follow-up, and Lynne Mathews-Bietenhalder for her help with the preparation of the manuscript.

\section{References}

1. Abenhaim $L$, Rossignol $M$, Valat JP, ef al (2000) The role of activity in the therapeutic management, of back pain. Report of the International Paris Task Force on Back Pain. Spine 25 [Suppl4]: 1S-33S

2. Bendix A, Bendix T, Haestrup C (1998) Can it be predicted which patients with chronic low back pain should be offered tertiary rehabilitation in a functional restoration program? Spine 23:1775-1784

3. Bendix AF, Bendix $T$, Lund $C$, Kirkbak $S$, Ostenfeld $S$ (1997) Comparison of three intensive programs for chronic low back pain patients: a prospectike, randomized, observer-blinded study with one-year follow-up. Scand J Rehabil Med 29:81-89

4. Breitenmoser B, Foffa D, Rouiller C, Donini F, Nydegger B (1999) 'Eingliederung vor Rente" realisierbares Zilel oder bloss wolı|tönender Slogan? Soz Sicherheit 6:28:8-294

5. Corey DT, Koepfler LE, Etlin D, Day HI (1996) A limited functional restoration progran for injured workers: a randomized trial. J Occup Rehabil 6: $239-249$

6. Fordyce W (1995) Back pain in the workplace: management of disability in nonspecific conditions. International Association for the Study of Pain, Seattle

7. Frey D, Kippele Emara C. Tyndall A (1997) Berentung unspezifischer Rückenschmerzen trotz multidisz.jplinärem Therapieprogramm - ein Systemversagen? Schweiz Med Wochenschr 127 [Suppl 901:127

8. Prymoyer.JW (1988) Back gain and sciatica. N Engl I Med 318:29\|-299

9. Hazatd R, Fenwick J, Kalish S (1989) Early prediction of chronic disability after occupational low back injury. Spine 14:157 -161

10. Hildebrand J, Pfingsten M. Saur P, Jansen J (1997) Prediction of success of a multidisciplinary treatment program for chronic low back pain. Spine 22:990-1001

11. Indahl A, Velund L, Reikerass $O$ (1995) Good prognosis for low brek pain when left untampered. A randomized clinical trial. Spine 20:473-477

12. Karas R, McIntosh $\mathrm{G}$, Hall H, Wilson L, Melles "T (1997) The relationship between nonorganic signs and centralization of symptoms in the prediction of return to work for patients with low back pain. Phys Ther $77354-360$; discussion: $61-69$

13. Kendall N, Linton S, Main C (1997) Guide to assessing psychosocial yellow flags in acute low back pain: risk factors for long-term disability and work loss. Accident Rehabilitation and Compensation Insurance Corporation of New Zealand and the National Health Committee, Wellington

14. Kool J Oesch P. Bachmann S (2000) Ist die Nationalizat prädiktiv für die Betrteilung der körperlichen Leistungstăhigkeit und fùr das Rehabilitationsresultat? Schweiz Arztez 81:2656-2659

15. Kummel BM (1996) Nonorganic signs of significance in low back pain. Spine 21:1077-1081

16. Loise: P, Abenhaim L, Durand P, et al (1997) A population-based, randomized elinical trial on back pain management. Spine 22:2911-2918 
17. Main CJ, Waddell G (1998) Behavioural responses to examination. A reapparsal of the interpretation of "nonorganic signs', Spine 23:2367-2371

18. Main CJ, Wood PL, Hollis S, Spanswick CC, Waddell G (1992) The Distress and Risk Assessment Method (DRAM). Spine 17:42-52

19. Mayer TG, Gatchell RI, Mayer H (1987) A prospective two year study of functional restoration in industrial low back injuries: an objective assessment procedure. JAMA 258:1763-1767

20. Mitchell RI, Cammen GM (1994) The functional restoration approwch to the treatment of chronie pain in patients with soft tissue and back injuries. Spine 19:633-642

21. Oesch P, Kool JP. Sloksnath U, Hasegawa A (1994) Die Zuverkassigkeit und Empfindlichkeit von 4 isonetrischen Muskeltests. Physiotherapie 6:4-12

22. Oesch P, Kool J. Wunderlin B. Knüsel O (1997) Rehabilitation von Patienten mit chronischen Ruckenbeschwerden: Assessment, Ergebnis and prädiktive faktoren. Phys Med Kurort Med 7:224-230

23. Oland $\mathrm{G}$, Tweiten $\mathrm{G}$ (1991) A trial of modern rehabilitation for chronic low back pain and disability: vocational outcome and effect of pain modulation. Spine 16:457-459

24. Roland M, Moris R (1983) A study of the matural history of back pain. Spine 8:141-150

25. Spitzer W (1987) Quebec Task Force Report. Spine 12:\$10-S53

26. Stratford P, Binklley J, Solomon P. Finch E, Gill C. Moretsund J (1996) Defining the minimum level of detectable change for the Roland-Morris Questionnaire. Phys Ther 76:359-365

27. Teasell RW (1996) Eunctional restoraion. Returning patients with chronic low back pain to work revolution or fad? Spine $21: 844-847$

28. "Thali A, Stem S, Rothenbülater B, Kran K (1994) The role of psychosocial factors in patients with chronic low back pain. Z Unfallohir Versicherangsmed $87: 31-44$

29. United States Department of Labor (1991) Dictionary of occupational titles, 4 th edn. United States Department of Labor, Washington, $\mathrm{DC}$

30. Villiger B, Egger K, Lerch R, Probst HP, Schneider W (1995) The 3-Minute Step Test. Jn: Villiger B (ed) Endurance. Thieme, Stuttgart

31. Waddell $\mathrm{G}$ (1991) Low back pain disability, a syndrome of western civilisation. Neurosurg Clin N Am 2 : $719-738$

32. Waddell G (1992) Biopsychosocial analysis of low back pain. Baillieres Clin Rheumatol 6:523-557

33. Waddell $\mathrm{G}$ (1998) The back pain revolution. Churchill Liwingstone, Edinburgh

34. Waddell G, McCulloch JA, Kummel E, Venner RM (1980) Non-organic physical signs in low back pain. Spine 5: $117-125$

35. Werneke MW, Harris DE, Lichter RL (1993) Clinical effectiweness of Behwioumal Signs for screenug chronic low back pain patients in a work-otiented physical rehabilitation progran. Spine $18: 2412-2418$ 


\section{Chapter 3}

\section{Exercise reduces sick days in patients with nonacute nonspecific low back pain: a meta-analysis}

Jan P. Kool', Rob de Bie ${ }^{2}$, Peter R. Oesch ${ }^{3}$, Otto Knisel", Piet van den Brandt ${ }^{2}$ and Stefan Bachmanin ${ }^{3,4}$

Affiliations of the authors

${ }^{1}$ Research Dpt., Rehabilitation Centre Valens, Switzerland

${ }^{2}$ Dpt. of Epidemiology, Maastricht University, The Netherlands

${ }^{3}$ Dpt. of Work Rehabilitation, Rehabilitation Centre Valens, Switzerland

${ }^{4}$ Dpt. of Rheumatology, Rehabilitation Centre Valens, Switzerland

Jomnal of Rehabilitation Medicine 2004: 36:49-62 


\section{Abstract}

Objectives: To investigate whether exercise alone or as a part of a multidisciplinary treatment reduces sick leave in patients with non-specific non-acute low back pain.

Methods: A meta-analysis of randomized controlled trials was performed. A qualitative analysis of the sick leave results was performed applying pre-defined levels of evidence. In studies comparing exercise with usual care, pooled effect sizes were computed.

Results: Fourteen trials were identified allowing 22 comparisons between treatments. The qualitative and the quantitative analysis showed strong evidence that exercise reduces sick days during the first follow-up year, the effect size $95 \%$ confidence interval) was $-0.24(-0.36,-0.11)$. In a subgroup of studies on the treatment of severely disabled patients ( $>90$ sick days under usual care) the effect size was $-0.30(-0.42$, -0.17 ). The effect size of the number of patients receiving a disability allowance was small and not significant.

Conclusion: The reviewed trials provide strong evidence that exercise significantly reduces sick days during the first follow-up year. 


\section{Introduction}

Work-related disability is a major problem in patients with non-specific non-acute low back pain (LBP). Ninety-five percent of all patients with acute LBP return to work within 4 weeks regardless of treatment. If patients do not return to work within 4 weeks, treatment to prevent chronic disability is recommended. ${ }^{2}$ It remains unclear whether sick leave can be reduced. Therefore the am of this meta-analysis is to investigate whether sick leave can be reduced by exercise, defined as pliysical activities, which people can carry out to benefit their health.

Evidence suggests that less than $15 \%$ of individuals with back pain can be assigned to a specific back pain category such as nerve root compression, vertebral fracture, tumour, infection, inflammatory diseases, spondylolysthesis, spinall stenosis and definite instability. ${ }^{3}$ In the majority of patients LBP is non-specific.

The direct costs related to the treatment of $1 \mathrm{BP}$ in the USA showed a rapid increase from $\$ 13$ billion in 1984 to $\$ 33$ billion in $1994{ }^{4}$ The major costs were caused by sick leave and long term disability. In Germany $\$ 24$ billion were paid for LBP-related disability allowances in 1998 , compared with $\$ 1.0$ billion for the treatment of LBP."

While no evidence has been found to support the effectiveness of transcutaneous electrical stimulation ${ }^{6}$ heat, massage, laser, traction, acupuncture and other modalities, injections ${ }^{8}$ and bed rest ${ }^{9}$, there is conflicting evidence regarding the long term effects of exercise therapy. ${ }^{10,11}$ A recent review of multidisciplinary interventions found strong evidence for the improvement of function, moderate evidence for the reduction of pain and contradictory evidence regarding vocational outcomes. ${ }^{12}$ Most multidisciplinary interventions include some form of exercise, which seems to be one of the most promising options for treatment. According to several guidelines, resuming normal activities including return to work is the primary goal of treatment in patients with subacute and chronic LBP. ${ }^{2,3}$ The outcome, sick leave in this case, is the starting point to search for evidence for clinical decision-making. In the majority of reviews, sick leave is not specifically evaluated. Usually pain, function and disability are reported but it is unclear whether improvements in these outcomes are accompanied by a reduction in sick days. The objective of this study was to investigate whether treatments using exercise alone or as a part of a multidisciplinary treatment reduce sick leave in patients with non-specific non-acute LBP. 


\section{Methods}

\section{IDENTIFICATION OF TRIALS}

The search strategy for the identification of trials, performed in December 2002, covered MEDLINE (1966 to Oct. 2002), EMBASE (1988 to Oct. 2002), PEDro (until Dec. 2002), the Cochrane Library (2002, Issue 4) and PsycLIT (1984 to Dec. 2002). Based on the strategy described by the Cochrane Back Review Group, a combination of search terms was used for: (i) randomized controlled trials (RCTs); (ii) patients with non-acute LBP; and (iii) sick leave outcome. ${ }^{13}$ References were checked for further trials.

\section{SELECTION OF STUDIES}

Only RCTs published in English, German or Dutch were included. Studies were included if the primary diagnosis in all patients was non-specific non-acute LBP with a duration of at least 4 weeks. Excluded were studies including persons with thoracic or cervicall pain, studies in specific low back pain caused by nerve root compression, vertebral fracture, tumour, infection, inflammatory diseases, spondylolysthesis, spinal stenosis and definite instability, and studies in pregnant women with LBP. Studies were included if the experimental treatments used exercise alone or as a part of a multidisciplinary treatment. Excluded were studies investigating the effect of treatments that did not contain any form of exercise such as respondent psychological interventions. Sick leave was the primary outcome in this meta-analysis. Therefore, studies were only included if at least $90 \%$ of the patients under treatment were available for the job market in that they were either employed or unemployed and seeking work.

Two researchers (JK, SB) applied the admission criteria. Disagreement was resolved by discussion with a third researcher (RB). Authors were contacted if the information regarding the eligibility of a trials or sick leave outcome was unclear.

\section{ASSESSMENT OF METHODOLOGICAL QUALITY}

Methodological quality may influence the results and validity of RCTs. Trials with inadequate allocation concealment have been associated with larger treatment effects compared with trials in which authors reported adequate allocation concealment. ${ }^{14}$ To assess the methodological quality of the included RCTs, studies were rated on a 10point quality scale from the Physiotherapy Evidence Database with minor adaptations as required for this review (Table 1). ${ }^{15}$

Two researchers (JK, SB) independently performed the quality rating, resolving disagreement by consensus or by discussion with a third researcher (RB). Assessment of sick leave outcome was regarded blinded if data were obtained from a database for 
financial compensation of sick leave blinded to the patients" assigmment. All authors were asked for further information regarding the methodological quality. Blinding of patients and therapists is not feasible in this field leading to a maximum seore of 8 points. In concordance with other reviews ${ }^{10-12}$ an arbitrary score of 5 or more points was considered to indicate high methodological quality.

Table 1: Criteria for methodological quality according to the PEDro-Scale. Adaptations are in italics and the cortesponding original descriptions are in brackets

1. Subjects were randomly allociated to groups

2. Allocation was concealed

3. The groups were simillar at baseline regarding the most important prognostic indicators

4. There was blinding of all subjects

5. There was blinding of all therapists who administered the therapy

6. There was blinding of sick leave measurement (all assessors who measured at least 1 koy outcome). Measurement by a patient questionmaire was not considered blinded. Obtaining sick leave data from a database was considered blind assessment.

7. Adequate follow-up; measures of sick leave (at least 1 key oulcome) were obtained from more than $85 \%$ of the subjects initially allocated to groups.

8. Intention-to-treat analysis: ail subjects for whom sick leave results (cutcome measures) were avaliable recelved the treatment or control condition as allocated or, where this was not the case, data for sick leave results lat laest 1 key outcome was) were analysed by "intention to treat".

9. The results of between-group statistical comparisons are reported for sick leave (at least 1 key outcome)

10. The study provides both point measures and measures of variablity for sich loave (at least 1 key outcome)

\section{QUALITATIVE SICK LEAVE ANALYSIS}

Two authors (JK, RB) extracted the results regarding sick leave outcome from the original publications. If necessary, the numbers required for the calculations were approximated from graphs and statistics in the publication.

Treatment contrasts in decreasing order are obtained by comparisons with placebo followed by usual care, and finally by other treatments also expected to be effective. Comparisons with placebo therapy are not possible in this field. As different types of comparisons should not be mixed in a meta-analysis, we first evaluated comparisons between experimental interventions and usual care. Usual care by the physician generally included rest, giving advice including written information, medication, sick. listing, and physical therapy. ${ }^{16,17}$ 
He qualitative analysis was performed using the levels of evidence as defined by the US Clinical Practice Guidelines for Acute Low Back Problems in Adults and repeatedly used by the Cochrane Back Review Group. ${ }^{12}$ The rating system consists of 4 levels of scientific evidence based on the quality and the outcome of the studies (Table 2). Results were considered contradictory if statistically significant results in favour of and against an experimental treatment were found.

Table 2: Levels of evidence (RCTs: randomized controlled trials)

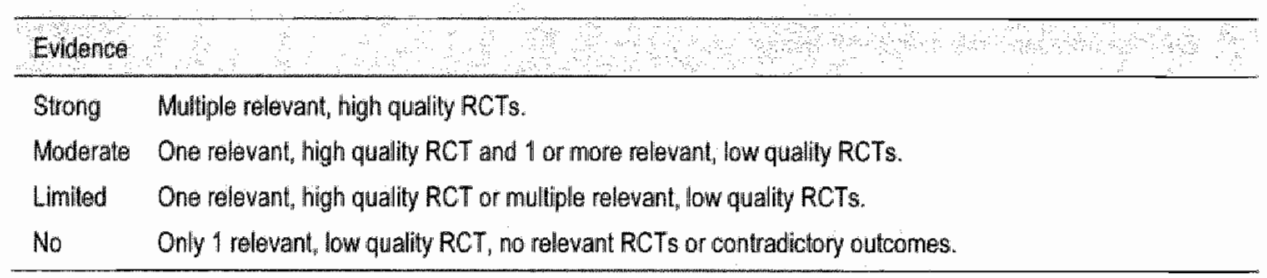

\section{QUANTITATIVE ANAL YSIS OF SICK LEAVE}

Statistical pooling of sick-leave-related outcome measures was performed in comparisons between experimental treatments and usual care. All analysis was conducted using Meta-View Rev-Man software version 4.1. (Cochrane Collaboration 1999). A random effects model was used because studies are likely to be heterogeneous with regard to treatments, and predictive factors for sick leave such as the duration of LBP, employment status, nationality and socio-economic background. The relative risk was computed in dichotomous data. If methods of continuous sick leave measurement were different among studies, data were analysed with the standardized mean difference (SMD) method. Effect sizes were computed with Hedges adjusted $g$, which is very similar to Cohen's $d$ but includes a correction for small sample sizes. ${ }^{18}$

\section{Results}

\section{STUDY SELECTION}

The systematic search in databases and references in reviews and RCTs resulted in 341 publications concerning $166 \mathrm{RCTs}$. Fourteen RCTs met the inclusion criteria. Five studies were conducted in Norway (N), 4 in Denmark (DK), 3 in Finland (SF) and 1 each in Canada (Can) and Sweden (S). All studies had been published since 1989 with 1 exception, a publication in 1966 reporting the results from 3 studies of which only the 
third (pp. 52-55) fulfilled the inclusion criteria. ${ }^{19}$ Two publications described the intervention as "secondary prevention". ${ }^{20,21}$ These studies were included because all patients had sick leave prior to treatment. Primary prevention trials in patients without a recent history of LBP were excluded.

One study was excluded because the publication was available in Finnish only. ${ }^{22.23}$ Twelve studies, investigating patients with pain in the lower back together with patients with pain in other body parts ${ }^{24-35}$, were excluded. Three excluded studies investigated patients with spondylolysthesis ${ }^{36-38}$ and 2 studies investigated women with LBP during pregnancy. ${ }^{39,40}$ Seven studies were excluded because less than $90 \%$ of the patients were gainfully employed and separate sick leave data for these patients were not available. ${ }^{41}$ 47 Two excluded studies investigated the effect of a psychological intervention in addition to the standard treatment of physical reconditioning through exercise ${ }^{43,45}$ One study was excluded because the method of randomization did not fulfil the applied methodological criteria as patients were alternatively allocated to the experimental and control group. ${ }^{48}$

Table 3: Methodological quality, criteria as specified in Table 1, * score based on communication with the author

\begin{tabular}{|c|c|c|c|c|c|c|c|c|c|c|c|}
\hline 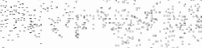 & Score & 1 & 2 & 3 & 4 & 5 & 6 & $?$ & 8 & 9 & 10 \\
\hline Alaranta 76 & 6 & 1 & - & 1 & 1 & * & & 1 & - & 1 & 1 \\
\hline Bendix 52.53 .56 .77 & 5 & 1 & - & 1 & - & - & - & 1 & - & 1 & 1 \\
\hline Bendix 52.58 .59 & 4 & 1 & . & 。 & - & - & r & 1 & - & 1 & 1 \\
\hline Bendix & 4 & 1 & - & 1 & - & - & . & - & - & 1 & 1 \\
\hline Hagen 故 & 7 & 1 & $\mathbb{1}$ & 1 & $4 * *$ & - & - & " & 1 & 1 & 1 \\
\hline Haärkäpää 58, : & 5 & 1 & - & 1 & 1 & - & - & 1 & " & 1 & - \\
\hline Hurri & 6 & 1 & - & 1 & - & . & . & 1 & 1 & 1 & 1 \\
\hline Lindström 56.577 . & 8 & 1 & $1^{*}$ & 1 & 1 & - & . & 1 & $1^{*}$ & 1 & 1 \\
\hline Ljunggren 20 & 7 & 1 & 1 & 1 & . & - & - & 1 & $1^{*}$ & 1 & 1 \\
\hline Lonn/Soukup 21.35 & 7 & 1 & $i^{*}$ & 1 & 。 & - & - & 1 & $1^{*}$ & 1 & 1 \\
\hline Petersen 80 & 6 & 1 & 1 & 1 & - & - & - & " & 1 & 1 & 1 \\
\hline Skouen & 6 & 1 & 1 & - & 1 & - & 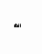 & 1 & - & 1 & 1 \\
\hline Torstensen & 6 & 1 & 1 & 1 & 1 & - & - & - & 1 & 1 & - \\
\hline White & 4 & 1 & - & 1 & - & . & - & 1 & . & 1 & . \\
\hline
\end{tabular}




\section{METHODOLOGICAL QUALITY}

The methodological quality of the 14 studies included ranged from 4 to 8 points (Table 3). Additional information from the authors improved the score in 4 studies. The methodological score was high in 12 studies (79\%) obtaining 5 or more points.

\section{QUALITATIVE SICK LEAVE ANALYSIS}

The included studies allowed 13 treatment comparisons between experimental treatments and a usual care control group (Table 4). Table 5 shows comparisons between 2 or 3 experimental treatments. Three studies contain comparisons with usual care, displayed in Table 4, as well as comparisons between 2 experimental treatments displayed in Table $5^{49-51}$ Bendix et al. combined the 5-year follow up results of 2 $\mathrm{RC} \Gamma$ s, data for the single treatment comparisons were not available. ${ }^{52}$

Five RCTs compared 3 treatments. Bendix et al. compared a work hardening programme with aerobic exercise and a psychological intervention. ${ }^{53}$ Härkäpää et al. compared inpatient rehabilitation (In) and outpatient rehabilitation (Out) with usual care. ${ }^{51,54}$ Skowen et al. compared a light and an extensive multidisciplinary programme with usual care..$^{50}$ Torstensen et al. compared medical exercise therapy (MET) and conventional physiotherapy (CP) with usual care including the advice for self-exercise by daily walks (SE) ${ }^{49}$ Soukup and Lonn used a common control group receiving usual care to evaluate an Active-Back-School (ABS) ${ }^{21}$ and exercise therapy according to the concept developed by Mensendieck (M). ${ }^{5 s}$ 
Table 4: Studies of experimental treatments compared with usual care

\begin{tabular}{|c|c|c|}
\hline $\begin{array}{l}\text { Author year country } \\
\text { subjects }\end{array}$ & Experimental treatment & $\begin{array}{l}\text { Sick leave outcome for the oxpermenta group (G) and } \\
\text { usual care contro group }(\mathrm{Cl} \text { (Mean and } \mathrm{SD})\end{array}$ \\
\hline \multirow{3}{*}{$\begin{array}{l}\text { Bendix } 1996, \text { DK }{ }^{52.5459} \\
106 \text { patients with }>6 \\
\text { months of disabling back } \\
\text { pain }\end{array}$} & \multirow{3}{*}{$\begin{array}{l}\text { Work hardening, } 3 \text { weeks, } 39 \\
\text { hourstweek, aerobics; weight } \\
\text { training, work hardening. } \\
\text { relaxation, psychological } \\
\text { group therapy, stretching }\end{array}$} & $\begin{array}{l}\text { Sick days (adapled from median, range and IOR): } \\
\text { Significant difference during the first } 4 \text { months, } E \text { : } 48 \text { (SD } \\
=50), C: 82(S D=50 \text { ) }\end{array}$ \\
\hline & & $\begin{array}{l}\text { Work capability as judged by a physician significantly } \\
\text { greater improwement al } 4 \text { nonths, } \mathrm{E} \text { : from } 27 \% \text { to } 64 \%, \mathrm{C} \text {. } \\
\text { from } 16 \% \text { to } 28 \% \text {, No difference after } 2 \text { years } \mathrm{E}: 52 \%, \mathrm{C} \\
51 \% \text {. }\end{array}$ \\
\hline & & 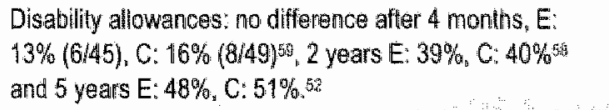 \\
\hline \multirow{3}{*}{$\begin{array}{l}\text { Hagen } 2000 \mathrm{~N} \text { o } \\
457 \text { patients with } L B P \\
\text { and sick leave } 8-12 \\
\text { weeks }\end{array}$} & \multirow{3}{*}{$\begin{array}{l}\text { Examination at spine clinic; } \\
\text { information, adwice to stay } \\
\text { active and go on dally walks, } \\
\text { individual instructions on } \\
\text { stretching and raining at } \\
\text { home by the physical } \\
\text { therapist }\end{array}$} & $\begin{array}{l}\text { Sick days: significant reduction during the 1st year }(E \text { : } \\
95.5(S D=102), C \cdot 133.7(S D=110) \mathrm{G}\end{array}$ \\
\hline & & 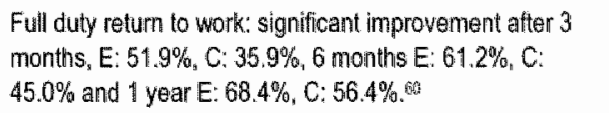 \\
\hline & & $\begin{array}{l}\text { Disability allowances: No difference after } 1 \text { year } E: 14 / 237 \text {, } \\
C_{1}: 14 / 220,0\end{array}$ \\
\hline \multirow{2}{*}{$\begin{array}{l}\text { Härkäpää } 1990 \text { SF51.5 } \\
476 \text { blue collar workers, } \\
\text { LBP since } 2 \text { years, sick } \\
\text { leave due to LBP during } \\
\text { the last } 2 \text { years }\end{array}$} & \multirow{2}{*}{$\begin{array}{l}\text { Inpatient rehabilitation; } 3 \\
\text { weeks, groups of 6-8 } \\
\text { patients, Swedish back } \\
\text { school, relaxation, heat or } \\
\text { electrotherapy prior to } \\
\text { exercise, } 2 \text { structured group } \\
\text { discussions, home } \\
\text { programme, rehearsal after } \\
1.5 \text { yoars }\end{array}$} & $\begin{array}{l}\text { Sick days: no difference after } 1.5 \text { years, E: } 5.5 .5 \mathrm{SD}= \\
25.0), \mathrm{C}: 7.5(\mathrm{SD}=25.0) \text {. Reesults disregard the first } 7 \\
\text { days of each episode of sickness absence leading to a } \\
\text { considerable underestimation of the days lost from work. } 5 \text { th }\end{array}$ \\
\hline & & $\begin{array}{l}\text { Disability allowances: no difference after } 4.5 \text { years } \mathrm{E} \text { : } \\
10 \%, \mathrm{C}: 12 \% \text {. }\end{array}$ \\
\hline \multirow{2}{*}{$\begin{array}{l}\text { Harkhapala } 1990 \text { SF51.54 } \\
476 \text { blue collar workers, } \\
\text { LBP since } 2 \text { years, sick } \\
\text { leave due to LBP during } \\
\text { the lasil } 2 \text { years }\end{array}$} & \multirow{2}{*}{$\begin{array}{l}\text { Outpatient treatment at the } \\
\text { woirk place or local health } \\
\text { centre; } 15 \text { sessions in } 2 \\
\text { months, groups of } 6-8 \\
\text { patients. Swedish back } \\
\text { school, relaxation, heat or } \\
\text { electrotherapy prior to } \\
\text { exercise, } 2 \text { structured group } \\
\text { discussions, home } \\
\text { programme, rehearsal after } \\
1.5 \text { years }\end{array}$} & 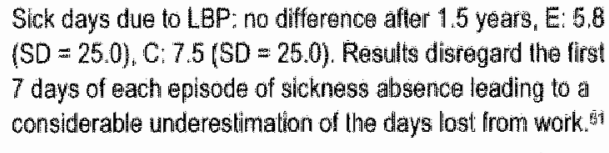 \\
\hline & & $\begin{array}{l}\text { Disability allowances no difference after } 4.5 \text { years E } 8 \% \text {, } \\
\text { C: } 12 \% .5\end{array}$ \\
\hline
\end{tabular}


Table 4 (continued): Studies of expermental treatments compared with ustual care

\begin{tabular}{|c|c|c|}
\hline $\begin{array}{l}\text { Auther, year, country } \\
\text { subjects }\end{array}$ & Experinental treatment & $\begin{array}{l}\text { Sick leave outcome for the experimental group (E) and } \\
\text { usual care control group (C) (Mean and SD) }\end{array}$ \\
\hline $\begin{array}{l}\text { Hurri } 1889 \text { SF } \\
80 \text { Feniale employees } \\
\text { with LBP }>12 \text { months }\end{array}$ & $\begin{array}{l}\text { Back school given by a } \\
\text { physical therapist; } 6 \text { sessions } \\
\text { of } 1 \text { hour in groups of } 11 \\
\text { patients. Education and } \\
\text { exercise. Two review } \\
\text { sessions after } 6 \text { months }\end{array}$ & $\begin{array}{l}\text { Sick days due to } \mathrm{LBP} ; \text { no difference during the } 1 \text { st year, } \\
\mathrm{E}: 8.1(\mathrm{SD}=26.9), \mathrm{C}: 11.1(\mathrm{SD}=26.6) \text { and during the } 2 \text { nd } \\
\text { year } E: 9.0(\mathrm{SD}=23.6), \mathrm{C}: 9.5(\mathrm{SD}=25.0) \text {, personal } \\
\text { communication }\end{array}$ \\
\hline \multirow{4}{*}{$\begin{array}{l}\text { Lindstròm } 1992 \text { Sse.57.79 } \\
103 \text { blue collar workers } \\
\text { sick listed } 6 \text { weeks, no } \\
\text { LBP' sick lisling in the } \\
\text { prior } 12 \text { weeks, able to } \\
\text { speak Swedisfi }\end{array}$} & \multirow{4}{*}{$\begin{array}{l}\text { Graded activity; measurement } \\
\text { of functional capacity, work } \\
\text { place visit, back school } \\
\text { individual submaximal } \\
\text { gradually increased exercise } \\
\text { programme }\end{array}$} & $\begin{array}{l}\text { Time until return to work: significantly shorter, } E: 10.0 \\
\text { weeks }(S D=12.7), C: 15.1 \text { weeks }(S D=15.6))^{.55}\end{array}$ \\
\hline & & $\begin{array}{l}\text { Return to work: significantly greater proportion of patients } \\
\text { relurned to work after } 6 \text { weeks, E: 59\% (30/51), C: } 40 \% \\
\text { (21/52) and } 12 \text { weeks, E: } 80 \%(41 / 51), C: 58 \%,(30 / 52) .5 \%\end{array}$ \\
\hline & & $\begin{array}{l}\text { Sick days during the } 2 \text { nd follow-up year (mean, } S D): E: 60 \\
(S D=92), C: 98(S D=103.5) .59\end{array}$ \\
\hline & & $\begin{array}{l}\text { Disability allowance: no difference after } 2 \text { years, } E: 1 / 51 \text {, } \\
C: 4 / 52.55\end{array}$ \\
\hline \multirow{4}{*}{$\begin{array}{l}\text { Lonn } 1999 \mathrm{~N} 21.81 \\
120 \text { persons with LBP } \\
\text { requiring treatment or } \\
\text { sick days }\end{array}$} & \multirow{4}{*}{$\begin{array}{l}\text { Active Back School (ABS); } 20 \\
\text { sessions of } 1 \text { hour during } 13 \\
\text { weeks, } 20 \text { minutes theory and } \\
40 \text { minutes exercise }\end{array}$} & $\begin{array}{l}\text { Sick days: significant reduction during the 1st year, } E: 1.9 \\
(\mathrm{SD}=4.1), \mathrm{C}: 11.9(\mathrm{SD}=15)^{21} \text { and during } 3 \text { years follow- } \\
\text { up, } E: 4.7(\mathrm{SD}=8.0), \mathrm{C}: 32.9(\mathrm{SD}=41.0){ }^{\text {t: }}\end{array}$ \\
\hline & & $\begin{array}{l}\text { Number of palients taking sick leave: no difference during } \\
\text { the first follow-up year }\left(\mathrm{E}: 7 / 38=18 \%{ }^{\mathrm{N}} \mathrm{C}: 11 / 35=31 \%\right)^{21} \\
\text { and during } 3 \text { follow-up years }(\mathrm{E}: 12 / 37=32 \%, \mathrm{C}: 18 / 35= \\
52 \%){ }^{\text {B1 }}\end{array}$ \\
\hline & & $\begin{array}{l}\text { Duration of sick leave in those patients who took sick } \\
\text { leave: significantly shorter duration during the 1st year. } E \text { : } \\
10.4(S D=9.3), C: 37.8(S D=28.0)^{21} \text { and during } 3 \text { follow- } \\
\text { up years, } E: 14.4(S D=12.7), C: 63.9(S D=76.3) .{ }^{81}\end{array}$ \\
\hline & & $\begin{array}{l}\text { Disability allowances: No difference after } 1 \text { year }(E: 0 / 38 \text {, } \\
\text { C: } 0 / 35)^{21}\end{array}$ \\
\hline \multirow{3}{*}{$\begin{array}{l}\text { Soukup } 1999 \mathrm{~N} \text { s.8. } \\
120 \text { persons with LBP } \\
\text { requiring treatment or } \\
\text { sick days }\end{array}$} & \multirow{3}{*}{$\begin{array}{l}\text { Mensendiack exercise group } \\
\text { (M) with 6-10 participants, } 20 \\
\text { sessions of } 60 \text { min. for } 13 \\
\text { weeks. Warm up and } \\
\text { stretching exercises, } \\
\text { ergonomic information }\end{array}$} & $\begin{array}{l}\text { Sick days: no difference during the } 1 \text { st year, } E: B .8(S D= \\
15), C: 11.9(S D=15)^{55} \text { and during } 3 \text { years follow-up } E \text { : } \\
22.0\left(S D=35.01, C: 32.9(S D=41.0)^{\text {ga }}\right.\end{array}$ \\
\hline & & $\begin{array}{l}\text { Number of patients taking sick leave: No difference during } \\
\text { the 1st year ( } E \text { : } 10 / 34=29 \%, C: 11 / 35=31 \%)^{55} \text { and } \\
\text { during } 3 \text { follow-up years }(E: 13 / 31=42 \%), C: 18 / 35= \\
52 \%)^{\text {.92 }}\end{array}$ \\
\hline & & $\begin{array}{l}\text { Duration of sick leave in those patients who took sick } \\
\text { leave: No difference during the } 1 \text { st year }(\mathrm{E}: 29.9(55.2), \mathrm{C} \text { : } \\
37.8(28.0))^{55} \text { and during } 3 \text { follow-up years }(\mathrm{E}: 14.4(12.7) \text {, } \\
\mathrm{C}: 63.9(76.3)) .\end{array}$ \\
\hline
\end{tabular}


Table 4 (continued): Shudes of expermental treatmernts compared with usual oane

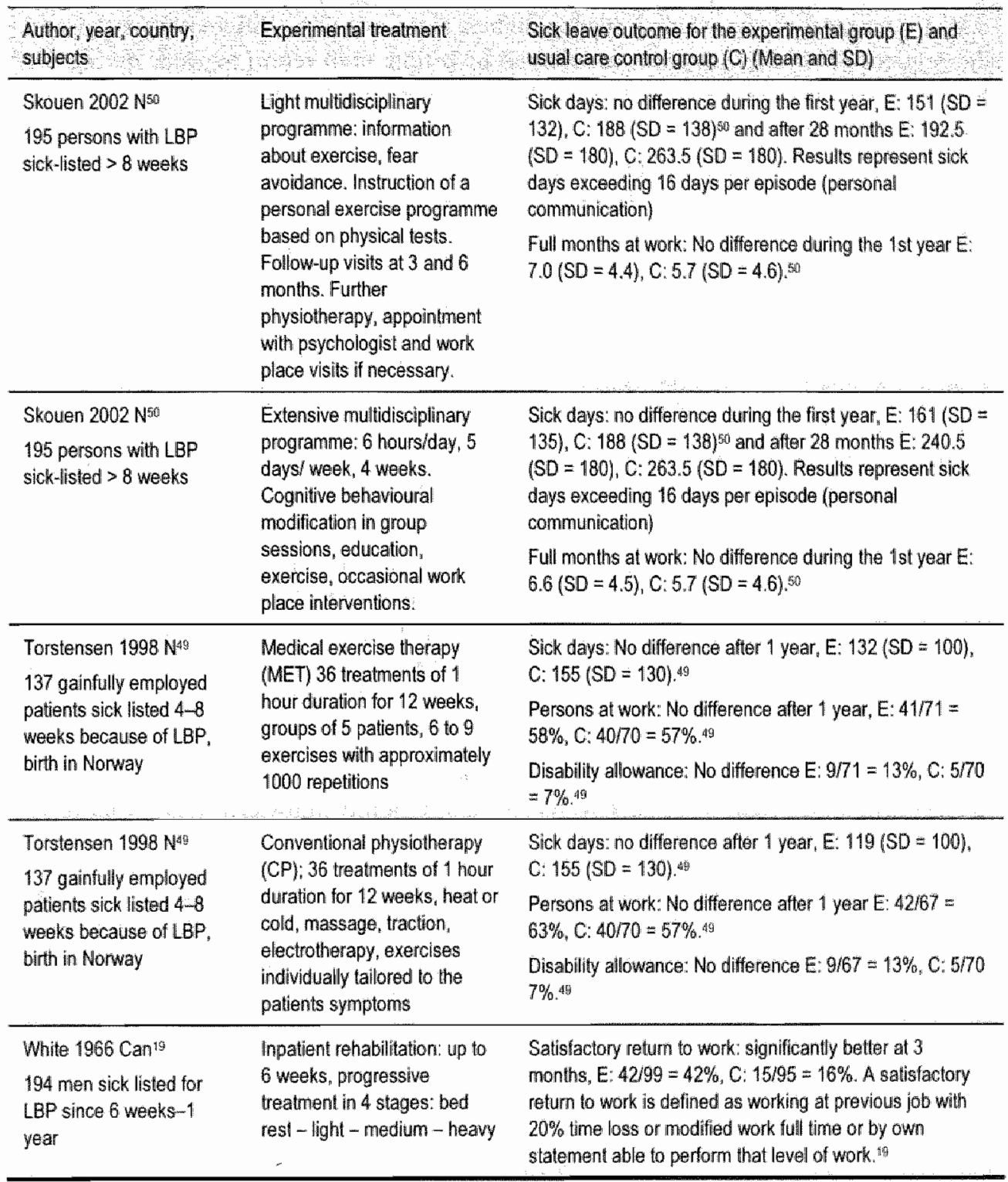


Two studies reported mean walues of sick days for the subset of patients taking sick leave during the follow-up year. ${ }^{21.55}$ These numbers were adlapted to mean values of sick days for the total group, which leads to numbers that seem to be different from those in the original publication. Lindstrơm reported both time untill return to work during the first year and the number of sick days during the second follow-up year. ${ }^{56,57}$ Soukup reported sick days" results both with and without an outlier that accounted for most of the sick days in the experimental group. ${ }^{55}$ In this review we used the results with the outlier, assuming that outliers balance out across studies.

Table 4 shows the sick-leave-related outcomes in 9 studies reporting 13 comparisons between experimental treatments and usual care. In general, positive results were reported for sick days and for the proportion of patients at work. Effects were smaller at longer follow-up intervals. Sick days were the most frequently used outcome reported in 8 studies with 12 comparisons. Results were significant and positive in 5 comparisons. Non-significant improvements were reported in 7 treatment comparisons. In 4 of these 7 treatment comparisons, the control group reported less than 15 sick days during the follow-up year. No benefits with regard to disability allowances were reported in 8 comparisons (6 studies). The results display a wide variety in the average level of workrelated disability. Sick days and disability allowances are minimal in some studies possibly leading to a floor effect in outcome measurement. Positive results are more frequently reported in studies with severely disabled patients. Based on the levels of evidence as defined in the methods, there is strong evidence that exercise alone, or as a part of a multidisciplinary treatment, reduces sick days one year after treatment in patients with non-acute non-specific LBP. Due to insufficient research, there is no evidence for the effectiveness or ineffectiveness after more than 1 year or for the effect of treatment on the number of persons receiving a disability allowance at any follow-up time up to 5 years.

Table 5 shows 9 studies comparing the effectiveness of 2 or 3 different experimental treatments. Only 1 study reported significant sick leave related benefits. ${ }^{s 8}$ All other studies showed no difference in any sick leave outcome. The number of patients in the comparisons of Table 5 was similar to those in Table 4 , but the smaller treatment contrast probably reduced the power in these comparisons. The variety of treatments makes it impossible to combine the results of the studies in Table 5. Based on the levels of evidence as defined in the methods, there is no evidence for the superiority of any type of exercise alone or as a part of a multidisciplinary treatment to reduce sick leave in patients with non-acute non-specific LBP.

To investigate the question regarding which patients might benefit more, several studies performed a subgroup analysis. Because different subgroups were analysed in the studies, and results were inconsistent, no conclusions can be drawn. We performed an 
analysis in a subgroup of studies investigating patients with more severe disability, which is described in the next section.

Table 5: Pragmatic studies comparing the effect of wo different treatments on sick leave

\begin{tabular}{|c|c|c|}
\hline $\begin{array}{l}\text { Author, year, country, } \\
\text { subjects }\end{array}$ & Treatment & Sick leawe oulcane. \\
\hline $\begin{array}{l}\text { Alaranta } 1994 \mathrm{SF}^{76} \\
293 \text { patients with } \\
\text { chronic LBP }>6 \\
\text { months, selected by } \\
\text { insurer }\end{array}$ & $\begin{array}{l}\text { A. Programme of } 3 \text { weeks duralion, } 37 \\
\text { hoursiweek of guided or selfocontrolled } \\
\text { physical exercise, } 5 \text { hoursiweek cognitive } \\
\text { behavioural disability management groups, } \\
\text { no passive trealments }\end{array}$ & $\begin{array}{l}\text { Sick days; no difference after } 1 \text { year }(A: 33,9 \\
\text { B: } 36,9)^{76} \\
\text { Disalbility allowances; no difference after } 1 \\
\text { year (A: } 41153=3 \%, B: 7 / 141=5 \%)^{76} \\
\text { Sick leawe (number of subjects): no difference } \\
\text { during the ist year }(A: 26 \%, B: 23 \%)^{76}\end{array}$ \\
\hline \multirow[t]{3}{*}{ 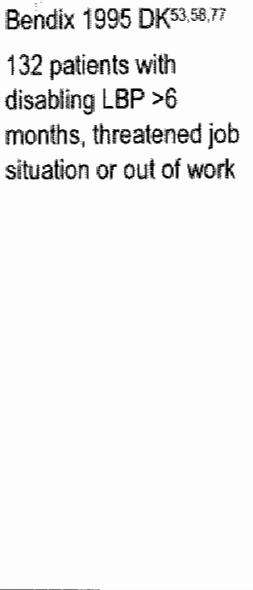 } & $\begin{array}{l}\text { A. Functional restoration; a ful-time } \\
\text { intensive 3-week multidisciplinary } \\
\text { programme, including active physical and } \\
\text { ergonomic training and psychological pain } \\
\text { management, followedl by } 1 \text { day weekly for } \\
\text { the subsequent } 3 \text { weeks. }\end{array}$ & 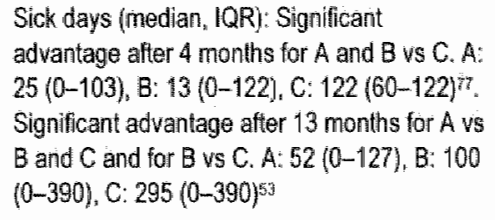 \\
\hline & $\begin{array}{l}\text { B. Active physical training, wice a week } \\
\text { for } 6 \text { weeks, for a tolal of } 24 \text { hours. } \\
\text { C. Psychological pain management } \\
\text { combined with active physical training, } 2 \\
\text { hours wice a week for } 6 \text { weeks }\end{array}$ & 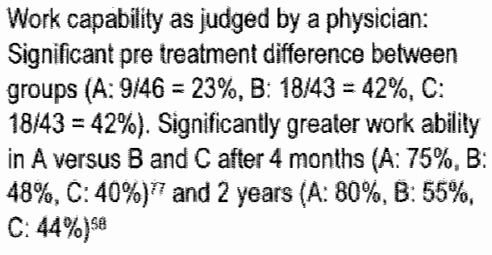 \\
\hline & & $\begin{array}{l}\text { Disability allowanco: Significant advanlage } \\
\text { after } 2 \text { years for A versus } C(A: 17 \% \text {, B: } 33 \% \\
\text { C: } 50 \% \text { ) }\end{array}$ \\
\hline \multirow{3}{*}{$\begin{array}{l}\text { Bendix } 2000 \mathrm{DK} \\
138 \text { pationts in a } \\
\text { precarious work } \\
\text { situation due to LBP }\end{array}$} & \multirow{3}{*}{$\begin{array}{l}\text { A. Three weeks of comprehensive } \\
\text { functional restoration, } 39 \text { hourstweek, } \\
\text { involving intensive physical and ergonomic } \\
\text { training and behavoural support } \\
\text { B. Outpatient intensive physical training; } \\
\text { aerobics and strengthening exercises for } \\
1.5 \text { hours } 3 \text { times/week for } 8 \text { weeks }\end{array}$} & \multirow{2}{*}{ 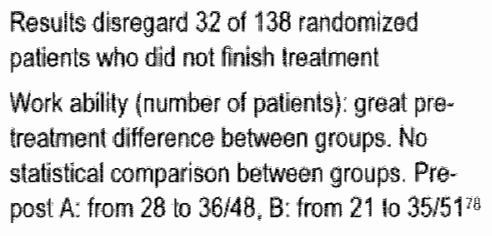 } \\
\hline & & \\
\hline & & 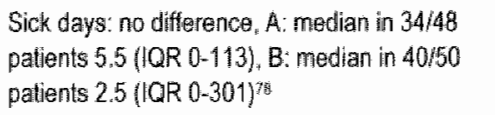 \\
\hline
\end{tabular}


Table 5 (continued). Pragmatic situdies comparing the effect of two difforent treatments on sick leave

\begin{tabular}{|c|c|c|}
\hline $\begin{array}{l}\text { Author year, country, } \\
\text { subjects }\end{array}$ & Treatment & Sick leave outconie \\
\hline \multirow[t]{3}{*}{$\begin{array}{l}\text { Harkâaa } 1990 \text { SF st:34 } \\
476 \text { blue collar } \\
\text { workers, } 2 \text { years of } \\
\text { chronic or intermittent } \\
\text { LBP, sick leave due to } \\
\text { LBP during the last } 2 \\
\text { years }\end{array}$} & $\begin{array}{l}\text { A. Inpatient rehabilitation; } 3 \text { weeks, groups of } \\
\text { 6-8 patients, Swedish back school, relaxation, } \\
\text { heat or electrotherapy prior to exercise, } 2 \\
\text { structured group discussions, horne } \\
\text { programme, rehearsal after } 1.5 \text { years } \\
\text { B Outpatient treatment at the work nlace or }\end{array}$ & \multirow{3}{*}{$\begin{array}{l}\text { Sick days due to LBP: no difference after } \\
1.5 \text { years } \mathrm{A}: 5.5(\mathrm{SD}=25.0), \mathrm{B}: 5.8(\mathrm{SD}= \\
25.0) \text {. Results disregard the first } 7 \text { days of } \\
\text { each episode of sickness absence teading } \\
\text { to a considerable underestimation of the } \\
\text { total days lost from work. } 51 \\
\text { Disability allowances: no difference after } 4.5 \\
\text { years } \mathrm{A}: 10 \%, \mathrm{~B}: 8 \% .51\end{array}$} \\
\hline & $\begin{array}{l}\text { B. Outpatient treatment at the work place or } \\
\text { local health centre; } 15 \text { sessions in } 2 \text { months, } \\
\text { groups of } 6-8 \text { patients, Swedish back school, } \\
\text { relaxation, heat or electrotherapy prior to } \\
\text { sxercise, } 2 \text { structured group discussions, } \\
\text { home programme, rehearsal after } 1.5 \text { years }\end{array}$ & \\
\hline & $\begin{array}{l}\text { C. Usual care, comparisons with the usual } \\
\text { care group see Table } 4\end{array}$ & \\
\hline \multirow[t]{2}{*}{$\begin{array}{l}\text { Ljunggren } 1997 \mathrm{~N} \text { - } \\
126 \text { persons with a } \\
\text { history of LBP. } \\
\text { occupationally active }\end{array}$} & $\begin{array}{l}\text { A. Home exercises with a training apparatus } \\
\text { called the TerapiMaster } 3 \text { times/week, } 15-30 \\
\text { minules, } 12 \text { months. Inilial instruction by } \\
\text { physical therapist, } 8 \text { control visits }\end{array}$ & \multirow[t]{2}{*}{$\begin{array}{l}\text { Sick days: no difference after the 1st year, } \\
A: 15.4(S D=5.3), B: 17.2(S D=6.0) \text { and } \\
\text { 2nd year, } A: 9.3(S D=3.1), B: 9.9(S D= \\
3.2) \text {.2. }\end{array}$} \\
\hline & $\begin{array}{l}\text { B. Conwentional training with home exercises. } \\
\text { Initial instruction by physical therapist, } 8 \\
\text { control visits }\end{array}$ & \\
\hline \multirow{5}{*}{$\begin{array}{l}\text { Lonn and Soukup } 1999 \\
\text { N21,55.82 } \\
120 \text { persons with LBP } \\
\text { requiring trealtment or } \\
\text { sick days }\end{array}$} & $\begin{array}{l}\text { A. Active Back School (ABS), } 20 \text { sessions of } 1 \\
\text { hour each during } 13 \text { weeks, } 20 \text { minutes theory }\end{array}$ & \multirow{2}{*}{$\begin{array}{l}\text { Sick days (mean, } S D) \text {, no difference after } \\
\text { the } 1 \text { st year, } A: 1.9(S D=6.1), B: 8.8 \\
\text { (33). 2i.ss Significant benefit for } A \text { companed } \\
\text { with } B \text { after } 3 \text { years, } A: 4.7(S D=8.0) \text {. B: } 22 \\
(S D=35) \text {. }\end{array}$} \\
\hline & \multirow{4}{*}{$\begin{array}{l}\text { B Mensendieck exercise group (Mi) with 6-10 } \\
\text { participants, } 20 \text { sessions of } 60 \text { minutes for } 13 \\
\text { weeks, Warm up and strelching exercises, } \\
\text { ergonomic information } \\
\text { C Usual care, comparisons with the usual care } \\
\text { group see Table } 4\end{array}$} & \\
\hline & & \multirow{2}{*}{$\begin{array}{l}\text { Sick leave (number of patients): no } \\
\text { difference during the 1st year, } A: 7 / 38= \\
18 \%, B: 10134=29 \% \text { 2: } 2: 5 \text { and during } 3 \\
\text { years follow-up, } A: 12 / 37=32 \% \text {, B: } 13 / 31= \\
42 \%, 8\end{array}$} \\
\hline & & \\
\hline & & 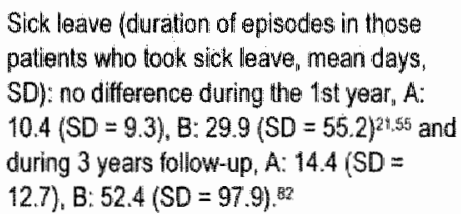 \\
\hline
\end{tabular}


Table 5 (continued): Pragmatic studies comparing the effect of two different treatments on sick leawe

\begin{tabular}{|c|c|c|}
\hline $\begin{array}{l}\text { Author, year, count ty, } \\
\text { subjeds }\end{array}$ & 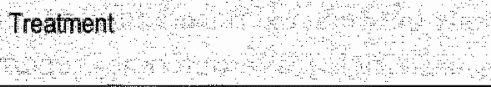 & Sick leave outcone \\
\hline $\begin{array}{l}\text { Petersen } 2002 \text { DKo } \\
260 \text { persons with LBP } \\
>8 \text { weeks }\end{array}$ & $\begin{array}{l}\text { A. Physical therapy using the Mckenzie } \\
\text { method: self-mobilization with repeated : } \\
\text { movements, mobilization by physiotherapist } \\
\text { B. Strengthening training of trunk flexors and } \\
\text { extensors in groups of } 6 \text { patients }\end{array}$ & $\begin{array}{l}\text { Sick leave (number of patients) mo } \\
\text { difference after } 2 \text { months, } A: 9 / 94=10 \%, B \text {; } \\
1286=14 \% \text { and } 8 \text { months, } A: 7 \% 94=7 \% \text {. } \\
B: 7 / 86=8 \% .\end{array}$ \\
\hline $\begin{array}{l}\text { Skouen } 2002 \text { Nsi } \\
195 \text { persons with LBP } \\
\text { sick-listed }>8 \text { weeks }\end{array}$ & $\begin{array}{l}\text { A. Light multidisciplinary programme: } \\
\text { information about exercise, fear avoidance. } \\
\text { Instruction of a personal exercise programme } \\
\text { based on physical tests. Follow-up visits at } 3 \\
\text { and } 6 \text { months. Futher physiotherapy, } \\
\text { appointment with psychologist and work place } \\
\text { visits if necessary. } \\
\text { B. Extensive multidisciplinary programme: } 6 \\
\text { hours/day, } 5 \text { days/week, } 4 \text { weeks. Cognitive } \\
\text { behavioural modification in group sessions, } \\
\text { education, exercise, occasional work place } \\
\text { interwentions. } \\
\text { C. Usual care, comparisons with the usual } \\
\text { care group see Table } 4\end{array}$ & 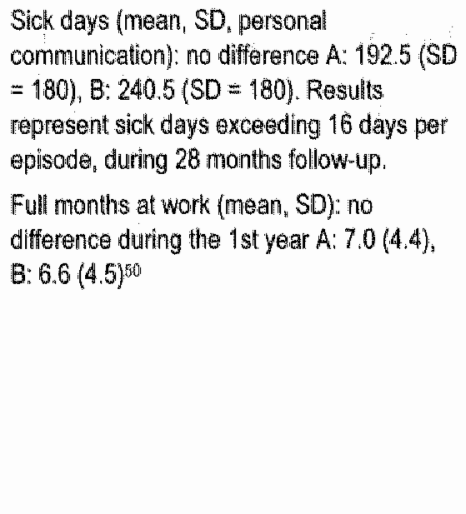 \\
\hline $\begin{array}{l}\text { Torstensen } 1998 \text { Nig } \\
137 \text { gainfully employed } \\
\text { palients sick-listed } 4-8 \\
\text { weeks because of } \\
\text { LBP, birth in Nonway }\end{array}$ & $\begin{array}{l}\text { A. Medical exercise therapy (MET) } 36 \\
\text { treatments of } 1 \text { hour duration for } 12 \text { weeks, } \\
\text { groups of } 5 \text { patients, } 6 \text { to } 9 \text { exercises doing } \\
\text { approximately } 1000 \text { repetitions } \\
\text { B. Conwentional physiotherapy (CP); } 36 \\
\text { treatments of } 1 \text { hour duration for } 12 \text { weeks, } \\
\text { heat or cold, massage, traction, } \\
\text { electrotherapy, exercises individually tailored } \\
\text { to the palient's symptoms } \\
\text { C. Usual care, comparisons with the usual } \\
\text { care group see Table } 4\end{array}$ & $\begin{array}{l}\text { Retum to work: no difference } 15 \text { monthsi } \\
\text { after inclusion } A: 41 / 71=58 \%, B, 4267= \\
63 \% . \\
\text { Disability benefit: no difference } 15 \text { montlis } \\
\text { after inclusion } A: 971=13 \%, 967= \\
13 \% \text {. }\end{array}$ \\
\hline
\end{tabular}




\section{QUANTITATIVE SICK LEAVE ANALYSIS}

Nine studies analysed 13 comparisons between exercise and usual care. The number of sick days was the most frequenty used sick leave outcome, reported in 12 treatment comparisons. ${ }^{21,49-51,55,56,59-61}$ Three studies reported sick days due to LBP..$^{21,51,55,61}$ Four studies reported sick days due to all diseases ${ }^{49,50,59,60}$ whereas 1 study did not clearly specify the reason for sick leave during the second follow-up year. ${ }^{56}$ Most studies reported work days lost due to sick leave. ${ }^{49-51,56,59,60}$ One study reported calendar days lost due to sick leave ${ }^{59}$ and 2 studies did not give detals on this aspect. ${ }^{21,55,61}$ One study recorded work capability as judged by a physician. ${ }^{59}$ Other studies reported the mean time until return to work ${ }^{36}$ or the rate of return to work. ${ }^{60}$ Because sick days were recorded with different methods, a standardized effects model was used for pooling. The sick days during the follow-up year ranged from $1.9^{21}$ to 155 days. ${ }^{49}$

The number of sick days, the proportion of patients who returned to work and the proportion of patients receiving a disability allowance were analysed separately for the different follow-up durations.

Figure 1 shows the number of sick days in 12 comparisons between exercise and usual care. The effect sizes were negative in all studies (between -0.18 and -0.67 ) favouring the experimental treatment. Ten treatment comparisons with 1998 patients reported sick days after 1 year. The 1 -year results were homogeneous (chi square $=15.61, p=0.075$ ) and the effect size was $-0.24(-0.36,-0.11, p=0.0002)$ in favour of the treatments using exercise. At the other follow-up times only 1 or 2 treatment comparisons with 1.06-291 patients were available with effect sizes of -0.67 ( 4 months, $p=0.0008$ ), -0.18 (second year, $p=0.31),-0.26\left(28\right.$ months $\left._{*} p=0.05\right)$ and $-0.62(3$ years, $p=0.07)$.

Figure 2 shows the sick days results in a subgroup of 5 studies describing 7 treatment comparisons in patients with an average of more than 90 sick days in the control group during the first follow-up year. All studies favoured the experimental treatment. The 1year results were homogeneous (chi square $=1.17, p=0.88$ ) and the effect size was $0.30(-0.17,-0.42, p<0.00001, n=1016)$. At the other follow-up times, the effect size was -0.67 ( 4 months), -0.38 (during the second year) and -0.26 (28 months). 
Figure 1. Sick days, comparisons between experimental treatments and usual care

\begin{tabular}{|c|c|c|c|c|c|c|c|c|}
\hline \multirow{2}{*}{$\frac{\text { Study }}{\text { of } 4 \text { moriths }}$} & $\begin{array}{l}\text { exercilise } \\
\text { n }\end{array}$ & \multirow[t]{2}{*}{ mean(sd) } & $\begin{array}{l}\text { usuall care } \\
\text { n }\end{array}$ & mean $(s \mathrm{~d})$ & \multicolumn{2}{|c|}{ 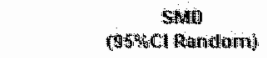 } & \multirow[t]{2}{*}{ Wowight } & \multirow[t]{2}{*}{ 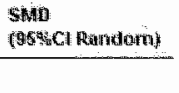 } \\
\hline & & & & & & & & \\
\hline Bervalix (9996) & 55 & $48.00(50.00)$ & 51 & 8200951 001 & 世和 & & tooto & $0.6 \%[-100 \%, 020]$ \\
\hline Sublidat $(95 \% \mathrm{C})$ & 55 & & 51 & & + & & 1000 & $.0 .87-106,0,200]$ \\
\hline \multicolumn{9}{|c|}{ 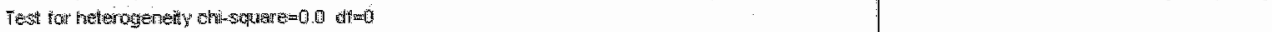 } \\
\hline \multicolumn{9}{|c|}{ Test for whe all eftect $z=3,34 \quad p=0.0000$} \\
\hline \multicolumn{9}{|l|}{ 02 9 year } \\
\hline Hoger & 237 & $55,50,102.00 \%$ & 220 & 133.70010 .001 & - & & 150 & $-0.30,0,0,0.19$ \\
\hline Hesti & 95 & $8.10,26.90)$ & 93 & 11.1026809 & & - & 16 & 01140.00181 \\
\hline 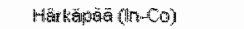 & $15 ?$ & 5.502500 & 160 & 75002500 & - & + & 13.8 & 0080.300144 \\
\hline 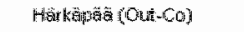 & 159 & $580(2500)$ & $\| 60$ & $7 . \sin 000$ & $\rightarrow$ & - & 139 & - 0170029015 \\
\hline Lonnsoulkus (ABS-Go) & 43 & 1904001 & 36 & $11.90(15.000)$ & 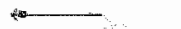 & & 5.5 & $-0.93[-1.39,40,4]$ \\
\hline Lanns:setikup $(k-6)$ & 39 & 8.801500 & 3ब & $11.90(15.00)$ & & 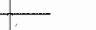 & 5.8 & 02010850241 \\
\hline Skouen (Extanis-con & 57 & $16400(135000)$ & es & $18800(138000)$ & & - & 8.7 & $-0.2010 .5,6141$ \\
\hline Skcuen (lightol-o) & $\$ 2$ & $15100013200)$ & 38 & $188,00(138,00)$ & & 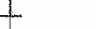 & . 4.4 & $0.27062 \% \%$ \\
\hline Morsterisen (CIP-CO) & 67 & 119000100000 & 70 & 155000130.000 & & & 9.6 & 0.3110 .646031 \\
\hline Tor siensen (MET-CO) & 71 & $132000(10000)$ & 70 & $15500(130.00)$ & & - & 6.8 & $0.401053,431$ \\
\hline Subtotal(95\%c) & 97 & & 1021 & & & & 1000 & $02410.36,0111$ \\
\hline \multicolumn{9}{|c|}{ 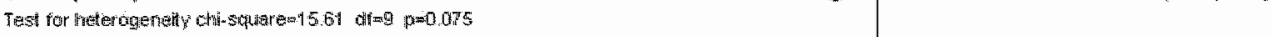 } \\
\hline \multicolumn{9}{|c|}{ Tesal tor axterall affect $I=3.76 \quad p=0.000$ ? } \\
\hline \multicolumn{9}{|l|}{ os and year: } \\
\hline Hurrí & 35 & 9.00023600 & 93 & $9.50(2500)$ & & & 56.9 & .00220319 .271 \\
\hline Lindstrabru & 51 & $6000(9200)$ & 52 & $9800(10350)$ & (1) & & 431 & 0.3810 .770001 \\
\hline Sublotald $95 \%$ (a) & 146 & & 145 & & & & 100.0 & $0.48[-0.53,646]$ \\
\hline \multirow{2}{*}{\multicolumn{9}{|c|}{ 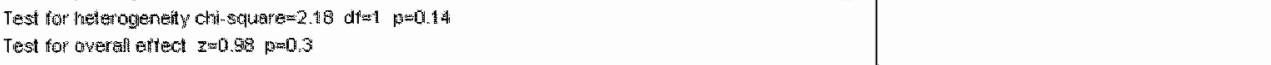 }} \\
\hline & & & & & & & & \\
\hline \multicolumn{9}{|l|}{ Gud 28 months } \\
\hline Skouen (Extens-Coi) & $5 \pi$ & $240.50(180.00)$ & 86 & 283.500180000 & 瑟- & —. & 51.6 & $-0.13-2,46,0.24$ \\
\hline Skouen (Ligtetto) & 52 & $19250(180.00)$ & 86 & 283.50060000 & - - & & 46.4 & $039\left[0.744^{2} 0.04\right]$ \\
\hline Sulftatal(95\%(a) & 109 & & 172 & & & & 100.0 & $-0.261-0.520 .001$ \\
\hline \multicolumn{9}{|c|}{ Test for heterogeneity chis square=t $16 \mathrm{df}=1 \mathrm{p}=0.28$} \\
\hline \multicolumn{9}{|c|}{ Teat for overall effect $z=1.99$ p-0.05 } \\
\hline \multicolumn{9}{|l|}{ 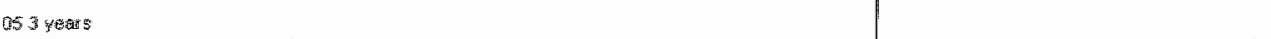 } \\
\hline Lothisaurup (ABS-Co) & 37 & $4700000)$ & 35 & $32.000(41.001)$ & 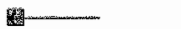 & & 499 & 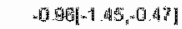 \\
\hline Lombsukug ( $M+C$ ) & 31 & $22000(3500)$ & 35 & 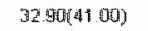 & - & - & 50.1 & $0.764 .7 \%, 0.201$ \\
\hline 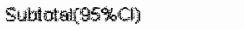 & 6) & & 70 & & 1 & & $100 . a$ & -06214.260041 \\
\hline \multicolumn{9}{|c|}{ 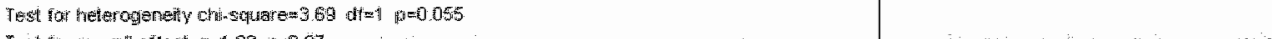 } \\
\hline 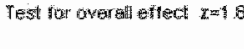 & $3 \beta=0.0 \%$ & & & & . & th & & \\
\hline
\end{tabular}


Figure 2. Sick days in studies with severely disabled patients $(>90$ sick days in the control group). Extens = extensive rethabilitation, $\mathrm{Co}=$ control group, Light $=\|$ ight rehabilitation, $C P$ = conventional physiotherapy, $M E T=$ medical exercise therapy

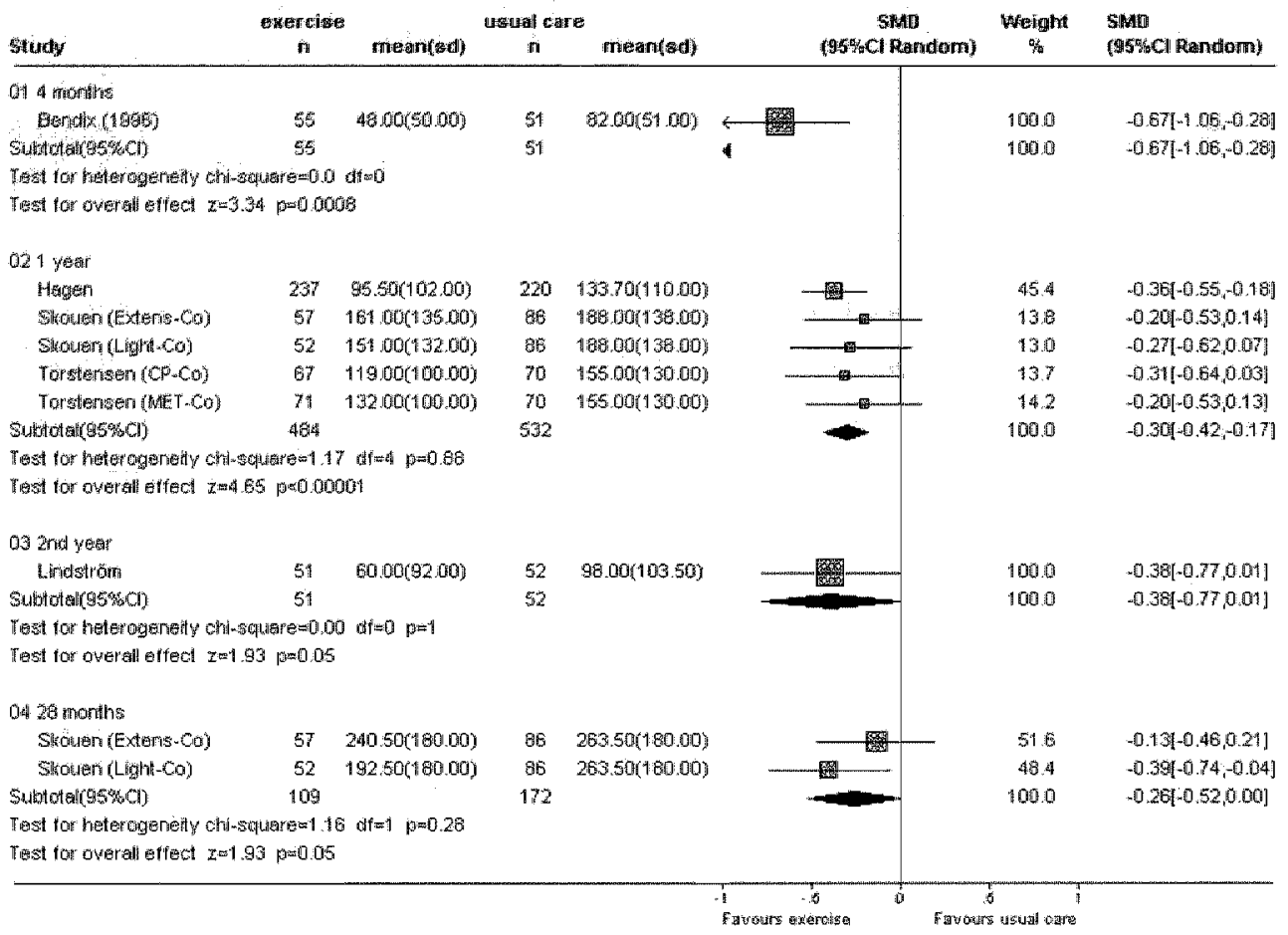


Figure 3. Proportion of patients not at work, comparisons between experintental treatments and usual care. $\mathrm{CP}=$ conventional physiotherapy, MET = medical exercise therapy, Co: control guroup

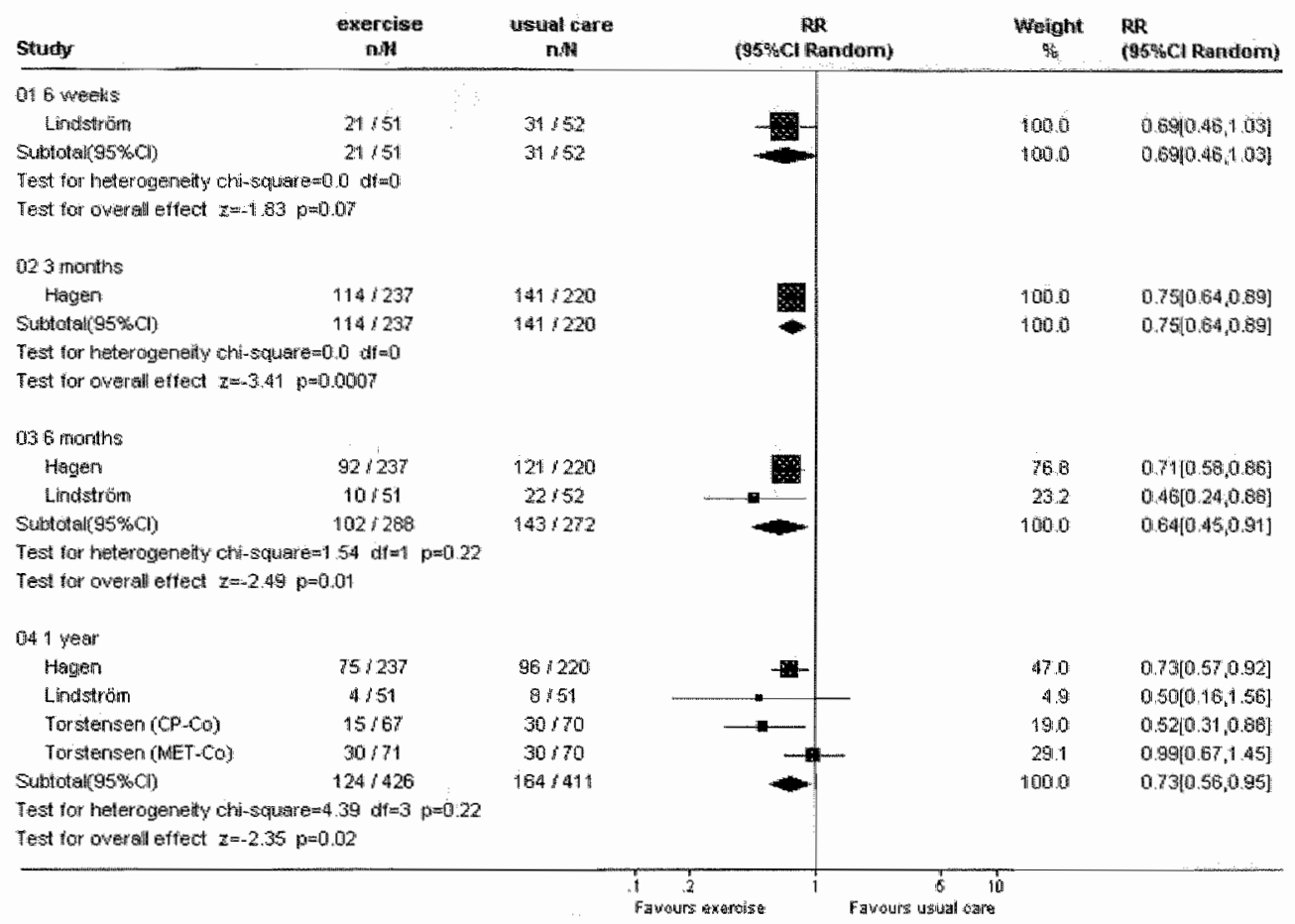

Three studies reported the proportion of patients who had returned to work, a desirable outcome generally favouring the experimental treatment. To obtain results with a meaning comparable to sick days and disability allowances, which tre undesirable outcomes, we computed the proportion of patients not at work, displayed in figure 3. The relative risk at the different follow-up times ranged from $0.64-0.75$ and was significant after 3 and 6 months and after 1 year. 
Figure 4. Disability allowances, comparisons between expermental treatmenis and usual care. ABS = active back school; $\mathrm{CO}=$ control group, $\mathrm{CP}=$ conventional physictherapy $\mathrm{MET}=$ medical exercise therapy; in $=$ inpatient rehabilitation, Out $=$ outpatient rehabilitation

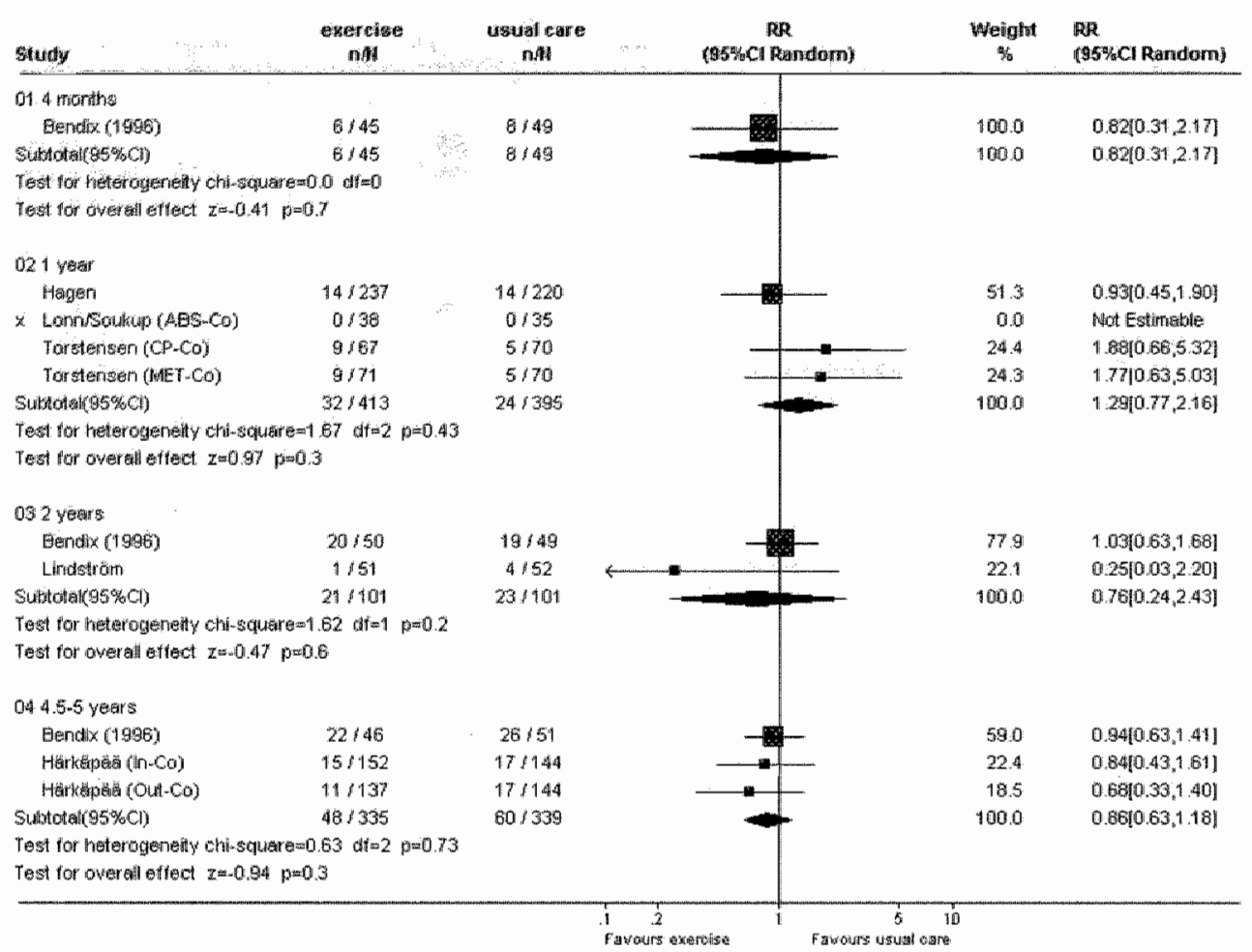

The number of patients receiving a disability allowance was reported in 6 studies with non-significant results in all studies (Figure 4). The pooled relative risk was not significant at any follow-up time and ranged from 0.76 to 1.29 . The prevalence of receiving a disability allowance was low in most studies, which reduces the power to detect a relevant difference. 


\section{Discussion}

The results of the qualitative and quantitative analysis are consistent. Treatments using exercise alone or as a part of a multidisciplinary treatment reduce sick leave in patients with non-specific non-acute LBP. The effects are greater in more severely disabled patients and tend to decline with increasing follow-up duration. It remains unclear whether the number of patients receiving a disability allowance is reduced, and there is insufficient research comparing the effectiveness of different treatments.

The methodological quality of the included studies shows flaws (Table 3). In approximately $50 \%$ of the studies randomization was not concealed, assessment was not blinded and the authors did not apply or describe analysis by intention-to-treat. Eight out of 10 treatment comparisons showed non-significant differences in the number of sick days during the first follow-up year (Figure 1). Considering the effect sizes found in this meta-analysis, the statistical power of the individual studies was too small because the number of patients and the homogeneity of the groups were insufficient. In addition, measurement of the number of sick days seems inappropriate when the number of sick days under usual care is small, leading to a floor effect and a decrease in power.

Previous reviews addressed the effects of vocational rehabilitation ${ }^{62}$, multidisciplinary biopsychosocial rehabilitation ${ }^{63}$, conservative ${ }^{10}$ or behavioural treatment ${ }^{11}$ without specifically investigating whether sick leave can be reduced. In 1997, conflicting evidence regarding the beneficial influence of back schools and exercise therapy on vocational outcome was found. ${ }^{62}$ Since then, several new studies were performed reporting return to work.

A recent review by Guzman reported a dose-response relationship and concluded that especially multidisciplinary rehabilitation of more than 100 hours is effective in reducing pain and function. ${ }^{2}$. This review shows, that treatments of much shorter duration can reduce sick leave. Guzman however, only included RCTs evaluating multidisciplinary rehabilitation. This review includes all RCTs using exercise alone or as a part of a multidisciplinary treatment, reporting sick leave. Some RCTs included by Guzman were excluded from this review because they did not report sick leave outcome $e^{24,64-67}$ or included patients with thoracic or cervical pain. ${ }^{24}$

We applied a limit of 5 or more out of the maximal obtainable 8 points as a cul-off point for good methodological quality. Although this choice is arguable, it accords with other reviews. ${ }^{10-12}$ The presentation of information about methodological quality and outcome allows the reader to form his or her own opinion. Correlation coefficients between the 
methodological quality and the treatment effect can be used to investigate whether methodological quality is related with the magnitude of the treatment effect. Significant negative correlations might hint at bias, prompting the inclusion of only the high quality studies. Ten treatment comparisons reported sick days during the first follow-up year. The methodological quality ranged from 5 to 7 . Higher quality was associated with a greater effect size, indicated by a significant positive correlation (Spearman Rho $=0.68$, $p=0,033)$. The other outcomes were reported in less than 6 comparisons and the determination of a correlation coefficient was considered inappropriate.

Using mean values and standard deviations for further statistical analysis in data with a skewed distribution is usually regarded as inappropriate. Data regarding sick days have a skewed distribution. The skewedness is probably similar across studies and does not bias the direction of the results in pooling. ${ }^{68}$ Other authors have advocated the use of parametric statistics in skewed data under these circumstances. ${ }^{69}$

An important point of consideration is the degree of heterogeneity of studies. We seriously considered this possible limitation but concluded that patients, treatments and outcome measurements showed satisfactory homogeneity. First of all, 13 of the 14 included studies were performed in Scandinavian countries among employed persons. The medical diagnosis is non-acute non-specific low back pain in all patients. The main conclusions of this review are all based on comparisons of an experimental treatment with usual care. Exercise, usually as a part of a multidisciplinary treatment, was applied in all studies. Different professions were involved in the treatment, but this was not considered to introduce serious heterogeneity since recent studies could not show a difference in effectiveness between behavioural treatments provided by lay leaders and comparable treatments provided by psychologists. ${ }^{70} \mathrm{~A}$ further indication of the homogeneity of the studies is the fact that the results of each outcome are similar across studies.

The inclusion of all studies using exercise alone or as a part of multidisciplinary treatment was also supported by previous research that could not identify any specific type of exercise as being more effective than another, leading to the conclusion that increasing activity seems to be the crucial element. ${ }^{71}$ This conclusion further relieves the concern about the heterogeneity of types of exercise in this review. Another remark must be made to the statements about treatments being "behavioural" or "based on the biopsychosocial concept". These statements can easily be misunderstood and do not mean that other treatments do not change behaviour. The authors strongly support the importance of behavioural aspects of treatment and think patient behaviour is not only changed by multidisciplinary treatment claiming to provide behavioural treatment. AlI forms of activity and exercise may change behaviour. A recent RCT in patients without clinical signs of specific LBP of 6 weeks duration showed that taking X-rays increased pain and reduced health status. Patients were not less worried about serious disease 
causing their low back pain. ${ }^{72}$ Even the advice to stay active has snall beneficial effects for patients with acute non-specific LBP. ${ }^{73}$

Differences in psychosocial prognostic factors among studies probably are the most justifiable factor that may have introduced heterogeneity in this review. Only a few psychosocial prognostic factors were mentioned in most studies and comparisons between studies were impossible. For future studies, a core set of predictive factors to describe participants in a standardized way would enable comparison of different study populations. Recommended predictive factors are age, sick days during the year prior to treatment, depression, workload, job satisfaction, fear avoidance beliefs and education. ${ }^{74}$

For future RCTs the number of days lost from work is probably the single most important measure, constituted by the sum of sick days, the time on a disability allowance and unemployment time. Each measure should be recorded during the year before treatment and during the follow-up period. The response to treatment is the between-group difference in the status before and after treatment. None of the reviewed. studies reported the response to treatment as previously defined.

There is no evidence in this review for the assumption that early intervention is more effective. The reduction in the number of sick days is greater in patients who had more sick leave. Future research should investigate which patients might benefit from expensive treatments. Some clinical tests have been investigated and their prognostic validity was confirmed, allowing their use as screening tests to exclude patients with less than a $5 \%$ probability to return to work and thereby increase cost-effectiveness. ${ }^{75}$

\section{Conclusion}

There is strong evidence that sick days are reduced during the first year after treatment $(\mathrm{SMD}=-0.24,95 \% \mathrm{CI}=-0.11,-0.36)$ especially in severely disabled patients witl $>90$ sick days per year under usual care in the control group ( $\mathrm{SMD}=-0.30,95 \% \mathrm{CI}=-0.17$, 0.42). There was insufficient research regarding the effect on sick days beyond 1 year and the number of patients receiving a disability allowance at any follow-up time.

Further research is needed regarding the relative cost-effectiveness of different treatments. The single most important sick leave outcome recommended is the number of days lost from work due to sick leave. Research is needed to identify political and psychosocial factors in-relation to the effectiveness of treament. The reduction of LBPrelated costs for society is an action demanding integrated efforts from health professionals, polliticians and economists. 


\section{Acknowledgements}

We thank all the authors of the primary papers who supplied additional information.

\section{References}

1. Waddell $G$. Volvo award in clinical sciences. A new clinical model for the treatment of low-back pain. Spine $1987 ; 12: 632-644$

2. Abenhaim L, Rossignol M, Valat JP, Nordin $M$, Avouac $B$, Blotman $F$, et al. The role of activity in the therapeutic management of back pain. Report of the International Paris Task Force on Back. Pain. Spine $2000 ; 25: 18-335$.

3. Spitzer WO. Sicientific approach to the assessment and management of activity-retated spinal disorders. A. monograph for clinicians. Report of the Quebec Task Force on Spinal Disorders. Spine 1987;12: S1-S59.

4. Frymoyer JW. The adult spine: principles and practice, 2 nd edn. In: The econonics of spinal disorders. Philadephia: Lippincott-Raven Publishers; 1997.

5. Bolten W, Kempet-Waibel A, Pforringer W. Analysis of the cost of illness in backache. Med Klin 1998; 93: $388-393$.

6. Birosseau $L$, Milne $\$$, Robinson $V$, Marchand $\$$, Shea $B$, Wells $G$, et al. Efficacy of the transcutaneous electrical nerve stimulation for the treatment of chronic low back pain: a meta-analysis. Spine 2002; $27: 596-603$.

7. Nordin M, Campello M. Physical therapy: exercises and the modalities: when, what, and why? Neurol! Clir 1999; 17: 75-89.

8. Nelemans PJ, de Bie RA, de Vet HC, Sturmans F. Injection therapy for subacute and chronic benign low back pain. Cochrane Database Syst Rev 2000; CD001824.

9. Koes BW, Van Den Hoogen HMM. Efficacy of bed rest and orthoses of low-back pain. A review of randomized clinical trials. Eur J Phys Med Rehabil 1994; 4: 86-93.

10. van Tulder MW, Koes BW, Bouter LM. Conservative treatment of acute and chronic non-Specific low back pain. A systematic review of randomized controlled trials of the most common interventions. Spine $1997: 22: 21: 28-2156$.

11. van Tulder MW, Ostelo RW, Vheyen JW, Linton SJ, Morley SJ, Assendelft WJ. Behawoural treatment for chronic low back pain. Cochrane Database Syst Rev 2000; CD002014.

12. Guxman d, Esinail $\mathbb{R}$, Karjalainen $K$, Malmivaara $A$. Irvin $E$, Bombardier $C$. Multidisciplinary rehabilitation for chronic low back pain: systematic review. BMJ 2001; 322: 1511-1516.

13. van Tulder M, Assendelf W, Koes B, Bouter L. Method guidelines for systematic reviews in the Cochrane Collabonation Back Review Group for spinal disorders. Spine 1997; $22: 2322-2330$.

14. Seluulz KF. Subverting randomization in controlled trials. JAMA 1995; 274:1456-14.58.

15. Verhagen AP, de Vet HC, de Bie RA. Kessels AG, Boers M, Bouter LM, et al. The Delphi list: a criteriat list for quality assessment of randomized clinical trials for conducting systematic reviews developed by Delphi consensus: I Clin Epidemial 1998; $51: 1235-1241$.

16. Burton AK, Waddall G, Tillotson KM, Summerton N. Information and advice to patients with back pain: can have a positive effect. A randomized controlled trial of a novel educational booklet in primary care. Spine $1999 ; 24: 2484-2491$.

17. Hazard RO, Reid S, Hatgh LD, McFarlane G. A controlled trial of an educational pamphlet to prevent disability after occupational low back injury. Spine 2000; 2001: 1419-1423.

18. Hedges L. Olkin 1. Statistical Methods for Meta-analysis. In. San Diego: Acadenic Press; 1985: Ch. 5.

19. White AW. Low back pain in men receiving workmen's compensation. Can Med Assoc J1966; 95: 5056.

20. Ljunggren $\mathrm{AE}$, Weber $\mathrm{H}$, Kogstad $\mathrm{O}$. Thom $\mathrm{E}$, Kirkesola $\mathrm{G}$. Effect of exercise on sick leave due to low back pain. A randomized, comparative, long-term study. Spine 1997; 22: 1610-1616. 
21. Lonn IH, Glomsrod B, Soukup MO, Bo K, Larsen S. Active baek sohool: prophylatic managenent for low back pain. A randomized, conmolled, L-year follow up study. Sphe 1999; 24: 865-871.

22. Lukimana A. Low back pain as a biopsychosocial problem. A controlled dinical frim and bosteffectiveness analysis (Finnish). Kanianelakelailoksen julkaisuja 1989: ML: 90 .

23. Lukinma A. Low back pain as a biopsychosocial disturbance: a controfled trial (Finish).

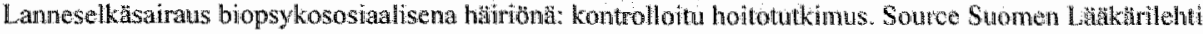
$1900 ; 45: 3197-3201$.

24. Mitchell RI, Carmen GM. The functional restoration approach to the treament of chronic pain in patients wh th soft tissue and back injuries. Spine 1994; 19:633-642.

25. Haldorsen EMH, Kronholm K, Skouen JS, Ursin M. Multimodal cognitive behavional treatment of patients sicklisted for nusculoskeletal pain; a randomized controlled study. Scand I Rhoumatol 1998: 27: $16-25$

26. Hemmila HM, Keinanen-Kiukannieni SM, Levoska S. Puska P. Long-term effectiveness of bonesetting, light exercise therapy, and physiotherapy for prolonged back pain: a randonized controlled trial. Manipulative Physiol Ther 2002; $25: 99-104$.

27. Hsieh CY, Adams AH, Tobis J Hong CZ, Danielson C. Platt K, et al. Effectiveness of four conservaltive treatments for subacute low back pain: a randomized clinical trial. Spine 2002; 27: 1142-1148.

28. Skargren EI, Oberg BE, Carlsson PG, Gade $M$. Cost and effectiveness anallysis of chiropmetic and physiotherapy treatment for low back and neck pain. Six-monch follow-up. Spine 1997; 22:2167-2177.

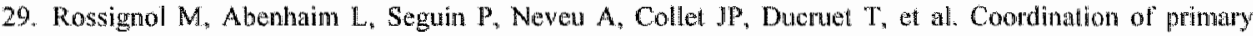
heal h care for back pain. A randomized controlled trial. Spine 2000; $25 ; 251-258$,

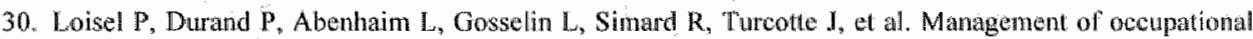
back pain: the Sherbrooke nodel. Results of a pilot and feasibility study. Occup Environ Med 1994; 5 ll: 597-602.

31. Jersen IB, Dahquist C, Nygren $A$, Royen E, Stenberg M. Treatment lor hatpless" women sulfering from chronic spinal pain: a randomized controlled 18-nonth follow-up study. J Occup Rethabil 1997; 7: 225238.

32. Kellett KM, Kellett DA, Nordholim LA. Effects of an exercise program on sick leave due to back pain. Phys Ther 1991; 71:283-291.

33. Linton SI, Ryberg M. A cognitive-behavional group interwention as prevention for persistent neck and back pain in st non-patient population. a randomized controlled trial. Pain 2001; 90: 83-90.

34. Linton SJ, Hellsing AL, Larsson 1. Bridging the gap: support groups do not enlance long-tem outcome in chronic back pain. Clin I Pain 1997: 13:221-228,

35. Linton S., Andersson T. Carn chrowic disability be prevented? A randomized trial of a countive-behawior intervention and wo lons of infomation for patients with spinal pain. Spine 2000; 25: 2825-2831.

36. O.Sulliwan PB, Phyty GD. Twomey LT, Allson GT. Evaluation of specifie stabilizinge exercist in the treatment of chronic low back pain with radiologic dagnosis of spondylolysis or spondy lolishesis. Spine $1997 ; 22: 2959-2967$

37. Spratt KF, Weinstein. JN, Lehmann TR, Woody I, Sayre H. Enficacy of flexion and gxtchsion treatments incorporating braces for lowback pain patients with retrodisplacement spondylolisthesis, or normal sagittal translation. Spine 1993;18:1839-1849.

38. Moller $H_{*}$ Hedlund R. Surgery versus conservative managenent in adult isthmic spondylolisthesis - a prospecive randomized study: Part 1. Spine $2000 ; 25: 1711-1715$.

39. Ostgaard HC, Zetherstrom G, Roos Hansson $\mathbb{E}_{*}$ Swanberg B. Reduction of back and postcrior polvio pein in pregrancy. Spine 1994: 19:894-900.

40. Kihtstrand M, Stenman B, Nilsson S. Axelsson O. Water-gymnastics rudduced the intensity of back/low back pain in pregnant wốmen. Acta Obstet Gynccol Soand 1999; 78: 180-185

41. Keijsers I. Steenbakkers M, Meertens RM, Bouter LM, Kok G. The erlicacy of the back school: a randomized trial. Arthritis Care Res 1990; 3:204-209..

42. Tumer JA. Comparison of group progressive-felaxation training and cogritiwe-betavional group therapy for chronic low back pain. J Consuli Clin Psychol 1982, 50: 757-765. 


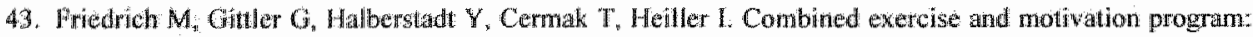
wect on the conpliance and level of disablity of patients with chronic low back pain a randomized controlled trial. Arch Phys Med Rehabill $1998 ; 79 ; 475-487$.

44. Bentgen 14 . Lindgarde $F$ Manihorpe $\mathbb{R}$. The effect of dynamic strength back exercise and ar a home training progom in 57 -yearold women with chronic low back pain. Results of a prospecive randomized study with 3-year follow-tup period, Spine 1997; 22: 1494-1500.

45. Almaier fM, Lehmann TR, Russell DW, Weinstein JN, Kao CF. The elfectrveness of psychological interventhons for the rehabilitation of low back pain: a randomized controlled trial evaluation [see comments]. [aid $1992 ; 49: 329-335$.

46. Klaber Moffet J, Torgerson D, Bell Syer $\mathrm{S}$, Jackson D, Llewlyn Phillips $\mathrm{H}$, Farmin $A$, ei al. Randomised controlled trial of exercise for low back pam: Clinical outcomes, costs, and preferences. Br Med $J 1999$ Jut; $31: 279-283$.

47. Jengen I, Bergston $G$, Ljungquist T, Bodin L, Nygren A. A randomized controlled componeyt analysis of a behaviorat medicine rehabilitation progran for chronic spinal pxin: Are the effects dependent on gender? Pain $2001 ; 91: 65-78$.

48. Indahl $A$, Velund $L_{*}$ Reikeraas 0 . Good prognosis for low back pain when left untampered. A randomized clinical trial, Spine $1995 ; 20: 473-477$.

49. Torstensen TA, Ljunggren AE, Meen HD, Odland E, Mowinckel P, Geijerstam S. Efficiency and costs of medical exercise therapy, conventional physiotherapy, and self-exercise in patients with chronic low back pain. A pragmalic, randomized, single-blinded, controlled trial with l-year follow-up. Spine 1998; 23: $2616-2624$

50. Skouen JS, Grasdal AL. Haldorsen EM, Ursin H. Relative costeffectiveness of extersive and light multidisciplinary treatment programs wersus treatment as usual for patients with chronic low back pain on long tern sick leave: randomized controlled study. Spine 2002; 27:901-910.

51. Härkaphat $K$, Mellin G, Jarvikoski A, Hurri H. A controlled study on the outcome of inpatient and outpatient treatment of low back pain. Part IT. Long-term follow-up of pain, disability, and complance. Scand I Rehabil Med 1990; 22: 181-188.

52. Bendix AE, Bendix T, Haestrup C, Busch E. A prospective, randomized 5-year follow-up study of functional restoration in chromic low back pain patients. Lur Spine J 1998; 7: 111-119.

53. Bendix AF, Bendix T, Lund C, Kirkbak S, Ostenfeld S. Comparison of three intensive programs for chronic low back pain patients: a prospective, randomized, observer-blinded study with one-year followup. Scand J Rehabil Med 1997; 29:81-89.

54. Markapabi K, Jarwikoski A, Mellin G, Murri H. A controlled study on the outcome of inpatient and outpatient treatment of low back pain. Part 1. Pain, disability, compliance, and reported treatment benefits three nonth alter treament. Scand I Rehabil Med 1989:21:81-89.

55. Soukup MG, Glomsrod B, Lonn JH. Bo K, Larsen S. The effect of a Mensendiack exercise program as secondary proplyylaxis for recurrent low back pain. A randomized, controlled trial with 12- month followup. Spine 1999; 24: 1585-1591.

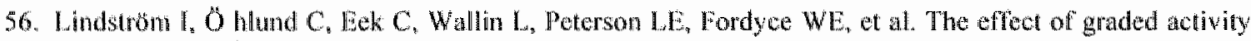
on patients wh subacule low back pain a randomized prospective clinical study with an operantconditioning behavioral approach. Phys Ther 1992; $72: 279-290$

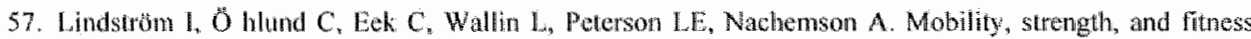
after a graded activity program for patients with subacute low back pain. A randomized prospective dinical study with a behavioral therapy approach. Spine 1992;17:641,-652.

58. Bendix AF, Bandix T, Labriola M, Boekgadrd P. Fumetional restontion for chronic low back pain. Twoyear follow-up of two randomized clinical trials. Spine 1998; 23:717-725.

59. Bendix AF", Bendix T", Vaegter $K_{\text {u, }}$ Lund $C$, Frolund $\mathrm{C}$, Holm L. Multidisciplinary intensive treatment for chronic low back pain: and randomized, prospective stucy. Cleve Clin J Med 1996; 63:62-69.

60. Hagen EM, Eriksen HR, Ursin H. Does enrly intervention with a light mobilization progtan reduce longterm sick leave for low back pain? Spine 2000; 25: 1973-1976.

61. Hurri H. The Swedish back school in chronic low back pair. Part I. Benefits. Scand J Rehabil Med 1989; $21: 33-40$. 
62. van der Weide WE, Verbeek JH, van Tuldex MW. Vocational outcome of untervention for low-back pain. Scand I Work Environ Healith $1997 ; 23: 165-178$.

63. Karjalianen $K$, Malmivaara $A$, van Tulder $M$, Roine $R$, Jauhiainen $M_{4}$ Hurri $H_{4}$ et al. Multidisciplinary biopsychosocial rehabilitation for subacute low back pain among working age adults (Cochrane Review).The Cochrane Library; 2000.

64. Basler HD, Jakle C. Kroner-Herwig B. lncorporation of cognitivebehaviosal treatment into the medical care of chronic low back patients: a controlled randomized study in German pain treatment centers. Patient Educ Couns 1997; $31: 113-124$

65. Jückel WH, Cziske R, Gerdes N, Jacobi E Assessment of the effectivness of inpatient rehabilitation measures in patients with chronic low back pain: a prospective randonised controlled study. Rehabilitation 1990; 29: 129-133.

66. Nichollas MK, Wilson PH, Goyen J. Comparison of cognitivebelavioral group treatment and tin alternative non-psychological treatment for chronic low back pain. Pain 1992; 48: 339-347.

67. Nicholas MK, Wilson PH, Goyen J. Operant-behawioural and cognitive-behavioural treatment for chronic low back pain. Behaw Res Ther 1991; 29:225-238.

68. Boneau $\mathrm{CA}$. The effects of violations of assumptions underlying the t test. Psychol Bull 1960; 57: 49-64.

69. Barber JA, Thompson SG. Analysis of cost data in randomized trials: an application of the nonparametric bootstrap. Stat Med 2000; 19: 3219-3236.

70. Von Korff M, Moore JE, Lorig K, Cherkin DC, Saunders K, Gonzalez VM, et al A randomized trial of a lay person-led selfmanagenent group interkention for back pain patients in primary care. Spine 1998; 23: $2608-2615$.

71. van Tuider M, Malmivaara A, Esmail R, Koes B. Exercise therapy for low back pain: a systematic review within the framework of the Cochrane Collaboration Back Review Group. Spine 2000; 25:2784-2796.

72. Kendrick $D_{n}$ Fielding K, Bentley E, Miller P, Kerslake R, Pringle M. The role of radiography in primary care patients with low back pain of at least 6 weeks duration: a randomised (unblinded) controlled trial. Health Technol Assess 2001; 5: 1-69.

73. Hilde $\mathrm{G}$. Hagen $\mathrm{KB}$, Jantvedt $\mathrm{G}$, Wimem $\mathrm{M}$. Advice to stay active as a single treatment for low back pain and sciatica. Cochrane Database Syst Rev 2002: CD003632.

74. Hildebrandt I, Pfingsten M, Saur $P$, Jansen J. Prediction of success from a multidisciplinary treatment program for chronic low back pain. Spine 1997; 22: 990-1001.

75. Kool J, Oesch P, de Bie R. Predictive tests for non-return to work in patients with chronic low back pain. Eur Spine J 2002; 11:258-266.

76. Alaranta H. Rytokoski U. Rissanen A, Talo $S$, Ronnemaa $T$, Pukka P, et al lintensive plysical and psychosocial training program for patients with chronic low back pain. A controlled clinical trial. Spine $1994 ; 19: 1339-1349$

77. Bendix AF, Bendix T, Ostenfeld S, Bush E. Andersen. Active treatment programs for patients will chronic low back pain: a prospective, randomized, observer-blinded situdy. Eur Spine I 1995; 4: 148-152.

78. Bendix T, Bendix A, Labriola M. Haestrup C, Ebbehoj N. Functional restoration versus oupatient physical training in chronic low back pain: an randomized comparative study. Spine 2000; 25: 2494-2500.

79. Lindströn 1. Ohlund C, Nachemson A. Physieal performance, pain, pain behavior and subjective disability in palients with subacute low back pain. Scand J Rehabil Med 1995; 27: 153-160.

80. Petersen T, Kryger P, Ekdahl C, Olsen S, Jacobsen S. The effect of MoKenzic therapy as compared with that of intensive strengthening training for the treatment of patients with subacute or chronic low back pain: A randomized controlled trial. Spine 2002; 27:1702-1709.

81. Glomsrod B, Lonn $\mathrm{JH}_{4}$ Soukup $\mathrm{MG}$, Bo K, Larsen $\mathrm{S}$. Active back school', prophylactic managenent for low back pain: three $y$ ear follow-up of a randonized, controlled trial. I Rehabil Med 2001; 33:26-30.

82. Soukup MG, Lown J, Glomsrod B. Bo K. Larsen S. Exercises and education as secondary prevention for recurrent low back pain. Physiother Res Int 2001:6:27-39. 


\section{Chapter 4}

\section{Increasing days at work using function- centred rehabilitation in nonacute nonspecific low back pain: three-month results from a randomized controlled trial}

Jan P. Kool', Peter R. Oesch ${ }^{2}$, Stefan Bachmann ${ }^{2,3}$, Otto Knüsel ${ }^{3}$, Judith G. Dierkes ${ }^{1.4}$, Mirella Russo', Rob A. de Bie, Piet A. van den Brandt ${ }^{4}$

Affiliations of the authors

' Research Dpt., Rehabilitation Centre Valens, Switzerland

${ }^{2}$ Dpt. of Work Rehabilitation, Rehabilitation Centre Valens, Switzerland

${ }^{3}$ Dpt. of Rheumatology, Rehabilitation Centre Valens, Switzerland

${ }^{4}$ Dpt. of Epidemiology, Maastricht University, The Netherlands

Archives of Physical Medicine and Rehabilitation 2005;86:857-64 


\section{Abstract}

Objective: To evaluate the effect of function-centred compared with pain-centred inpatient rehabilitation in patients whose absence from work is due to chronic nonspecific low back pain (LBP).

Design: Single-blinded randomized controlled trial with follow-up assessments immediately after treatment and at 3 months.

Setting: Center for work rehabilitation in Switzerland. Participants: Patients with more than 6 weeks of work absence due to chronic nonspecific LBP (N=174; 137 men, 37 women; mean age \pm standard deviation, $42 \pm 8 \mathrm{y}$; mean sick leave before study, $6.5 \mathrm{mo}$ ).

Interventions: Function-centred treatment ( $\mathrm{FCT}, 4 \mathrm{~h} / \mathrm{d}, 6 \mathrm{~d} / \mathrm{wk}$, for $3 \mathrm{wk}$ ) consisted of work simulation, strength, endurance, and cardiovascular training. Pain-centred treatment (PCT, 2.51/d, 6d/wk, for $3 \mathrm{wk}$ ) used a mini back-school, individually selected passive and active mobilization, stretching and low-intensity strength training.

Main Outcome Measures: The number of days at work in 3 months after treatment, self-efficacy, lifting capacity, pain, mobility, strength, and global perceived effect. Effect sizes (ESs, Cohen d) were defined as smal1 (ES 0.2-0.5), moderate (ES 0.5-0.8) and large (ES $>0.8)$.

Results: Groups were comparable at baseline. Small to moderate ESs for the FCT group versus PCT group were found for days at work (25.9d vs $15.8 \mathrm{~d}, \mathrm{ES}=36, \mathrm{P}=.029)$, selfefficacy (5.9 points vs -7.4 points, $\mathrm{ES}=.55, \mathrm{P}=.003$ ), and lifting capacity $(2.3 \mathrm{~kg}$ vs $0.2 \mathrm{~kg}, \mathrm{ES}=.54, \mathrm{P}=.004$ ).

Conclusions: Function-centred rehabilitation increases the number of work days, selfefficacy, and lifting capacity in patients with nonacute nonspecific LBP. 


\section{Introduction}

Chronic low back pain (LBP) is a major health problem in Western Europe and North America. The total expenses of the Swiss Disability Insurance fund increased from SFr 4 billion (US $\$ 3.5$ billion) in 1990 to SFr 10 billion (US $\$ 8.75$ billion) in 2002 . Compared with 10 other European Organization for Economic Cooperation and Development countries, Switzerland showed the highest rate of increase. Musculoskeletal disorders, including LBP, were the primary diagnosis in $31 \%$ of all patients receiving disability pensions. Among musculoskeletal disorders, nonspecific disorders showed the largest increase, at $7.9 \%{ }^{2}$ LBP is nonspecific in $85 \%$ of all patients. ${ }^{3}$ Psychosocial factors reduce the success of purely medical treatment and thus have led to the development of multidisciplinary approaches.

Meta-analyses show strong evidence that exercise ${ }^{5.6}$ and multidisciplinary rehabilitation ${ }^{7}$ reduce disability and pain in patients with nonacute LBP. Work absenteeism is reduced by exercise, in comparison with usual care." Several investigators ${ }^{6,9,10}$ found no evidence that favoured 1 particular type of exercise over other types.

Exercise therapy in patients with LBP still relies on a biomedical model of disease that is mainly focused on somatic issues. Diagnosis of the underlying pathologic condition provides the basis for rational physical treatment of the illness. Pain intensity is used to determine the intensity of the exercises and leads to restrictive recommendations regarding activity and work. ${ }^{1 !}$ This approach seems to increase behaviours such as taking pain-killers, seeking health care, stopping work, limping, guarding, and talking about pain. $^{12}$

The biopsychosocial model, applied with patients with nonspecific LBP and other musculoskeletal disorders, emphasizes the role of psychologic factors such as personal beliefs, illness behaviour, and fear avoidance, as well as social factors such as family, work, and the wider social network in the development and maintenance of symptoms." Based on this model, work hardening ${ }^{13}$ and functional restoration progranns ${ }^{14}$ were developed with the intent to overcome dysfunctional illness behaviour and implement ergonomic and social interventions to facilitate return to work.

So far, it appears that the key to success in the treatment of nonspecific nonacute LBP is physical activity in any form, rather than through any specific activity." It remains unclear whether treatment based on the biomedical model with its restrictive recommendations is more effective in reducing work absenteeism than is the treatment based on the biopsychosocial model primarily emphasizing activity.

Our purpose in this study of patients with sick leave resulting from nonspecific nonacute LBP was to evaluate the effect of 3 weeks of function-centred rehabilitation 
compared with pain-centred inpatient rehabilitation on the number of days at work in the first 3 months of follow-up. Secondary outcomes were self-efficacy, lifting capacity, pain, mobility, strength, and patient satisfaction.

\section{Methods}

\section{DESIGN AND SETTING}

We conducted a randomized controlled trial (RCT) to compare the effect of a functioncentred treatment (FCT) versus a pain-centred treatment ( $\mathrm{PCT}$ ) in patients with nonacute nonspecific LBP. Patients were treated by 2 independent multidisciplinary teams in a rehabilitation center specializing in work rehabilitation in Valens, Switzerland. The primary outcome was the number of days at work after discharge. Secondary outcomes were the number of patients at work after 3 months, self-efficacy, lifting capacity, patient satisfaction, pain, and mobility. Included were patients seen between January 2000 and May 2003. Based on a power analysis before the studly, we estimated that 90 patients were needed in each group to detect a difference of 10 days at work during the first 3 months of follow-up, with $80 \%$ power and $\alpha$ equal to .05 . The study was approved by the ethics committee of the Canton of St Gallen. The objectives and the primary and secondary outcomes of the study, described in the outcome measures section, were reported in an earlier publication. ${ }^{\text {is }}$ Publication before a study is begun helps prevent post hoc changes in the reporting of the primary outcome, as well as publication bias.

\section{INCLUSION CRITERIA AND RANDOMIZATION}

Patients were eligible for the study if they were between 20 and 55 years of age, had nonacute nonspecific LBP, and were referred to our center for inpatient rehabilitation. Not eligible were patients with specific LBP from nerve root compression, vertebral fracture, tumor, infection, inflammatory diseases, spondylolisthesis, spinal stenosis, and definite instability. ${ }^{16}$ Two rheumatologists (SB, OK) determined the eligibility of patients.

Inclusion criteria were checked by 2 researchers (JPK, PRO). Patients were included if they had had at least 6 weeks of sick leave in the previous 6 months and were either employed or unemployed and looking for a job. Patients with cardiovascular, pulmonary, or psychiatric disease or some other comorbidity that would reduce working capacity were excluded. Based on the results of an earlier study, we used 4 predictive tests for nonreturn to work; patients with 2 or more positive predictive tests were excluded. $^{15,17}$ These tests were (1) preliminary cessation of a 3-Minute-Step-Test, (2) preliminary cessation of the Triceps-Brachii-Pseudo-Strength-Test, (3) a positive 
Waddell Test result, ${ }^{18}$ and (4) a momentary pain intensity of 9 or 10 on a numeric rating scale (NRS) rated from 0 to 10 . All patients who met the inclusion criteria were told that 2 generally accepted treatments were currently used in the rehabilitation center, and that this study would evaluate whether 1 of the 2 treatments was more effective in reducing LBP-related disability. Patients were accepted if they understood German or Italian well enough to follow instructions during the physical assessment. Patients were excluded if they were unable to read the information about the study and the informed consent form, which was available in German, Italian, Serbo-Croatian, Albanian, Turkish, French, Spanish, and Portuguese. Patients who gave their written informed consent were divided into strata based on 2 predictive factors identified in a previous cohort study. ${ }^{17}$ The 4 strata were defined by work status (unemployed, employed) and workload (1-2 or $3-5$ ) according to the definition of the US Department of Labor: 1, sitting; 2 , maximum load lifted 5 to $10 \mathrm{~kg} ; 3$, maximum load lifted 10 to $25 \mathrm{~kg} ; 4$, maximum load lifted 25 to $45 \mathrm{~kg}$; and 5 , maximum load lifted greater than $45 \mathrm{~kg} .{ }^{19}$ An independent and blinded research assistant performed concealed randomization within these 4 strata using a randomization schedule with blocks of 2 generated on a computer by an independent researcher.

\section{TREATMENT}

All patients were treated 6 days a week, and the length of stay (LOS) considered necessary was 3 weeks. Indlependent teams of therapists were responsible for the 2 different treatments. In both groups, a rheumatologist prescribed medications such as analgesics and nonsteroidal anti-inflammatory drugs and might also have applied local infiltrations. The physician of the rehabilitation center determined the working capacity after rehabilitation for all patients. Treatment after rehabilitation was at the discretion of the patient's primary physician. Table 1 lists important differences between the 2 treatments.

\section{Function-centred treatment}

All patients were treated by a rheumatologist, a physical and occupational therapist trained in ergonomics, a sports therapist, a social worker, and a nurse. If required, a psychologist offered counseling. The FCT was based on work hardening and functional restoration programs. The primary goal of the FCT group during its 4 hours of treatment a day was to increase work-related capacity. Treatment emphasized improving selfefficacy, defined as the patients' confidence in their ability to carry out normal activities of daily living (ADLs). The rheumatologist informed patients about the results of the imaging and other diagnostic procedures and about the benign character of nonspecific LBP. Patients were told that degenerative changes, if diagnosed, were within the normal range (eg, not causing pain in the majority of people). The therapist performed a workrelated assessment that included a job profile describing the physical demands and an 
evaluation of job-relevant physical activities such as lifting and carrying loads, working in a bent position, or performing overhead activities. Treatment activities were chosen based on a patient's required capacities, as identified in the work-related assessment. Treatment consisted of work simulation, strength and endurance training through isokinetic exercise, cardiovascular training performed by walking and aqua-aerobics, sports therapy, and self-exercise: Patients were told that increasing activity might cause more pain because the body had to adjust to the activity again. All team members emphasized that patients should continue therapeutic activities even if their pain increased. The treatment protocol did not contain massage, hot packs, and other passive treatments because we did not believe that they facilitate an increase in activity and selfefficacy, nor has the research literature shown them to be effective.

Table 1: Differences in patienlintormation according to the treatment prolocol used in the 2 groups

\begin{tabular}{|c|c|c|}
\hline & $\mathrm{FCT}$ & PCT \\
\hline Goals & $\begin{array}{l}\text { Increase work-related capacity. Improve self- } \\
\text { efficacy. Return to work }\end{array}$ & $\begin{array}{l}\text { Pain reduction. Strength and mobilify training. } \\
\text { Return to work }\end{array}$ \\
\hline $\begin{array}{l}\text { Role of the } \\
\text { trealing leam } \\
\text { members }\end{array}$ & $\begin{array}{l}\text { Coach palients. Determine goals with patients. } \\
\text { Primary focus on improvement of function }\end{array}$ & $\begin{array}{l}\text { Treal patients to reduce pain, mobilize joints, } \\
\text { and enthance relaxation. Increase pain-free } \\
\text { movement. }\end{array}$ \\
\hline $\begin{array}{l}\text { Explanation of } \\
\text { complaints }\end{array}$ & $\begin{array}{l}\text { Loss of function contributes to pain. LBP-related } \\
\text { complaints are nonspecific there are no } \\
\text { abnomal changes in the lumbar spine } \\
\text { constituting a contraindication for work-rellated } \\
\text { training. }\end{array}$ & $\begin{array}{l}\text { L8P is explained by somatic findings such as } \\
\text { disk degeneration, joint stiffness, and trigger } \\
\text { points diagnosed in the clinical, imaging, and } \\
\text { other examinations. }\end{array}$ \\
\hline Troalment & $\begin{array}{l}\text { Work simulation, strenght, and endurance } \\
\text { training, cardiovascular training }\end{array}$ & $\begin{array}{l}\text { Massage, relaxation, hot packs, and } \\
\text { electrotherapy. Passive and active mobilization }\end{array}$ \\
\hline $\begin{array}{l}\text { Advice if pain } \\
\text { Ancreases during } \\
\text { activily or } \\
\text { treatment }\end{array}$ & $\begin{array}{l}\text { Pain is not an alarm sign for potential damage. } \\
\text { Try to incrigase function even if pain increases. }\end{array}$ & $\begin{array}{l}\text { Reduce intensity of exercise if pain increases. } \\
\text { Avoid activities that increase pain. Use } \\
\text { modalites and relaxation if pain increases. }\end{array}$ \\
\hline
\end{tabular}

\section{Pain-centred treatment}

All patients were treated by a rheumatologist, a physical therapist, and a murse. If required, a psychologist or a social worker was consulted. The primary goal in the PCT group was to reduce pain. The secondary goal was to increase strength and decrease disability. The physical therapist examined the patients to identify painful movements and limitations in mobility, strength, and muscle length in the lumbar region and lower 
extremities. Treatment was for 2.5 hours a day and consisted of individually selected passive and active mobilization, stretching, strength training, and a mini back-school, Unlike with the FCT group, patients in the PCT group were told to stop activities when pain increased. Passive pain modulating treatments such as hot packs, electrotherapy, or massage were used daily. Low-intensity movement therapy in the pool and progressive muscle relaxation further enhanced relaxation. Progressive muscle relaxation used systematic contraction and relaxation of specific muscle groups. Patients were encouraged to incorporate relaxation techniques into daily living as a coping skill to reduce stress, muscle tension, and pain..$^{20,21}$

\section{OUTCOME MEASUREMENTS}

Days at work and other work-related outcomes were assessed with a questionnaire sent to employers and the patients' primary physicians, who were blinded to the patients" group assignments. Nonresponders received a reminder and, if necessary, a phone call from the blinded research assistant. A blinded research assistant (MR) recorded the work-related predictive factors and performed the physical measurements before and after rehabilitation. The research assistant was not involved in any patient treatment in the rehabilitation center. Assessments were performed in a separate room to prevent unmasking of the assessor. Patient questionnaires were used to assess self-efficacy, satisfaction with treatment, and pain. We evaluated adherence to the treatment protocol because protocol deviations are a potential cause of insignificant results. The amount of treatment received was evaluated by recording the LOS and attendance at scheduled appointments. Therapists' and physicians' adherence to the treatment protocol for the 2 different concepts was assessed. Tape recordings of the verbal information given to patients were made on 25 consecutive occasions. Seven experts, who were blinded to the treatment, independently rated the information given to the patients. In acdition to an overall rating, separate ratings were given for the formulated goals, information about the treatment plan, explanation of the source of the complaints, and advice about coping with pain. A score of more than 7.5 on a visual analog scale from 0 (not at all according to the treatment protocol) to 10 (perfectly according to the treatment protocol) was considered adequate adherence to the protocol.

Patients could not be blinded to treatment but every effort was taken to keep patients unaware of any expected advantage in effectiveness, a condition that is sometimes called naive. We recorded on a 7-point Likert scale overall satisfaction with treatment, satisfaction with the advice received, knowledge about the complaints, and the perceived possibilities to have an influence on the complaints. If the scores for satisfaction with treatment in the 2 groups were comparable, we considered the efforts to keep patients unaware or naive to have been successful. 


\section{PRIMARY OUTCOME}

The number of days at work was the primary outcome. Each calendar day within a period at work was counted, leading to a maximum of 90 days at work during the 3 month follow-up period. This method is insensitive to the fact that patients work on different days of the week. Because Switzerland does not have a central database that tracks sick leave, we assessed days at work with questionnaires sent to employers and primary physicians after 3 months. Inconsistencies were resolved through additional phone calls to the people involved. We also computed the proportion of patients at work after 3 months, an outcome that has been used in several other studies."

\section{SECONDARY OUTCOMES}

Self-efficacy, defined as the patients' confidence in their ability to carry out normal ADLs, was assessed before and after treatment with the Performance Assessment and Capacity Testing ${ }^{22,23}$ (PACT) instrument. The PACT consists of 50 daily activities done in varying sitting and standing postures. The activities are illustrated to reduce language-related difficulties. Patients are instructed to rate the degree of difficulty in performing these activities on a 5 -point scale ( 1 , unrestricted ability to perform the activity; 2 , slightly limited; 3 , moderately limited; 4 , severely limited; 5 , unable to perform the activity). The PACT includes a consistency check that indicates whether the patient understands the instructions. For patients who did not answer the questions consistently, the research assistant repeated the instructions.

Before and after rehabilitation, the maximum lifting capacity within security limits was assessed from floor to waist, from waist to crown, and horizontally at waist level. The research assistant was trained and experienced in this method and its reliability has been confinaned. ${ }^{2426}$

The perceived effect was assessed after treatment and after 3 months with a questionnaire that encompassed physical capacity, general well-being, and overalll improvement. We used a 7-point Likert scale. ${ }^{27}$

Momentary, maximal, and minimal pain in the last week was rated on an 11-point NRS ranging from 0 (no pain) to 10 (the worst pain I can imagine). ${ }^{28}$ Pain measurements were taken before and after treatment and after 3 months.

Before and after treatment, the following physical measurements were performed. The finger-to-floor distance was used as a measure of active spinal and hip mobility in flexion. ${ }^{29}$ Spinal mobility in extension was measured in degrees with an inclinometer. ${ }^{30}$ Muscle performance was assessed by recording the maximum duration of isometric hip and trunk extension and flexion against gravity. ${ }^{11,32}$ 


\title{
PREDICTIVE FACTORS
}

Before treatment, we used a questionnaire to assess work satisfaction, using a 7-point Likert scale ranging from very satisfied to very unsatisfied.

\begin{abstract}
ANALYSIS
Analysis was performed by intention-to-treat. Between-group comparisons at baseline, after treatment, and at 3 months follow-up were performed with chi-square tests for categorical variables. Independent samples $t$ tests were applied in continuous variables with a normal distribution and a Mann-Whitney $U$ test was used in nonparametric continuous variables. We used the general linear method in repeated measurements of continuous variables and performed a subgroup analysis of days at work stratified for sex, nationality, age, workload, and unemployment, using univariate analysis of variance and Bonferroni adjustment for multiple post hoc comparisons.

Effect sizes (ESs) were computed for all outcomes. In continuous variables with a normal distribution, the Cohen $d$ was computed by dividing the mean difference in change between the 2 groups by the standard deviation (SD) of the change in the control group. If results were analyzed with the general linear method, we derived the ES from $\eta^{2} .^{33}$ Positive values of ESs display desirable effects. ESs were considered small between .20 and .50 , moderate between .50 and 0.80 and large above $.80 .^{34}$ Statistical analysis was performed with SPSS, version 11.5. Alpha was set at .05.
\end{abstract}

\section{Results}

Between January 1,2000 and May 1, 2003, 260 eligible patients were referred to the relabilitation center, and 174 participated in the study (figure 1). During the treatment phase, I patient in the FCT group dropped out because he was diagnosed with necrosis of the head of the femur and underwent surgery. The measurements after treatment were missed for 2 patients in the PCT group because of reductions in the LOS of 1 and 4 days that were not noticed by the research assistant. 
Figure 1: Siudy flow chart

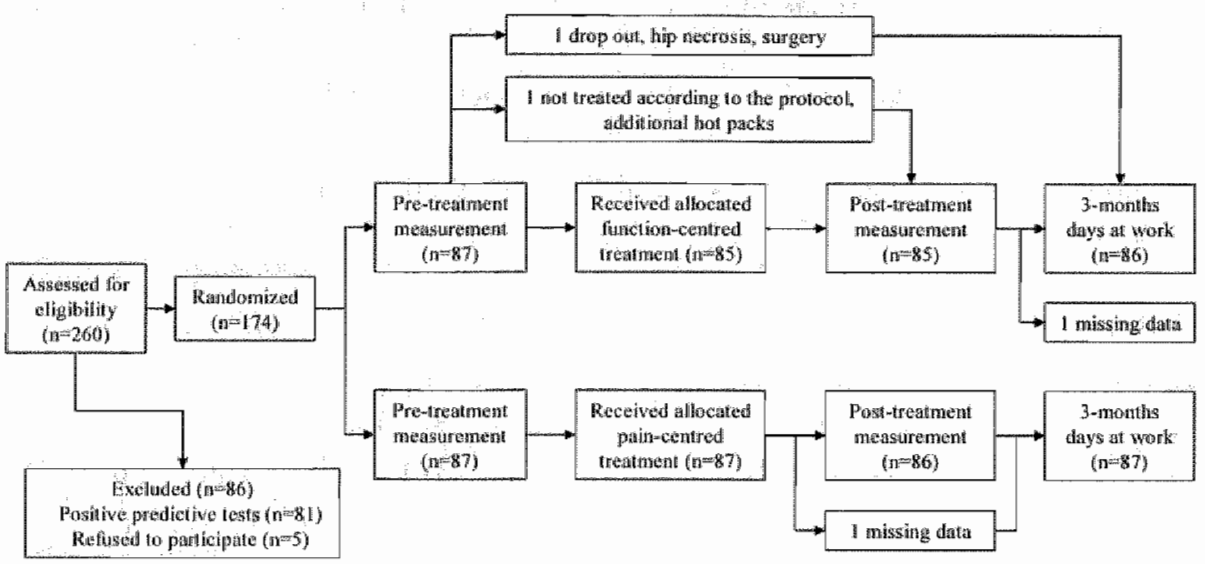

The number of days at work was obtained for $99 \%$ of the patients. No data were available for 1 patient in the FCT group. The return rate of the 3 -month follow-up questionnaires was $93 \%$ in patients, $84 \%$ in employers, and $82 \%$ in primary physicians. There was no difference in the retum rates of the 2 treatment groups.

\section{BASELINE COMPARABILITY}

Table 2 displays the baseline comparability of the 2 groups for the most important prognostic and outcome variables. There were no significant differences between the groups after randomization. Two patients in each group received a $50 \%$ disability allowance. There were 16 patients with litigation problems in the $\mathrm{FCT}$ group and 9 in the PCT group. Work satisfaction was slightly better in the FCT group (1.8土2.1 vs $2.4 \pm 2.9, \mathbb{P}=.134)$. 
Table 2: Comparability of the treatment groups at baseline. Values are mean \pm standand deviation; $n$ op $n$ (n)

\begin{tabular}{|c|c|c|}
\hline 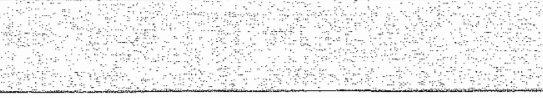 & $\begin{array}{c}\text { FCT Group } \\
(\mathrm{m}=8 \mathrm{~T})\end{array}$ & $\begin{array}{l}\text { PCT group } \\
\text { n }=87)\end{array}$ \\
\hline Age (years) & $41.6 \pm 8.4$ & $42.5 \pm 8.4$ \\
\hline Sex (men/women) & $69 / 18$ & $68 / 49$ \\
\hline Body mass index $\left(\mathrm{kg} / \mathrm{m}^{2}\right)$ & $26.7 \pm 4.2$ & $27.2 \pm 4.0$ \\
\hline \multicolumn{3}{|l|}{ Nationality } \\
\hline Switzerland & 38 & 35 \\
\hline Italy & 17 & 11 \\
\hline Yugoslavia & 11 & 16 \\
\hline Bosnia & 5 & 6 \\
\hline Macedonia & 5 & 5 \\
\hline Croatia & 4 & 5 \\
\hline Spain, Portugal ${ }_{i}$ Turkey & 7 & 9 \\
\hline Unemployed & $18(21)$ & $20(23)$ \\
\hline Workload: liffing > $25 \mathrm{~kg}$ & $68(78)$ & $68(78)$ \\
\hline No professional education & $38(44)$ & $42(48)$ \\
\hline Days of sick leave during 2 years before treatment & $184 \pm 156$ & $199 \pm 135$ \\
\hline Self-efficacy (PACT) & $110 \pm 39$ & $102 \pm 42$ \\
\hline \multicolumn{3}{|l|}{ Lifting capacily (kg) } \\
\hline Floor-waist & $15.8 \pm 5.4$ & $15.6 \pm 7.3$ \\
\hline Horizontal & $20.4 \pm 7.6$ & $18.9 \pm 7.8$ \\
\hline Waist-shoulders & $13.2 \pm 4.3$ & $13.0 \pm 4.8$ \\
\hline Pain (NRS range; $0-10$ ) & $5.5 \pm 2.0$ & $5.7 \pm 2.2$ \\
\hline \multicolumn{3}{|l|}{ Muscle performance (s) } \\
\hline Extension hip/trunk & $30.4 \pm 3.2 .3$ & $25.9 \pm 25.9$ \\
\hline Flexion trunk & $30.4 \pm 28.5$ & $25.5 \pm 22.8$ \\
\hline Finger-to-floor distance $(\mathrm{cm})$ & $22.8 \pm 13.5$ & $26.7 \pm 15.1$ \\
\hline Lumbar extension (degrees) & $12.1 \pm 7.6$ & $10.6 \pm 6.5$ \\
\hline
\end{tabular}




\section{ADHERENCE TO THE PROTOCOL}

LOS was comparable in both groups, with $22.2 \pm 3.7$ days in the FCT group and $22.3 \pm 3.8$ days in the PCT group. All patients attended at least $90 \%$ of the scheduled treatments: One patient in the FCT group was not treated according to the protocol because she insisted on having hot packs and massage for pain relief.

Overall satisfaction with treatment, satisfaction with advice received, knowledge about the complaints, and the perceived possibilities of having an influence on the complaints were the same in the 2 groups, indicating that the effort to keep patients unaware of any expected treatment advantage was successful.

The expert ratings of the adherence to the 2 different treatment concepts were greater than 7.5. The average overall score for therapists and physicians was 8.8 in the FCT group and 8.9 in the PCT group.

\section{OUTCOME MEASUREMENT}

Table 3 shows the main results. There was a small to moderate ES favouring the FCT group for the primary and most of the secondary outcomes. More patients were at work in the FCT group than in the PCT group ( $47 \%$ vs $27 \%, \mathrm{ES}=.15, \mathrm{P}=.037)$, and the unemployment rate was slightly smaller in the $\mathrm{FCT}$ group ( $19 \%$ vs $24 \%, \mathrm{ES}=.05$, $\mathrm{P}=637$ ).

Subgroup comparisons for the number of days at work showed a significant negative effect of unemployment on work absenteeism without an interaction between unemployment and group. No effect was found for sex, age, workload, and nationality (Bonferroni adjustment, $\alpha=.01$ ),

Regarding the secondary outcomes after treatment, the FCT group had improved significantly more in self-efficacy, in all 3 tests for lifting capacity, and for the perceived effect. The moderate ESs for the perceived effect after rehabilitation were not maintained during the 3-month follow-up period. Pain intensity was significantly lower in the FCT group after treatment. During the 3-month follow-up, pain increased in both groups, but the difference in favor of the FCT group remained. No difference was found in back and hip extensor strength, trunk flexor strength, and spinal mobility.

Because the size of the study sample was considered sufficient to detect clinically relevant differences in the outcomes used, we did not perform a power analysis of nonsignificant results. 
Table 3: Outcome after treatment and 3 months. Values are mean $\pm \mathrm{SD}$. "Measurement after 3 months:

$\dagger$ Mann-Whitney U test: $\ddagger$ Measurement after treatment. if Mixed between-within subjects analysis of variance.

\begin{tabular}{|c|c|c|c|c|c|c|}
\hline Variables & FCT & $\mathrm{N}$ & $\mathrm{PCT}$ & $\mathrm{N}$ & $\mathrm{ES}$ & $\mathrm{P}$ \\
\hline Days at work & $25.9 \pm 32.2$ & 86 & $15.8 \pm 27.5$ & 87 & .36 & $.029+$ \\
\hline Self efficacy (changet PACT) & $5.9 \pm 32.5$ & 86 & $-7.4 \pm 24.4$ & 85 & .55 & $.003_{11}^{\mathrm{m}}$ \\
\hline \multicolumn{7}{|l|}{ Liffing capacity changet $(\mathrm{kg})$} \\
\hline Floor-waist & $2.3 \pm 5.4$ & 86 & $0.2 \pm 3.9$ & 85 & .54 & $.004 \|$ \\
\hline Horizontal & $1.7 \pm 5.9$ & 86 & $-0.2 \pm 6.0$ & 85 & .32 & $.049_{11}^{4}$ \\
\hline Waist-shoulders & $1.3 \pm 3.2$ & 86 & $-0.2 \pm 3.7$ & 85 & .41 & .006 \\
\hline \multicolumn{7}{|l|}{ Perceived effect4 } \\
\hline Physical capacily & $4.1 \pm 2.11$ & 86 & $2.9 \pm 1.7$ & 85 & .71 & .001 \\
\hline General well-being & $4.0 \pm 2.1$ & 86 & $3.1 \pm 1.9$ & 85 & .47 & .005 \\
\hline Overall improvement & $4.4 \pm 2.0$ & 86 & $3.6 \pm 2.0$ & 85 & .40 & .009 \\
\hline \multicolumn{7}{|l|}{ Pain change (NRS range, 0-10) } \\
\hline Post & $-0.25 \pm 2.1$ & 86 & $0.55 \pm 1.9$ & 85 & .42 & $.023 \|$ \\
\hline 3 mo & $0.35 \pm 2.1$ & 86 & $0.89 \pm 1.9$ & 85 & .28 & $.094 \|$ \\
\hline \multicolumn{7}{|l|}{ Muscle performance change } \\
\hline Extension hip/trunk & $8,6 \pm 26.2$ & 86 & $2.5 \pm 24.9$ & 85 & .24 & $.121: 11$ \\
\hline Flexion trunk & $0.7 \pm 21.6$ & 86 & $-1.9 \pm 18.4$ & 85 & .14 & 39818 \\
\hline Finger-to-flocr distance changet $(\mathrm{cm})$ & $-2.9 \pm 7.7$ & 86 & $0.0 \pm 8.3$ & 85 & .44 & .018 ii \\
\hline Lumbar extension changef (deg) & $-1.0 \pm 6.3$ & 86 & $0,4 \pm 7,0$ & 85 & -20 & $.166 \%$ \\
\hline
\end{tabular}

\section{Discussion}

This is the first RCT in Switzerland to evaluate work-related rehabilitation in patients with LBP. Work absence was significantly reduced, and more patients had returned to work after 3 months. The ESs were small for work absence (.36), moderate for selfefficacy $(.55)$, and small to moderate for lifting capacity $(.32-.54)$, and pain intensity (.42). The PCT group did not achieve the goal of pain reduction. Pain intensity increased in this group and decreased in the FCT group. At the onset of the study, physicians and therapists criticized the FCT because they feared that encouraging the patients to move regardless of pain would lead to an increase in pain intensity. The pain 
reduction experienced by the FCT group supports the hypothesis that fear of pain may be more disabling than pain itself. ${ }^{35}$

Compared with other studies, our results are renarkable because 2 experimental treatments were compared, resulting in a relatively small treatment contrast. In a recent review, only 1 of 9 comparisons between 2 experimental treatments showed a significant effect. ${ }^{8}$ The $\mathrm{ES}$ for work absence in this study is similar to the $\mathrm{ES}$ in 5 studies that compared intensive treatment with usual care. ${ }^{36-40}$ Usual care essentially consisted of treatment by a general practitioner who gave advice and prescribed medications.

The treatment duration in the FCT group in this study was 70 hours. Authors of a recent review $^{41}$ reported that only treatments with duration of at least 100 hours were effective. That review, however, was limited to multidisciplinary rehabilitation. Other treatments using exercise or activity, with duration of 20 to 40 hours, have also been effective. ${ }^{37,39,42}$ Previous studies in Switzerland either did not randomize patients ${ }^{43}$ or lacked a control group. 15

Exclucling patients who will not benefit from treatment is essential to increasing the statistical power and efficiency of an RCT. Our positive results and the high follow-up rate were in part the result of excluding patients with positive predictive tests for nonreturn to work, as identified in a previous study. ${ }^{17}$ In an attempt to evaluate whether exclusion was justified, we evaluated work absence by sending questionnaires and reminders to the first 40 excluded patients, who had also attended 3 weeks of rehabilitation. The nonresponse rate in this group was $30 \%$, and only 1 patient had returned to work, confirming the value of the predictive tests.

An important question is which treatment elements may have been essential to the effectiveness of the FCT. The program consisted of 4 hours of activity, 6 days a week, for 3 weeks. The FCT primarily focused on reducing work absence by improving workrelated capacity and self-efficacy. Patients were encouraged to move even if their pain increased. One big challenge for the team members was to give consistent information. Patients were repeatedly assured that the spine was not seriously damaged and would benefit from intensive training. Work-related activities were used to improve functional capacity. Lifting capacity improved and pain intensity decreased in the FCT group despite the higher level of activity. However, it is questionable whether the moderate improvement in lifting capacity explains the increased number of work days, or whether self-efficacy is more important. It would be helpful to identify the relative contributions of the different elements of the multidisciplinary rehabilitation to the treatment effect. As others have stated, the answer to this question remains unknown.

In the health care systems of many countries, a 3-week inpatient intervention is not available. Some countries offer intensive outpatient programs that make it possible for 
patients to gradually resume work while receiving treatment. $\mathrm{PCT}$ may be considered unethical because it is not in accordance with current guidelines. The PCT applied light to moderate exercise. Modalities were used to support treatment. The essential characteristic of the PCT was that pain reduction and the avoidance of pain was the primary goal. Despite the guidelines, PCTs are still more frequently used than FCTs."

Blinding of patients is not possible for the type of treatments we evaluated. The excellent adherence to the treatment protocol and the comparable satisfaction with treatment in both groups indicate that we succeeded in keeping patients naive with regard to any expected treatment adwantage.

Although the number of work days was increased significantly in the FCT group, the problem of LBP-related work absence and disability is obviously not solved. Considering the remaining amount of work absence, the effect of the FCT was small and disappointing. The investigated group, however, was characterized by histories of long-standing sick leave, heavy work, and low education, resulting in a limited possibility of reducing work demands. Return to work was additionally limited because less demanding jobs are scarce in the employment market. Only 2 patients found new jobs.

Measurement of the number of days at work was essential in this study. Its internal validity was increased by the nearly complete follow-up data for days at work. The reliability of work days" measurement was increased by sending questionnaires to both the primary physicians and the employers, who were blinded to the treatment group. Several previous studies obtained sick day totals from a national database for sick leave compensation. There is no such database in Switzerland. The questionnaires we used may introduce more random measurement error, but the advantage of our method is that the initial days of each period of sick leave are also covered, which increases the reliability of the ES estimate. Databases used in other studies did not cover the first $7^{37}$ or 16 days $^{44,45}$ of each work absence. Many studies that reported sick days did not describe how work absence due to unemployment and work absence in patients receiving a full disability allowance were analyzed. To avoid the problem of these different types of work absence, we used days at work as the primary outcome.

Knowledge of the Swiss national languages was limited in more than $50 \%$ of the patients participating in our work rehabilitation program. Treatment was developed to be applicable to these patients. The key element of the FCT was activity offered as isokinetic and work-related training, walking, and sports therapy. This treatment did not require proficient verbal communication and could be applied to this group of patients, thus increasing the study's external validity.

The external validity of this study is further supported by the patient population, representative of patients in Switzerland with LBP who are at risk of permanently losing 
working capacity, becoming unemployed; or becoming dependent on a disability allowance. The majority of the patients were accustomed to heavy work, were born in other countries, were poorly educated, and had insufficient personal resourcesparticularly insufficient knowledge of the Swiss national languages. All of these factors made it difficult for them to participate successfully in vocational measures. Other studies $37,35,46,47$ included only patients with proficient knowledge of the national language, which gave them a better perspective to participate in vocational measures and to find lighter work. Patient questionnaires in this study had to be either available in all required languages or be independent of language. The PACT self-efficacy assesment does not require proficient knowledge of language because it uses pictures of physical activities.

The cost effectiveness of the FCT needs further analysis. The average cost of 1 day of work absence is estimated to be 6155 (US $\$ 213$ ). ${ }^{4}$ The savings during the first 3 months are $\epsilon 1550$ (US $\$ 2130$ ) per person and $\in 135,000$ (US $\$ 18,600$ ) for the total FCT group. The costs of rehabilitation paid by health insurance are 6220 (US $\$ 303$ ) per day or 64900 (US \$6749) per patient in the FCT and PCT groups. The 1.0 work-days benefit for the FCT group is considered relevant. For definitive conclusions, we plan a detailed analysis of cost effectiveness, including medical treatment in the first follow-up year and disability pensions. If the benefit for work absence in the FCT group is maintained until the 1-year follow-up, the experimental treatment may be cost effective.

The results of this single-center study should be confirmed in other centers for work rehabilitation.

\section{Conclusions}

Function-centred rehabilitation decreases work-related disability. Our ESs were small to moderate. The number of days at work during the 3 months of follow-up was 10 days higher in the FCT group, and the number of patients who returned to work was significantly larger. Self-efficacy, lifting capacity, and pain intensity improved significantly in the FCT group. A subgroup analysis showed a significant negative effect of unemployment without an interaction between unemployment and group. The number of days at work did not depend on sex, age, workload, or nationality. FCT should be used in place of the still widely used PCT. 


\section{Acknowledgements}

We thank Patricia Bigger, who performed the postal follow-up measurements persistently and with admirable patience. Alexandra Gossmann, Trix Janssen, Franziska Heigl, Ursula Reich-Zwiegart, Verena Fischer, Beatrice Silvestri, and Franziska Denier evaluated the adherence of the therapists and physicians to the treatment protocol.

\section{References}

1. Marin B, Prinz C. Faets and figures on disability welfare A pictographic portrait of an OfCD report. Paris: European Centre of the $\mathrm{OECD} ; 2003$.

2. Buri M. Disability insurance: statistics. Berne: Swiss Federal Social Insurance office; 2003.

3. Fordyce WE. Back pain in the workplace: management of disability in nonspecific conditions. A Report of the Task Force on Pain in the Workplace of the Intemational Association. Seattle: IASPP Pr; 1995.

4. Waddell $G$. The back pain revolution. Vol 1 . New York: Churchill Livingstone; 1998. p 223-40.

5. Van Tulder M, Koes BW, Bouter LM. Conservative treatment of acute and chronic nonspecific low back pain. Spine 1997;22:2128-55.

6. Brox II, Hagen KB, Juel NG, Storheim $\mathrm{K}$. [Is exercise therapy and manipulation effective in low back pain?] [Norwegian]. Tidsskr Nor Laegeforen 1999;119:2042-50.

7. Guzman J, Esmail $\mathbb{R}$, Karjalainen $\mathbb{K}$, Malmivaara A, Irvin $\mathbb{E}$, Bombardier C. Multidisciplinary rehabilitation for chronic low back pain: systematic review. BM. 2001;322:1511-6.

8. Kool J, de Bie RA, Oesch P, Knüsel $O$, van den Brandt P, Bachmann S. Reduction of sick leave in patients with non-acute non-specific low back pain. J Rehabil Med 2004;49-62.

9. Abenhaim L, Rossignol M, Valat JP, et al. The role of activity in the therapeutic management of back pain. Report of the International Paris Task Force on Back Pain. Spine 2000;25(4 Suppl): 1S-33S.

10. Koes BW, van Tulder MW, Ostelo R, Kim Burton A, Waddell G. Clinical guidelines for the management of low back pain in primary care: an international comparison. Spine 2001;26:2504-13.

11. Rainville J, Carlson $\mathbb{N}$, Polatin P, Gatche RJ. Indahl A. Exploration of plysicians" reconmendations for activities in chronic low back pain. Spine 2000,25:2210-20.

12. Ostelo RW, Koke AJ, Beurskens $\mathrm{AJ}_{\mathrm{t}}$ el al. Behavioural-grated activity compared with usual care alter first-time disk surgery; considerations of the design of a randomized clinical trial. J Manipulatiwe Physiol Ther $2000 ; 23: 312-9$.

13. Matheson LN, Ogden LD. Violette K, Schultz K. Work hardening: occupational therapy in indiustrial rehabilitation. Am d Occup Ther 1985;39:314-21.

14. Mayer TG, Gatchel RJ, Mayer $H_{*}$ Kishino ND, Keeley J, Mooney V. A prospective lwo-year study of functional restoration in industrial. low back injury. An objective assessment procedure. JAMA $1987 ; 258: 1763-7$.

15. Bachmann $S$, Oesch P, Kool J, Knüsel $O$. Behandlung von Patienten mit chronischen Ruckenschunerzen in einem Ergonomietrainingsprogramm: lassen sich dadurch arbeiltbezogene Funktionsparameter, Schmerzparametr und die Arbeitstätigkeit nach 12 Monaten vertindern? Plays Rehabil Kur Med 2003;13:263-70.

16. Scientific approach to the assessment and management of activityrelated spinal disorders. A monograph for clinicians. Report of the Quebec Task Force on Spinal Disorders. Spine 1987;12(7 Suppl): \$1-59.

17. Kool J, Oesch P', de Bie R. Predictive tests for non-return to work in pattients with chronic low back pain. Eur Spine J 2002;11:258-66.

18. Waddell G, McCulloch JA, Kummel E, Venner RM. Nonorgenic physical signs in low-back pain. Spine $1980 ; 5: 117-25$.

19. US Department of Labor. Dictionary of occupational itles. 4th ed. Washington (DC): DOL; 1991 


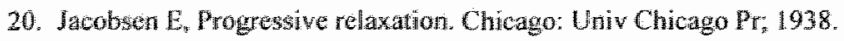

21. Cartson $\mathrm{C}$, Hoyle $\mathrm{R}$. efficacy of abbreviated progressiwe musile telaxation thaning: a quanitative rewiew of betwaw wa mediche research. J Consult Chin Psychol 1993;61:1059-67.

22. Matheson I, Mooney W, Grant J, et all. A test to measure lift capacity of physically impaired adults. Part 1: Development and reliability testing: Spine 1995,20:2119-29.

23. Matheson LN. Matheson M. Spinal function sort. Performance assessment and capacity testing. Trabuco Canyon PACT, 1989 .

24. Cross DP" Battie MC Reliablity of safe maximum lifting determinations of a functional capacity evaluation. Phys Thet $2002 ; 82: 364-71$.

25. J.sernhagen S\%, Hant DL, Matheson L.M. Ueliability of independent observer judgmenis of level of lif effort in a kinesioplaysical Functional Capacity Evaluation. Work 1999;12:145-50.

26. Brouwer S, Reneman M, Dijkstra P, Grootholf J, Schellekens J, Goveken. L. Test-retest reliability of the Isernhagen Work Systems Functional Capacity Evaluation in patients with chronic low back pain. J Occup Retrabil 2003;13:208-18.

27. Beurskens AJ, de Vet HC, Koke AJ. Responsiveness of functional staths in low back pain: a comparison of different instruments. Pain 1996;65:7 \-6.

28. Ferraz M, Qumesina M, Aquino L, Atra E, Tugwell P, Goldsmith C. Relliability of pain scales in the assessment of literate and illiterate patients with rheumatoid arthritis. \& Rheumatol 1990; 17: 1022-4.

29. Heikkilla $\mathrm{S}_{*}$, Vitanen JW, Kautiainen H, Kauppi M. Sensitivity to change of mobility tests; effect of short term intensive physiotherapy and exercise on spinal hip and shoulder measurements in spondyloathropathy. I Rheumatol $2000 ; 27: 1251-6$.

30. $\mathrm{Ng} J \mathrm{~K}$, Kippers $\mathrm{V}$, Richardson CA, Parnianpour $\mathrm{M}$. Range of motion and lordosis of the lumbar spine: reliability of measurement and normative values. Spine $2001 ; 26: 53-60$.

31. Lathimet , Mather $\mathrm{CG}$, Refshauge $\mathrm{K}, \mathrm{Colaco}$ I. The reliabulity and walidity of the Biering-Sorensen test in asymptomatic subjects and subjects reporting current on previous nonspecific low back pain. Spine $1999,24: 2085-9$.

32. Oesch P, Kool JP, Sloksnath U, Hasegawa A. Die Zuverlâssigkeit und Empfindlichkeit von 4 isometrischen Muskeltests. Physiotherapie 1994;4-12.

33. Rosenthal R. Parametric measures of effect size. In: Cooper H, Hedges L, editors. The handbook of research synthesis. New York: Russell Sage Foundation; 1994. p. $231-44$.

34. Cohen ل. Statistical power analysis for the behavioural sciences. 2nd ed. Hilsdale: Lawrence Eribaum; 1988.

35. Vlatyen JW de Jong $J$, Geilen $M$. Heuts $P H$, van Breukelen $G$. The treatment of fear of novement/(b)injary in chronic low back pain: further evidence on the effectiveness of exposure in vivo. Clin I Pain $2002: 18: 251-61$.

36. Hogen KB. Holte HH, Tambs KK, Bjerkedal T. Socioeconomic factors and disability retirement from back pain: 1983-1993 population-based prospective study in Norway. Spine 2000;25:2480-7.

37. Skouen JS, Grasdal AL. Haldorsen EM. Ursin H. Relative costeffectiveness of extensive and light multidisciplinary matment programs versus treatment as uswal for patents with chronic low back pain on lorig-tem sich leave; randomized controlled sudy. Spine 2002:27:901-9.

38. Torstensen TA, Ljunggren AE, Meen HD, Odland E, Mowinckel P, Geijerstam S. Efficiency and costs of medical exercise therapy, conventional pltysiotherapy, and self-exercise in pantients with chrontc low back pain. A pragnntic, randonized, single-blinded, controlled trial with 1-year follow-up. Spine $1908 ; 23: 2616 ; 24$

39. Lindstrom $\mathbb{t}_{\text {, }}$ Onlund $\mathrm{C}_{4}$ Eek $\mathrm{C}$, et al. The efect of graded activity on patients with subacute low back pain: a randomized prospective clinical study with an operent-conditioning behavioural approach. Phys Ther 1,992,72:279-90; discussion $91-3$.

40. Bendix AF, Bendix $T$, Vaegter $K$, Lund $C$, Frolund L. Holm L. Multidisciplinary intensive treatment for chronic low back pain: at rondonized prospective study. Cleve Clin J Med 1996;63:62-9.

41. Guznan I, Esmail R. Karjahinen K, Malmivaara A, Irvin E, Bonbardier C. Multidisciplinary biopsycho-Social rehabilitation tor chronic low back pain. Cochrane Database Syst Rev 2002(1): CD000963.

42. Lonn IH, Glomstod B, Soukup MG, Bo K, Larsen S. Active back school: prophylactic management for tow back pain. A randomized, controlled, 1-year follow-up study. Spine 1999;24:865-71. 


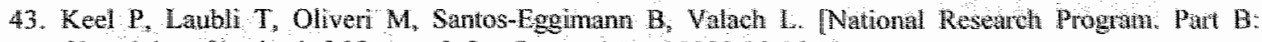
Chronicity of backache] [German]. Soz Praventivmed 1990,35:46-58.

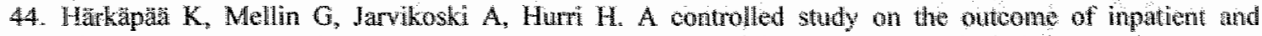
outpatient treatment of low back pain. Part IIL Long-tam tollow up of pain, distility, and conpliance. Scand I Rehabil Med 1990;22:181-8.

45. Harkaapaa K, Jarwikoski A, Mellin G, Hurri M. A controlled study on the outconte at inpatient and outpatient treatment of low back pain. Part I. Puin, disability, compliance, sand reported treatment benefits three months after treatment. Scand J Rehabil Med 1989;21.81-9.

46. Torstensen TA, Koes B, Glomsrod E, Selfert L, Glomsrod B, Hagen O. The eflect of conserwative therapies on patients suffering from chronic low back pain. Spine 1996;21:656-7.

47. Bendix AF, Bendix T, Ostenfeld S, Bush E, Andersen A. Active treatment programs for patients with chronic low back pain: a prospective, randomized, observertblinded study. Eur Spine $\mathbf{1 9 9 5 ; 4 : 1 4 8 - 5 2 .}$

48. Knuti $\mathrm{R}$, Schwaniger U. Arbeit und Gesundheit. In: Kocher G, Oggier W. Gesundheltswesen Sohwerz 2004-2006. Solothurn (Switzerland): KSK; 2004. p. 27-33. 


\section{Chapter 5}

\section{Function-centered rehabilitation increases days at work in patients with non-acute nonspecific low back pain: one year results of a randomised controlled trial}

Kool JP', Bachmann $\mathrm{S}^{2,3}$, Oesch PR ${ }^{2}$, Knüsel $\mathrm{O}^{3}$, de Bie RA ${ }^{4}$, van den Brandt $\mathrm{PA}^{4}$

Affiliations of the authors

'Research Dpt., Rehabilitation Centre Valens, Switzerland

${ }^{2}$ Dpt. of Work Rehabilitation, Rehabilitation Centre Valens, Switzerland ${ }^{3}$ Dpt. of Rheumatology, Rehabilitation Centre Valens, Switzerland ${ }^{4}$ Dpt. of Epidemiology, Maastricht University, The Netherlands 


\begin{abstract}
Introduction: Days lost from work are responsible for the major costs related to low back pain (LBP). A function-centered treatment (FCT) was developed for workers in Switzerland with limited knowledge of the national language. Although multidisciplinary rehabilitation is effective compared with usual care, it is unknown whether FCT is superior to pain-centered treatment (PCT). This study evaluates the effectiveness of the FCT, performs a subgroup analysis and determines predictive factors.
\end{abstract}

Methods: Randomised controlled trial. FCT, 4 hrs/day, 3 weeks, emphasised activity in spite of pain and coping, and consisted of work simulation, strength, endurance and cardiovascular training in groups. PCT, $2.5 \mathrm{hrs} / \mathrm{day}, 3$ weeks, emphasised pain reduction and consisted of a mini back-school and individual therapy with passive and active mobilisation, stretching and strength training. Analysis was by intention-to-treat. The primary outcome was the number of workdays during the follow-up year. Predictive factors for workdays were determined with stepwise regression.

Results: We considered 260 patients, 174 were included. During the follow-up year, the FCT group had more workdays (118 \pm 134$)$ than the PCT group $(74 \pm 114$, ES $=0.35$, $p=0.011$ ). The effect was larger in patients performing light work and independent of nationality, sex or unemployment. Predictive factors were the maximum load carried with the right hand, pain behaviour, pain intensity, unemployment, nationality, the patients' belief about return to the previous work and workload.

Conclusion: FCT is more effective than PCT for increasing workdays in patients with non-acute nonspecific LBP. 


\section{Introduction}

Exercise, multidisciplinary rehabilitation and functional restoration reduce sick days in patients with low back pain (LBP) if compared with usual care. ${ }^{1.2}$ Eight of 14 studies of rehabilitation in LBP, summarised in a recent review, only included patients with sufficient knowledge of the national language. ${ }^{3}$ In Switzerland, the majority of patients at risk of developing permanent disability come from southern European countries and have limited knowledge of the national languages. It is uncertain whether the results from previous studies are applicable to our patients because of the difference in psychosocial factors known to influence outcome. Moreover, the economic cost of LBP has increased. The total expenses of the Swiss Disability Insurance rose from SFr 4 billion in 1990 to SFr 10 billion in 2002. Nonspecific disorders including LBP showed the largest annual increase." Compared with 10 other European OECD countries, Switzerland showed the highest rate of increase. ${ }^{5}$ With a view to reducing this increase, we evaluated the effect of function-centered and pain-centered multidisciplinary inpatient rehabilitation in this patient group.

Several studies identified prognostic factors for work-related disability and sick days in chronic LBP. ${ }^{6-8}$ Physical predictors identified in previous studies are the severity and duration of LBP and sick leave, body mass index, physical capacity including lifting capacity and walking velocity, and leg pain. Demographic, work-related and psychological factors include age education, employment status, job satisfaction, job qualification, salary, workload, lifting time per day, work postures, expectations of treatment effect, perceived risk of not recovering, behavioural responses to examination, fear avoidance behaviour and depression.

We conducted a pragmatic randomised controlled trial to analyse the effect of a function-centered versus a pain-centered three-week rehabilitation programme in patients with non-acute nonspecific LBP. Treatments are further described in the methods section. After three months the FCT group showed a significant benefit, compared with the PCT group, for the number of days at work (Cohen"s d effect size, $\mathrm{ES}=0.36)$, self-reported disability $(\mathrm{ES}=0.55)$, lifting capacity $(\mathrm{ES}=0.54$ ) and pain intensity $(E S=0.42){ }^{9} \quad$ This publication presents workdays and other work-related outcomes after one year and compares workdays in different subgroups. This study finally identies predictive factors for work activity that are important to improve treatment. 


\section{Methods}

\section{DESIGN}

We conducted a randomised controlled trial according to the CONSORT guidelines. ${ }^{10}$ We recruited patients between January 2000 and May 2003 in a centre for work-related rehabilitation in Valens, Switzerland. Randomisation was concealed and assessment of the primary outcome, workdays, was blinded. Independent tearns of therapists treated patients six days per week in three weeks. Patients could not be blinded to treatment; therefore patient reported outcomes were not blinded. Patients in both groups were not informed about the treatment of the other group. After 3 months and one year we sent follow-up questionnaires to the patients, physicians, employers, health insurance and disability insurance. The study was approved by the ethical committee of the canton St Gallen.

\section{INCLUSION AND EXCLUSION CRITERIA}

Eligible were patients between 20 and 55 years with a primary diagnosis of non-acute nonspecific LBP, and at least 6 weeks of sick leave in the previous 6 months. Patients with co-morbidity interfering with treatment or working capacity, and patients with two or more positive predictive tests for non-return-to-work, were excluded. "Predictive tests were 1) preliminary cessation of a 3-Minute-Step Test, 2) preliminary cessation of the Triceps-Brachii-Pseudo-Strength Test, 3) a positive Waddell Test ${ }^{12}$ and 4) a pain intensity of 9 or 10 on a $0-10$ Numeric Rating Scale. We also excluded patients if they were unable to understand German or Italian sufficiently to cooperate with the initial assessment, or to read the written information about the study and the informed consent form, which was available in German, Italian, Serbo-Croatian, Albanian, Turkish, French, Spanish and Portuguese. The patient information according to the Helsinki declaration described that the effect of two currently used treatments for disability, pain, and work absence was being evaluated.

\section{RANDOMISATION}

An independent blinded assistant performed randomisation in four strata depending on work status (unemployed or employed) and workload (1-2 or 3-5). Workload categories, based on the maximum load that had to be lifted at work, were $1:<5 \mathrm{~kg}, 2: 5-10 \mathrm{~kg}$, 3: 10-25 kg, 4: $25-45 \mathrm{~kg}, 5: \geq 45 \mathrm{~kg}{ }^{11,13}$ An independent researcher prepared the randomisation schedule with blocks of two in each stratum. 


\section{FUNCTION-CENTERED TREATMENT}

The multidisciplinary team providing function-centered treatment (FCT) consisted of a theumatologist, a physical and occupational therapist trained in ergonomics, a sports therapist, a social worker and a nurse. FCT was based on work hardening and functional restoration programmes for 4 hrs per day. The primary goal was to increase workrelated capacity while emphasising improving self-efficacy. The rheumatologist informed patients about the results of the imaging and other diagnostic procedures and about the benign character of nonspecific LBP. Treatment was based on the patient's job demands, revealed in a work-related assessment, and consisted of work simulation, strength, and endurance training through isokinetic exercise, cardiovascular training performed by walking and aqua-aerobics, sports therapy, and self-exercise. Patients were encouraged to continue their activities even if their pain increased and they were informed that pain provoked by exercises and activity should not be interpreted as harm. The work certificate after rehabilitation was based on the patient's work-related physical capacity and on medical findings.

\section{PAIN-CENTERED TREATMENT}

The pain-centered treatment (PCT) team consisted of a rheumatologist, a physiotherapist and a nurse and the primary goal was pain reduction. The secondary goal was to increase strength, decrease disability and improve return to work. The duration of treatment was 3 weeks and $2 \frac{1}{2} \mathrm{hrs} /$ day. Physical therapy used individually selected mobilisation, stretching, strength training and a mini back-school. In contrast to the FCT group, patients in the PCT group were told to stop activities when pain increased. Passive pain-modulating treatments such as hot packs, electrotherapy or massage were used daily. Low intensity movement therapy in the pool and progressive muscle relaxation further enlhanced relaxation. Progressive muscle relaxation used systematic contraction and relaxation of specific muscle groups. After rehabilitation, the physician of the rehabilitation centre determined the patients' working capacity. His work certificate was based on medical findings only.

In both groups, a rheumatologist prescribed madications such as analgesics and nonsteroidal anti-inflammatory drugs and might also apply local infiltrations. If required, a psychologist offered counselling. Restrictive fitness for work certificates may reduce return to work. ${ }^{14}$ Theretore we assessed the time reduction in the fitness for work certificates. We used questionnaires to the health insurance to record treatment after rehabilitation, which was at the discretion of the patient's primary physician.

\section{COMPLIANCE}

We monitored patients' compliance by recording attendance at scheduled appointments and length of stay. In addition, the treating physiotherapist rated patient-compliance 
using four subscales: a) patient showing interest in information about complaints, treatment and goals, b) active participation with treatment, c) performance of selfexurcises and d) following advice that facilitates recovery. The total score was between 0 and a maximum of 8 points.

We also assessed the therapists" and physicians' compliance with FCT and PCT. A researcher audiotaped the verbal information the therapist or physician gave to patients on 25 consecutive occasions. Seven blinded experts independently rated the goals formulated, information about the treatment plan, explanation of the source of the complaints and advice about coping with pain. Adequate adherence to the protocol was arbitrarily defined as an average overall score of more than 7.5 on a Visual Analogue Scale from 0 , representing "not at all according to the treatment protocol", to 10 , representing 'perfectly according to the treatment protocol'.

\section{SATISFACTION WITH TREATMENT}

Blinding of patients was not possible. Instead, we undertook every effort to keep patients unaware of any expected treatment advantage, and to satisfy patients in both groups equally. This was important to avoid expectation bias and prevent contamination of the two groups by protocol violations. Comparable satisfaction in the two treatment groups was considered important and indicating that patients were unaware of any expected treatment advantage. All patients expressed their satisfaction with treatment on a numeric rating scale from 0 , extremely dissatisfied, to 10 , completely satisfied.

\section{OUTCOME MEASUREMENT}

We assessed work-related outcomes with a questionnaire sent to employers and primary physicians who were blinded to the patients' group assignment. Non-responders received reminders from the independent and blinded research assistant. A blinded research assistant performed the physical measurements before and after rehabilitation in separate room. Patient questionnaires were used to assess self-efficacy, satisfaction with treatment and pain. Primary outcome was the number of calendar days at work in the follow-up year, and the proportion of patients at work in the entire year, accounting for time-reduced work. We analysed the number of patients receiving a full disability allowance, adjusting for the percentage of the allowance, and the number of unemployed patients. The return of follow-up questionnaires by patients was facilitated by a stamped return envelope and a monetary incentive of SFr 10 to responders. 


\section{PREDICTIVE FACTORS}

Before treatment, we recorded demographic, physical, psychological and work-related factors, expected to be predictive for the number of workdays.

Demographic factors were age, sex, marital status, living arrangement, nationality, sick leave in 2 years before treatment, litigation, education, and the number of children financially supported.

Physical factors were the maximum load carried with the right or left hand over a distance of 15 metres, the maximum load lifted from the floor to the waist, and from the waist to the shoulders, the maximum load lifted horizontally at waist level and the load pushed and pulled..$^{15-17}$ We analysed the number of pain regions on a pain drawing. Momentary, maximal and minimal pain intensity in the last week was rated on an 11point Numeric Rating Scale (NRS) ranging from 0, "no pain', to 10, 'the worst pain I can imagine'. The finger to floor distance was used as a measure of active spinal and hip mobility in flexion. ${ }^{18}$ Spinal mobility in extension was measured in degrees with an inclinometer. ${ }^{19}$ We assessed muscle performance by recording the maximum duration of isometric hip and trunk extension (Biering-Sørensen test) and trunk flexion against gravity. We assessed the knee extensors in a squat position with $90^{\circ}$ knee flexion, and the shoulder flexors holding two weights of $3 \mathrm{~kg}$ with $90^{\circ}$ flexion in the shoulders and elbows. ${ }^{20,21}$

Psychological factors were beliefs and behavioural responses. We assessed the patients" expectations about return to work and their beliefs about their own physical capacity using the Performance Assessment and Capacity Testing (PACT) ${ }^{22,23}$ The PACT consists of 50 daily activities in varying sitting and standing postures. Patients are instructed to rate the degree of difficulty performing these activities on a 5-point scale. Behavioural responses to examination were assessed with Waddell's test. ${ }^{8}$ Aspects of pain behaviour such as rubbing, guarding, sighing and grimacing were systematically recorded. ${ }^{24}$

Work-related factors expected to influence outcome were salary, job qualification, employment status and the workload of the current or last job as described under randomisation. Patients rated the degree of satisfaction with their previous work on an 11-point NRS ranging from 'very unsatisfied' to 'very satisfied'. 


\section{STATISTICS}

Power calculation with a power of 0.80 , accepting a type 1 error of 0.05 , indicated that 90 patients per group were needed to detect a difference of 40 workdays $(\mathrm{SD}=95$ ) between the two groups. We used SPSS Version 11.5 for data entry and statistical analysis. Analysis was by intention-to-treat. We used expectation maximisation to substitute values missing at random and missing values $<5 \%$. Substitution by regression analysis was used if $>5 \%$ of the values were missing non-random. ${ }^{25}$

The proportion of patients at work was analysed with a two-way between group analysis of variance using group (PCT and $\mathrm{FCT}$ ) and time in weeks after treatment as factors. We accounted for time-reduced work. In a patient who worked with a $25 \%$ time reduction, each day counted as 0.75 day at work. The between group difference in the number of workdays in the follow-up year was analysed with a Mann-Whitney-U test. The difference in unemployment rate and in the number of patients receiving a disability allowance after one year was analysed with a Chi-square test and with a Kaplan-Meier analysis.

We investigated the influence of age (18-34, 35-50 and $>50)$, sex, job satisfaction, employment status (employed, unemployed), workload (DOT $\leq 2$ or DOT $\geq 3$ ) and nationality (Switzerland, South East Europe, South West Europe) on the number of workdays with a two-way between groups analysis of variance. We computed Cohen's $d$ effect sizes (ES's) which were considered small between .20 and .50 , moderate between .50 and .80 and large if $>.80 .^{26}$

We assessed potentially predictive demographic, physical, psychological and workrelated factors for workdays with multiple regression analysis. Skewed continuous variables were transformed using square root, logarithmic or inverse transformations as appropriate. The overall effects of the factors were determined with standard regression. We used stepwise regression ( $\mathrm{p}$-in $=0.05, \mathrm{p}$-out $=0.10$ ) to identify those factors that predict outcome best.

\section{ROLE OF THE FUNDING SOURCE}

The Swiss federal office of Health, the organisation that provided the grant, did not influence the design of the study, the collection, analysis and interpretation of the data, or writing and submitting the paper. 


\section{Results}

Figure 1: Trial profile

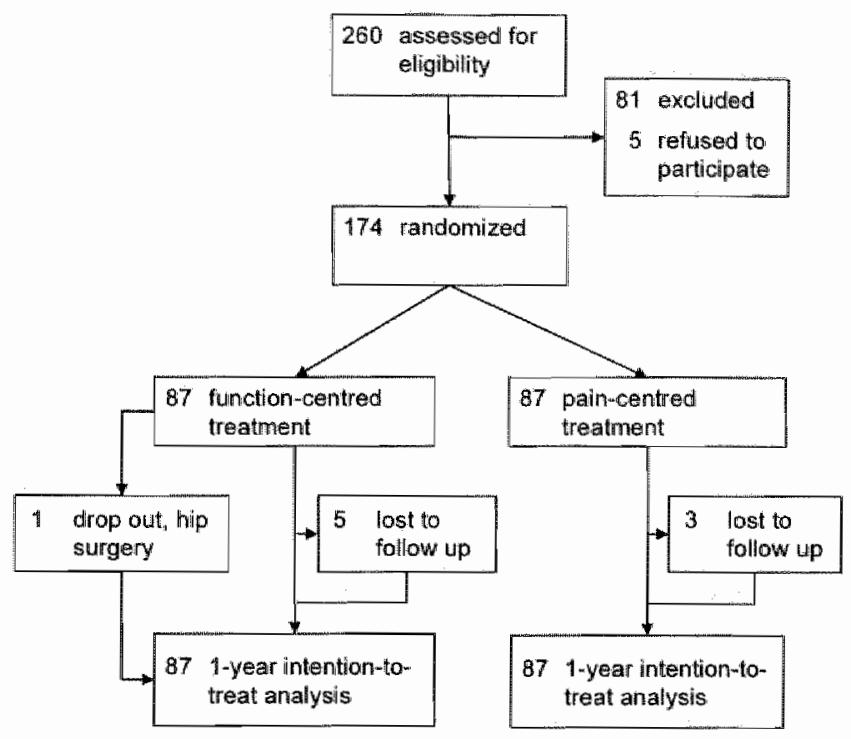

\section{PATIENTS AND COMPLIANCE}

We assessed 260 eligible patients between January 2000 and April 2003 and 174 participated in the study (Figure 1). During rehabilitation, one patient was diagnosed with a necrosis of the femoral head and referted for surgery. All other patients attended at least $90 \%$ of the scheduled treatments. Table 1 displays the baseline comparability of the two groups for the most important prognostic factors and outcome variables. There were no significant differences between the groups. Treatment duration, protocoll compliance of therapists and treatment compliance of patients were comparable in both groups (Table 2),

After rehabilitation, the physician of the rehabilitation centre determined fitmess for work. The time restriction to work activity after rehabilitation was lower in the FCT group (FCT: mean $30.2 \%, \mathrm{SD}=32.6 \%$, PCT: mean $40.1 \%, \mathrm{SD}=36.1 \%$, n.s.). 
Table 1: Baseline charam terishics, number of patients and \% unless otherwise siated. "Mann-Whithey U $p=0.039$

\begin{tabular}{|c|c|c|c|c|}
\hline \multirow[b]{2}{*}{ Age (years, mean, SD) } & \multicolumn{2}{|c|}{$\begin{array}{l}\text { Funclioncentered trealment } \\
\qquad(\mathrm{n}=87)\end{array}$} & \multicolumn{2}{|c|}{$\begin{array}{l}\text { Pain-centered treatment } \\
\qquad(\mathrm{n}=87)\end{array}$} \\
\hline & 41.6 & $(8.4)$ & 42.5 & (8.4) \\
\hline Gender (men/women) & \multicolumn{2}{|c|}{$69 / 18$} & \multicolumn{2}{|c|}{$68 / 19$} \\
\hline \multicolumn{5}{|l|}{ Diagnosis } \\
\hline Low back and leg pain (ICD M 54.4) & 73 & (84) & 71 & $(81)$ \\
\hline Low back pain (ICD M 54.5) & 14 & $(16)^{2}$ & 16 & $(19)$ \\
\hline Use of medication for pain $(N, \%)$ & 67 & (77) & 62 & (71) \\
\hline Body Mass Index (SO) & 26.7 & $(4.2)$ & 27.2 & $(4.0)$ \\
\hline \multicolumn{5}{|l|}{ Marital status } \\
\hline Single & 13 & (15) & 10 & $(11.5)$ \\
\hline Married & 63 & (72) & 67 & $(77)$ \\
\hline Divorced & 11 & (13) & 10 & $(11.5)$ \\
\hline \multicolumn{5}{|l|}{ Living arrangement } \\
\hline Alone & 15 & (17) & 16 & (18) \\
\hline With partner or farnilly & 67 & (77) & 68 & (78) \\
\hline Living alone, family lives in original country & 5 & (6) & 3 & (3.5) \\
\hline Children (N, SD) & 2.0 & $(1,3)$ & 2.0 & (1.4) \\
\hline \multicolumn{5}{|l|}{ Citizenship status } \\
\hline Swiss citizen & 38 & (44) & 35 & $(40)$ \\
\hline Permanent ilimmigrant citizen & 40 & (46) & 42 & (48) \\
\hline Permit depending on employment & 8 & (9) & 9 & (10) \\
\hline Limiled permil (< 1 year) & 1 & (1) & 1 & $(1)$ \\
\hline \multicolumn{5}{|l|}{ Nationality } \\
\hline Switzerland & 38 & (44) & 35 & (40) \\
\hline South East Europe & 31 & (35) & 39 & (45) \\
\hline South West Europe & 18 & (21) & 13 & $(15)$ \\
\hline \multicolumn{5}{|l|}{ Education } \\
\hline 6 yoars (primary schocl) & 11 & $(13)$ & 14 & (16) \\
\hline 79 years & 66 & (76) & 66 & $(76)$ \\
\hline$>9$ years & 10 & (11) & 7 & (B) \\
\hline No professisional education & 38 & (44) & 42 & $(48)$ \\
\hline Unemployed & 18 & (21) & 20 & (23) \\
\hline \multicolumn{5}{|l|}{ Qualification at last job } \\
\hline Unskilled worker & 38 & (44) & 42 & (48) \\
\hline Skilled worker & 49 & (56) & 45 & $(52)$ \\
\hline Salary (SFr, SD) & 4501 & $(1274)$ & 4522 & $(1248)$ \\
\hline Heavy work, workload $>10 \mathrm{~kg}$ & 58 & (78) & 68 & 78 \\
\hline Work satisfaction (mean, SD) & 1.8 & $(2.1\}$ & 2.4 & $(2.9)$ \\
\hline Sick leave 2 years before trealment (mean days, SD) & 184 & $(156)$ & 199 & $(135)$ \\
\hline Wark relaled litigation" & 16 & $(18)$ & 9 & $(10)$ \\
\hline
\end{tabular}


Table 2: Treatment duration, compliance and satistaction (median and IOR unless otherwise stated, no significent differences)

\begin{tabular}{lrlrl}
\hline & \multicolumn{1}{c}{ FGT } & \multicolumn{1}{c}{ PCT } \\
\hline Treatment duration (mean, $\mathrm{SO}$, number of days) & 22.2 & $(3.7)$ & 22.3 & $(3.8)$ \\
Protocol compliance therapists $(0-10)$ & 8.7 & $(7.3-9.6)$ & 9.2 & $(7.7-10)$ \\
Treatment compliance (0-8) & 8 & $(5-8)$ & 7 & $(5-8)$ \\
Patient satisfaction (1-7) & & & & \\
$\quad$ treatment & 6 & $(4-7)$ & $(4-7)$ \\
explanations about complainis & 5 & $(3-7)$ & 5 & $(3-6)$ \\
advice about coping with complaints & 6 & $(4-7)$ & 6 & $(5-7)$ \\
increased ability to control complaints & 5 & $(3-7)$ & 5 & $(3-7)$ \\
\hline
\end{tabular}

\section{DAYS AT WORK}

We retrieved the number of workdays and the daily time reduction in the one-year follow-up period for $82 / 87(94 \%)$ and $84 / 87(97 \%)$ of the patients in the FCT and PCT groups respectively. The mean (SD) number of workdays was 118 (134) in the $\mathrm{FCT}$ group and 74 (114) in the PCT group; the effect-size $(95 \% \mathrm{CI})$ was $0.35(0.05-0.65)$. The number of days at work was larger in the FCT group (Mann-Whitney U Test $\mathrm{p}=$ 0.011 ). The proportion of patients at work full-time, accounting for time reduction, was significantly larger in the FCT group (two-way ANOVA, $p=0.029$, Figure 2).

\section{UNEMPLOYMENT AND DISABILITY}

The unemployment rate after one year was slightly lower in the $1 \mathrm{C} T$ group $(37 / 87=$ $43 \%$ vs. $45 / 87=52 \%, \mathrm{OR}=0.69,95 \%$ Cl $0.38-1.26$, chi-square $\mathrm{p}=0.14)$. Three of 24 patients, who were unemployed before rehabilitation, found a job in the follow-up year. Before treatment, 2 patients in each group received a $50 \%$ disability allowance. At oneyear follow-up the disability insurance reported that fourteen additional patients had been awarded a disability allowance retrospectively and starting before rehabilitation. After one year, $32 / 87$ patients in the FCT group and $38 / 87$ patients in the PCT group received a disability allowance. The difference was not significant (Kaplan Meier Log rank $\mathrm{p}=0.26$,

Figure 3). The average degree of disability was smaller in the FCT than in the PCT group (FCT: 24\%, PCT: 33\%, Mann-Whitney $U p=0.20$ ). The decision about a disability allowance was still pending in 8 cases in the FCT group and 10 cases in the PCT group. 
Figure 2: The percentage of patients at work, accouning for time-reduced work, was significantly larger in the function-centered treatment group ( $\mathrm{FCT}$ ) than in the pain-centered treatment group (PCT).

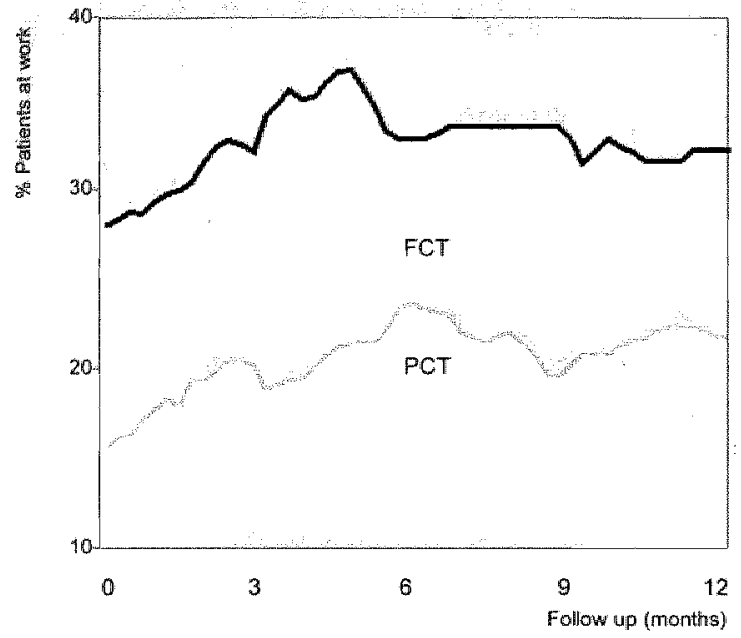

Figure 3: The percentage of patients receiving a disability allowance increased more in the PCT than in the FCT group.

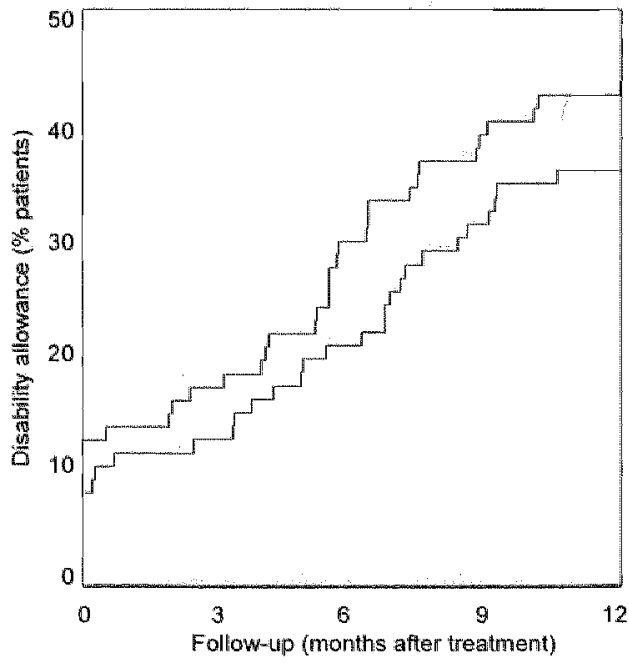




\section{SUBGROUP ANALYSIS}

Figure 4 compares the overall ES's with the $\mathrm{ES}$ of subgroups of different gender, age, nationality, workload, job qualification and employment status. Due to a reduction in power, most of the subgroup ES's were smaller and insignificant. FCT was more effective in female and in younger patients, and in workers with a low workload. In patients with a high job qualification, there was a small benefit for the PCT.

We analysed the effect of treatment and other factors with a two-way analysis of variance. Workload had no effect on workdays $(\mathrm{F}=0.38, \mathrm{p}=0.5)$ but there was a significant interaction between workload and treatment group $(F=5.36, p=0.022$, Figure 5). Nationality had a significant effect on workdays $(F=12.06, p<0.0001$, Figure 5), but no interaction with treatment $(F=0.03, p=0.9)$. ES's were similar in unemployed and employed patients (Figure 4) but the number of days at work was significantly lower in unemployed than in employed patients $(F=12.72, p=0.0004)$ in both groups. The number of workdays was larger in patients with a high compared with a imoderate or low qualification at the last job $(\mathrm{F}=3.08, \mathrm{p}=0.048)$. 
Figure 4: Standardised ES's $(95 \%$ Cl) of the number of workdays of different subgroups, compared with the overall effect size, displayed by the dotted line. FCT, function-centered treatment. PCT: pain-centered treatment.

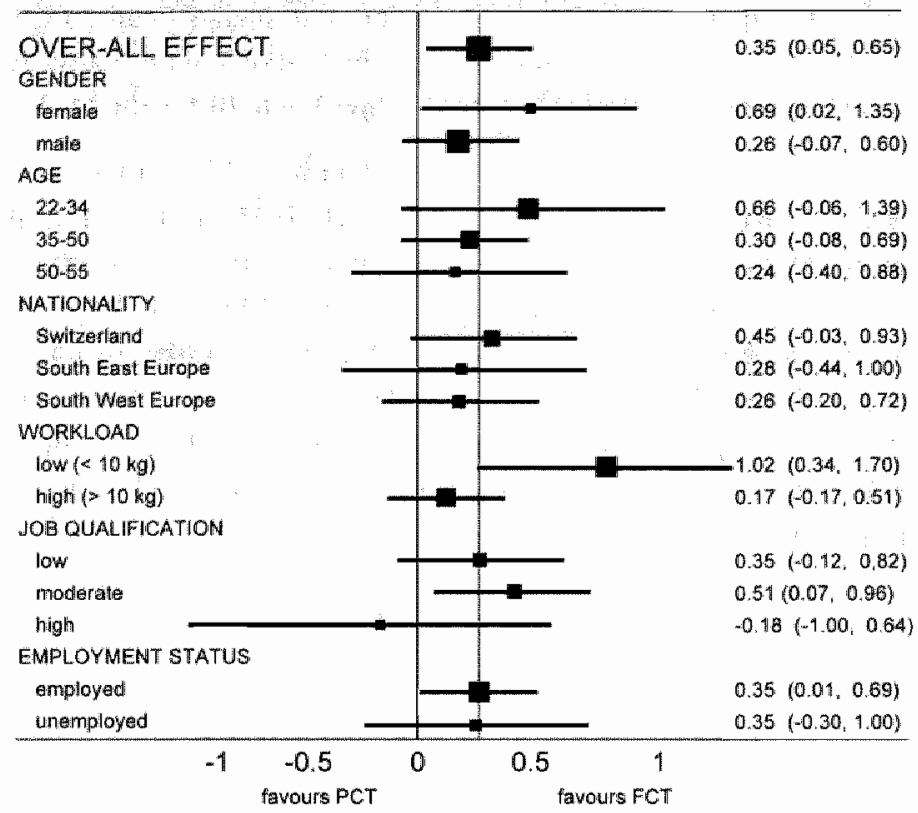

\section{PREDICTIVE FACTORS}

Demographic factors accounted for $14 \%$ of the variation of workdays. Demographic factors showing a significant positive association with workdays after one year were being employed, a shorter duration of previous sick leave, Swiss nationality, the number of years living in Switzerland and the number of children financially supported by the patient. A significant negative association with the number of days at work existed for patients involved in legal issues and for patients from other countries whose family lived outside Switzerland. No association existed between the number of workdays and age, sex, marital status and living alone or with a family. The stepwise regression model. of workdays and demographic factors included Swiss nationality, off-work duration before rehabilitation and being involved in legal issues $(R=0.415$ and adjusted $R$ squared $=0.160$ ). 
Figure 5: There was a significant interaction between workoad and treatment. Nationality had a significant effect on work days but there was no interaction.

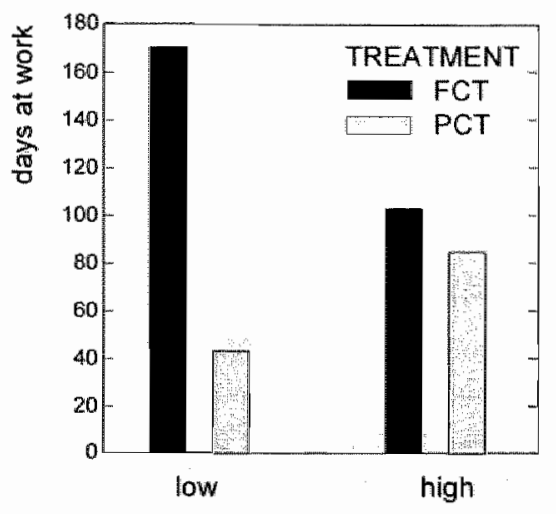

WORKLOAD

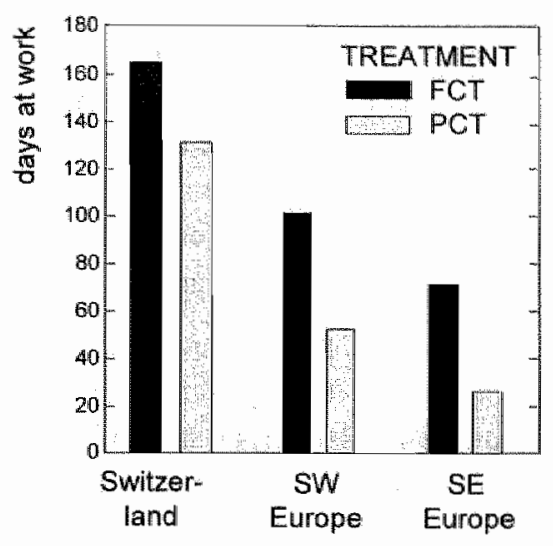

NATIONALITY

Plyysical factors explained $24 \%$ of the variance in workdays. A significant association with workdays after one year was found for the maximum load carried with the right or left hand over a distance of 15 metres, the maximum load lifted from the floor to the waist and from the waist to the shoulders, the maximum load lifted horizontally at waist level, the load pushed and pulled, isometric endurance of the back, shoulder and knee musculature, the finger to floor distance when bending forward with straight knees, the range of motion of the lumbar spine measured with an inclinometer, degrees of straight leg raise and the momentary, minimal and maximal pain intensity. No association was found between workdays and the body mass index, isometric strength of the abdominal musculature, the lumbar flexion and extension measured with the modified Schober test and the number of pain regions. The stepwise regression model explaining workdays with physical capacity factors included four factors: the maximum weight safely carried with the right hand over a distance of 15 meter, the minimal pain in the last week, maximal pain in the last week and the finger to floor distance ( $R$ was 0.542 and adjusted R squared 0.294). 
Psychological factors explained $26 \%$ of the workdays" wariance. Positively correlated with workdays were self-rated physical capacity, the self-estimated probability to return to the previous work and the patient"s belief of the necessary time reduction when returning to the previous work. A significant negative correlation with workdays was found for Waddell's test for behavioural responses to examination and pain behaviour. The stepwise regression model included three factors: self-rated ability (PACT), guarding pain behaviour and the patient's belief about the possibility to return to the previous work $(R=0.513$, adjusted. $R$ squared $=0.250)$.

Work-related factors explained $13 \%$ of the variance in workdays. A significant association was found between workdlays and work satisfaction, professional education and qualification at the last job. A significant negative association existed with workload. No association existed between workdays and the salary or the number of years on the job. The three factors included in the model were the level of professional education, work satisfaction and workload $(R=0.400$, adjusted $R$ squared $=0.145)$.

Overall, $39 \%$ of the variance in workdays could be explained by pre-treatment measurements. If we included all of the above-mentioned factors in a stepwise regression analysis, the final model included the maximum weight carried with the right arm, guarding pain behaviour during the assessment, the maximum pain intensity in the previous week, employment status, Swiss nationality, the patients" belief about the possibility to return to the previous work and physical workload $(\mathrm{R}=0.642$, adjusted $\mathrm{R}$ squared $=0.388$ ).

\section{INTER VENTIONS IN THE FOLLOW-UP PERIOD}

We assessed interventions in the follow-up period by means of a questionnaire sent to the health insurance. The return rate was $78 \%$. Interventions after rehabilitation were comparable in the ICT and PCT group. Diagnostic procedures, mainly $x$-ray, MRI, and $\mathrm{CT}$, were used in 44 and $39 \%$ of the patients. Almost all patients, 90 and $94 \%$ in the FCT and PCT group respectively, used analgesics, antidepressiants and other medications. Physical and occupational therapy was prescribed to 83 and $78 \%$ of the patients.

\section{Discussion}

FCT is more effective than PCT to increase workdays in patients with non-acute nonspecific LBP. The unemployment rate and the number of patients receiving a disability allowance after one year was slightly smaller in the FCT group. FCT was more effective in patients with a physical workload below $10 \mathrm{~kg}$. 
Strengths of this study were the relatively large number of patients compared with many other studies, excellent compliance, and applicability of the treatment to Swiss patients and immigrants with limited knowledge of the national language. Blinding was not possible in patients and in the members of the multidisciplinary teams. We kept patients unaware of the treatment of the other group and of any expected treatment advantage, which was the best available alternative. The excellent treatment compliance in both groups and the comparable patient satisfaction indicate that this attempt was probably successful.

Therapists were equally skilled because their professional experience was more than 5 years in both groups and they were recruited according to their own preference for either PCT or FCT. At the time when we started the trial, more physicians favoured PCT and found it difficult to encourage patients to move in spite of pain. By the end of the study, the preference for the two treatments became more balanced.

The population under study was representative for the population in Switzerland at risk to develop permanent LBP disability. The studied group was characterised by a long duration of LBP and sick leave and a large proportion of predominantly male workers with a low education level. We did not exclude patients with only minimal knowledge of the German or Italian language as many clinics do.

We did not use cognitive psychological interventions. This would have required limitation of the study to patients with more profound knowledge of the German language. We were concerned about this limitation but we found no randomised controlled trials showing that cognitive psychological treatment improves return to work in this patient population. Operant behavioural treatment was an important aspect of our intervention. The group treatments with training and walking offered many opportunities for the therapists to discuss patients" thoughts, beliefs and concerns.

Compared with a study in Sweden by Lindström at $a l_{,}^{27}$ our study included fewer immigrants $(58 \%$ vs. $75 \%$ ). In our study, the off-work duration was longer and pain intensity was higher ( 5.6 vs. 3.3 points on a 10 -point scale). In the Lindström study, treatment also focused on supporting patients in returning to work by increasing activity, reducing pain behaviour and giving them confidence by using a graded activity programme. As in our study, the time until return to work correlated with the initial severity and duration of complaints. One of the limitations of our study is that we did not conduct a workplace visit which might have improved the results. ${ }^{27,28}$

An important question is whether the effect could be explained by the different treatment duration of 4 hrs per day in the FCT and $2 \frac{1}{2}$ hours per day in the PCT group. Pain intensity, lifting capacity and self-efficacy deteriorated in the PCT, and improved in the FCT group. In case of a dose response relationship, a smaller and not an opposite direction of the effects would be expected in the two groups. We therefore think that the 
treatment effect was caused by the difference in treatment concept, and not by the difference in the duration of treatment.

Many psychological and physical aspects of treatment may have contributed to the treatment effect. Patients in the FCT group had reduced pain, rated their physical capacity higher and their lifting capacity had increased more. Work certificates were less restrictive in the $\mathrm{FCT}$ group. All these factors correlated with workdays and contributed to the significant effect.

The difference in the proportion of patients at work between groups declined after six months. A future reduction of work-related disability may be possible by combining rehabilitation and work place interventions, in cooperation with politicians and insurance companies in Switzerland. Today, incentives for employers and involved insurance are non-existent in Switzerland. The workers compensation insurance, which would benefit from sick leave reduction, is unwilling to pay for treatment because this is the responsibility of the health insurance.

The effect of FCT on the number of disability allowances and the unemployment rate was not significant. This is in accordance with other studies. ${ }^{3}$ The power of this study to detect a $20 \%$ reduction in disability allowances is only 0.19 . In the light of the workdays' effect, we expect that the number of disability allowances will increase more in the PCT group and an analysis of the results after three years is planned. Work days were better predicted by physical ( $24 \%$ ) and psychological factors (26\%) than by workrelated $(13 \%)$ and demographic factors $(14 \%)$. This is important because work-related and demographic factors cannot be modified by FCT or PCT. Several physical and psychological factors were improved by the FCT: carrying loads, lifting, pain, and selfrated physical capacity. There are, however, limitations to our model to predict workdays. Firsty, workdays" prediction in this study is limited to the recorded predictive factors. Not recorded were for example general health status, smoking, sports activities and work-related factors such as vibrations, job-related stress, and the possibility of job adaptation. The external validity of the predictive model is limited to comparable patients. Many factors identified in this study have been shown to be predictive for workdays in other studies, such as the severity of the symptoms, physical capacity and disability, the sick-leave duration, illness behaviour, patients' beliefs, workload and education. ${ }^{6,7}$ As in other studies, no single factor seems to have a strong impact. $^{29}$

In conclusion, FCT increased workdays, compared with PCT, especially in patients with a workload below $10 \mathrm{~kg}$. Predictive for workdays were the maximum weight carried with the right arm, guarding pain behaviour, the maximum pain intensity in the previous week, employment status, Swiss nationality, the patients" belief about the possibillity to return to the previous work and the workload. 
We plan a three-year follow-up and cost-effectiveness analysis of the FCT. Further research is also needed to identify the essential elements of treatment and to develop cheaper outpatient programmes. Management to reduce work-related disability must be improved, probably emphasising early intervention and job adaptation and involving legal and financial incentives for both workers and employers.

Based on these results, we recommend that function-centered rehabilitation should be applied instead of the still widely used pain-centered treatment.

\section{Acknowledgements}

Mirella Russo performed the physical assessments and collected the predictive and descriptive information. Judith Dierkes evaluated the adherence to the treatment protocol of the therapists and physicians. Patrizia Bigger sent the follow-up questionnaires and made numerous phone calls to patients, physicians, employers, health insurances and disability insurances.

\section{References}

1. Guzman J, Esmail $\mathbb{R}$, Karjalainen $K$, Malmivaara A, Irvin E, Bombardier C. Muliudisciplinary rehabilitation for chronic low back pain: systematic review. Bmi 2001:322(7301):1511-1516.

2. Schonstein E, Kenny D, Keating J, Koes B. Herbert RD. Physical conditioning progrims for workers with back and neck pain: a cochrane systematic review. Spine 2003;28(19):E391-395.

3. Kool $J$ de Bie R, Oesch P, Knusel $O$, wan den Brandi P, Gachmann $S$. Exercise reduces sick leatve in patients with nor-acute nonspecific low back pain a meta-analysis. I Rethabil Med 2004;360(2);49.62.

4. Buri M. Disabilaty Insuranee - Stutistics. Swiss Federal Social Insurance Oftice 2003.

5. Marin B, Prinz C. Facts and figures on disalaility welfare. A pictographic portrail of an ol:CD teport. Eutopean Centre of the OECD Vienna/Pan is 2003.

6. Karjalainen $K$. Malmivaata $A$, Mutanen $P$, Pohjolanen $T$, Roine $R$, Harr $H$. Oncome determinanis of subacute low back pain. Spine 2003:28(23):2634-2640.

7. Schultz IZ, Crook IM, Berkowit, J, Meloche GR, Miner R, Zuberbier OA Metoche W. Biopsychosochal multivariate predictiwe nodel of occupational low tack disability. Spine 2002,27(23):2720-2725.

8. Mair CJ, Waddell G. Behasional responses to examination. A reappraisal of the interprettion of "nonorganic signs". Spime 1998;23(21):2367-2371.

9. Kool J, Oesch P, Bachmann S, Knibse O. de Bie R, wan den Brand P. Increasing days at work using function-centered rehabilitation in non-acute nonspecific low back pain: a randomized controlled trial. Arch Phys Med Rehabil 2005;86(5):857-864.

10. Altman DG, Schulz KF Moher D, Egger M, Davidoff f, Elboume D, Golzsche PC. Lang $T$. The revised CONSORT statemen for reporting randomized trials: explanation and elaboration. Ann Intern Med $2001 ; 134(8): 663-694$.

11. Kool JP, Oesch PR, de Bie RA. Predictive tests for non-retum to work in patients with chronic low badk pain. Eur Spine J 2002; 1 (3):258-266. 
12. Waddell O, MoCullow J,A, Kummel E, Vanmer RM. Nonorganic physical signs in lowmack pain. Spine $1980 ; 5(2): 117-125$

13. Dictionary of Oecupational Titles, 4fH Editon. Washington DC: United States Department of Labor, 1991.

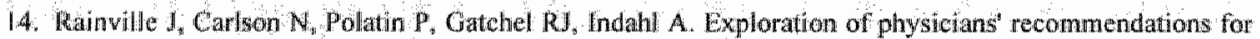
activities in chronit low back pain spine $2000,25(17): 2210-2220$.

15. Cross DP, Dattic MC. Reliability of safe maximum lifting determinations of a functional capacity evaluation. Phiys ither 2002;82(4):364-371.

16. Isemhagen SJ, Hari DL, Matheson LM. Reliability of independent observer judgements of level of lift effort in a kinesiophysical functional Capacity Evaluation. Work 1999; 2 (2):145-150.

17. Brotwer $S$, Renenan $M$, Dijkstra P, Groothoff J, Schellekens J, Goeken L. T"est-retest reliability of the Iserthagen Work. Systems functional Capacig Ewaluation in patients with chronic low back pain. I Occup Rehabil $2003 ; 13(4): 208-218$.

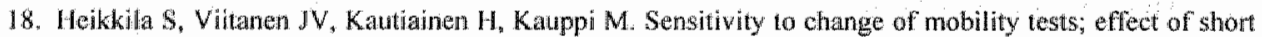
term intensive physiotherapy and exercise on spinal, hip, and shoulder measurements in spondyloarthropathy. I Rheumatol 2000;27(5):1251-1256.

19. Ng JK, Kippers $\mathrm{W}$, Richardson $C A$, Parnianpour M. Range of motion and lordosis of the lumbar spine: reliability of measurement and normative values. Spine $2001 ; 26(1): 53-60$.

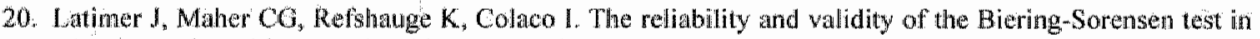
asymptomatic subjects and subjects reporting current or previous nonspecific low back pain. Spine $1999: 24(20): 2085-2089$

21. Oesch P, Kool JP, Sloksnath U, Hasegawa. A. Die Zuverlassigkeit und Emplindichkeit won 4 isometrischen Muskeltests. Physiotherapie 1994(6):4-12.

22. Matheson L, Mooney $\mathrm{V}$, Grant J. Affeck M, Hall H, Melles T, Lichter R, McIntosh G. A lest to measure lift capacity of physically impared adults. Part 1 : Development and reluability testing. Spine $1: 995 ; 20(19): 2 \mid 19-2129$

23. Matheson LN, Matheson M. Spinal function sort, rating of perceived capacity. Performance Assessment and Capacity Testing PACT. Trabuco Canyon, Califonata: Performance Assessnent and Capacity Testing PACT, 1989

24. Keefe FJ, Wilkins RH, Cook WA. Direct observation of pain behavion in low back pain patients during physical examination. Pain 1984;20(1):59-68.

25. Hollis $\mathrm{S}, \mathrm{Crampbel} \mathrm{F}$. What is meant by untention to treat analysis? Survey of published randomised controlled trials. Bunj 1999:319(7211):670-674.

26. Cohen J. Statistical power analysis for the behavional seiences. 2nd ed. New Jersey: Lawrence Fribaum, 1988.

27. Lindstrom 1, Ohlund C. Eek C., Wallin L, Pexterson LE. Fotdyce WE. Nachemson AL. The efrect of grided activity on patients whth subacule low back pain: a randomized prospective clinical study with an operant-conditoning behavioral approich. Phys ther 1992,72(4),279-290.

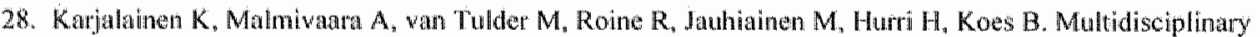
biopsychosocial rehabilitation foll subacute low back pain in working-age adults: a systematic reviaw within the limework of the Cochrone Collaboration. Back Review Giroup. Spine 2001; 26(3):262-269:

29. van Tulder M, Koes B, Bombardier C. Low back pain. Best Pract Res Clin Rhoumatol 2002;16(5);761775 


\section{Chapter 6}

\section{Inconsistency of test performance during functional capacity testing and medico-legal consequences}

Jan P. Kool', Peter R. Oesch' ${ }^{2}$, Stefan Bachmann ${ }^{2,3}$, Piet van den Brandt and Rob A. de Bie ${ }^{4}$

Affiliation of the authors

'Research Dpt., Rehabilitation Centre Valens, Switzerland

${ }^{2}$ Dpt. of Work Rehabilitation, Rehabilitation Centre Valens, Switzerland ${ }^{5}$ Dpt. of Rheumatology, Rehabilitation Centre Valens, Switzerland ${ }^{4}$ Dpt. of Epidemiology, Maastricht University, The Netherlands submitted 


\begin{abstract}
Introduction: An Isernhagen Work Systems" Functional Capacity Evaluations (FCE) consists of 23 standardized tests. FCES are used to determine a client"s work-related maximum physical capacity. Inconsistencies between the tests of an FCE are systematically observed using 13 items and interpreted as submaximal performance if 3 or more items are positive. The Swiss Disability Insurance uses FCE reports to determine the level of a disability allowance. Inconsistent FCE-results may result in a lower level of disability and a smaller disability allowance. It is important to validate the assessment of inconsistency because disagreement of clients with the Disability Insurance's decision has induced medico-legal issues. The purpose of this study is to analyze the internal consistency of the 13 consistency checkpoints of an FCE-test.
\end{abstract}

Methods: Retrospective analysis of 56 consecutive full FCEs. We determined the internal consistency of the 13-items for inconsistent performance with Cronbach Alpha and defined a value $>0.6$ as satisfactory. Omitted from the scale were items with an item-total correlation $<0.2$.

Results: The median number of inconsistent results in the FCE was $3 / 13$ (range 0-9, IQR $1-9)$ and $\geq 3$ inconsistencies were found in 32 of $56(57 \%)$ clients. Three redundant items were omitted. Internal consistency was satisfactory; 0.71 in the 13-point scale and 0.74 in the 13-point scale.

Conclusion: The results support the validity of the assessment of FCE test consistency, its consideration in the determination of work-related disability and its use in medicolegal issues. 


\section{Introduction}

\section{OVERVIEW}

The focus of this publication is the assessment of the consistency of a client's performance on different tests conducted within a Functional Capacity Evaluation (FCE). The Swiss Disability Insurance uses FCE reports to determine work-related disability and the level of a disability allowance. FCEs include multiple standardized tests and are used to determine a client's work-related maximum physical capacity. In order to determine maximum physical capacity, the observation of maximal effort is required. Inconsistencies between FCE-test items are systematically observed and interpreted as submaximal performance. The FCE-report, written by the assessor, includes the results of the assessment of test consistency. In case of inconsistent results, the report states that the work-related capacity should be considered higher than the client's demonstrated performance. Thus, the Disability Insurance can consider a higher work-related capacity to be reasonable, resulting in a lower level of disability and a smaller disability allowance. A client's disagreement with the decision of the Disability Insurance may induce medico-legal situations (Figure 1).

Figure 1: Reporting inconsistent performance an FCE tests may reduce the disability allowance of the inwolved person.

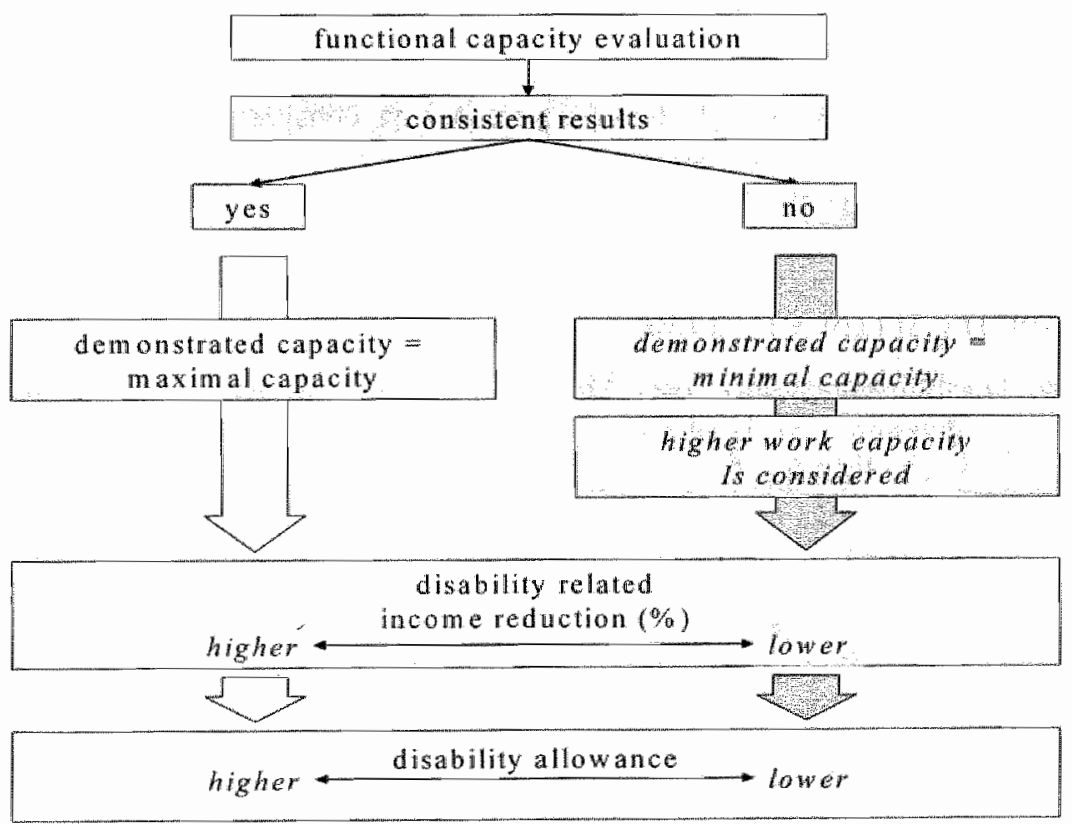




\section{FUNCTIONAL CAPACITY EVALUATIONS AND INCONSISTENT RESULTS}

Work-related disability is not judged by the impairment of body function but by the extent of the functional loss regarding the demands of the previous work ${ }^{\text {I }}$ Different types of FCEs are avallable. This study concerns the FCE according to the Isernhagen Work Systems ${ }^{2}$, described in more detail in the methods section and in table 2. An FCE independently observes function and pain. Critical job demands are assessed by an interview with the employer, employee or existing job descriptions. The physical capacity found in the FCE is compared with the client's required physical job demands.

Internal consistency of FCE tests is important for several reasons. Consistency of the interrelated test results is a psychometric requirement of tests evaluating a client's performances The judgment of the consistency of a client's performance must be reliable to prevent invalid conclusions because wrongly describing test results as inconsistent can have the effect that a client may not receive the appropriate disability allowance. Moreover, the reliability of the judgment of consistency of FCE-test performance is very important because FCEs are increasingly used before court.

The consistency of performance during FCE-testing is assessed with 13 items displayed in table 2. The basic characteristic is to observe the expected concordance between interrelated FCE-tests. Concordance is expected based on theory as well as on the clinical observation that the majority of clients show the expected concordance between the interrelated FCE-tests. None of the single items has perfect specificity. Arbitrarily, 3 or more positive items of inconsistency, not associated with physical problems, were defined to indicate an inconsistent performance. ${ }^{3}$ Inconsistent results indicate nonmusculoskeletal functional limitations.

The written FCE report includes a statement concerning the consistency of test performance. If the client's FCE test performance is consistent, the demonstrated performance is considered the maximal performance. In case of an inconsistent test performance, the $\mathrm{FCE}$ report states that test results were inconsistent and that the client did not show maximum performance.

\section{THE DISABILITY ALLOWANCE LEVEL}

The Swiss Disability Insurance uses FCEs in combination with other sources of information to determine work-related physical capacity and the level of a disability allowance. "A reduced ability to work is caused by an impairment of physical, mental or psychic health which leads to full or partiall incapability to do reasonable work in the previous occupation or field. In case of long duration of limited work capacity, reasonable occupation in another profession or field has also to be taken into consideration"."

If unrestricted return to the previous work is not possible due to permanent disability, two criteria are considered: time restriction and job adaptation or alternative work. 
The salary the client could earn with this adapted or altemative work is then compared with the salary of the previous work. The level of a disability allowance depends on the reduction of the client's sallary.

\section{MEDICO-LEGAL ISSUES}

Clients may disagree with the decision of the Disability Insurance regarding the level of disability and the amount of the monthly disability allowance inducing medico-legal situations. Among the available evidence at court, FCE-reports take a centrall place. Judges frequently prefer FCE-reports to the medical judgment of work capacity. Pathology and findings of diagnostic procedures and physical examination correlate poorly with work-rellated physical capacity. The statements in the FCE-reports concerning work-related physical capacity, effort level and consistency of test performance are a frequent matter of dispute at court. Studies of the psychometric properties of the judgment of consistency are urgently needed.

\section{PURPOSE OF THIS STUDY}

The purpose of this study is to determine the internal consistency of the 13 consistency checkpoints of an FCE-test, since this can be considered a prerequisite for the validity of the assessment.

\section{Methods}

\section{DESIGN}

We retrospectively analyzed 56 full FCEs, conducted by physical therapists in our department for work rehabilitation. The FCEs were performed in two parts on two consecutive days.

\section{FUNCTIONAL CAPACITY EVALUATION}

An FCE evaluates work-related physical capacity with 23 standardized tests (Table 1). Test-retest reliability of several FCE test items has been confirmed.

Within an FCE, the client's self-rated physical capacity is evaluated with the Performance Assessment and Capacity Testing (PACT). ${ }^{6,7}$ The PACT consists of 50 daily activities in varying sitting and standing postures. Clients are instructed to rate the degree of difficulty performing these activities on a 5-point scale ranging from "impossible" to 'possible without difficulty'. Self-rated ability is compared with the results of physical capacity testing. Substantial underestimation of one's own physical capacity is noted as inconsistency. 
Table 1: Tests used in a Functional Capacity Evaluation ("Performed boith on the first and second day of testing)

\section{LIFTS}

1 Floor to waist.

2 Waist to overthead*

3. Horizontal*

PUSH/PULL

4. Statitic

5 Dynamic

CARRY

6 Front

7 Right or left-handed

ELEVATED WORK

8 Overthead

FORWARD BENDING TOLERANCE

9 Sitting

10 Standing

UPPER EXTREMITY

11 Grip strength

12 Coordination

\section{UNWEIGHTED ROTATION TOLERANCE}

13 Sitting

14 Standing

LOW ACTIVITIES

15 Craw

16 Kneel

17 Crouch

18 Repetitive squat

AMBULATION ACTIVITIES

19 Walking

20 Stair climbing

21 Stepladder climbing

STATIC WORK

22 Sitting

23 Standing

\section{CONSISTENCY OF FCE TEST RESULTS}

An FCE includes 13 consistency checkpoints which are rated after completion of the $\mathrm{FCF}$ (Table 2). The consistency checklist was developed by Isernhagen Work Systems USA and included in the standardized FCE. Item 8 was added in Switzerland.

\section{STATISTICS}

Descriptive data and results of the 13 -item consistency checklist were entered in SPSS Version 11.5, checked for completeness and analyzed. We determined the internal consistency of the 13-items for inconsistent performance with Cronbach Alpha and defined a value $>0.6$ as satisfactory. ${ }^{8}$ Omitted from the scale were items with an itemtotal correlation $<0.2$, highly inter-correlated and, therefore, redundant items, and items with the same scote for most persons $(>95 \%){ }^{s}$ 
Table 2: The 13 items used to assess the consistency of a client's perfomance during FCE-testing. $D-2=$ consistent; $\geq 3=$ inconsistent

1 There should be a link between the physical problems identified in the prelininary musculoskeletal evaluation and actual functional perfomance (i.e tightness or inability to tolerate low back flexion would be reproduced turing the FCE subtests requiring fonward bending at the waist in sitting standing).

2 Heart rate reflects level of stress or the amount of effot the person is using. Heart rate goes up with an increase in level of effort. Increase in weight will increase heart rate. Painful positions can also increase heart rate fl.e. a clitint stops a test giving maximal effort as neason. Meainwhile, the heart rate does not indicate meximal effort. This is considered an inconsistency).

3 Floor to waist lift correlates with repetitive squal test. Fonward bending capacity is similar in squatting and lifting with a minimal weight.

4 Overhead lift correlates with overhead work test. An example of inconsistent findings is the ability to lift $5 \mathrm{~kg}$ overhead and the inability to perform owerhead work for 10 seconds.

5 Hoizontal lift correlates with two-handed carry. The difficuliy of these two tasks is comparable. If the weights differ more then $2.5 \mathrm{~kg}$, this is considered an inconsistency.

6 One-handed carry correlates with hand grip measurement. Hand grip sthould be higher than carry.

7 Pull force should be greater than push force.

8 Maximum weight is higher in horizontal lifting than in lifting from the floor to the waist.

9 Low level activities of crawling, kneeling, crouching and squatting should be consistent with limitations in llower extremity strengih, range of motion and Irunk flexion limitations.

10. Sitting tolerance during the client history musculoskeletal evaluation should be consistent with sitting tolerance subtest in the FCE.

11 Perceived ability on the Spinal Function Sort test should be consistent with actually demonstrated functional ability during the test.

12 Hand grip sublest scores should reflect a bell-shaped curve.9. Grip strength is maximal in an inlermedialo hand position and lower in more closed or opened hand positions. A bell-shaped curve correlates with a maximal affort. it

13 Consistent performance on the first and second day. If differences are present, these can be explained by physica reasons such as joint irritation or muscle soreness. 


\section{Case report: Ms Miller}

This case report describes the context of evaluating and judging a client's consistency of performance during FCE-testing.

Ms Millei had been suffering from low back pain (LBP) for nime years Imaging and other diagnostic procedures revealad no specific cause of the complaints. She did not have surgery. Ms Miller started lier last job 1.5 years ago. She cleaned office rooms during 15 hours per week. After three months she was sick listed because of LBP. Her employer dismissed her and she fiad been unemployed since then: Ms Miller was severely limited in household activities. She applied for a disability allowance.

The Disability Insuranice teferred Ms Miller to our centre to determine work-related physical capacity with a Functional Capacily Eyaluation (FCE). The work demands of Ms Miler's last job included lifting weights of $2.5 \mathrm{~kg}$ from the foor to the waist and from the waist to the shoulders, carrying weights of $7.5 \mathrm{~kg}$ with the left or right hand, pushing $(8 \mathrm{~kg})$, pulling (10 $\mathrm{kg}$ ) and holding objects with a grip sirength of $10 \mathrm{~kg}$. She performed her work in the following body positions: sitting, kneeling, squatting, forward bending while sitting or standing, and rotating the trunk while sitting or standing. Her work required several means of mobility: walking, crawling, ladder and stair climbing.

Ms Miller's performance during FCE-lesling was severely inconsistent. The following observations were made and described in the FCE-repert:

- The results of the clinical assessment were not consistent with the results of functional testing. Because of muscle weakness, Ms Miller was unable to lift her arms and extend her elbows in a supine position. During crawling, another functionall test, she carried a substantial part of her trunk on her arms. During clinical testing of mobility the finger-to-floor distance was $31 \mathrm{~cm}$. After the assessment Ms Miller laced her shoes while standing with straight knees.

- An increase in heart rate expressing exertion or pain was not abserved.

- The maximum load duting two-handed carrying over a distance of 10 meters was much larger $(7.5 \mathrm{~kg})$ than during carrying over a short distance of 1 meter $(2.5 \mathrm{~kg})$.

- Unexpectedly, strength during isometric pulling was smaller than during isometric pushing.

- Contrary to the expectations, the maximum weight during two-handed carrying over a short distance $(2.5 \mathrm{~kg})$ was not larger than the weight lifted from the floor to the waist $(2.5 \mathrm{~kg})$.

- Self-rated physical capacily, assessed with the PACT, was clearly below the physical capacily demonstrated during FCE lesling.

- Grip strengith measurements with the left hand did not show a bell-shaped curve.

In addition to the judgment of consistency, the FCE-report included the client's job profile and an extensive description of the results of the 23 FCE-tessts; The physiotherapist performed a climical neurological examination and a physical assessment of strength and mobilly of the lumbar spine and the lower extremilies.

The conclusion of the FCE weport was that the dient's relevant wark-related problem was a severe reduction of functional capacity. The client's performance was too low to perform any job. The results of the physical examination did not explain the FCE results. The client did not show a maximal effort and test performance was severely inconsistent. Therefore, the observed perfomance could mol be used lo determine the client's remaining work capacity and her degree of work-related disabililyty"

In considteration of the FCE-report, the Disabuty Insurance decided it reasonable for the client to perform light work uncluding household and cleaning tasks with a time reduction of 2 hours per day. This capacily was abowe the level demonstraled during FCE lesting. The reduction in salary the dient could earn amounted to $25 \%$

Ms Miller did not accept the decision; she considered herself incapable of warking and expected a full disability allowance. At court, her lawyer criticized the statement that his client's performance was inconsistent and argued that it was discriminating. The judge, howewer, regarded the descriptions in the FCE-report as objective, clear and value free. Hence, the clienl's objection against the decision of the Disability Insurance was not acknowledged. The client lost her case and received a $25 \%$ disability allowance instead of the $100 \%$ disability allowance she had expected to receive. 


\section{Results}

The persons of whom we retrospectively assessed FCEs consisted of almost equal proportions of male and female persons; half of them came from Switzerland and neighboring German speaking countries (Table 3). The majority of clients was sick listed. Of all the 56 cases only item 11 showed two missing values; all other items were complete. Item 11 compares lifting capacity with self-rated disability (PACT). Two clients presented themselves unable to follow the instructions written in their native language. Inconsistent test results $(\geq 3$ inconsistencies) were found in $32(57 \%)$ clients. The median number of inconsistent results in the FCE was 3 (range 0-9, interquartile range $1-9)$.

Table 3: Subjects (number and percentage unless othewise stated, $\mid Q R=$ inter quartile range)

\begin{tabular}{|c|c|c|c|}
\hline \multicolumn{2}{|c|}{ Female } & 25 & 44.6 \\
\hline \multicolumn{2}{|c|}{ Male } & 31 & 55.4 \\
\hline \multicolumn{2}{|c|}{ Age (years, SD) } & 44.3 & $11: 2$ \\
\hline \multicolumn{4}{|c|}{ Nationality } \\
\hline \multicolumn{2}{|c|}{ Switzerland, Germany, Austria, Liechtenstein } & 29 & $5 \# .8$ \\
\hline \multicolumn{2}{|r|}{ Bosnla, Turkey ${ }^{\prime}$ Albania ${ }^{\prime}$ Macedonia } & 16 & 28.6 \\
\hline \multicolumn{2}{|r|}{ \|taly, Spain, Portugal } & 8 & 14.3 \\
\hline & Other countries & 3 & 5.4 \\
\hline \multicolumn{4}{|c|}{ Body part } \\
\hline \multicolumn{2}{|r|}{ Back } & 48 & 86 \\
\hline \multicolumn{2}{|r|}{ Lower extremity } & 6 & 10 \\
\hline & Upper extremity & 2 & 4 \\
\hline \multicolumn{2}{|c|}{ Disease } & 40 & 71.4 \\
\hline \multicolumn{2}{|c|}{ Acoident } & 16 & 28.6 \\
\hline \multicolumn{2}{|c|}{ Off-work duration (years mediam, IOR) } & 4.9 & 1.42 .4 \\
\hline \multicolumn{4}{|c|}{ Work certificate time reduction } \\
\hline \multicolumn{2}{|c|}{$100 \%$} & 40 & 711.4 \\
\hline \multicolumn{2}{|r|}{$50 \%$} & 9 & 16.1 \\
\hline & $0 \%$ & 7 & 12.5 \\
\hline \multicolumn{2}{|c|}{ Employed } & 13 & 23.6 \\
\hline \multicolumn{2}{|c|}{ Unemployed } & 43 & 76.4 \\
\hline \multicolumn{4}{|c|}{ Physical work diemands } \\
\hline \multicolumn{2}{|c|}{ Sedentary $(<5 \mathrm{~kg})$} & 8 & 14.3 \\
\hline \multicolumn{2}{|r|}{ Light (5-10kg) } & 12 & 21.4 \\
\hline \multicolumn{2}{|r|}{ Medium $(10-25 \mathrm{~kg})$} & 13 & 23.3 \\
\hline \multicolumn{2}{|r|}{ Heavy (25-50kg) } & 9 & 16.1 \\
\hline \multicolumn{2}{|r|}{ Very heavy $(>50)$} & 14 & 25.0 \\
\hline \multicolumn{4}{|c|}{ Qualification presentlast job } \\
\hline \multicolumn{2}{|r|}{ Unskilled worker } & 28 & 50.0 \\
\hline \multicolumn{2}{|r|}{ Skilled worker } & 28 & 50.0 \\
\hline
\end{tabular}




\section{RELIABILITYY}

Reliability analysis of the 13-item inconsistency scale showed significant item-total correlations above 0.2 for 10 item (Table 4 ). Internal consistency of the seale was satisfactory, Cronbach Alpha $=0.71$. After excluding the three items with insufficient contribution to the scale, Cronbach Alpha slightly increased to 0.74 . The correlations between the 10 items were all bellow 0.5 . Applying a cut-off point of $\geq 3$ inconsistencies to judge test results as inconsistent, the results of the 13 and 10 -point scale were the same in $55 / 56$ persons (Kappa 0.96, $\mathrm{SE}=0.04$ ).

Table 4: Frequency of positive findings on the items of the inconsistency assessment ( ${ }^{*}$ itern tolal correlation $<.20$ )

\begin{tabular}{llrrr}
\hline & & & & \\
\hline
\end{tabular}

\section{Discussion}

The internal consistency of the assessment of test performance consistency in an FCE was confirmed; Cronbach Alpha of the 13-item scale was .71. The same results could be obtained with 10 items, disregarding items 9,10 and 13. Item 9 is probably not appropriate in this population where most clients had LBP. Item 9 may be more appropriate in a population with limited function of the lower extremities because it 
observes whether low level activities such as crawling, squating and hneeling are consistent with limitations in lower extremity strength and range of motion. This should be studied with clients who have functional limitations of the lower extremities. Item 10 observes whether sitting tolerance is consistently observed in two situations. These two situations may be too similar, and in case of consistent submaximal performance no inconsistency is observed. Item 13 observes the consistency of performance on the same tests on the first second day. As in item 10, consistent submaximal performance does not lead to positive results. In addition, positive results on item 13 were very rare and occurred only for three clients. Because these clients had several other inconsistent test results, item 13 did not change the over-all conclusion regarding the consistency of FCE-test performance.

This study has some limitations that need to be addressed. The examined group was small. The item-total correlations of several items were close to the cut-off point of $r=2$. Therefore, these results do not yet warrant definite exclusion of test items. In addition, the time gain from item reduction is below one minute because, in a full FCE, all tests are performed anyway. The largest reduction in time needed for FCE testing would be possible by defining stop criteria for an $\mathrm{FCE}$, for instance after observing three inconsistencies during testing.

The two missing values in the PACT did not influence the overall judgnnent of consistency. The clients themselves expressed language problems as the cause. Several other clients showed language problems, but were able to answer the PACT after receiving additional explanation and practicing a few examples. The two persons who did not complete the PACT displayed four and seven other inconsistencies. Therefore, self-limitation is considered as a reason for not completing the PACT.

We assessed the bell-shaped curve of grip strength at different positions of the hand. Grip strength is expected to be maximal in an intermediate hand position and lower in a more opened or closed position. The bell-shaped curve of grip strength measurements had a good item total correlation. Some studies support the use of the bell-shaped curve as indicator of submaximal effort. 11,12 Others reported limited accuracy of the bellshaped curve to detect submaximal effort. ${ }^{13}$ In our study population, the sensitivity of the bell-shaped curve to detect inconsistent performance was 0.57 , comparable with Matheson who found a sensitivity of $0.44 .^{14}$ The bell-shaped curve is not valid as a single item but it gives a significant contribution to the total scale.

Inconsistent performance during FCE testing correlated with several psychosociall and physical factors. We found a significant nonparametric correlation $>0.2$ between inconsistency and unskilled work (.35), self-limitation (.63), low professional education (.31), high pain level (.28), unemployment (.25) and non-Swiss nationality (.25). A significant negative correlation was also found between inconsistencies and grip strength left $(-.26)$, grip strength right $(-.30)$ and walking speed $(-0,40)$. No correlation existed between inconsistencies and age, heart rate at rest, being married or workload.

An FCE assesses physical capacity. Psychosocial factors are not assessed. If the client presents inconsistencies and behavioral signs, the FCE-report states that the contribution of other factors, including psychological or psychiatric pathology, was not assessed. It has, therefore, proven helpful to combine an $\mathrm{FCE}$ with the consultation of a rheumatologic and psychiatric assessment. 


\section{Conclusion}

The internal consistency of the assessment of the consistency performance during FCE testing was confirined Cronbach Alpha of the 13-item scale was .71 . The item-total correlation was $>2$ in $I 0 / 13$ items and $<2$ in $3 / 10$ items. Omission of these three items reduced the scale to 10 points; Cronbach Alpha was .74. The 10-point scale led to the same conclusion in $55 / 56$ clients. The result supports the validity of the assessment of FCE test consistency, its consideration in the determination of work-related disability and its use in medico-legal issues.

\section{References}

1. Meyer-Blaser U. Der Rechtsbegriff der Arbeitsunfähigkeit und seine Bedeutung in der Soziatwersicherung, namentlich für den Einkommensvergleich in der Invalidiätsbemessung. In* Prof. B. Ehtrenzeller PRS, Prof, I. Schwander, ed. Schmerz und Arbeitsunfähigkeit. St. Gallen: Schriftenreibe des Institutes für Rechtswissenschaft und Rechtspraxis, 2003: 35-57.

2. Isernhagen S., Hart DL. Matheson LM. Reliability of independent observer judgements of level of lift effort in a kinesiophysical Functional Capacity Evaluation. Work 1999;12(2):145-150.

3. Isernhagen SJ. Functional capacity evaluation. Work Injury: Management and Prevention. Gaithersburg: Aspen Publishers lnc, 1988: 139-174.

4. BG. Arbeitsunfähigkeit. Bem: Bundesgesetz über den Allgemeinen Teil des Sozialwersicherungsrechts (ATSO), 2003: 4. IV-Revision, Art, 6, Ziff 2.

5. Brouwer $\mathrm{S}$, Reneman M, Dijkstra P. Groothoff J, Schellekens I, Gdeken L. Test-retest reliability of the Isernhagen Work Systems Functional Capacity Evaluation in patients with chronic low back pain. $J$ Occup Rehabil 2003;13(4):208-218.

6. Matheson L, Mooney V, Grant J, Affleck M, Hall H, Melles T, Lichter R, McIntosh G. A test to measure lift eapacity of physically impaired adults, Part 1: Developinent and rellability testing. Spine $1995 ; 20(19): 2119-2129$

7. Mathicson LN, Mathesion M. Spinal function sort, xating of perceived capacity. Performance Assessment and Capacity Testing PACT. Trabuco Canyon, California: Performance Assessment and Capacity Testing PACT, 1989.

8. Klein $\mathbf{P}$. The handbook of psychological testing. London: Routledge, 1993.

9. Bechol $\mathrm{CO}$. Grip test; the use of a dynamometer with adjustable handle spacings. J Bone Joint Surg Am $1954 ; 36-A(4): 820-824$.

10. Goldman S, Cathalan TD, An KN. The injured upper extremity and the JAMAR five-handle position grip lest. Am I Phys Med Rehabil 1991;70(6);306-308.

11. Lemsita M, Olszynski WP, Enright W. The sensitivity and specificity of functional capacity ewaluations in determining maximal effort: a randomized trial. Spine 2004,29(9):953-959.

12. Stokes HM. The seriously uninjured hand-weakness of grip. IJ Occup Med 1983;25(9):683-684.

13. Niebuhr BR, Marion R. Voluntary control of submaximal grip strength. Am J Phys Med Rehabil 1990;69(2):96-101.

14. Matheson L, Bolar P. Hart D. Use of maximurn voluntary effort grip strength testing to identify symptom magnification syndrome in persons with low back pain. J of Back and Musculoskeletal Rehabil $1998 ; 10: 125-135$ 


\section{Chapter 7}

\section{The influence of a functional capacity evaluation on fitness for work certificates in patients with nonspecific chronic low back pain}

Peter R. Oesch', Jan P. Kool', Stefan Bachmann!, Jason Devereux ${ }^{2}$

Affiliations of the authors

'Dpt of Rheumatology, Rehabilitation Center Valens, Switerland

${ }^{2}$ European Institute of Health and Medical Sciences, University of Surrey, Guildford, Surrey, United Kingdon

Work accepted 


\section{Abstract}

Background: Comprehensive medical assessments in the majority of patients with low back pain (LBP) have failed to assess working capacity. Functional Capacity Evaluation (FCE) has become increasingly popular in the evaluation of working capacity in patients with LBP. This study investigates the influence of functional testing on decision making concerning medical fitness assessments for work.

Methods: A randomized controlled trial comparing the effect of a function-centred (FCT) versus a pain-centred treatment (PCT) in patients with LBP was performed. According to the legal requirements physicians issued Fitness for Work Certificates (FWCs) after rehabilitation. In the FCT group physicians were in possession of the results of FCE while this was not the case in the PCT group. Three experts assessed the FWCs and rated the quality and the information provided regarding working capacity in the previous work.

Results: Rating of the issued FWCs proved reliable (ICC $=0.77-0.92)$. Quality of FWCs and information regarding working capacity in the patient's previous work differed significantly between the two groups (chi-square, $\mathrm{p}=0.03$, resp. $=0.008$ ). There was a trend towards a higher attested work capacity in the FCT group (MannWhitney, $p=0.071$ ).

Conclusions: Functional Capacity Evaluation positively influences quality and information regarding working capacity of medical Fitness for Work Certificates in patients, with chronic LBP. 


\section{Introduction}

Determining whether a patient is fit for work in Switzerland is by law the responsibility of physicians. They are required to deternine inability to work which is defined as follows: "Inability to work is caused by an impaiment of physical, mental or psychic health which leads to full or partial incapability to do reasonable work in the previous occupation or field. In case of long duration, reasonable occupation in another profession or field has also to be taken into consideration". Inability to work must not be judged by the impairment of body function but by the extent of the functional loss regarding the demands of the previous work. ${ }^{2}$

Traditionally, attempts to predict the long-term outcome of low back pain (LBP) were based on diagnostic and prognostic medical information derived from medical histories and physical examination. ${ }^{3}$ Evidence indicated in the 1980 s that few objective physical or biomechanical measures were associated with return-to-work. ${ }^{4} \mathrm{~A}$ recent study to determine the prognostic value of a comprehensive medical assessment for the prediction of return-to-work produced similar results. The authors were unable to identify any medical variables that accounted for a significant proportion of variance in return-to-work. A prognostic model to predict receiving worker's compensation benefit found just one predictive clinical finding (pain referred into the leg). ${ }^{6}$ Furthermore, the American Medical Association's Guide to the Evaluation of Permanent Impaiment has been the focus of considerable controversy. Criticism has focused on internal deficiencies, including the lack of a comprehensive, valid, reliable, unbiased, evidencebased system for rating impairment, and on the lact that the impairment rating does not reflect actual loss of function. ${ }^{7}$ These inadequacies might have already been recognized in 1926 when Wentworth remarked: „Lawyers and judges appear to have a pretty generally formed opinion that a doctor"s statement concening disability of the lower back is largely a matter of guesswork ${ }^{k} .8$

Consequently, to meet the need for a function-oriented measure of a person's physical capacity for work, Functional Capacity Evaluations ( $\mathrm{FCEs}$ ) were developed. An FCE is a standardized battery of clinical tests that purport to measure a patient's safe physical ability for work-related activity. Physical capacity as found in the FCE testing is compared to the required physical job demands of the patient's occupation. Critical job demands are assessed by a job analysis involving collecting relevant information by either direct observation, an interview with the employer or employee, or existing job descriptions. This comparison of the work demands with the needs of the worker reassembles the Ergonomics approach to a work-related problem. The following situations may arise: 
Capacity meets or exceeds all job demands. The patient is deemed ready to returm to his or her previous work without modification.

Capacity does not match all job demands. It must be considered whether the patient's capacity can be improved by physical exercise as applied in a Work Hardening programme or whether modifications on the job are required.

Capacity is far below the demands of the previous work. Neither training nor job modifications will enable the patient to return to his of her previous work. Alternative work is the only solution to enable work in the future.

Capacity does not allow a return-to-work. Retirement on grounds of ill health is indicated.

Work-related assessments must have proof of their reliabillity and validity. Despite the fact that FCEs have been commercially available since the $1980 \mathrm{~s}$, their psychometric properties have scarcely been studied. Reviews concerning the reliability and validity of FCEs published in the 1990s drew similar conclusions: the evidence for the reliability and validity of $F C E$ s was either non-existent or was insufficiently investigated. No single FCE had been thoroughly investigated for all aspects of reliability and validity. 12 In the meantime, more research has been done on the reliability and validity of Isernhagen Work Systems' FCEs. Good reliability of the material handlings tests in healthy subjects as well as in patients has been found in several studies. .3.18 $^{-1}$ Acceptable test-retest reliability was found for 15 out of 19 non-material handling tests in 30 patients with LBP and selected for rehabilitation treatment. ${ }^{17}$ A similar study of 26 healthy adults confirmed most of these results. ${ }^{1.8}$ The construct validity of a kinesiophysical FCE assessing function independent of pain is supported by the study of Gross en all. ${ }^{19}$ There was moderate relationship only between FCE and the Pain Disability Index and Pain Intensity while there was a high correlation between Pain Disability Index and Pain Intensity. ${ }^{19}$ Additionally, the validity to determine effort level by visual observation of a lifting test has been demonstrated. ${ }^{40}$ There is contradictory evidence regarding the predictive validity of $\mathrm{FCE}$ findings for return-to-work. In the study of Matheson et al. ${ }^{20}$ all three lifting tests were related to the return-to-work level. However, only a weak association was found by Gross et al. between better performance measured by the number of failed FCE tasks and a faster recovery. ${ }^{21}$ In the same sample of patients a lower number of failed FCE tasks were consistently associated with higher risk of recurrence. ${ }^{22}$ However, there is serious doubt about the validity of these findings as the "total number of failed tasks" is not a valid measure to determine whether a client is capable of doing a certain job. It is also questionable whether the chosen outcome measures "time receiving total temporary disability benefits" is a valid surrogate for return-to-work. ${ }^{2 x}$ 
The additional information regarding the residual physical capacity for work seems to overcome the shortcomings of the traditional measures to determine fitness for work and help physicians to decide whether patients are capable of continuing with their previous work, whether modifications are required, whether only alternative work is possible, or whether the workers are permanently disabled. This results in an increasing demand for FCEs in Switzerland. FCEs are performed in medico-legal cases as well as in work hardening programs where FCE results serve as the baseline data to define deficits and to outline a specific rehabilitation programme. At discharge, the relevant FCE test items are reassessed and serve as a decision tool to determine fitness for work. ${ }^{24}$

The question arises how the results obtained from functional testing influences decisions made by physicians on medical fitness for work. Ergonomics is concerned with the interaction of work demands with the capacity of the worker while medicine is primarily concerned with the diagnosis of the disease or disorder. By focusing on workrelated issues it can be hypothesised that the additional ergonomics information from the FCE will improve the quality of Fitness for Work Certificates for patients with. nonspecific chronic LBP. A further hypothesis is that the attested Fitness for Work based on objective information obtained from functional testing is only higher than the attested Fitness for Work based on subjective complaints and clinical findings from medical examination. Therefore, the aim of this study is to assess the influence of an FCE on Fitness for Work Certificates in patients with nonspecific chronic LBP.

\section{Methods}

\section{STUDY DESIGN}

This study is based on a randomized controlled trial that was conducted in Switzerland and approved by the Ethical Committee of the Canton of St Gallen. Patients were included between January 2000 and May 2003. Inclusion criteria were age between 20 and 55 years, presenting with non-acute nonspecific LBP and at least 6 weeks of sick leave during the previous 6 months. Patients with comorbidity that would reduce working capacity were excluded. Detailed objectives and results of the study were summarized in an earlier publication. ${ }^{25}$

\section{FUNCTIONAL CAPACITY EVALUATION AND JOB ANALYSES}

A blinded research assistant, not involved in any patient treatment in the rehabilitation centre, performed FCE Tests according to the Isernhagen test protocol. ${ }^{26}$ She assessed lifting, carrying, pushing and pulling ability, ambulation and sitting before and after rehabilitation. Assessments were performed in a separate room to prevent unmasking of 
the assessor. She also determined the heaviness of the current or the previous work according to the DOT categories by means of a short patient interview. ${ }^{27}$ In the FCTgroup, the treating therapists additionally performed a standardized interview with the patient: Quantitative information regarding relevant job requirements was collected. Additional FCE tests were performed by the treating therapist in the FCT group if patients in the job analyses reported further work demands than routinely tested. At the end of the rehabilitation stay a comparison of the critical job demands, as identified by the job analysis, with the physical work strength assessed by the FCE at discharge was performed. Based on this comparison a preliminary conclusion regarding future fitness for work was made by the treating therapist.

\section{MEDICAL DETERMINATION OF FITNESS FOR WORK}

Physicians who issued FWCs were not assigned to treatment groups but to hospital wards. Therefore, physicians were responsible for patients in both treatment groups. Information regarding the physical capacity of their patients differed according to the patient's assignment to the two treatment groups. The physician received the therapist"s preliminary conclusion regarding fitness for work only for patients of the FCT group. In the PCT the physician determined working capacity based on medical findings only (Figure 1):

Pigure 1: Determination of fitness for work at discharge

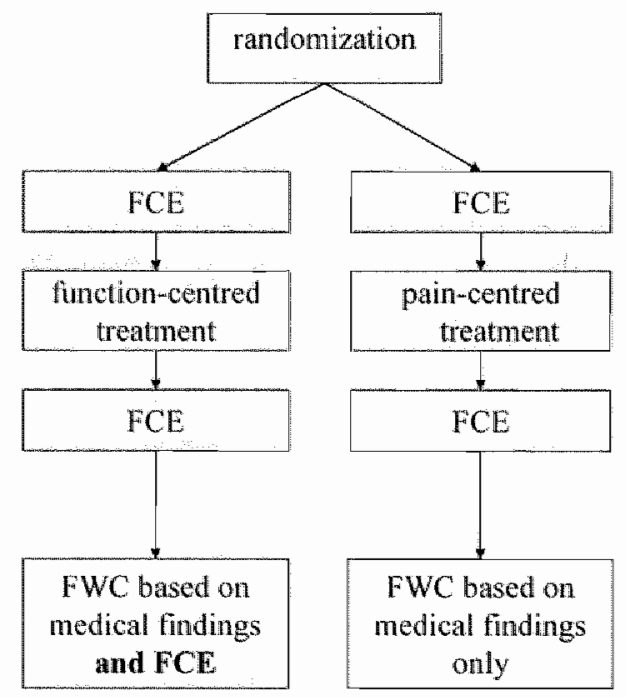




\section{QUALITY RATING OF THE FITNESS FOR WORK CERTIFICATES}

We developed a quality rating for FWCs based on the legal tequirements in Switzerland (Table 1). The quality of FWCs was considered high if all legal requirements were met.

\section{RATING OF THE ATTESTED WORK CAPACITY}

If a FWC is of high quality, it will relate to the previous work. It was expected that some of the certificates would not meet this standard and would only define the remaining capacity of the patient. To obtain as much information as possible, this study evaluated the attested work capacity in two steps. In the first step, we analysed working capacity as a percentage of a full working day and the heaviness of work according to the DOT classification. In the second step, we analysed whether the attested working capacity was related to the previous work using the following definitions ${ }^{28}: 1$. Fit for usual work, 2. Fit for modified work with the same employer, 3. Fit for alternative work with the same employer, 4. Fit for alternative employment, 5. Fit for sheltered work, 6. Retirement on grounds of ill health. These criteria (except $\mathrm{Cr}$. 6) were also used by Matheson in his study investigating the relationship of lifting ability, grip force, and return-to-work. ${ }^{20}$ Based on these criteria, we compared recommended return-to-work level in the two groups. From an ergonomic perspective, the recommendation for alternative work, either with the same (3.) or a different employer (4.), does not differ. The reason for recommending alternative work is a mismatch between the individual's capacity and the demands of work. ${ }^{28}$ Therefore, these items were combined. For the purpose of this research a $6^{\text {th }}$ category "missing information" was added. 
Table 1: Quality rating for finess for vwork certificates

\begin{tabular}{|c|c|c|}
\hline $\begin{array}{l}\text { Gually } \\
\text { derel }\end{array}$ & Finess for work certicate states the following & $\begin{array}{l}\text { Quality critena regarding the logal } \\
\text { requilements }\end{array}$ \\
\hline \multirow[t]{2}{*}{ High } & Worker matches the demands of the previous work! & $\begin{array}{l}\text { Because worker matches the demands of } \\
\text { the previous work (criterion 1), criterion } 2 \\
\text { is not required }\end{array}$ \\
\hline & $\begin{array}{l}\text { If the worker does not match the demands of the previous work } \\
\text { or matches only part of th the remaining work capacity in time } \\
\text { percentage and heaviness (DOT) with respect to other activities } \\
\text { must be described. }\end{array}$ & Critteria 1 and 2 are met \\
\hline \multirow[t]{2}{*}{ Medium } & $\begin{array}{l}\text { Worker does not match the demands of the previous work or } \\
\text { matches only part of it, but no information regarding the } \\
\text { remaining work capacity is provided. }\end{array}$ & $\begin{array}{l}\text { Criterion } 1 \text { is met but not criterion } 2 \text {. This } \\
\text { would be required as the worker does not } \\
\text { match the demands of the previous work. }\end{array}$ \\
\hline & $\begin{array}{l}\text { Only general remarks regarding work capacity in percentage } \\
\text { and heaviness (DOT) without any reference to the previous } \\
\text { work. }\end{array}$ & $\begin{array}{l}\text { Criterion } 2 \text { is met without reference to } \\
\text { criterion } 1\end{array}$ \\
\hline Low & $\begin{array}{l}\text { Only general remarks regarding work capacity in percentage or } \\
\text { heaviness (DOT). }\end{array}$ & $\begin{array}{l}\text { Criterion } 1 \text { is not met and criterion } 2 \text { just } \\
\text { partly }\end{array}$ \\
\hline No & Missing information & Wo oriteria met. \\
\hline
\end{tabular}

\section{DATA COLLECTION AND RATING EXPERTS}

The principal researcher copied the wording of the FWCs, not the information about the patient's identity and treatment group. Three blinded experts in work-related rehabilitation independently applied the above mentioned rating criteria. To improve interrater reliability we performed a training session using ten FWCs of patients not included in this study. The raters resolved uncertainties during a consensus meeting. If in the ratings of the investigated FWCs two ratings were the same and one was different, the rating of the majority (two experts) was used. If all ratings were different, an agreement was reached by a consensus meeting.

\section{STATISTICAL ANALYSIS}

We performed statistical analysis with SPSS Version 11.5. Alpha was set at 0.05 . We analysed nominal variables with a chi square test, continuous variables with a normal distribution with an independent sample T-test, and non-parametric continuous wariables with a Mann-Whitney U Test. We analysed interrater reliability of the three experts by determining the Kendall-tau-b Intraclass Correlation Coefficient. Values $>0.75$ were considered to represent satisfactory reliability. 


\section{Results}

\section{BASELINE COMPARABILITY}

We obtained the FWCs from all 174 patients randomized to the two groups displays the baseline comparability of the two groups for the most important work-related variables. There were no significant differences between the groups after randomization. ${ }^{25}$

Table 2: Comparability of the treatnent groups al baseline

\begin{tabular}{|c|c|c|c|c|c|}
\hline \multirow{2}{*}{$\frac{\text { Age (SD) }}{\text { (SD) }}$} & $\begin{array}{r}8 \\
\\
\end{array}$ & \multicolumn{2}{|c|}{$\begin{array}{l}\text { Fot group } \\
n=87)\end{array}$} & \multicolumn{2}{|c|}{$\begin{array}{l}\text { PGT group } \\
\text { (n=87) }\end{array}$} \\
\hline & & 41.6 & $(8.4)$ & 42.5 & (8.4) \\
\hline \multicolumn{2}{|l|}{ Gender (men/women) } & \multicolumn{2}{|c|}{$18 / 69$} & \multicolumn{2}{|c|}{$19 / 68$} \\
\hline \multicolumn{2}{|l|}{ Body Mass Index (SD) } & 26.7 & $(4,2)$ & 27.2 & $(4.0)$ \\
\hline Nationality & $\begin{array}{l}\text { tzerland } \\
\text { oslavia } \\
\text { nia } \\
\text { edonia } \\
\text { atia } \\
\text { in, Portugal „Turkey }\end{array}$ & & $\begin{array}{l}38 \\
17 \\
11 \\
5 \\
5 \\
4 \\
7\end{array}$ & & $\begin{array}{l}35 \\
11 \\
16 \\
6 \\
5 \\
5 \\
9\end{array}$ \\
\hline \multicolumn{2}{|l|}{ Unemployed $(\mathrm{N}, \%)$} & 18 & (21) & 20 & (23) \\
\hline \multicolumn{2}{|c|}{ Heawiness of previous work: DOT $>3(N, \%)$} & 68 & (78) & 68 & $(78)$ \\
\hline \multicolumn{2}{|c|}{ No professional education $(\mathbb{N}, \%)$} & 38 & $(44)$ & 42 & $(48)$ \\
\hline \multicolumn{2}{|l|}{ Litigation problems $\left(\mathbb{N}_{i} \%\right)$} & 16 & $(18)$ & 9 & $(\| 0)$ \\
\hline \multicolumn{2}{|l|}{ Work satisfaction (SD) } & 1.8 & $(2.1)$ & 2.4 & (2.9) \\
\hline \multicolumn{2}{|c|}{ Sick leave during 2 years before treatment (mean, SD) } & 184 & (156) & 199 & {$[135)$} \\
\hline Liffing capacity (kg, SD) & $\begin{array}{l}\text { floor-waist } \\
\text { horizontal } \\
\text { waist-shoulders }\end{array}$ & $\begin{array}{l}15.8 \\
20.4 \\
13.2\end{array}$ & $\begin{array}{l}(5.4) \\
(7.6) \\
(4.3)\end{array}$ & $\begin{array}{l}15.6 \\
18.9 \\
13.0\end{array}$ & $\begin{array}{l}(7.3) \\
(7.6) \\
(4.8)\end{array}$ \\
\hline
\end{tabular}


INTERRATER RELLABILITY OF THE FWCS UNDER STUDY

\section{Quality}

Interrater reliability of the quality rating was above 0.75 among all experts. (Table 3 ) With the exception of one FWC, at least two experts came to the same conclusion. The remaining FWC was re-evaluated by all experts and full agreement was obtained.

\section{Percentage}

Interrater reliability of the attested working capacity in percentage of a full working day was above 0.75 among all experts (Table 3) Experts 1 and 3 were unable to identify an estimation of the attested working capacity in percentage in three FWCs and expert 2 in two FWCs. This reduced the number of FWCs rated. Except in two FWCs, at least two experts came to the same conclusion. The remaining two FWCs were re-evaluated by all experts and full agreement was obtained.

\section{$D O T$}

Interrater reliability of the attested DOT categories was above 0.75 between experts 1 and 2. Expert $3^{\circ}$ s correlation with Expert 2 was 0.727 . Re-evaluation of expert 3 of the FWCs where disagreement had been identified improved interrater reliability to $>0.75$ among all experts (Table 3 ) Based on this rating in all FWCs at least two experts came to the same conclusion.

Table 3: Interraler reliability, Kendall-Tat-b * Correlation is significant at the 0.01 level (2 -lailed)

\begin{tabular}{llllll}
\hline Experts & Quality & Percentage & Dof & Previous work \\
\hline I vs.2 & $0.842^{*}$ & $0.868^{*}$ & $0.766^{*}$ & $0.790^{*}$ \\
1 vs. 3 & $0.811^{*}$ & $0.916^{*}$ & $0.884^{*}$ & $0.757^{*}$ \\
2 vs. 3 & $0.767^{*}$ & $0.855^{*}$ & $0.849^{*}$ & $0.849^{*}$ \\
\hline
\end{tabular}

\section{Work capacity in relation to the previous work}

Interrater reliability was above 0.75 between experts 1 and 2 applying the defined criteria regarding "Previous Work". Expert 3 did not correlate sufticiently with experts $1(\mathrm{ICC}=0.643)$ and $2(\mathrm{ICC}=0.720)$. Re-evaluation by expert 3 of the FWCs where disagreement had been noted improved interrater reliability to $>0.75$ (Table 3) Based 
on this rating, except in two FWCs, at least two experts came to the same conclusion. The remaining two FWCs were re-evaluated by all experts and full agreement was found.

\section{RATING COMPARISONS BETWEEN THE TWO GROUPS}

\section{Quality rating}

FWC quality was significantly better in the FCT group (chi-square, $p=0.03$ ). While 26 FWCs were rated as medium quality in the FCT group, $44 \mathrm{FWCs}$ were rated as medium quality in the PCT group. In the FCT group 50 were of high quality as were 33 in the PCT group. (Figure 2) One rating was of no quality in the FCT group. Analysis of this FWC showed that this patient was a drop-out due to an acute hip problem and for this reason was referred to an acute hospital.

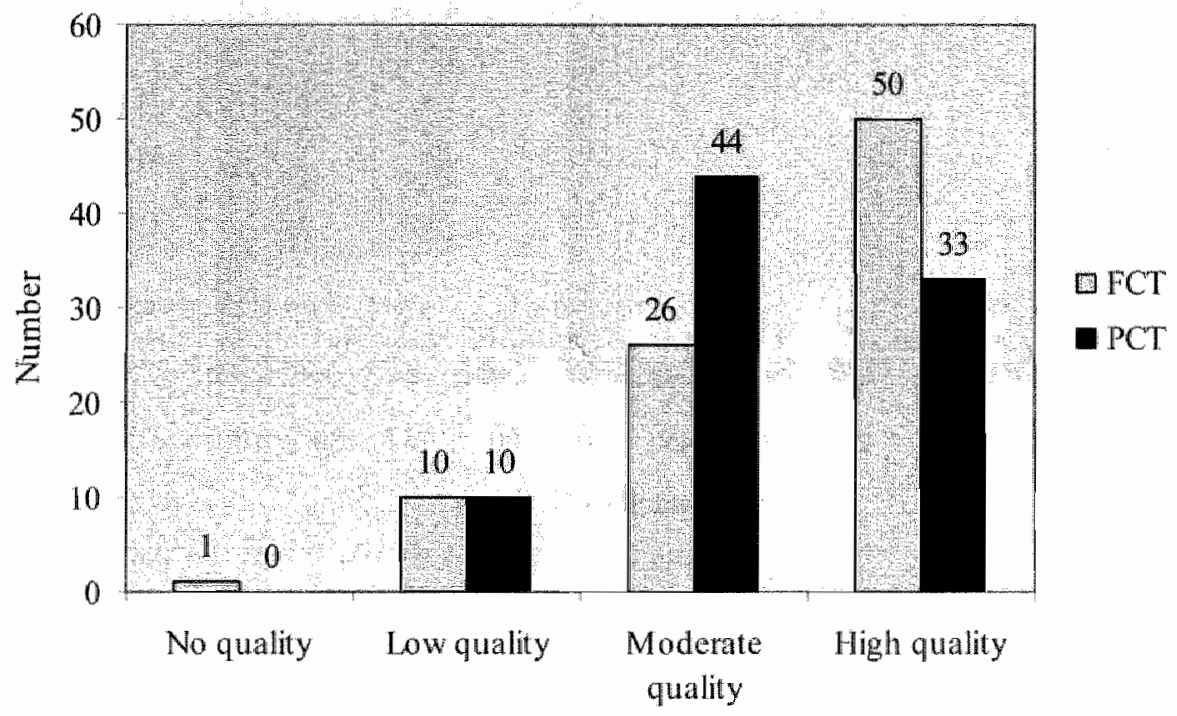

Figure 2: Quakily rating in the two groups 


\section{Percentage}

There was a trend towards a higher working capacity in the FCT group (Mann-Whitney $p=0.07) .7$ patients of the FCT group and 15 patients of the PCT group were judged not fit for work at discharge. 32 patients were considered as $100 \%$ fit for work in the PCT group and 42 in the FCT group (). The number of patients considered $50 \%$ fit for work was comparable in the two groups (34 vs. 35 cases). In the PCT group more different percentages of a full working day were used than in the FCT group but this difference was not significant.

Figure 3: Estimated work capacily as a percentage of a full working day

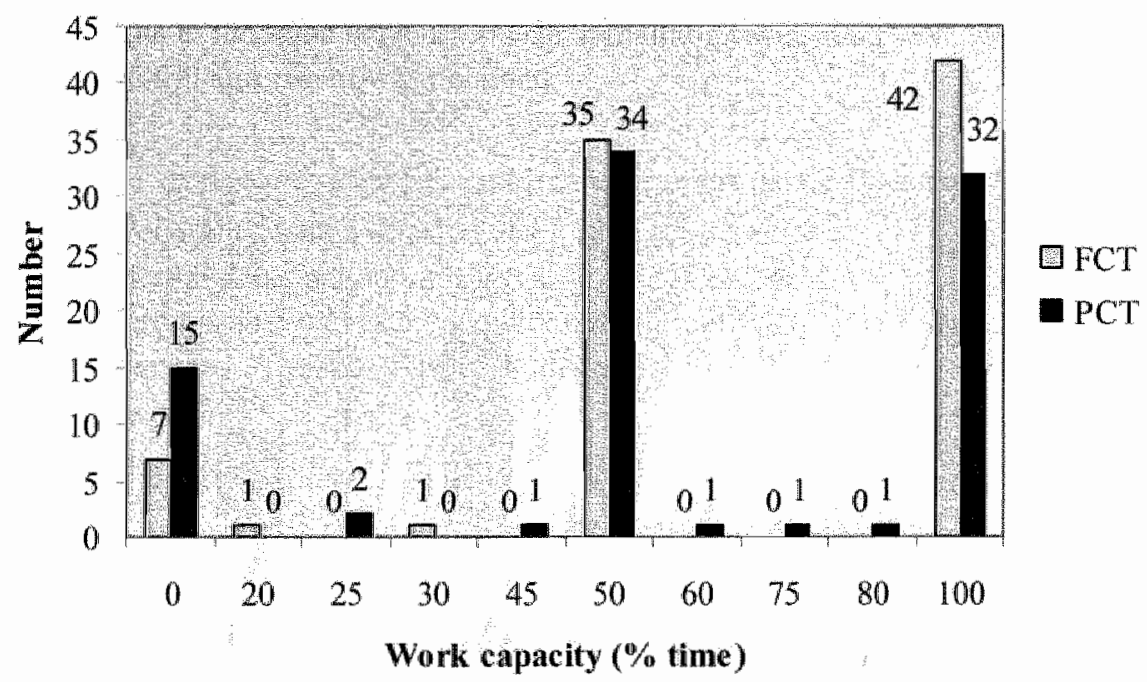

\section{$D O T$}

Workload according to the DOT categories was analyzed in those 151 patients judged to be fit for work either part-time or full-time. In $50 \mathrm{FWCs}$ the issuing physicians referred to the previous work and the DOT category was not specified. In these cases the authors used the information on work heaviness of the previous work obtained by the therapist performing the $\mathrm{FCE}$. This reduced the missing DOT information to 16 patients of whom 5 were in the FCT group and 11 in the PCT group. In the FCT group all DOT categories were used while in the PCT group 3 DOT categories were used (see Figure 4). 
Differences between the two groups were statistically significant (Chi-square, $p=$ $0.038)$

Figure 4: DOT categories

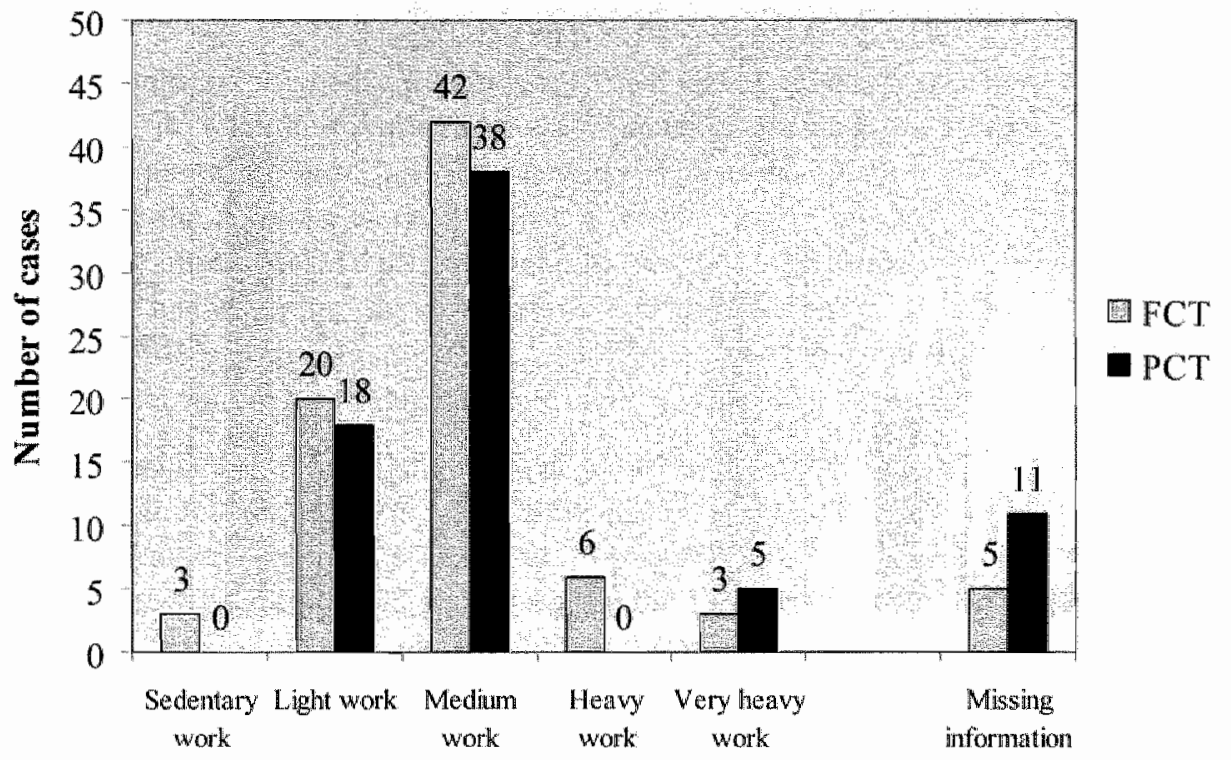

\section{Work capacity in relation to the previous work}

There are significant differences in the attested work capacity in relation to previous work (Chi-Square, $p=0,008$ ). Whille in the PCT group 20 patients were considered fit for the previous work either with modification $(n=18)$ or without $(n=2)$, there were 31 in the FCT group (19 with modification and 12 without). Missing information occurred more frequently in the PCT group $(n=39)$ than in the FCT group ( $n=22)$ (Figure 5). In the FCT group 34 patients were judged fit for alternative work and 27 in the PCT group. One patient was judged fit for sheltered work. Retirement on grounds of ill health was never concerned. A subgroup analysis of the patients considered fit for their previous work revealed that in the FCT groups all DOT categories were used while in the PCT group only light and medium work was used. An analysis of the modifications revealed 
the following: While in the FCT group all DOT categories were used but only 2 categories of adapted working hours, in the PCT group only 3 DOT categories were used but 5 categories of adapted working hours.

Figure 5: Work capacity in re ation to previouls work

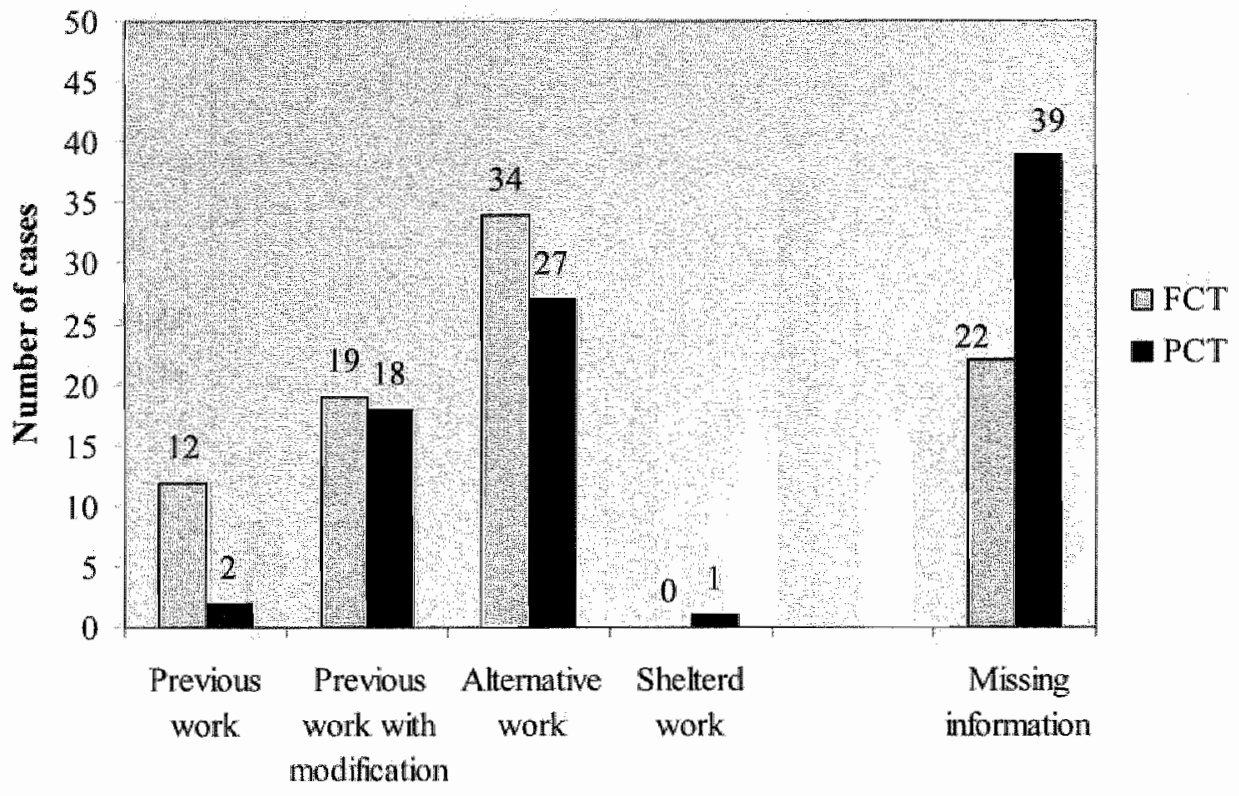

\section{Discussion}

FCE results improved the quality of FWCs and increased the attested working capacity. For the purpose of this study, quality criteria for FWCs were defined by the authors, based on the legal requirements in Switzerland. Three experts in work-related rehabillitation applied these criteria independently and with good reliability.

Several reasons could cause differences in the FWCs issued at discharge. Sociodemographic factors such as age, gender, professional education and heaviness of 
work can affect return-to-work decisions. Analysis of the sociodemographic data of the two groups under study at baseline revealed equal distribution of these factors. $A$ substantial improvement of physical capacity in one of the two groups could have contributed to the higher attested work capacity in the FCT group. Despite a significantly higher improvement of lifting and carrying capacity in the function-centred treatment group, this could hardly explain a higher attested working capacity as the mean improvement from entry to discharge was only $2.5 \mathrm{~kg}^{25}$ This improvement is smaller than the smallest differences of the DOT categories which is $5 \mathrm{~kg}$ between sitting and light work and $20 \mathrm{~kg}$ between medium and heavy work. ${ }^{27}$

FCE results improve the quality of FWCs including the determination of wonking capacity in relation to the previous work. This information differed significantly between the two groups. Less information was missing and more patients were regarded as fit for the previous work. This has a serious impact on decision makng regarding disability allowances. A patient is eligible to apply for disability insurance services if from the medical point of view a return to the previous work is judged impossible. ${ }^{29}$ if the FWC does not relate to working capacity, it can be questioned by the client in court and further fitmess for work evaluations will have to be performed.

The question arises why the quality of the FWCs and the level of the attested working capacity in relation to the previous work were better in the FCT group. A likely answer to that question may be found in the rehabilitation goals of the two treatment approaches. The primary treatment goal in the PCT group is to relieve pain and then to improve function. During the rehabilitation stay little attention is paid to work-related matters. Consequently, less work-related information is collected and will be missing for fitness for work evaluations at discharge. In contrast to this traditional PCT approach, the primary focus in a work hardening programme is on return-to-work. FCE and job analyses are performed at entry, and treatment goals ane defined by the mismatch of work demands and physical capacity. At discharge mismatch is reevaluated by FCE and the FWC will be based on these findings. This continuing focus on work capacity in conjunction with the detalled information on work demand and residual work capacity is most likely the reason for the better quality of the FWC issued and the less missing information regarding previous work.

A recent study has shown that workers exposed to both physicall work risk factors and psychosocial work risk factors report more work-related stress and that perception of stress at work increased the risk of onset of musculoskeletal disorders. ${ }^{30}$ It can be expected that the reduction of physical work risk factors, in this study initiated by the adaptation of work tasks or the recommendation for alternative work, will therefore also have an effect on work-related musculoskeletal disorders. Additionally, it can be hypothesised that patients with higher self-efficacy experience less fear of injury. ${ }^{31}$ fear of injury has been identified as a risk factor for work-related stress. ${ }^{32}$ The combination 
of these wo factors could cause a reduction of work-related stress and, consequently, facilitate return-to-work.

A sub-analysis of the interventions "adaptation of working hours" and "adaptation of work tasks" in the category "fit for the previous work with modifications" revealed that in the FCT group, where the physician was informed about the patient's lifting capacity, the whole range of DOT categories was used but only 2 categories of working-hour adaptations. In the PCT group, where the physician did not know the patient's lifting capacity, only 3 DOT categorjes were used but 5 categories of working hours" adaptations. Therefore, it seems that the availability of information about the patient's lifting capacity enables the physician to refer to weight categories. If this information is not avallable, the physician refers to the adaptations of working hours.

Research showed that the rate of return-to-work was twice as high for workers who were provided with modified jobs as for those with no such accommodation in employment. The question arises which of the two modifications used in the study will be more effective regarding return-to-work. Both have shown their effectiveness in a previous study on ergonomic interventions after LBP. Adaptation of working hours and adaptation of work tasks were equally effective in increasing the return-to-work rate and as adaptation of the workplace. ${ }^{33} \mathrm{~A}$ three-month follow-up of the patients revealed that working days were significantly higher in the FCT group. ${ }^{25}$ However, due to the complex interventions applied in the two groups, it cannot be analyzed which treatment component of FCT was essential for the treatment effect. The FCT programme as a unit, combining medical and ergonomic methods, was more effective regarding return-towork than the traditionall pain-centred treatment approach.

19 patients of the FCT group and 2 patients of the PCT group were sent back to their previous work. It can be questioned whether this is ethical without adapting the workplace to the worker's needs. The reason for sending them back to their previous work was the matching of work demands and work capacity as found in the job match performed in the FCT group. From a medical as well as an ergonomic point of view this decision is reasonable. Not sending them back to work which they are capable of doing would be an underestimation of their capabilities. This risk in the judgement for fitness for work has been described by the International Labour Organisation. "Caution should be exercised when a diseased or physically disabled person is examined for fitness for employment. There is a major risk to underestimate an intelligent and determined person's ability to overcome a disability and produce satisfactory results in a job that might be beyond such determination". "34 This risk might have occurred in the PCT group, where only two patients were sent back to their previous work. One patient was considered fit for light and one fit for medium work. This is a common finding in medical statements often attesting "fit for light work only". "It could be the result of the missing information regarding work capacity preventing a comparison with work 
demands. In order not to expose a worker to a possible risk, only work which is unlikely to cause harm is recommended.

Attested work capacity expressed in the percentage of an 8-hour working day is high in both groups considering mean days of sick leave during 2 years before treatment which was 184 days in the FCT group and 199 days in the PCT group. At discharge, only 22 patients were confirmed not to be fit for work. These results cannot be explained with successful treatment only. The Valens Clinic has a vast experience in work-related rehabilitation and, consequently, in issuing fitness for work certificates. The general policy is not to overestimate $x$-ray findings and subjective complaints as several studies have shown no causal relationship between radiographic findings and nonspecific $\mathbb{L B P}^{35,36}$ Observations during three weeks inpatient rehabilitation, including general functioning in daily life activities, are used in decisions regarding fitness for work in both groups. This could explain the high attested working capacity in both groups compared to the long off-work duration before rehabilitation.

Due to the remote location of the rehabilitation centre, the limited resources in staff to visit each individual workplace, and the fact that some of the patients were unemployed, direct observation as a means to perform a workplace analysis was not performed. The most feasible option to analyse the patients' work demands was by a structured interview with the worker taking into account that the respondents were not committed to giving correct answers and may have been influenced by what they believed the interviewer required, or what they themselves wished to portray. ${ }^{37,38}$ There was at considerable range of bias in how the questioners might understand the answers, and the subjective information collected might have been misleading or inaccurate. The only possibility to correct inaccuracy was the comparison of the reported work demands with the domain knowledge of the interviewer. All therapists performing the structured interview were experienced in the field of work-related rehabilitation and trained in workplace analysis according to Ahonen. ${ }^{39}$

Further limitations of this study are the limited number of tests performed. Only material handling capacity was assessed. Additional tests assessing stail climbing and balance, stoop, kneel, crouch and crawl; reach, handle, and hand coordination were only performed if identified in the structured interview as an essential work demand. It must be assumed that in some patients an important physical capacity was not tested because the interview failed to identify this demand.

\section{Conclusion}

The use of FCEs significantly improves the quality of medical $\mathrm{FWC}$, increases attested work capacity, and a reference to the previous work is made in significantly more 
patients. This might have an impact on disability allowance decisions, reduce the level of work related disability and, consequently, decrease costs:

The results of this study must be further evaluated regarding the validity of the attested FWCs. A one-year follow-up will be performed assessing work performance of the workers and a three-year follow-up will investigate disability insurance allowances. Further research should also look at the effectiveness of ergonomic work place interventions in combination with the interventions applied in a work hardening programme. It can be hypothesized that this additional component further improves the effectiveness in work-related rehabilitation.

\section{Acknowledgement}

The authors wish to acknowledge the contribution of Mirella Russo who performed the Functional Capacity Evaluation measurements persistently and with admirable patience. We also wish to thank the participating patients and the members of the rehabilitation team inwolved in the treatment. Karin Schenk, Claire Lise Lippuner and Stefan Bachmann assessed the Fitmess for Work Certificates for quality and information regarding working capacity.

\section{References}

1. Bundesgesetz uber den Algemeinen Teil des Sozialversioherungsrechts. Arbeitsunthigkeit. Berm, 2003; 4. V. Revision. Ant. 6, Zilt.2.

2. MagewBlaser U. Der Recinsbegriff der Arbeitsunfahigkeit und seine Bedeutung in der Soxialwersicherung, namentich fur den Einkommensvergleich in der Imwaliditutshemessung. In: Prof. B.

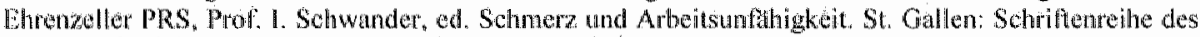
Institures for Rechtswissenschaft und Rechtspraxis, 2003: 35-57.

3. Crook J. Moldofsky $H$. Slumon H. Determinants of disability after a work related musculoskeletal

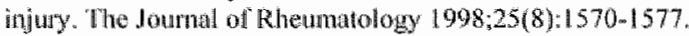

4. Gallogher RM, Ranli V, Haugh LD, Milhous R, Callas PW, Langelier R, McClallen IM, Frymoyer J. Determinants of neturn-tomork among low back pain patients. Pain \$989;39(1):55-67.

5. Hunt DG. Zuberbier OA, Kozlowski AJ, Berkowize J, Sohulz 1Z, Milner RA, Crook JM, Turk DC. Are components of a comprehensive medical assessment predictive of work disability after an episode of ocetpational low back trouble? Spine 2002;27(23):2715-2719.

6. Mclntosh, frank 1, Hogg-Johnson S, Claire Bombardier C, Hall H. Prognostic factors for time recenving Workers' Conpensation benefits in a cohort of patients with low back pain. Spine 1999;25(2):147-157.

7. Cocchianella $\mathrm{L}$, Turk MA. Andersson $\mathrm{G}$. Improving the evaluation of permanent impaiment. Joumal of the American Medical Assoctation 2000,283(4):532 -533.

8. Wenworth 'T. Systematic diagnosis in backehe. Joumal of Bone and loint Surgery 1926;8:137-170.

9. Isemhagen S. Contemporary issues in functional capacity evaluation. In: Isernhagen $S_{\text {, ed. The }}$ comprehensive guide to work injury management. Gathersburg: Aspen Publishers, $1995: 410-429$ 


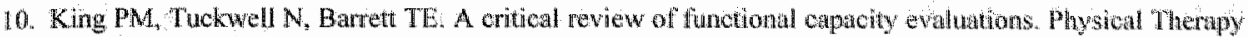
$1998 ; 78(8): 852-866$

11. Innes E, 3trater L. Validity of work-related assessments. Wonk 1999,13(2) 125-152:

12. Innes E, Straker L. Relability of work-related assesments. Work 1999,13(2),107,124.

13. Isernhagen SJ. Hart DL, Matheson LM. Reliabilaty of independent observer judgments of lewel of lift affort in a kinesiophysical Functional Capacity Evaluation. Work 1999,12(2):145-150.

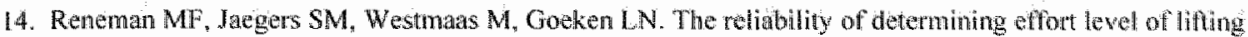
and carrying in a functional capacio ewaluation. Work $2002 ; 18(1): 23-27$.

15. Reneman MF, Dijkstra PU, Westmaas M. Goeken LN. Test-retest rellability of lifting and carry ng in a 2 . day functional capacity evaluation. Iotmat of Occupational Rehabilitation $2002,12(4): 269-275$.

16. Gross DP. Battie MC. Reliability of safe maximum lifting determinations of a functional eapacty evaluation. Pbysical therapy $2002,82(4): 364-37$.

17. Brouwer S. Reneman MF, Dijkstra PU, Groothoff JW, Schellehens JM, Gooken LN, Iost-retest reliability of the Isemhagen Work Systems Functional Capacity Evaluation in pattents with chronic low back pain. Joumal of Occupational Rehabilitation $2003 ; 13(4): 207-218$.

18. Rereman MF, Brouwer S, Meinema A, Dijkstra PU, Geenzen JH, Groohoff JW. Test-tetest netinbility o: the Isernhagen Work Systems Functional Capacity Evaluation in healtiy adults. Joumat of Occupational Rehabilitation $2004 ; 14(4): 295-305$.

19. Gross DP, Batie MC. Construct validity of a kinesiophysical functional capacty evaluation admintered within a worker"s compensation envitonment. Joumal of Occupational Rehabilitation 2003;13(4):287295

20. Matheson LN, Isemhagen SI, Hart DL. Relationships among lifting ablity, grip force, and return to work. Physical Therapy 2002;82(3):249-256.

21. Goss DP, Battie MC, Cassidy JD. The prognostic value of functional capacity evaluation han patisnts with chronic low back pain: pan I: timely return to work. Spine 2004;29(8):914-9:19.

22. Gross DP. Batie MC. The prognostic value of functional capacity evaluation in patients with chronic low back pain: part 2: sustained recovery. Spine $2004,29(8) \div 920-924$.

23. Oliweri $M$, Jansen $T$, Oesch $P$, Kool J. The prognostic value of functional capacity evaluation in patients with chronic low back pain part 1: timely return to work. And pant 2: sustained recovery. Spine $2005 ; 30(10): 1232-1233$; author reply 1233-1234.

24. Bachmana $S$, Oesch $P$, Kool J, Persili $S$, Knüsel $O$. Behandlung von Patienten mil chronischen Rhickenschmerzen in einem Ergonomietrainingsprogramm: Lassen sich dadurch arbeitsbezogene

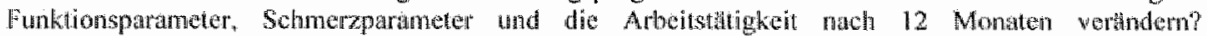
Physikatische Medizin. Rehabilitationsmedizin, Kurortmedizin 2003:13:149-158.

25. Kool IP. Oesch PR, Bachmana $S_{4}$ Knuesel $O$. Dierkes JG, Russo M, de Bic RA, van den Brandt PA. Increasing days at work using function-centered rehabilituiton in nonacule nonspecilic low back puin: a randomized controlied trial. Archives of Physical Medicine and Rehabilitation 2005;86(5):857-864

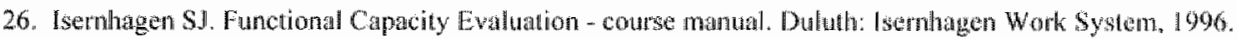

27. United States Departement of Labot. Dictionairy of Occupational Tilles (DOT). Washington, 1981.

28. Edwards F, McCallum R. Taylor P. Fitness for Work: The medical aspects. New York: Oxford Universily Plessin 1991.

29. Bundesant fir Sozialversicherung. Leistungen der (nwalidenversicherung (IV), Bem, 2004.

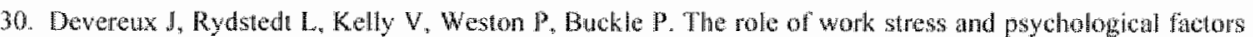
in the development of musculoskelent disonders. Guildord Lealth and Safety Executive, 2004 .

31. Rydsted L, Devereux I, Furnham A. Are lay theories of work stress related to distress? A longitudinat study in the British workforce. Work and Stress 2004:18(3):245-25,4.

32. Cox T. Griffith A, Rial-Gonalez E. Research on work retated stress. Luxembourg: fiuropean Agency for Safety who Heath at Work, 2000 .

33. Anema JR, Cuelenaere $B$, van der Beek A, Knol DLi, de Vet HC, wan Mechelen $W$. The aflectiventss of ergonomic interventions on return-lo-work after low beck pain; a prospective two year colnort study in six countries on low back pain patients sicklisted for $3-4$ months. Oecupational and Fnvironmental Medicine $2004,61(4): 289-294$ 
34. Intemational Labotir Organisation. Technical and ethical guidelines for workers health surveillance. Geneva 1997.

35. Boos $\mathrm{N}_{8}$ Lander $\mathrm{PH}$. Chincal efficacy of maging modalities in the diagnosis of low-back pain disorders. European Spine Journal 1996;5(1):2-22.

36. van Tulder MW, Assendelft WJ, Koes BW, Bouter LM. Spinal radiographie findings and nonspecific low back pain. A systematic rewiew of observational studies. Spine $1997 ; 22(4): 427-434$.

37. European Commission Telematics Application Progranme (Transport Sector). Ergonomics Methods and Tools. 2000 .

38. Vikari-Juntura $\mathrm{E}$, Rauds 5 , Martikainen $\mathrm{R}$, Kuosma $\mathrm{E}$, Rimimaki $\mathrm{H}_{*}$ Takala EP, Saarenmaa $\mathrm{K}$. Validity of selfreported physical work load in epidemiologic studies on musculoskeletal disorders. Scandinavian Journal of Work, Environment \& Heath 1996,22(4):251-259.

39. Ahonen $M$, Ilmarinen J, Kuorinka I, Launis $M$, Lehtelä J, Leskinen $T$, Luopajärvi $T$, Saari J, Seppalla $P$, Stahlhammar H. Ergononic Workplace Analysis: Finnish Institute of Occupational Health, 1989.

40. Reneman MF, Fokkens AS, Dijkstra PU, Geertzen JH, Groothoff JW. Testing lifting capacity; walidity of" deternining effort level by means of observation. Spine 2005,30(2): E40-46. 


\section{Chapter 8}

\section{Reconditioning of patients with chronic low back pain: the influence of the symptom magnification syndrome}

Peter R. Oesch ${ }^{1,2}$, Stefan Bircher ${ }^{2}$, Jan P. Kool ${ }^{3}$, Otto Knüsel ${ }^{1,2}$, Stefan Bachmann ${ }^{1.2}$

Affiliations of the authors

'Dpt. of Work Rehabilitation, Rehabilitation Centre Valens, Switzerland "Dpt. of Rheumatology, Rehabilitation Centre Valens, Switzerland

${ }^{3}$ Research Dpt.., Rehabilitation Centre Valens, Switzerland

Published in German in Physikalische Medizin, Rehabilitation und Kurortmedizin 2003;13:149-158 


\begin{abstract}
Introduction: Work hardening programs requiring exercise tolerance are recommended to improve the physical capacity of patients with chronic low back pain (CLBP). Some patients met the definition of the Symptom Magnification Syndrome (SMS), a conscious or unconscious self-destructive socially reinforced behavioural response pattern. The purpose of this study is to investigate whether patients with CLBP with SMS benefit equally from an intensive function and training centred rehabilitation program as patients with CLBP without SMS.
\end{abstract}

Methods: Prospective cohort study in 20 patients referred for a 3-week work hardening program. The SMS group included patients with $\geq 4$ SMS signs; patients in the control group had $\leq 1$ SMS sign. Treatment including daily endurance training was identical in both groups. Before and after treatment we assessed physical capacity and disability.

Results: Psychosocial factors correlating with poor prognosis of CLBP were more frequent in the SMS group than in the control group. The SMS group had a significantly lower physical capacity, more severe disability, and a lower endurance. After rehabilitation, endurance and strength in the SMS group remained unchanged. Strength increased significantly in the control group.

Conclusion: Three weeks of intensive rehabilitation requiring exercise tolerance does not improve physical capacity and endurance, and should therefore not be prescribed to patients with $\geq 4$ symptoms of SMS. The presence of $\geq 4$ symptoms of SMS, compared with $\leq 1$ symptom of SMS, is associated with lower physical capacity, more severe disability, and with psychosocial factors related to poorer prognosis of CLBP. Physical pathology cannot explain the difference in treatment effect. The higher prevalence of psychosocial factors related to poorer outcome probably plays an important role. 


\section{Introduction}

During the past decades, disability as a consequence of musculoskelletal disorders has increased dramatically in most western countries. ${ }^{1,2}$ Patients with nonspectic low back pain (LBP) constitute one of the major subgroups. In addition to a medical challenge, LBP has also become a political and economic problem. ${ }^{3}$ Approximately $8 \%$ of all patients who initially show acute LBP develop chronic work related disability. This relatively small percentage of patients causes approximately $80 \%$ of the total LBP. related costs. ${ }^{4,5}$

Because of the economic impact of LBP-related disability, effective treatment strategles for patients with LBP are urgently needed. Until recently, most physicians and therapists predominantly applied passive treatments. However, it is nowadays generally accepted that rehabilitation should restore function and include strength as well as endurance training based on scientific principles. ${ }^{6}$ The primary goal of treatment is not to reduce or even eliminate pain but to increase the level of activity and physical capacity $^{7,6}$ with the primary goal to return to work. ${ }^{5,8}$

Many patients present a deconditioning syndrome; a vicious circle usually initiated by pain, causing not only inactivity and rest to relieve painful structures and to avoid pain, but also deconditioning of the movement and cardiovascular system. Strength, endurance, and mobility deteriorate resulting in an increasing imbalance between the person's physical capacity and his or her work-related requirements. As a consequence, pain increases.

In addition to improving physical capacity, treatment aims at increasing the patient's self-efficacy and confidence in his or her own competence. This psychological aspect of training is considered crucial for patients with the Symptom Magnification Syndrome (SMS), an abnormal illness behaviour defined as a self-destructive, socially reinlorced behavioural response pattern consisting of displays of symptoms which function to control the life, the social environment and the psychological balance of the sufferer" (Table 1$)^{9}$

We evaluated the working activity after rehabilitation in a previous cohort study." Working activity remained unchanged in patients with moderate or severe SMS whereas it improved in patients without SMS symptoms. We did not evaluate the change in aerobic or physical capacity after rehabilitation. Thus, it remains unclear whether the unimproved working activity was caused by psychosocial factors such as education and nationality or by an insufficient increase in physical capacity. Patients with SMS have a lower physical capacity. ${ }^{10}$ With appropriate endurance and strength training, we would generally expect larger improvements in patients who have a lower initial level of physical capacity. 
Table 1: Definition and assessment of the Symptom Magnification Syndrome.

\begin{tabular}{|c|c|}
\hline Definitlon of the Syrnptom Magnificatlon Syndromes & Diagnostic tests applied in this study \\
\hline \multicolumn{2}{|l|}{ 1. Description of symptoms } \\
\hline Diffuse description of symploms & $\begin{array}{l}\text { 1. More than } 4 \text { regions on a pain drawing cannot be } \\
\text { explained by physical pathology }{ }^{19}\end{array}$ \\
\hline High pain intensity & $\begin{array}{l}\text { 2. Momentary pain intensity of } 9 \text { or } 10 \text { on a } 0-10 \\
\text { Numeric Rating Scale, }\end{array}$ \\
\hline \multicolumn{2}{|l|}{ 2. Social importance of the symploms. } \\
\hline $\begin{array}{l}\text { Symploms take a central place in the patient's life. The } \\
\text { Patients is captivated by the symptoms. The symptoms } \\
\text { not the patient controt the social environment and future } \\
\text { goals. }\end{array}$ & $\begin{array}{l}\text { 3. A score }<80 \text { points on the PACT assessing the } \\
\text { patient's perceived capacity. } 6 \text { : }\end{array}$ \\
\hline \multicolumn{2}{|l|}{ 3. Level of efforl and consistency of performance } \\
\hline $\begin{array}{l}\text { Consistency of performance and behavioural responses to } \\
\text { examination }\end{array}$ & $\begin{array}{l}\text { 4. Positive Waddell's test }(>2 / 5 \text { points) for behavioural } \\
\text { responses to physical examination }{ }_{e}^{* 7}\end{array}$ \\
\hline $\begin{array}{l}\text { Level of effort reduced and insufficient for participation in } \\
\text { an exercise based rehabilitation program }\end{array}$ & 5. Preliminary cessation of a 3-minute step test.t. \\
\hline Reduced cooperation, rules are followed insufficiently & 6. Preliminary cessation of a pseudo-strength test. ${ }^{8}$ \\
\hline
\end{tabular}

This study of patients with chronic nonspecific LBP investigates the difference in physical capacity and psycliosocial factors in patients with and without SMS. Secondly, we compare the effect of a 3 -week function-centred rehabilitation program, which included endurance training on a stationary bicycle, on physical capacity and selfefficacy.

\section{Methods}

We conducted a prospective cohort study and included patients with chronic nonspecific LBP as defined by the Quebec-Task-Force Report. ${ }^{5}$ All patients participated in a 3-week function-centred treatment (FCT) program in our rehabilitation centre in Valens. We assessed SMS using the criteria described in table 1.

Patients pointed out the painful regions of the body on a pain drawing. The lower trunk, the region from below the thorax until the groins and buttocks, was counted as one region. The legs each consisted of a region above and below the knee. 
The PACT consisted of 50 daily activities done in warying sitting and standing postures. The activities were illustrated to reduce language-related difficultes. Patients were instructed to rate the degree of difficuly in performing these activities on a 5 -point soale (1, unrestricted ability to perform the activity; 2 , slightly limited; 3 , moderately limited, 4, severely limited; 5 , unable to perform the activity). The PACT included a consistency check which indicated whether the patient understood the instructions or not. For patients who did not answer the questions consistently the research assistant repeated the instructions.

In the SMS group we included 10 consecutive patients with $\geq 4$ symptoms of SMS. Ten patients with $\leq 1$ sympton of SMS were admitted to the control group. All patients received the same treatment and measurements. The study was part of a large randomized controlled trial comparing the effectiveness of function centred and pain centred treatment.

\section{FUNCTION CENTRED TREATMENT}

The standardized function centred treatment (FCT) was introduced in our rehabilitation centre in 1998. FCT is based on the PRIDE-treatment concept (PRIDE = Productive Rehabilitation Institute of Dallas for Ergonomics). ${ }^{6}$ Return to work is facilitated by an increasing physical capacity. FCT was offered in open groups; patients could enter the program at any time. The group size was limited to a maximum of 9 patients. Table 2 displays the time schedule. Treatment was on Monday-Friday during the whole day, and on Saturday until 12 am. FCT included self-exercise, medical exercise training, walking, work-specific training, ergonomic advice and instructions, pool exercise and sports. 
Table 2. Function centred treatriant

\begin{tabular}{|c|c|c|}
\hline Tine & Treatment & Content and goals emphasizing observations related to relieve deconditioning \\
\hline $7.30,8.00$ & Self-exercise & $\begin{array}{l}\text { The patient independently performs exercises that have been selected and } \\
\text { nstructed by a physiotherapist }\end{array}$ \\
\hline 8.00 .900 & Walking & Walking in the surrounding area of the clinic to increase cardiowascular endurance \\
\hline $9.30-10.15$ & $\begin{array}{l}\text { Endurance } \\
\text { training }\end{array}$ & $\begin{array}{l}\text { Merobic endurance training on a stationany bicycle during } 30 \text { minutes, work-level } \\
\text { based on aerobic capacity determined by previous testing }\end{array}$ \\
\hline \multirow[t]{2}{*}{$10.30-12.00$} & $\begin{array}{l}\text { Work-specticic } \\
\text { training }\end{array}$ & Training in simulated work situations, ergonomic insiructions and advice \\
\hline & $\begin{array}{l}\text { Medical exercise } \\
\text { therapy }\end{array}$ & Endurance and strength iraining to increase physical capacity \\
\hline $13.30-14.15$ & Sporfs & $\begin{array}{l}\text { Sports and games to increase motor coordination and to enjoy exercising and } \\
\text { moving. }\end{array}$ \\
\hline $1600-17.00$ & Pool-exercise & Strengih, coordination and endurance training \\
\hline Parallel & Information & $\begin{array}{l}\text { During the group treatments, therapists give information about the chronic but } \\
\text { benign character of the disease, chronic pain and deconditioning, the physiology of } \\
\text { strength and endurance training, biomechanics, goals for the future, possibilities of } \\
\text { refurning to work. }\end{array}$ \\
\hline
\end{tabular}

Patients performed 30 minutes of aerobic endurance training on a stationary bicycle 6 days per week for three weeks. Before training, a sports-therapist determined the patient's aerobic capacity and training intensity. Twice a week patients performed intensive strength training. ${ }^{13.14}$

The behavioural component is an important aspect of the FCT. We applied the principles of selfefficacy training as described by Matheson." Patients should take responsibility for their own back pain and improve confidence in their own abilities. An important difficult first step is accepting that back pain can occur during activities but does not mean that the spine is harmed. Another aspect of improving self-efficacy is learning to "negotiate with symptoms". This means that patients accept an increase in pain with activity, knowing that the pain intensity will gradually recede to the previous level. It is vital that patients realize that increasing activity will eventually improve function, whereas avouding pain and activity will lead to increasing pain and disability. Another way of improving self-efficacy is by strengthening the active control over the disability. Instead of avoiding painful activities, patients should learn new active strategies to reduce pain during the activities (for instance by taking breaks or changing posture) instead of passive measures (like reducing activities, taking pain killers or lying in bed). Group treatments offer many opportunities to guide patients towards improving self-efficacy. 


\section{MEASUREMENTS}

\section{Disability, physical capacity, mobility}

We recorded disability with the Oswestry Disability Index (ODI) assessing 10 activities of daily life on a 5-point scale. The percentage of the total score indicates the level of disability $(0-20 \%=$ minimal disability, $20-40 \%=$ moderate disability, $40-60 \%=$ severe disability, $60-80 \%=$ very severe disability, $80-100 \%=$ bedridden). ${ }^{15}$ We determined the physical capacity with a selection of tests according to the Isernhagen Work Systems Functional Capacity Evaluation. We assessed the maximum lifting capacity within safety limits from floor to waist, from waist to crown, and horizontally at waist level. We also assessed the maximum grip strength of both hands and static pulling and pushing while standing. The research assistant was trained and experienced in this method and its reliability has been confirmed. ${ }^{16,17}$ Mobility was assessed using the finger-to-floor distance in centimetres and the straight leg raise in degrees with an inclinometer.

\section{Aerobic capacity}

Maximal aerobic capacity was assessed on a stationary bicycle (Ergoline 800@, Pilger Medizintechnik, Switzerland). At the end of the progressive test and at the limit of aerobic capacity, we recorded the maximum performed work (Watt), maximum oxygen intake $\left(\mathrm{VO}_{2 \max }\right)$ and maximum heart rate. We measured the oxygen intake during each inhalation with a respiratory mask (Cosmed $b^{2}(B)$ ) and heart rate with a Polar Accurex Plus ${ }^{\mathrm{TM}}$ B. Values of oxygen intake and heart rate were transferred to a personal computer by telemetry. For security reasons we monitored heart functions with a 12channel ECG. During the first three minutes, the patient was silting on the bicycle without pedalling and adapted to the breathing mask. The efficiency of the stationary bicycle is optimal at a pedalling frequency of $40-60$ rounds per minute. ${ }^{18}$ We instructed the patients to keep the pedalling frequency constant at 60 rounds per minute. After three minutes warming up without additional resistance, the pedalling load was increased by 10-25 Watt per minute. A test-duration of at least eight minutes is required to obtain sufficient data. If the increase in load per minute is too large, this may result in earlier exhaustion of the patient. This should be avoided. The maximal test duration is 12 minutes. Longer testing decreases motivation and increases the risk of termination before the aerobic limit is observed. The magnitude of the increase of workload was estimated before onset by the assessor. The test was stopped when the patient reached his or her subjective limit of performance. Causes for termination by the patient were shortness of breath, general exhaustion, insufficient leg strength and LBP. We used the following safety limits to terminate testing: the occurrence of significant ST-drops on the ECG, an absence of the expected increase in blood pressure, a sudden decrease in blood pressure, and a blood pressure $>230 / 120 \mathrm{~mm} \mathrm{Hg} .{ }^{19}$ After reaching the maximal 
Watt-level, the patient continued pedalling without resistance on a low pace to avoid an extreme reduction in blood pressure and to facilitate recovery. Indicators of maximal effort were a plateau in oxygen intake in spite of an increase in workload and respiration, an increase of the respiratory quotient $>1.1$ and reaching the maximal heart rate $(220$-age). We used the results of the assessment of aerobic capacity to determine training intensity.

\section{Hip and back extension strength}

We used the "Back Extension' (Cybex(B) Strength Systems, New York, Figure 1) to assess isometric and dynamic back and hip extension strength. During dynamic strength measurement we recorded the strength-time relationship with a force plate adapted to the lever in contact with the patient's back (DigiMax Power-Control, LMT AG, Switzerland). This system records the effective force exerted during the entire range of movement.

Maximal isometric strength was recorded three times each at 30,50 and $70^{\circ}$ of hip flexion. ${ }^{22.23}$ The assessor instructed the patient to exert maximal pressure against the fixed back lever for approximately 5 seconds. ${ }^{24}$ The assessor told the patient to stop as soon as he observed a decline in the exerted force, displayed on the monitor visible to the patient and the assessor.

Figure 1: Assessment of maximum strength with the Cybex (a) 'Back Extension'

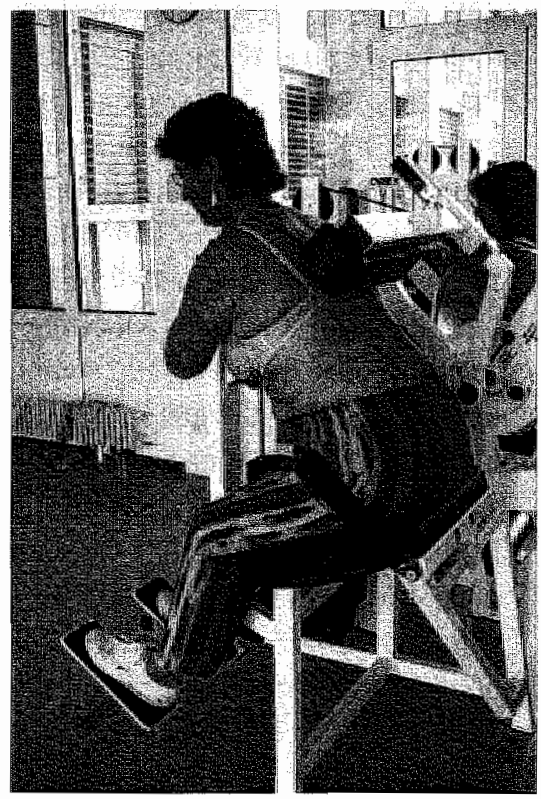


Before dynamic testing, the patient was taught the correct pattern of movement with stable legs and neutral head aligiment. The patient was instructed to nove between 30 and $70^{\circ}$ of hip flexion with a frequency of 60 repetitions per minute following an auditory pace. We started dynamic testing with an initial load of approximately $40 \%$ of the maximal isometric load. The duration of one series of concentric and eccentric contractions was 45 seconds. The assessor made corrections to the patient"s performance and motivated the patient to continue. After each series the weight was increased by $5.7 \mathrm{~kg}$ until the patient reached his or her limit of performance or stop criteria were observed. Stop criteria included inability to keep the pace, cervical extension, inability to stabilize the feet on the foot plates, pressed breathing, and uncontrolled movement. We recorded blood lactate before the first and after each series with a Hand Lactate Measurement device (Lactate Pro ${ }^{T M}$ LT-1710, Axon Lab AG, Switzerland). We used the results of the assessment of dynamic strength to determine the intensity of training.

\section{Perceived effect}

At the end of the three-week rehabilitation program, patients completed a questionnaire with nine questions and rated each of them on a seven-point Likert scale ranging from "to agree completely' to 'to disagree completely'. The questions evaluated achievement of the individual goal, reduction of the complaints, increased understanding of the complaints, increased general well-beung, finding treatment helpful, satisfaction with treatment, increased control over the complaints, having received helpful information and advice, and increased physical capacity.

\section{STATISTICS}

We analyzed between group differences before treatment with a $\chi^{2}$-test in nominal variables. The change within groups during treatment was analyzed with a paired "T-test for normally distributed variables and with a Wilcoxon test for non-parametric variablles. We compared groups using an unpaired T-test for normally distributed data and a Mann-Whitney test for non-parametric variables. All analysis was performed with SPSS 10 , alpha was set at 0.05 .

\section{Results}

\section{BASELINE CHARACTERISTICS}

Baseline characteristics are displayed in Table 3. Patients of the SMS groups were slightly older, had a longer history of LBP and were severelly disabled. Patients in the SMS group generally were unskilled workers, poorly educated and the majority came 
from Southeast Europe. Two patients in each group had had back surgery more than 6 months before rehabilitation. The frequency of the different signs of SMS is displayed in Table 4.

Table 3: Anthroporretric and sociondemographic characteristics of the wo groups at baseline

\begin{tabular}{|c|c|c|c|}
\hline 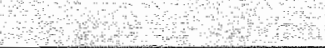 & SMS group & Control group & $P$ \\
\hline Age (years, SD) & $46.1(6.0)$ & $40.9(8.4)$ & n.s. \\
\hline Length (cm, SO) & $172.1(11.7)$ & $171.8(12.6)$ & 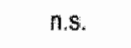 \\
\hline Weight (kg, SD) & $77.8(13.9)$ & $84: 0(24.2)$ & n.s. \\
\hline Sex (maleffemale) & $8 / 2$ & $7 / 3$ & n.s. \\
\hline Duration of LBP (months, SD) & $26.3(15.11)$ & $13.6(14.8)$ & n.s. 0.087 \\
\hline Disability & $60.4(15.5)$ & $35.2(18.2)$ & $P<0.05$ \\
\hline SMS-signs & $4.7(0.7)$ & $0.6(0.5)$ & $P<0.05$ \\
\hline \multicolumn{4}{|l|}{ Nationality } \\
\hline Switzerland & 0 & 5 & \\
\hline South-East Europe & 7 & 2 & $x^{2} p=0.02$ \\
\hline Other countries & 3 & 3 & \\
\hline \multicolumn{4}{|l|}{ Professional education } \\
\hline yes & 1 & 8 & $x^{2} p=0.02$ \\
\hline no: & 9 & 2 & \\
\hline \multicolumn{4}{|l|}{ Job qualification } \\
\hline Skilled worker & 1 & 8 & $x^{2} p=0.02$ \\
\hline Unskilled worker & 9 & 2 & \\
\hline
\end{tabular}

\section{COMPARISON OF GROUPS BEFORE AND AFTER TREATMENT}

During rehabilitation, the number of positive SMS signs slightly decreased in both groups (Table 4). Table 5 displays physical capacity, range of motion and disability in the two groups before and after treatment. Physical capacity was significantly lower in the SMS group in all tests with the exception of pushing. Girip strength of men in the SMS group was below the $90 \%$ range of healthy persons of comparable age. The 8 men had an average grip strength at the right side of $27.5 \mathrm{kp}$ (normal 90\% range $=29.5-70.4$ ) and $28.3 \mathrm{kp}$ and left side (nomal 90\% range $=26.3-72.6$ ). Grip strength of the two women belonging to the SMS group was at the lower end of the normal range: $18 \mathrm{kp}$ in the right hand (normal $90 \%$ range $=17.7-45.4$ ) and $19.5 \mathrm{kp}$ in the left hand (normal 
$90 \%$ range $=16.8-37.3$ ). Range of motion was larger in the control group and this group showed more improvement than the SMS group. Disability, measured with the Oswestry Disability Index, was significantly higher in the SMS group (severe) than in the control group (moderate). The SMS group slightly deteriorated during treatment whereas the control group significantly improved in the majority of measurements of physical capacity, range of motion and disability.

Table 4: Pasitive signs of SMS in the two groups before and after rehabilitation

\begin{tabular}{|c|c|c|c|c|}
\hline 8 & betione & IS & bolore & $\begin{array}{l}\text { thol } \\
\text { afler }\end{array}$ \\
\hline$>4$ Pain regions & 8 & 8 & 6 & 2 \\
\hline Momentary pain 9 or 10 & 5 & 5 & 0 & 1 \\
\hline$P A C T<80$ & 10 & 8 & 0 & 0 \\
\hline Behawioural responses & 10 & 8 & 0 & 0 \\
\hline Cessation of step test & 4 & 4 & 0 & 0 \\
\hline Positive pseudo strength test & 10 & 8 & 0 & 0 \\
\hline Total & $4.7(0.7)$ & $4.1(1.5)$ & $0.6(0.5)$ & $0.3(0.4)$ \\
\hline
\end{tabular}

Aerobic capacity was significantly higher in the control group and remained unchanged after treatment in both groups. Blood lactate values demonstrate an impressive difference between the two groups. The SMS group did not reach values of $2 \mathrm{mmol} / \mathrm{l}$ while the control group arrived at $4 \mathrm{mmol} / \mathrm{l}$ (fig 2). 


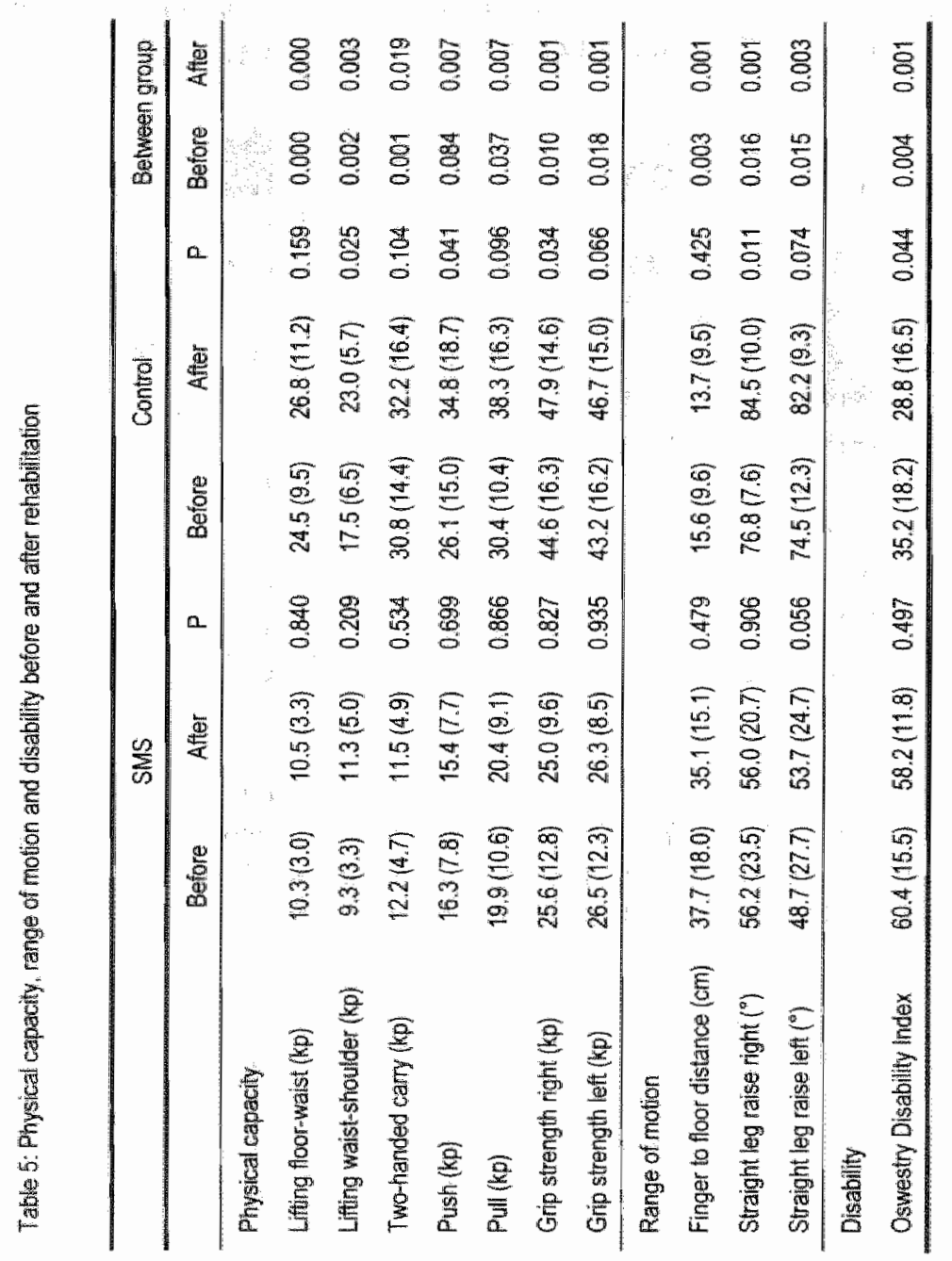


Six patients in the control group and only one patient in the SMS group reached maximum capacity as defined in the methods $\left(\chi^{2} p=0.03\right)$. Increased LBP limited higher activity in most patients of the SMS group.

The results in strength testing were similar. Isometric and dynamic strength were significantly lower in the SMS group than in the control group. In the SMS group, pain caused preliminary cessation of dynamic strength testing for three patients while the maximum strength of the other seven patients could not be determined because they were unable to keep up with the pace of movement. Muscle strength did not improve in the SMS group while it significantly increased in the control group (Table 6).

Figure 2: Blood lactate values were significantly lower in the SMS group and remained the same after rehabilitation. The control group's values improved significantly after treatment.
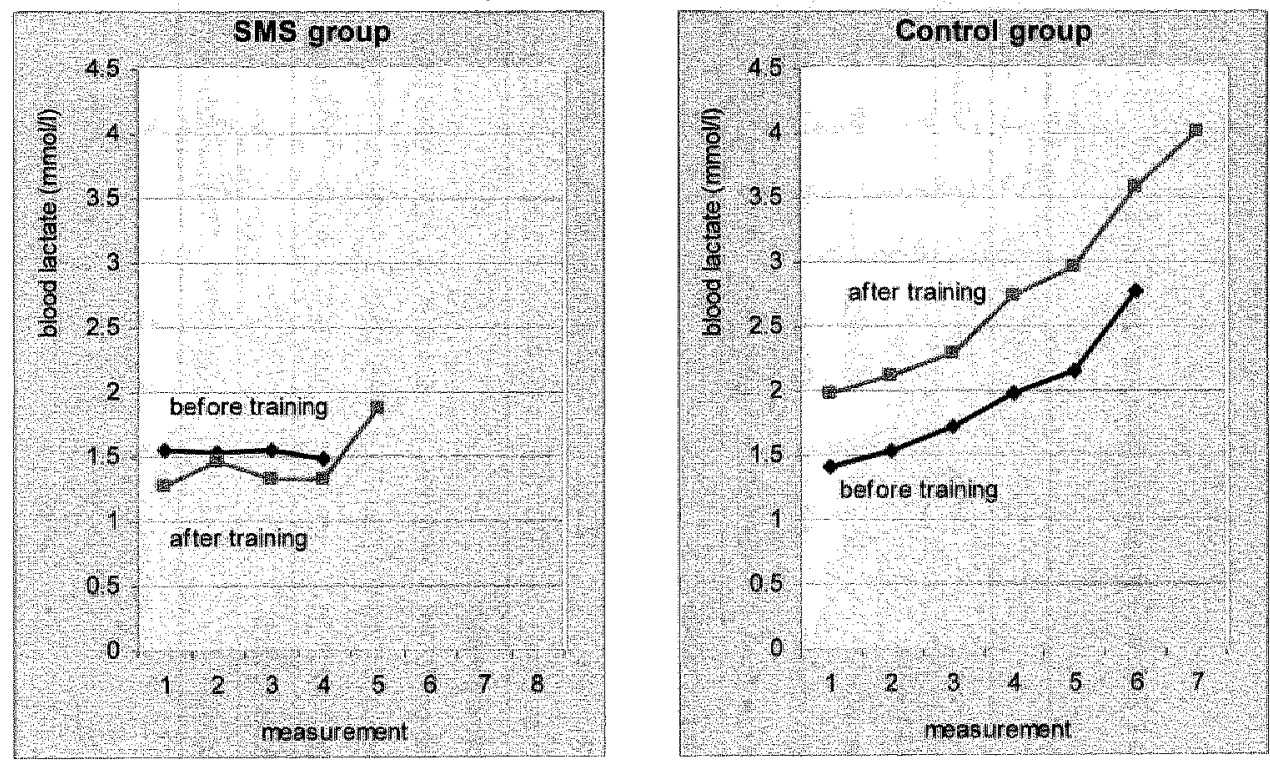

The number of positive SMS signs and disability (Oswestry Disability Index) remained unchanged after treatment in the SMS group. Patients in the SMS group scored significantly lower on seven out of nine questions of the treatment evaluation (Figure 3). 
144 Chapter

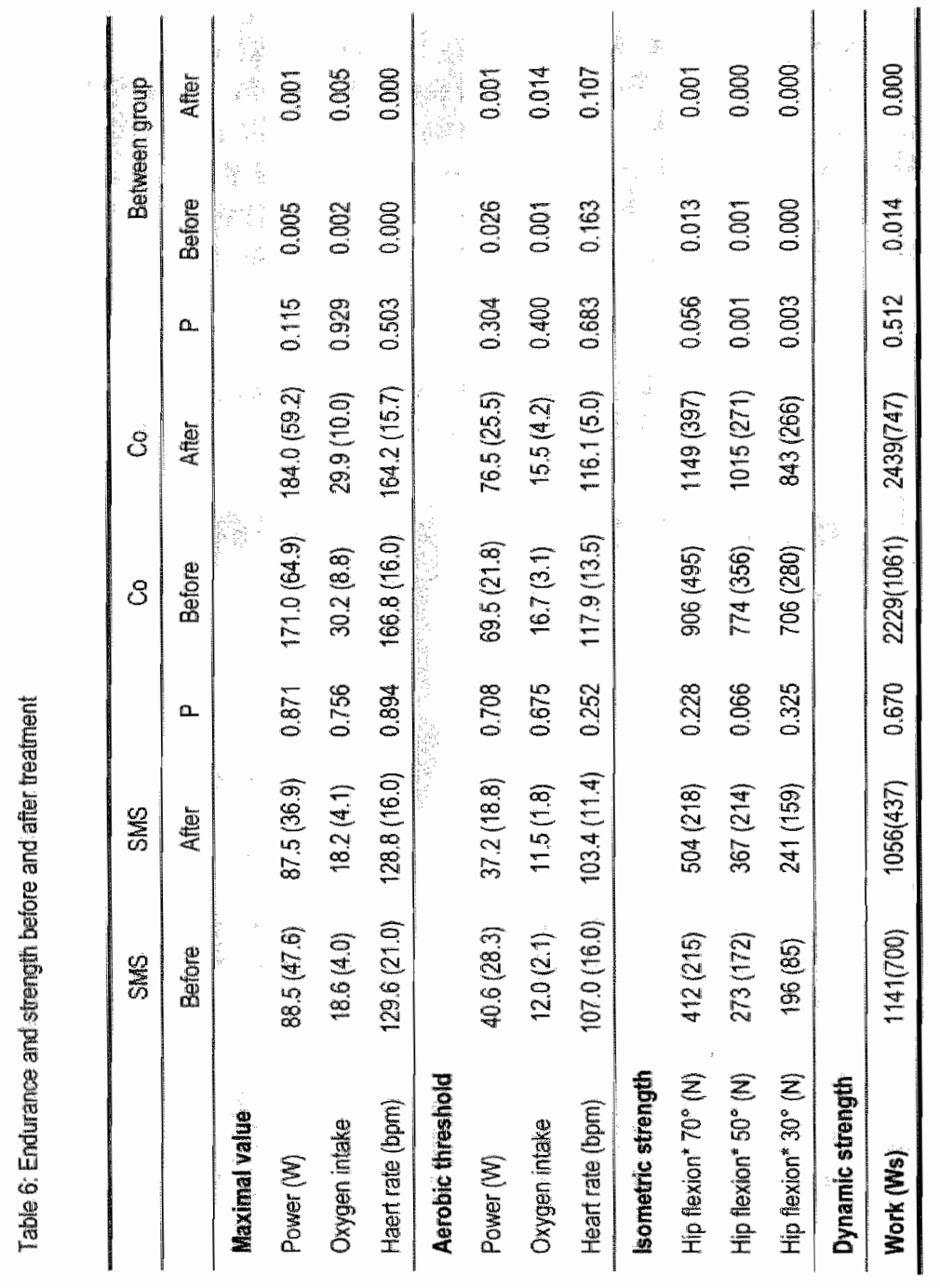


Figure 3: The patien's' judgement of the rehabilitation was better in the control group than the SMS group, ratings went from $1=$ "to disagree completely" to $7=$ "to agree conpletely". "Mann-Whitney p 0.05 .

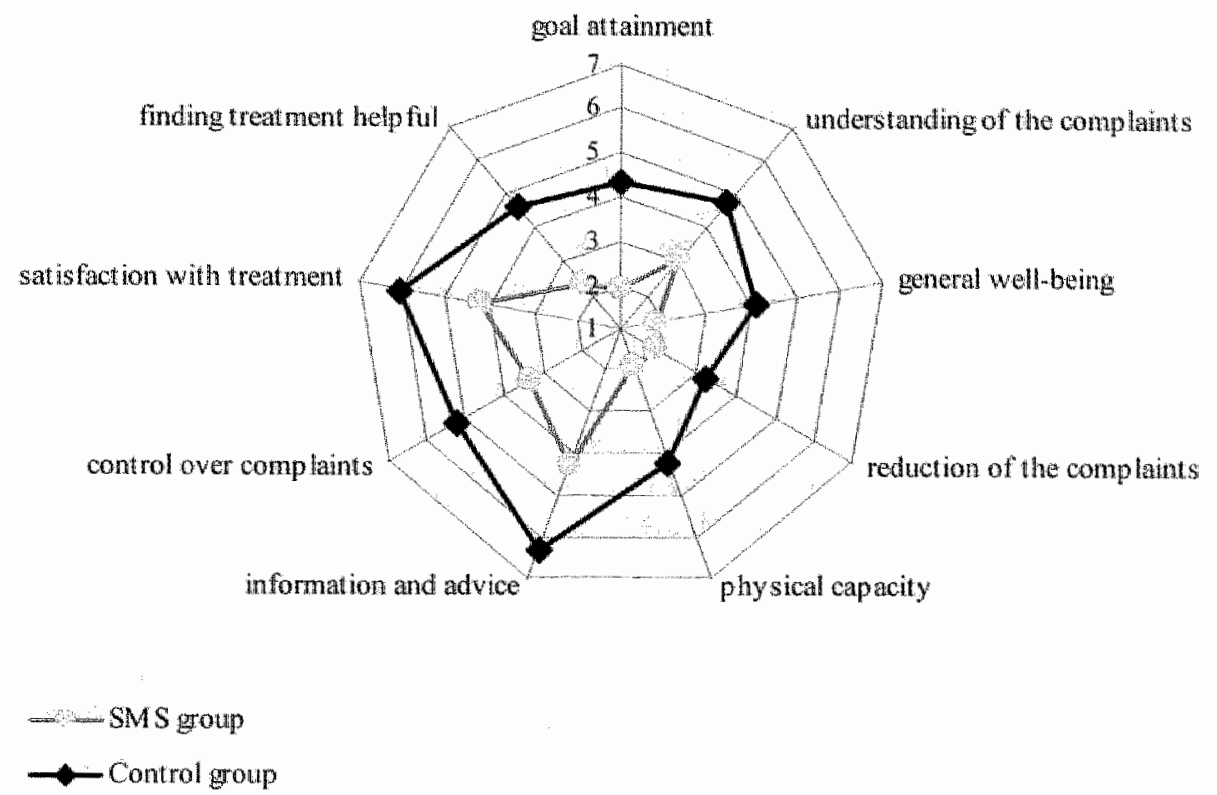

\section{Discussion}

Psychosocial factors associated with a poor prognosis are more frequent in patients with SMS. Patients with SMS have a lower physical capacity, less mobility and higher disability. Intensive rehabilitation including endurance and strength training does not improve physical capacity, strength and disability in patients with SMS.

The significant baseline difference between the two groups is the result of different admission criteria. As expected, the SMS grotup showed longer off-work duration and a longer history of the complaints. Pain, avoidance behaviour and deconditioning are a 
vicious circle. When SMS develops with increasing duration of LBP, fear for pain and insufficient self-efficacy reduce the activity level and, consequently, the effort level during tests and exercises. ${ }^{28-30}$

According to the Glasgow Illness Model ${ }^{3+}$, biologica $\rrbracket_{3}$ psychological and social factors all contribute to the process of chronification. The initial physical problem is influenced by social factors, illness behaviour, attitudes and beliefs. Chronification is less a physical than a psychosocial phenomenon. This is also demonstrated by the facts that SMS patients had a lower education levell and lower job qualifications and that all patients in the SMS group were immigrants, compared with only $50 \%$ in the control group. Many immigrants perform heavy unskilled work; associated with low job satisfaction which plays an important role in the chronification of LBP. ${ }^{32-35}$ Poorly educated unskilled workers hardly have professional perspectives. Due to their LBP, their physical capacity is reduced and they are incapable of performing their previous work which in most cases included lifting heavy material. Hence, they no longer have value on the working market and lose their self-confidence. The reaction of the social environment often reinforces disability. Members of the family, in a well meant attempt to help, take over physical activities at home, thereby increasing the patients" illness behaviour. Moreover, physicians and physical therapists reinforce illness behaviour by overprotection. Examples are sick listing, prescribing rest and telling patients they will never be able to do some of their job tasks. ${ }^{36}$

Pre-treatment measurements of physical and aerobic capacity are significantly lower in the SMS group. Applying the criteria from the Swiss Department of Sports, endurance is "very low" in the SMS group and 'satisfactory' in the control group. ${ }^{37}$ Judgement of $\mathrm{VO}_{2 \mathrm{mnx}}$, however, is limited because $90 \%$ of the patients in the SMS group and $40 \%$ in the control group did not show maximal effort during testing. ${ }^{38}$ Although LBP was present during testing in both groups, pain limited performances during tests much more in patients from the SMS group. Relative oxygen intake at the maximal aerobic capacity allows a judgement of the maximal aerobic capacity in patients with a very low endurance level. ${ }^{39}$ Oxygen intake was significantly lower in the SMS group compared with the control group (12.0 SD 2.1 and $16.7 \mathrm{SD} 3.1 \mathrm{ml} / \mathrm{min}^{*} \mathrm{~kg}$ ). Therefore, aerobic capacity was significantly lower in the SMS group. $\mathrm{VO}_{2 \text { max }}$ in the control group of our study was comparable with the results of another study investigating the effects of a work hardening program on cardiovascular litness in patients with chronic LBP 30.2 and $30.5 \mathrm{ml} / \mathrm{min}^{*} \mathrm{~kg}$ ). ${ }^{40}$ The results of straight leg raise of the control group in our study is comparable with results of straight leg raise in the study by Hartigan ( 74.5 and $\left.75^{\circ}\right) .^{4 !}$ These comparisons indicate that patients in the SMS group show significantly lower values in oxygen intake and mobility, displaying more pronounced deconditioning. 
Because baseline values of endurance and physical capacity are lower in the SMS group a larger effect of training might be expected. Contrary to this expectation, the SMS group did not improve at all; it even deteriorated in some measurements, and the difference between the two groups increased. This pattem was observed consistently in all outcome measures: physical capacity, disability, mobility and patient satisfaction.

Medical findings and diagnosis cannot explain the unsuccessful rehabilitation in the SMS group. All patients suffered from nonspecific LBP. Medical findings do not explain the low grip strength, the inability to perform the pseudo strength test or the severe disability in the SMS group. Complaints were always the reason for low performance in the SMS group. The effort level was significantly higher in the control group. In spite of behavioural treatment aiming at increasing self-efficacy and reducing fear of movement, rehabilitation did neither reduce SMS signs nor improve function.

The question arises if nonspecific LBP combined with severe SMS can be considered a medical problem. The results of this study are in line with the observation that "disability due to chronic LBP depends on psychosocial factors, not on the severity of" the complaints'. 42 These factors apparently are so dominating that our relabilitation program is ineffective.

Some readers may criticize the heterogeneity of the patients. Patients were, however, quite similar with regard to the medical diagnosis and the duration of the complaints. The investigated treatment is currently offered to all patients with such a condition and the question arises if the effectiveness is equal in different subgroups, for instance in patients with or without SMS. This study demonstrates that treatment is ineffective for patients with SMS.

The measurements in this study were very time consuming. Therefore, we chose a study design that allowed us to answer the question of the study with a small number of patients. In order to increase the statistical power of the study, we excluded patients with moderate SMS $(2-3$ positive signs), and selected only patients from the lower $(\leq 1)$ and upper $(\geq 4)$ range of the SMS. So far, research has only identified few effective treatments for chronic LBP. ${ }^{43}$ Many other widely used treatments have been shown to be ineffective. Even worse, these treatments probably are a major cause of LBP-related problems. $^{44}$ This study does not prove the effectiveness of our treatment for patients without SMS. It only shows that training does not improve endurance in patients with SMS. The effectiveness of our treatment in increasing days at work is being investigated in a randomized controlled trial with a control group receiving pain centred treatment. 


\section{Conclusion}

Deconditioning in patients with chronic nonspecific LBP is more severe in patients with $\geq 4$ signs of: SMS than in those without SMS ( $\leq 1$ signs). Patients with SMS show insufficient effort during training, contributing to the ineffectiveness of the treatment. An assessment of SMS signs predicts the success of rehabilitation to improve cardiovascular fitness. Patients without SMS showed a significant improvement of strength and reduction of disability after the treatment.

Patients with SMS did not improve after rehabilitation. Psychosocial factors may constitute a principal barrier to improvement in this group. The question whether other available treatments can resolve the problem in these patients or not remains unanswered. Further studies are, of course, needed. Many interventions addressing psychosocial barriers to return to work admit only patients who understand one of the national languages. We fear that other treatments have no or only limited success in resolving the condition.

\section{References}

1. Frymoyer JW, Cats-Baril WL. An overview of the incidences and costs of low back pain. Orthop Clin North Am 199:22(2):263-7\|

2. Waddell G. Biopsychosocial analysis of low back pain. Baillieres Clin Rheumatol 1992;6(3):523-57

3. Jäckel W, Gerdes N. Medizinische Rehabilitation bei Rückenschmerzen - die Situation in Deutschland. In: Pfüngsten M, Hildebrandt J, eds. Chronischer Rückenschmerz. Göttingen: Huber Verlag, 1998

4. Bigos S, Spengler D, Martin N, Zeh J, Fisher L, Nachemson A, Wang M. Back Injuries in Industry: A. Reirospective Study II. Injury Factors. Spine 1986;11:246-251

5. Spitzer WO. Scientific approach to the assessment and management of actiwity-related spinal disorders. A Imonograph for clinicians. Report of the Quebec Task Force on Spinal Disorders. Spine 1987;12(7):SI$\$ 59$

6. Mayer T. Gutchel R. Functional Restoration for Spinal Disorders: The Sports Medicine Approach. Pluiladelphia: 1991

7. Matheson LN, Ogden LD, Violette K, Schultz K. Work hardening: occupational therapy in industrial rehabilitation. Am J Occup Ther 1985;39(5):314-21

8. Abenhaim L. Rossignol M, Valat JP, et all. The role of activity in the therapeutic management of back pain. Report of the International Paris. Task Poree on Back Pain. Spine 2000;25(4 Suppl): is-33S

9. Mathesoun L. Symptom magnification syndrome. In: Isernhagen $S$, ed. Work injury: management and prevention, $1988: 257-282$

10. Hant D. Rellation between Three Measures of Function in Patients with Chronie Work Related Pain Syndromes. I Rehabil Outcome Mearures 1998;2:1-14

11. Oesch P, Kool J. Starke chronische Rückenschmerzen fenlinterpretiert, eine prospektive Kohortstudie mit Nachkontrolle mach 3 und 12 Monaten. Krankengymaastik 2000;52(5):800-815

12. Bachmanu $S_{1}$ Oesch $P$. Rehabilitation von Patienten mit chronischen Schmerzen des Bewegungsapparates in einem interdisziplinăren Ergonomietrainingsprogramm. Phys Rehab Kur Med 2000(10):11-19

13. Denner A. Muskuläre Profile der Wirbetsäule. Band 2, Anallyse- und Trainingskonzept. Köln: 1995 


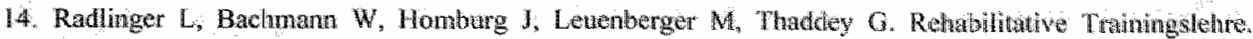
Stuttgart New York: 1998

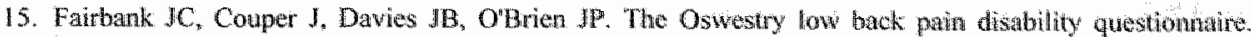
Physictherapy $1980 ; 66(8): 271-3$

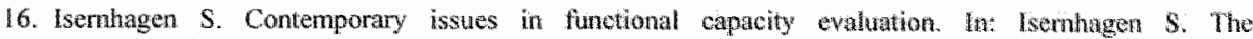
comprehensive guide to work injury mamagement, $1995 \cdot 410-429$

17. Schreiber T, Bak P, Petrovitch A. Anders C, Maller W, Smotenski U, Fvaluation der Funtionellen Leistumgshigheit - Uberblick uber Metnoden und Testsysteme. Phys Rehab Kur Med 2000; 10:108-119

18. Stegemann J, Ausdauertraining. In: Shepard. RJ; Astrand, PO. (Hrsg). Ausduer in Spont. Koln: 1984

19. Abbruchkriterien in der Ergometrie. Sportäratebund-Nordihen, Mitglieder-Jourmal. 1999/2: www sportacratebund de/Mitgleder-Journal 2 , 99 htm

20. Wassermann $K$, Hamsen JE, Sue DY, Casaburi $R$, Whipp B. Principles of Exercise Testung ind Interpretation. $3^{\text {ra }}$ Edition. Pliladelphia: 1999

21. Duncain $\mathrm{G}$, Howley E, Johnson B. Applicability of VO2 max criteria: discontinuous versus continous protocols. Med Sci Sports Exerc 1997:29:273-278

22. Futton $M$, Jones $G$, Pollock $M$, Graves I, Cirulii J, Legzett $S$. Carpenter D, Jones $A$. Hower-back problems, catuse and effect. University of Florida. Department of Medicine and Drencise and Sport Sciences, des Tallahassee Memorial Regional Medical Center. 1990

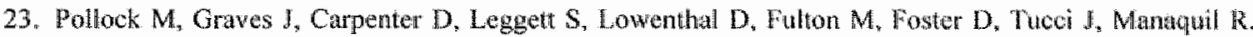
Effects of isolated lumbar extension resistance training on bone mineral density of the alderly. Medicine and Science in Sports and Exercise $1992,24(66)$

24. Kraemer WJ, Schemitsch EH, Lewer J, MoBroom RJ, McKee MO, Waddell IP. Functionel outcone of thoracolumbar burst fractures without neurological deficit. J Orthop Trauma $1996 ; 10(8): 541-4$

25. Demer A. Muskuläre Profile der Wirbelsatule. Band 1, Gundlagen. Köln:1995

26. Mathiowetz $W$, Kashman $N$, Vollan $G_{*}$ Weber $K$, Dowe M, Rogers $S$; Grip and pinch strength: Normatiwe data for adults; Phys Med Rethail 1985;66:69-74

27. Brady $S$, Mayer $T$, Gatchel RJ. Physical progress and residual imparment quantification after functional restoration. Part 1I: Isokinetic trunk strength. Spline 1994;19(4):395 400

28. Aberg J. Evaluation of an advanced back pain rehabilitation program. Spine 1984;9(3):317-8

29. Troup J, Foreman T, Baxter C, Brown D. 1987 Volvo award in clinical scicnces. The perception of back pain and the role of psychophysical tests of lifting capacity. Spine 1987;12:645-657

30. Hazard RG. The Multidisciplinary Approach to Occupational Low Back Pain and Disabilily. I Am Acad Orthop Surg 1994:2(3):157-163

31. Waddell $G$, Main $C$, Morris E, Di Paola M. Cray I. Chronic low beck pain, psychologic disuress, and illness behaviour. Spine 1984;9:209-213

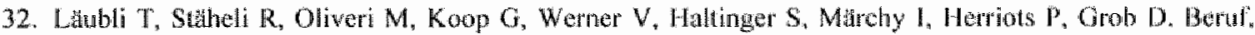
Rückenbelasfung atm Arteilsplatz, klinische Befunde und Motorik bei Splalangestellen mil noweren und langihrigen Schmeren. In: Chronifizurtug von Rackenschmerzen - Hintergrinde, Auswege. Basel: 1996

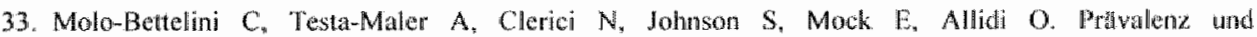
Chronifzietungsfaktoren von Iumbalen Rick thschmerzen: Die Bedeutung von psychosozialen und berthichen Einflüsen. Im: Chonifizierung von Rruckenschmerzen - Hintergunde. Auswege. Basel: 1996

34. Ranacioti D, Von Allmen M. Manghi M. Lumbale Ruckenschmerzen, Benuf und Lebersstil. In: Chronifizierung von Rúckenchmerzen - Hintergrinde. Auswege. Basel: 1996

35. Keel P, Perini C, Schäz-Petitjean D. Chronifizierung von Rúckenschmenzen - Hintergrunde, Auswege Basel: 1996

36. Kopp $G$, Oliver M, Thali A. Erfassung und Umgang mit Symptomatusweitung. In: Med. Mitteilungen det SUVA. 1998; 50:56-75

37. Marti $B$, Laukkanen $R$, Held $T$. Betrteilumg der Ausdater aufigrund det VO2-max: Slandards dex Bundesamtes fur Sport. Schweizerische Zwitsclwift fur Spormedizin und Sportramatologic. $1999 \cdot 47: 173-174$ 
38. Neyer T. Kindeman W. Die maximale Satuerstofaufnalime (VOmak). Deutsche Zeitschrift Pur Sporthedizin 1999-50:285-286

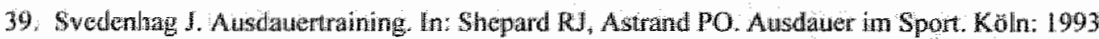

40. Roben J, Blide RW, Mo Whonter $K$. Coursty $C$. The affets of a work hardenimg program an cardiowascollar finess and musculat strength. Spine $1995 ; 20$ (10): 1 187-93

41. Hartigan $C_{3}$ Miller L, Liewehr SC. Rehabilitation of acute and subacute low back and reck pain in the wotk- inyured patient Orthop Clin North Ain 1996;27(4),841-60

42. Waddell 0 , The Bad Jain Revolution: Churchill Livingstone, 1998

43. van Tulder MW, Koes BW, Bouter LM. Conservative treatmeit of alcute and chronic non-specifio low back parm. A systematie review of randomized controlled trials of the most common interventions. Spine $1997,22(18) \cdot 2128-56$

44. Fordyce WE. Back pain in the workplace: management of disability in nonspecific conditions: IASP Press: 1995

45. Kool $\mathbb{J}$, Oesch $\mathbb{P}$, de Bie $\mathbb{R}$. Predictive tests for non-return to work in patients with chronic low back pain. Eur spine II 2002;11)(5):258\%66

46. Matheson L, Matheson M. Spinal Function Sort. Rating of Perceived Capacity. Test Booklet and Examiners Manual. Performance Assessment and Capacity Testing PACT. 1989

47. Waddell $\mathrm{G}$. McCulloch JA, Kummel E, Venner RM. Nonorganic physical signs in low back pain. Spine $1980,5(2): 117-125$

48. Oesch $P$, Kool $j$, Wunderlin $B$, Kndisel $O$. Rehablitation von Patienten mit chronischen Rilckenbeschwerden: Assessment Lrgebnisse und pradiktive Faktoren. Phys Rehab Kur Med 1997;7:224230 
Chapter 9

General discussion 


\section{Introduction}

This final chapter discusses the main results, the limitations and the impact of this research on physiotherapy and on the rehabilitation of patients with chronic nonspecific low back pain (LBP) in Switzerland. Finally, I will discuss my recommendations for future research.

\section{Main results and discussion of literature}

\section{PREDICTIVE TESTS}

We have confirmed the predictive validity for non-return to work of 4 clinical tests in a cohort study in 99 patients.' The investigated tests are increasingly used by referring physicians to select patients for rehabilitation. We think this has contributed to a more appropriate referral for work-related rehabilitation. As in most other conditions, it is extremely difficult to identify those patients who will only improve working activity with rehabilitation. Many factors are associated with outcome. The associations with most factors are too weak to allow patient selection for treatment.

Before we performed this study, the length of stay was longer in patients with positive predictive tests, but without any success as the cohort study showed. Today, the length of stay in our clinic is shorter in patients with positive predictive tests for non-return to work.

Using the predictive tests for non-return to work, we excluded $30 \%$ of the patients from our randomized controlled trial ( $R C T){ }^{2}$. If we had included these patients we would have reduced the between-group difference in work days by $30 \%$, thereby reducing the statistical power of our study.

\section{META-ANALYSIS}

Our meta-analysis was the first to prove that exercise leads to a reduction of sick days, especially in patients with non-acute nonspecific LBP and severe work-related disability. Since 1987, the guidelines for treatment of patients with non-acute nonspecific LBP have stated that the primary goal is return to work or normal activities. When planning the RCT in 1999, available meta-analyses of RCTs in patients with non-acute LBP mainly reported a reduction of pain and disability. ${ }^{5}$ One review ${ }^{6}$ found limited evidence for the efficacy of antidepressants in chronic patients and concluded that the effect of rehabilitation on work-related outcomes was still unclear. 
Before we finished our meta-analysis, another meta-analysis mvestigating the effect of multidisciplinary rehabilitation on $\angle B P$ had been published. The conclusion of this review was that sick leave could be reduced only after at least 100 hours of multidisciplinary treatment. In our rehabilitation centre, we discussed the problem that our function centred treatment (FCT) did not include cognitive behavioural treatment by a psychologist for all patients because Serbo-Croatian, Alban, Turkish, Italian, Spanish and Portuguese were the native languages of the majority of patients. Another important reason why we did not want to limit our study to German speaking patients was because this would have reduced the external validity of our results, therewith limiting the use of its findings in our clinic. Furthermore, the duration of recruitment would have increased to approximately 5 instead of 2.5 years.

Some of the studies concerned with reducing sick days used treatments which were performed by a specialized physical therapist alone and only during 20 hours. Many effective treatments did not include cognitive behavioural treatment by a psychologist. Our results strongly support the evidence that intensive physical training or work hardening programs with a cognitive-behavioural component are more effective than ustal care in reducing work absenteeism in workers with non-acute LBP."

However, what we did not expect was that patients with a longer history of L.BP benefited more from the treatment. In half of the RCTs included in our meta-analysis sick leave in the control group was below 12 days and no benefit for the exercise group was demonstrated. These studies stated that they wanted to start treatment early to prevent chronic disability, as recommended by many guidelines. The results demonstrate how difficult it is to demonstrate an effect of early treatment. A recent review of primary prevention of LBP showed limited evidence for a moderate effect of exercise and no evidence at all for the effect of lumbar supporis and educational interventions."

Our results are confirmed by later reviews of exercise programs ${ }^{10-12}$ and are similar to another review on return to work interventions. ${ }^{13}$ The researchers concluded that multidisciplinary programs seem the most promising treatment and that exercise is allso effective in reducing days lost from work. Nevertheless, the underlying mechanisms of exercise leading to the observed effect remain unclear. The review further concludes that the evidence in favour of education is limited to an improvement in knowledge while no evidence for the effectiveness of ergonomic interventions could be found. ${ }^{13}$ The impressive effects of ergonomic interventions, demonstrated in a large multinational cohort study published after the previously mentioned review of return to work interventions, await confirmation by RCTs. ${ }^{14}$ A recent review of workplace interventions to prevent LBP among employees concluded that these interventions have to be considered with caution and that only exercise and comprehensive multidisciplinary interventions have a documented effect on LBP. ${ }^{5}$ The recently 
published European Guideline for the treament of chronic nonspecific $L B P^{8}$ confirms the results of our meta-analysis. It recommends cognitive behavioural therapy, exercise therapy, brief eclucational interventions and multidisciplinary (bio-psycho-social) treatment. Our FCT did not include physical therapy modalities (TENS, heat/cold, traction, laser, ultrasound, short wave, interferential, massage, corsets). These treatments are still not recommended or lack effectiveness in chronic LBP patients.

\section{RANDOMIZED CONTROLLED TRIAL}

Our study showed that FCT increased the number of work days compared with pain centred treatment (PCT). ${ }^{2}$ Even though many health professionals assumed that patients from Southeast Europe would have poorer results, the treatment effect turned out to be independent of nationality. We sent questionnaires to the employers and the patients" physicians to measure sick days in our trial. A recent study showed that the quality of data obtained from employers is better than data obtaned from patient questionnaires although the researchers did not find systematic differences. ${ }^{16}$

\section{The Balkan war}

When we planned the RCT during the late nineties, there was an increasing awareness for LBP-related disability. The direct and indirect costs from LBP-related disability increased rapidly. Many people mainly attribute these problems to citizens originating from Southeast Europe, especially former Yugoslavia. More important, however, seems the fact that persons from Southeast Europe are overrepresented in the group of unskilled workers at risk of becoming permanently disabled.

Switzerland employed a large number of unskilled workers from Yugoslavia before the Balkan war. Many workers returned to their country of origin after several years, reducing the number of applicants for a disability pension. During the Balkan war, a Jarge number of refugees came to Switzerland and the number of persons retuming to former Yugoslawia decreased. At the same time, the economy in Switzerland declined and the unemployment rate increased. Financial compensation is lower for unemployment than for disability, contributing to the increasing number of disability allowances related to LBP.

\section{Diagnosis}

When we planned the $\mathrm{RCT}$, I read some rewiews about diagnostic classifications for LBP. Most diagnostic classifications describe mutually exclusive subgroups. The Quebec Task Force and other experts distinguish between nonspecific and specific LBP. Although there is general consensus among guidelines for acute and chronic LBP recommending the use of red flags to diagnose specific LBP, even the evidence base for these red flags is quite narrow. ${ }^{17}$ 
There is some progress in the classification of nonspecific LBP based on the preferred direction of movement. ${ }^{18}$ Using this single characteristic is only a first step to describe subgroups of patients with non-acute nonspecific LBP. Nonspecific LBP is not a clinical entity and diagnosis, but rather a symptom of patients in very different stages of impairment, disability and chronicity. The bio-psycho-social model displays that nonspecific LBP is not a monocausal disease but is determined by multiple factors. Yellow flags can be regarded as prognostic factors reflecting the future course of LBP. European Guidelines ${ }^{8}$ recommend the assessment of work-related factors, psychosocial distress, depressive mood, severity of pain, functional impact, prior episodes of LBP, extreme symptom reporting and patient expectations. All these factors should be included in the diagnosis of patients with nonspecific chronic LBP. The number of patient profiles is almost unlimited. This makes diagnostic classifications of mutually exclusive diagnoses practically impossible. The precise identification of pain generators and pain mechanisms may be a topic for future research .

\section{Function centred treatment}

The effect sizes in our study are rather modest, which is in accordance with other results in many therapeutic procedures including cognitive-behavioural interventions encouraging activity and exercise. ${ }^{8}$

Multidisciplinary treatment is recommended for patients with non-acute LBP who have received monodisciplinary treatment options without success. ${ }^{8}$ FCT fulfilled the recommendation by the European Guideline for the treatment of chronic nonspecific $\mathrm{LBP}^{8}$ that defines 'true' multidisciplinary treatments as programs which have to include medical (pharmacological treatment, education), physical (exercise), vocational and behavioural components and have to be provided by at least three health care professionals with different clinical backgrounds (physician, physiotherapist, psychologist). All our patients were treated by a rheumatologist, a physical and occupational therapist trained in ergonomics, a sports therapist, a social worker, a nurse and a psychologist if required.

It seems that physical therapists should be specialized in this field. Exercise and advice provided by an unspecialized physical therapist was just as effective as one hour of advice in a recent trial in the United Kingdom. "In several other studies in our metaanalysis, exercise provided by a specialized physiotherapist alone was effective in reducing sick leave. 3

\section{INCONSISTENCY OF THE RESULTS OF A FUNCTIONAL CAPACITY EVALUATION}

There are similarities between the observation of test consistency during a functional capacity evaluation (FCE), presented in chapter 6, and the interpretation of the predictive tests for non-return to work, presented in chapter 2 . The predictive tests 
assess abnormal behavioural responses according to Waddell, as well as preliminary cessation of the step test and the triceps biachii pseudo-strength test. Our interpretation that positive results of these predictive tests cannot be explained by the mechanical consequences of non-acute nonspecific LBP is similar to the assessment of inconsistencies during an FCE.

These assessments offer objective tools for the management and treatment of patients with LBP. When I studied physiotherapy and manual therapy, I was taught to always believe patients. Considering non-mechanical reasons for limited capacify was associated with "not beliewing the patient" or even saying "the patient consciously simulated complaints'. This is not why we developed these tests. One of the most useful applications is preventing overuse of medical care. In general, patients with abnomal behavioural responses should not undergo back surgery. Rehabilitation in our centre is not successfull for patients with positive predictive tests for non-return to work. Furthermore, the limitation of physical capacity, used to determine the level of a disability allowance, should be assessed based on consistent test performance.

\section{FITNESS FOR WORK CERTIFICATES}

The results of the material handling tests in the FCT-group improved the quality of the fitness for work certificates (FWCs). The FWCs were less restrictive in the FCT-group than the PCT-group. ${ }^{20}$ One has to keep in mind that the work days" benefit in favour of the FCT-group, possibly was in part caused by the difference in FWCs. A nonrandomized study supports this hypothesis. ${ }^{21}$

Initially we planned to use identical procedures for the determination of fitness for work. and for FWCs in both treatment groups but this was not feasible. In the FCT-group work related physical capacity is a central issue during FCT. During rehabilitation, physicians in the FCT-group receive extensive information about work related physical capacity. In the PCT-group the primary focus is on the reduction of pain. The patients" progress in lifting capacity and other work related physical activities are not discussed routinely. FWCs in PCT are \#argely based on diagnostic information and impaiments while physical capacity is greatly disregarded.

\section{RECONDITIONING}

Patients with severe disability and 4 or more signs of the symptom magnification syndrome (SMS) did not improve endurance measured on a stationary bicycle. ${ }^{22}$

The values of maximum aerobic capacity presented in the SMS-group in our study must be interpreted with caution. They do not indicate deconditioning in a physiological. sense. The submaximal effort during testing also displays psychological limitations. In 
our study, 9 out of 10 patients with SMS did not reach maximum capacity, indicating that psychological factors were the limiting factor.

Two different definitions of the deconditioning syndrome are used. According to one description, the deconditioning syndrome includes both physiological aspects, such as decreased cardilovascular endurance and muscle strength, and psychological aspects, for instance behavioural responses to pain and coping behaviour. ${ }^{23}$ Recent publications introduced the term 'disuse syndrome' for physical, psychological and social changes caused by prolonged decrease in the level of physical activity. ${ }^{24}$ The term deconditioning by this second definition only included physical changes, such as muscle atrophy, changes in metabolism and obesity, and functional changes including decreased cardiovascular capacity, decreased muscle strength and impaired motor control.

Some studies doubt whether deconditioning plays a role in disability and rehabilitation of patients with chronic LBP because some authors argued that the physical activity level (PAL) of patients with chronic LBP and controls was the same. ${ }^{25}$ Other studies found a reduction of the PAL in patients with chronic LBP. ${ }^{24}$ The contradictory results are probably caused by different methods of assessment and different degrees of disability among the investigated populations. I assume that patients in the SMS-group were deconditioned because most patients were unemployed and had a long history of sick leave, leading to a reduced PAL compared to their previous life performing heavy work.

Some experts advocate reconditioning in patients with 2 or more positive predictive tests for non-return to work and criticized us for excluding these patients from our RCT. All patients in the SMS-group had 2 or more positive predictive tests for non-return to work. The results of this reconditioning study support our opinion that treatment to improve endurance and physical capacity is not indicated for patients with SMS.

\section{Limitations}

\section{THE PROBLEM OF LBP-RELATED DISABILITY IS FAR FROM RESOLVED}

The research presented in this thesis and the large number of other studies of the past decade contributed to some progress in the management of LBP-related disability, but overall, the results are' still unsatisfactory and the problem is obviously far from resolved. There are over 1000 RCTs concerning nonspecific back and neck pain and related disability, and numerous systematic reviews, meta-analyses end evidence-based guidelines. Nonspecific back pain is probably the most thoroughly studied nonspecific pain condition. 


\section{UNSKILLED WORKER}

Many unskilled workers in our study have been performing heavy work for over 20 years. The salary for heavy work is much higher than for light work. Work related physical capacity declines with age, yet age-related decline in physical capacity does not entile people to receive a disability allowance. If physical capacity declines, the worker is therefore expected to reduce work load and find lighter work. The consequence is a reduction of the salary of up to $40 \%$ at an age between 40 and 50 . At this age, the expenses of many workers with a family and children are high. This circumstance contributes to the fact that many unskilled workers perform heavy work for too many years. It may also explain why the investigated FCT was less effective in heavy workers.

Heavy workers can improve their value on the working market and their salary by participating in continuing education, changing their job and thereby reducing their workload. Most Swiss brick layers further qualify themselves and perform lighter work within 10 years after becoming a brick layer. The majority of unskilled workers in our RCT had insufficient cognitive capabilities and knowledge of the national language to participate in continuing education. Their value on the working market depends on their physical health and capacity. If this capacity declimes with age, their value on the working market decreases. A disability allowance improves their financial situation compared with unemployment benefits. The low level of education further explains why FCT was less effective for unskilled workers.

\section{Impact of this research}

\section{APPLICATION OF PREVIOUS RESEARCH EVIDENCE}

From a researcher"s point of view it may not be clear why this research was needed. Since 1987, guidelines for the treatment of LBP advocate active treatment and return to work as primary goal. "Dissemination of research results and changing treatment habits of health care professionals is time-consuming and involves much effort from researchers and clinicians. When we started our research, treatment in Switzerland was not according to these guidelines. Similar situations have been described in other countries. ${ }^{26}$ We think that our research significantly contributed to the development of the rehabilitation of patients with LBP in Switzerland during the past years. 


\section{REHABILITATION OF PATIENTS WITH POSITIVE PREDICTIVE TESTS IFOR NON- RETURN TO WORK}

The cohort study confirmed the predictive validity for non-return to work of the 4 tests and induced a change in clinical practice. Before this cohort study, patients who were considered unlikely to retum to work had on average a llength of stay (LOS) in our rehabilitation centre which was 7 days longer. The treatment was predominantly based on a bio-medicall model. Physicians and therapists overused diagnostic procedures and frequently applied passive treatments. Physicians found it unacceptable to stop rehabilitation as long as the patients' symptoms did not improve. Therefore, patients with positive predictive tests for non-return to work had longer LOS. In spite of the longer LOS, pain and disability increased and return to work was $<5 \%$ for patients with positive predictive tests. The cohort study increased our knowledge about the biopsycho-social model and its application on patients with chronic nonspecific LBP. The development of our FCT was accelerated. We reduced the application of PCT on this patient group and LOS decreased for patients with positive predictive tests for nonreturn to work.

\section{Recent research}

Regarding the enormous research efforts during the past decade, the advances in patient outcomes have been disappointing, 10 years ago, the First Primary Care Forum in Seattle formulated priorities for future research, including the identification of subgroups of patients requiring specific treatment, possibilities to reverse the epidemic of LBP disability and costs, the identification of effective primary care, psychosocial interventions and other treatments. None of the issues have been definitely resolved ${ }^{27}$ it seems that, on the level of patient outcomes, a 'back pain revolution', as Gordon Waddell named his book ${ }^{28}$ "has not taken place. The only "revolution" may be, that many health professionals have changed their way to look at LBP from a biomedical to a bio-psycho-social perspective.

Some progress has been made in the treatment of patients with non-acute nonspecific LBP. Research showed that patient expectations should be considered in treatment planning. An RCT compared the effectiveness of acupuncture and massage and recorded patients' expectations before treatment. Patients who expected greater benefit from massage than from acupuncture were more likely to experience better outcomes with massage, and vice versa. ${ }^{29}$ Work related outcomes were not assessed in this study. 


\section{Future research}

\section{ADMISSION CRITERIA}

Depending on the research question, future research about patients with non-acute honspecific pain could include patients with lumbar, thoracic as well as cervical pain. This would facilitate patient recruitment. Several arguments can be made to do so. Multidisciplinary management is similar for all patients with non-acute nonspecific back pain. Management is tailored to the individual needs of the patient. An assessment of the patient's physical capacity is compared with his job profille to determine work related deficits. Activities for work specific training are selected based on these deficits. The same principle is applied for the management of other barriers to return to work, such as the presentation of fear avoidance behaviour. Among all factors influencing the future course of the patient"s complaints and work related disability, the fact whether the pain is localized in the lumbar or other part of the back is only of minor importance. Finally, a clear distinction between lumbar and other back pain can often not be made. More than $30 \%$ of the patients with the diagnosis of non-acute LBP have widespread pain $^{30}$ and/or other related comorbidity. We made similar observations in our cohort study and RCT. Other authors performed studies in mixed groups of patients with lumbar, thoracic, cervical or diffuse back pain. ${ }^{31-39}$

\section{BEHAVIOURAL TREATMENT IN PHYSIOTHERAPY}

Future research could improve the application of cognitive behavioural principles in physiotherapy. I think a clear distinction between exercise therapy based on physiological principles, and cognitive-behavioural treatment, is impossible. Exercise which does not influence behaviour is very rare or even inexistent. As others have stated, "the "active ingredient" of exercise programmes is largely unknown." I think that in the majority of applied exercises, behavioural mechanisms probably play the most important role and further investigations are needed in this field of physiotherapy. Research could help to develop behavioural treatment which can be applied by physiotherapists. In a second phase, research could evaluate the application of behavioural treatment. Our investigation of the health professionals" compliance to the treatment protocol of the PCT and the FCT was a small step into this field. Results showed that it is more difficult for health professionals to focus on function than to focus on pain.

\section{PASSIVE PHYSICAL TREATMENTS}

1 do personally not recommend research evaluating the combination of certain passive physical treatments for symptomatic pain relief with more "active" treatments aimed at reducing disability (e.g. massage, hot packs or TENS together with exercise therapy). 
Others gave this recommendation", probably based on research funded by Proctor and Gamble who developed a new thermal treatment which was successfully used for patients with acute LBP in a study with a follow-up duration of 4 days. ${ }^{40}$ From ny experience in the rehabilitation of patients with $L B P$, passive physical treatments decrease the patients' self efficacy. If the 'feel-good-trip' of passive treatments for pain relief decreases activity, patients may end up in a "feel-good trap". We did not include these treatment options in our FCT because we consider then to reward pain behaviour and we feared that they may increase the patients' focus on pain. Who knows, maybe future research will show us that massage and hot packs are of greater vallue in functional restoration programs than I consider them today.

\section{PREDICTORS OF OUTCOME}

Predictors of outcome need further assessment. Important factors are treatment credibility, stages of change, expectations regarding outcome, beliefs (coping resources, fear-avoidance) and catastrophising. ${ }^{8}$ In my opinuon a serious problem is that predictors differ between groups of patients and settings, limiting the external validity of studies about predictive factors. A possible relief of this problem could be the development of generally applicable systems using regression analysis to develop models for treatment planning and outcome prediction. This method is used in the rehabilitation of stroke patients. Demographic variables and pre-treatment measurements are used to develop predictive equations for several outcomes such as mobility and arm function, length of stay and for the place of living after rehabilitation. ${ }^{41}$

\section{DifFERENTIATING AGE-RELATED FROM LOW BACK PAIN-RELATED LIMITATIONS IN PHYSICAL CAPACITY}

Research should develop instruments that can differentiate age-related and LBP-related changes in physical capacity. Health insurances have denied paying for rehabilitation in our centre because they considered themselves not responsible for rehabilitation to improve return to work. This opinion can be supported by the fact that plysical capacity reduces with increasing age. Consequently, health insurances are not responsible for financing the treatment of age related changes. They should, however, support the rehabilitation of a LBP-related decline in physical capacity. Sometimes it can be quite difficult to assess whether insufficient physical capacity was caused by age ot $L$ BP.

\section{IMPROVING MANAGEMENT}

A major barrier to improved management is the fact that different insurance companies pay treatment, sick leave compensation and disability allowances. The European Guidelines recommend that "studies are needed to determine how and by whom interventions are best delivered to specific target groups". It is important to broaden the 
focus of research from "treatment" (looking at single interventions) to "management" (evaluating multidisciplinary treatment). ${ }^{42}$ I doubt whether primary physicians have the expertise to plan optimal management strategies for individual patients with nonspecific LBP who do not return to work within four weeks. In addition, there are no incentives for primary physicians and physiotherapists who take the effort to improve the work activity of patients with LBP. Many patients who consider themselves uncapable of returning to work change their physician if he or she does not agree with sick-listing. Physiotherapists in primary care are in a similar situation.

Specialists from rehabilitation centres and the Disability Insurance usually come into action after several months which is too late. Sick leave compensation insurances increasingly employ case managers particularly for patients with a whiplash injury and other patients at risk of developing high indirect costs. This recent development is now seriously considered in our centre because we have repeatedly felt that insufficient participation of all involved parties prevents successful rehabilitation. Research should evaluate the effectiveness of this managed care.

\section{Conclusion}

This was the final chapter of my thesis about patients with disability related to nonacute nonspecific LBP. I have discussed the main results, the limitations and the impact of this research on physiotherapy and rehabilitation, as well as my recommendations for future research.

Our predictive tests are far from perfect, but at this moment no other tests are available for patient selection. Our neta-analysis was the first to demonistrate that exercise reduces sick leave. The results are in line with later publications. The RCT showed that multidisciplinary FCT reduces the number of days lost from work. Compared with other treatments, our intervention included only little cognitive psychological treatment. Current evidence confirms that behavioural aspects as applied in our study are sufficient to improve the outcome. I assume that future diagnostic classifications for patients with non-acute nonspecific LBP will not use mutually exclusive subgroups of patients but describe patient profiles using work-related, physical, psychological, and social factors.

I recommend future research in patients with nonspecific back pain without the restriction to the lower back, which is possible in several research questions. Research in the field of behavioural physiotherapy has only recently started and should therefore be continued. I doubt whether predictors for outcome are generally applicable. I therefore suggest developing clinically applicable systems to form local prediction models tailored to the patient population of each specialist centre. Most importantly, I propose that the management of patients with LBP-related disability should be reorganized. This needs cooperation between health care insurances, sick leave compensation insurances, the Disability Insurance and politicians. 


\section{References}

1. Kool JP, Oesch PR, de Bie RA. Predictive tests for non-return to work in patients with chronic low back pain. Eur Spine J $2002 ; 11(3): 258-266$.

2. Kool J, Oesch $P$, Bachmam $S$, Knüsel $O$, de $B$ te $R_{a}$ van den Brandi $P$. Increasiog days an work using function-centered relabilitation in non-acute non-speciffe low back pain a randonized controlled trial. Arch Phys Med Rehabil 2005;86(5):857-864.

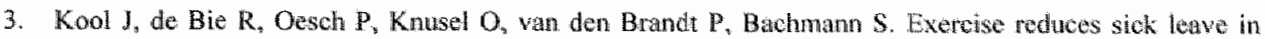
patients with non-acute non-specific low back pain: a meta-analysis. I Rehabil Med 2004;36(2);49-62.

4. Spitzer. Quebec Task Force Report. Spine 1987;12(7):\$10-\$53.

5. van Tulder MW, Koes BW, Bouter $L M$. Conservative treatment of acute and cluronic non-specific low back pain. A systematic review of randomized controlled trials of the most common interventions. Spine 1997:22(18):2128-2156.

6. van der Weide WE, Verbeek $\mathrm{JH}$, van Tulder MW. Vocational outcome of intervention for low-back pain. Scand J Work Enwiron Health $1997 ; 23(3): 165-178$.

7. Guzmen J, Esmail R, Karjalainen K, Malmivaara A, Irwin E, Bombardier C. Multidisoiplinary rehabilitation for chronic low back pain: systenatic review. BMJ 2001;322(7301):1511-1516.

8. Hildebrandt J, Airaksinen O, Brox J, Cedraschi $\mathrm{C}$, Klaber-Molfet J, Kovacs $\mathrm{F}$, AF M, Reis S, Staal I. Ursin $\mathrm{H}$, Zanoli $\mathrm{G}$. European guidelines for the management of chronic non-specific low back pair: COST B 33 Working Group, 2004.

9. van Poppel MN, Hooftman WE, Koes BW, An update of a systematic review of controlled elinical trials on the primary prevention of back pain at the workplace. Occup Med (Lond) 2004:54(5):345-352.

10. Liddle SD, Baxter GD, Gracey JH. Exercise and chronic low back pain: what works? Pain 2004;107(12): 176-190.

11. Rainville J, Ahern DK, Phalen L, Childs LA, Sutherland R. The association of pain with physical activities in chronic low back pain. Spine 1992;17(9):1060-1064.

12. Hayden JA, van Tulder MW, Malmivaara AV, Koes BW. Meta-analysis: exercise therapy for monspecilic low back pain. Ann Intern Med 2005; 142(9):765-775.

13. Staal JB, Hlobil H, van Tulder MW, Koke AJ, Smid "T, van Mechelen W". Return-tomwork interventions for low back pain: a descriptive review of contents and concepts of working mechanisms. Sports Med $2002 ; 32(4): 251-267$

14. Anema I, Cuelenaere B, wan der Beek A, Knol D, de Vet $H$, van Mechelen W. The effectiveness of ergonomic interventions on return-to-work after low back pain; a prospective two year colort study in six countries on low back pain patients sicklisted for 3-4 months. Occup Environ Med 2004;61:289-294.

15. Tveito TH, Hysing M, Eriksen HR. Low back pain interventions al the workplace: at systematio literature review. Oecup Med (Lond) $2004 ; 54(1): 3-13$.

16. van Poppel MN, de Vet HC, Koes BW, Smid T, Bouter U.M. Measuring sick leave: an comparison of selfreported data on sick leawe and data from company records. Occup Med (Lond) 2002;52(B):485-490.

17. wan den Hoogen HM, Koes BW, van Eijk IT, Bouter LM. On the accuracy of history, physical examination, and erythroeyte sedimentation rate in diagnosing low back pain in general practice. A criteria-based review of the literature. Spine 1995;20(3):318-327.

18. Long A, Donelson R, Fung T. Does it Matter Which Exercise? A randomized controlled tial of exercise for low back pain. Spine 2004;29(23):2593-2602.

19. Frost H, Lamb SE, Doll HA, Carver PT, Stewart-Brown S. Randomised controlled triali of physiotherapy compared with andvice for low back pain. BMill 2004;329(7468):708.

20. Oesch P. Kool J, Bachmann S. Devereux I. The influence of a functional capacity evaluation on fitness for work certifieates in patients with non-specific chronic low back pain. Work 2005, utecepled.

21. Hall H, Melntosh $G$, Melles $T$, Holowachuk $B$, Wai E. Effect of discharge recommendations on outcome. Spine 1994;19(18):2033-2037.

22. Oesch P, Bircher S, Kool J, Knäsel O, Bachman S. Trainierbarkeil von Patienten mit chronisclacn Rückenbescherden in einer funktionsorientierten Rehabilitation: Wie wichlig sind die Hinweise aul" Symptomausweitung? Phys Med Rehab Kurort 2003;13:1449-1158. 
23. Mayen $T$; catchel: $\mathbb{R}$. Functional restonation for spinal disorders: the sports medicine approach. Philadelphia: Lea and Febiger 1988:8-9.

24. Verbunt JA, Seelen HA, Vlaeyen JW, yan de He jiden GJ. Heuts PH, Pons K, Knotnerus JA Disuse and decondhioning in chuonic low back pain concepts and hypotheses on contributing mechanusms. Eur $J$ Pain $2003 \% 7(1) 9-21$

25. Hazard RO, Genwck JW, Kalisch SM, Redmond J, Reeves V, Reid S, Frymoyer JW. Functional restoration with behavional suppont. A one-year prospective study of patients with chronic low-back pain. Spine $1989 ; 42 \% 157-161$.

26. Ratrvile 1, Carlson N, Bolatm P. Gatehel RJ, Indall A. Bxplotation of physicians recommendations for activities in dhonic bow bak pan. Spine $2000,25(17): 2210-2220$.

27. Chetkin D. Is the back pain Theld moving forward. Alberta International Forum VII 2005, Edmontom, Ciniatla:

28. Waddell G. The back pain revolution: Chutchill Liwingstone, Edinburgh, 1998 .

29. Kalauokalani D, Cherkin DC, Sheman KJ. Koepsell TD, Deyo RA. Lessons from a tral of acupumcture and massage for low back pant patient expectations and treatment effects. Spine $2001,26(13): 1418-1424$.

30. Von Korf M, Crane P, Lame M, Migliorett DL, Simon G, Saunders K, Stang P, Brandenburg W, Kessler R. Chronic spinal pain and physical-mental comorbidity in the United States: results from the national comorbidity survey replicaition. Paim 2005;113(3):331-339.

31. Inton $S J$, Bradley LA, Jensen I, Spangfore $\mathbb{E}$, Sundel L. The secondary prevention of low back pain: a controlled study with follow-tip: Pain 1989;36(2):197-207.

32. Linton $\mathrm{SJ}$, Ryberg M. A cognitive-behavioral group intervention as prevention for persistent neck and back pain in a non-patient population: a randonized controlled trial. Pain 2001;90(1-2):83-90.

33. Loisel P. Abenhaim L, Durand P, Esdaile M, Suissa S, Gosselin L, Smard R, Turotte J, Lemaire J. A population-based, randomized clinical tral on back pain management. Spine 1997;22(24):2911-2918.

34. Haldorsen EMH, Kronholm $\mathrm{K}$, Skouen IS, Ursin H. Multimodal cognitive behavioral treatment of patients sicklisted for museuloskeletal pan: A randomized controlled study. Scandinavian Journal of Rheumatology $1998 ; 27(1): 16-25$.

35: Henmila HM, Keinanen-Kkikaamiemi SM, Levoska $S_{n}$ Puska P. Does folk medicine work? A randomized elinical trial on patients with prolonged back pain. Arch Phys Med Rehabil 1997; 78(6):571577.

36. Jensen $1 B$, Bodin L. Multimodal cognitive-behavioural treatment for workers with chronic spinal pair: $A$ matehed cohort study with an 18-month follow-up. Pain 1998;76(1-2):35-44.

37. Kellet KM, Kellet DA, Nordholm LA. Effects of an exereise progran on sick leave due to back pain. Phys Ther 1991; 1 14):283-201.

38. Rossignol M, Abenthin $\mathrm{L}$, Seguin P, Neveu A, Collet JP, Ducruet T, Shapiro S Coordination of primary health eate for back pain. A randomized controlled trial. Spine 2000:25(2):251-258.

39. Willams AC, Richardson PH, Nicholas MK, Pither CE Harding VR, Ridout KL, Ralphs JA, Richardson H. Justins DM, Chanbertain JH. Inpatient vs. outpatient pain management: results of a randomised controtled trial Pain 1996;66(1):13-22

40. Nadler Si, Stener D., Grasaln GN, Hengehold DA, Hinkle RT, Beth Goodale M, Abeln SB, Weingand KW. Continuous low-level hoa wrap therapy provides more effeacy than lbuprofen and acetaminophen for acute low back pain. Spine 2002;27(10):1012-1017.

41. Gowland C, Van Hullenaar S, Torresin W, Moreland J, Vanspall B, Barreca S, Ward M, Hujibrechts M, Strationd P, Barclay-Goddard R. Chedoke-MoMaster stroke assessment, development. validation and administration manual. Hamilton: McMaster Press 1995.

42. Wyatt M. Underwood MR, Sicheel IB, Cassidy JD. Nagel $\mathbb{B}$. Back pain and health policy research: the what, why, how, who, and whan. Spine $2004 ; 29(20): \mathrm{E} 468-475$. 


\section{Summary}

This thesis concerns the rehabilitation of patients with low back pain (LBP)-related sick leave. The primary purpose of treatment is the reduction of sick leave. Physical therapists play an important role in the treatment and assessment of physical capacity of such patients.

LBP is specific in only $15 \%$ of all cases. Examples of specific cases are vertebral fractures, spinal stenosis with compression of the spinal cord, rheumatoid arthritis and tumour. In case of specific LBP, treatment mainly focuses on the cause of the disease. In $85 \%$ of the cases LBP is nonspecific which means that none of the above mentioned causes of LBP are diagnosed but the physical therapist notices that certain movements are painful and palpation of certain parts of the back may also provoke pain. The cause of LBP remains unclear. The lifetime prevalence of LBP is $90 \%$ indicating that LBP is normal and not at all exceptional. Sometimes the cause of LBP is specific, for example in case of a dise protrusion with nerve root compression. This condition may cause the back to get locked and pain may irradiate to one of the legs. In most of these cases spontaneous recovery is very good and within a week most patients will be able to resume their usual activities including work. This thesis concerns patients with nonspecific LBP who did not recover spontaneously.

Pain is a warning sign in acute complaints. Normally tissue damage is present and the function of increasing pain under mechanical stress is to prevent further damage. During recovery the pain decreases and the person can generally resume normal activities within three weeks. Sometimes pain persists and becomes chronic. Dealing with chronic pain is much more difficult because it is also interpreted as an alarm signal by the patient who of course wants to prevent pain. Accordingly, the treatments by physicians and physiotherapists are also focusing on pain reduction. This is contrary to the recommendations of international guidelines which focus on active treatment and movement in spite of pain.

In Chapter 1 I describe the most important steps of my career in research and explain why the different studies described in the following chapters were initiated. I became at physical therapist in 1980 and have been working in the rehabilitation centre Valens since 1984. I started to read scientific publications but my knowledge was insufficient to distinguish between studies of higher and lower methodological quality. At a party in December 1991 a colleague informed me that a 2-year Masters of Science program for physical therapists was planned to start in 1992. This moment was an important milestone in my career. I lived in Geulle with my family and studied in Maastricht from 1992. until 1994. After I returned to Valens I started to study the rehabilitation of patients with nonspecific LBP. By that time, the goal of treatment had shifted from pain 
reduction towards increasing activity resulting in an initial pain increase in several patients. One day a patient expressed his complaints about increased pain after workrelated training to Otto Knisel, the leading rheumatologist. Otto asked Peter Oesch to treat this patient twice daily with - predominantly passive - manual therapy. Peter thought the patient's complaints were primarily non-mechanical and preferred to continue active function centered treatment. Otto agreed with the proposed treatment but asked Peter to identify objective assessments to support similar observations in the future. This initiated the use of the assessment of behavioural responses during examination as described by Gordon Waddell. We had also observed that several patients showed themselves incapable of performing two simple active tests, and that some patients complained about extremely high pain intensity. We started a cohort study to evaluate the predictive validity of these tests. Chapter 2 describes the results of this study. We then wanted to compare the effect of a function-centered (FCT) and a pain-centered treatment (PCT). The results of this study are presented in Chapter 4 and 5. When we planned this study we analyzed international studies in this field. This literature review is presented in Chapter 3 . The studies presented in Chapter 6,7 and 8 were conducted during the large randomized controlled trial (RCT).

Chapter 2 describes a cohort study in 99 patients with LBP-related sick leave and investigates which patients return to work after rehabilitation. Before rehabilitation we assessed factors expected to be predictive for return to work. We were particularly interested in the correlation between work resumption and 4 tests: Waddell's behavioural responses, pain intensity on a Numeric Rating Scale from 0-10 and preliminary cessation of two active tests. During the 'Step-Test' the patient is asked to step up and down a 30 centimetre high step for 3 minutes. The 'Pseudo-Strength-Test'

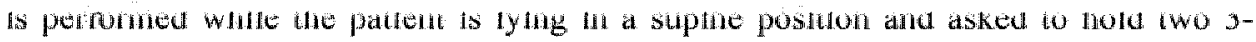
kilogram weights with extended arms towards the celling. These tests do not strain the lumbar spine or the arms. We also evaluated the association between work resumption and medical factors such as the diagnosis and the duration of the complaints. In addition, we recorded personal factors such as age, education, wationality and workload. Only $20 \%$ of the patients resumed their work after a year. Return to work could not be predicted from the variables collected before treatment but 2 or more of the 4 evaluated predictive tests were positive in $45 \%$ of the patients who had not returned to work after 1 year. Unemployment, nationality and workload were less predictive. Using the 4 predictive tests improves the cost-effectiveness of relhabilitation. Moreover, compared with the nationality of the patient, these tests are objective and not discriminating. We improved the efficiency of our research by excluding patients with 2 or more positive predictive tests from the randomized controlled trial presented in chapter 4 and 5 .

The meta-analysis presented in Chapter 3 evaluates whether exercise reduces sick leave in patients with non-acute nonspecific LBP. A meta-analysis in a literature review summarizes previous studies which is useful because comparable studies frequently 
come to opposite conclusions. In addition, many readers prefer reading one netaanalysis instead of 20 study reports. Meta-analyses are also used to develop healthcare guidelines. In our meta-analysis we included only RCTs. We searched 5 different databases and identified 14 RCTs. Methodological quality was poor in some studies and was rated with 4 to 8 points on an 8 -point scale. Quality was considered good in 12 out of 14 RCTs ( $79 \%$ ) with 5 or more points. In a second step we described the study results in two groups: 1) 13 comparisons between exercise and usual care, and 2) 9 comparisons between different forms of exercise. Exercise reduces the sick leave up to one year after treatment, compared with usual care. The effect is larger in higher quality studies. While various types of exercise were compared, the numbers of patients involved in these studies were too small to detect and demonstrate a difference. Due to insufficient results we were unable to evaluate the effect of exercise on the number of patients receiving a disability allowance. The standardized effect size (ES) of the number of sick days one year after treatment with exercise was small (ES $=-0.24$ ). Exercise was more effective in patients with more severe $\mathrm{LBP}(\mathrm{ES}=-0.30)$. The result of our meta-analysis is that exercise reduces sick leave. This is important for physical therapy.

Chapter 4 and 5 present the results of an RCT of patients with 6 or more weeks of sick leave related to non-acute nonspecific LBP before rehabilitation. The trial compares the number of work days during the year after the treatment. The patients were divided into two groups who received function-centered (FCT) or pain-centered treatment (PCT). Patients with two or more positive predictive tests for non-return to work (chapter 2) and patients whose insufficient knowledge of German or Italian prevented them to understand the instructions during the initial assessment were excluded. Between January 2000 and May 2003 we included 174 patients. Less than $50 \%$ were Swiss. We collected information about work, complaints, expectations from rehabilitation and satisfaction with treatment using questionnaires which were available in Gernan, Italian, Serbo-Croatian, Albanian, Turkish, French, Spanish, and Portuguese. A blinded independent physiotherapist performed the physical examination and assessment of all patients before and after treatment. A blinded secretary sent over 1000 questionnaires to the patients, physicians and employers for the follow-up assessments after 3 months.

Function-centered treatment $(\mathrm{FCT}, 4 \mathrm{~h} / \mathrm{d}, 6 \mathrm{~d} / \mathrm{wk}$ for $3 \mathrm{wks})$ consisted of work simulation, strength, endurance, and cardiovascular training. Return to work was the primary goal during FCT. Patients were repeatedly reassured that it was safe to move their back. Complaints were explained with loss of function caused by non-use. Therefore, the primary goal of treatment was to increase activity, even if pain initially increased. Pain should not be interpreted as harmful. The team members" role was to coach the patients. 
Pain-centered treatment $(\mathrm{PCT}, 2.5 \mathrm{~h} / \mathrm{d}, 6 \mathrm{~d} / \mathrm{wk}$, for $3 \mathrm{wks})$ used a mini back-school, individually selected passive and active mobilization, stretching, and low-intensity strength training. The reduction of pain was the primary goal of PCT. The ultimate goal was to facilitate retum to work. Complaints were explained to the patients by somatic findings such as disk degeneration, joint stiffness, and trigger points diagnosed in the clinical, inaging, and other examinations. Patients were instructed to reduce the intensify of exercise if pain increased, to avoid activities that increased pain, and to use modalities and relaxation if pain mereases.

Some minor problems occurred during the study. Some patients in the FCT-group noted an increase of pain and one patient in the same group insisted on having hot-packs for pain relief which was not in accordance with the treatment protocol. During the treatment phase, I patient in the FCT-group dropped out because he was diagnosed with necrosis of the head of the femur and underwent surgery. Following the intention-totreat principle, all patients were included in the analysis. Patients' satisfaction with treatment was comparable in the two groups indicating that the effort to keep patients unaware of any expected treatment advantage was successful. After treatment, lifting capacity, strength of the trunk flexors and extensors, and self efficacy had increased far more significantly in the FCT-group than in the PCT-group. Moreover, pain had decreased considerably in the FCT-group in spite of the fact that patients were encouraged to increase activity regardless of pain. One year later the number of work days was significantly larger in the FCT-group (118) than in the PCT-group and the effect-size was 0.35. After treatment pain increased in both groups and the difference was no longer significant after 3 months. The number of patients receiving unemployment benefits or a disability allowance was larger in the PCT-group but this difference was small and not significant. The work days' effect-size was greater among younger patients with a low workload $(10 \mathrm{~kg}$ are the maximum load to be lifted at work). In both groups the number of work days was smaller for unemployed patients but the effect-size was similar for unemployed and employed patients. Nationality had an effect on work days but the FCT-effect-size was independent of nationality.

We assessed potentially predictive demographic, physical, psychological and workrelated factors for workdays with a multiple regression analysis. $39 \%$ of the variance in work days could be explained by the maximum load lifted, behavioural responses to examination, pain intensity, unemployment, nationality and the patient's expectations about the possibility to return to work and workload. A 3-year follow-up study of costeffectiveness is planned. Expenses related to unemployment benefits and disability pensions will play an important role.

Chapter 6 investigates the results of a study concerning the assessment of a client's test consistency during a Functional Capacity Evaluation (FCE). FCEs are performed to determine a client's work-related physical capacity. An FCE includes 23 tests such as 
lifting, stooping, carrying, stair climbing and overhead work. We used 5 FCE-tests for" lifting capacity in the RCT described in chapter 4 and 5. FCEs are frequently used to determine the level of a disability allowance. Consistency of the different FCE-tests is important for the final FCE-report. Inconsistencies between FCE-tests are systematically observed using 13 items and interpreted as submaximal performance if 3 or more items are positive. The Swiss Disability Insurance uses FCE-reports to determine the level of a disability allowance. Inconsistent FCE-results may lead to a lower level of disability and a smaller disability allowance. It is important to validate the assessment of a client's inconsistency because disagreement of clients with the Disability Insurance's decision has often induced medico-legal issues. The purpose of this study was to analyze the internal consistency of the 13 consistency checkpoints of an FCE-test. We retrospectively analyzed 56 consecutive full FCEs and determined the internal consistency of the 13 items for inconsistent performance with Cronbach Alpha. A value $>0.6$ was considered satisfactory. Items with an item-total correlation of $<0.2$. were omitted from the scale. 3 or more inconsistencies in the FCE-results were found in 32 of 56 clients. The average number of inconsistent results was $3 / 13$ (range $0-9$, IQR 1 9) and $\geq 3.3$ redundant items were omitted. Internal consistency was satisfactory; 0.71 in the 13-point scale and 0.74 in the 11 -point scale. The results support the validity of the assessment of FCE-test consistency, its consideration in the determination of workrelated disability and its use in medico-legall issues.

Chapter 7 evaluates whether informing the physician about the FCE-results has an effect on Fitness for Work Certificates (FWCs). In the randomized controlled trial presented in Chapters 4 and 5 the physician issued the FWCs after rehabilitation. If patients received function-centered treatment (FCT) the physician was informed about the results of the FCE (FCE + ). This information was not available in the pain-centered treatment ( $\mathrm{PCT}$ ) group (FCE-). 3 raters independently used a 4-point scale to evaluate the quality of the FWCs. We computed intra-class-correlation coefficients to assess inter-rater reliability. We compared the time reduction and the limitation of workload in the FWCS of the two groups. Inter-rater reliability was satisfactory with ICCs between 0.77 and 0.92 . The quality of FWCs was signilicantly higher in the FCE+ group. The maximum workload was significantly heavier in the $\mathrm{FCE}+$ group. Time reduction was smaller in the FCE+ group but this difference was not significant $(p=0.07)$. Information about the results of an FCE improves the quality of an FCE and the attested level of fitness for work is higher.

Chapter 8 compares the effect of training on two groups of 10 patients with nonspecific chronic LBP. In our RCT (chapter 4 and 5) we excluded patients in case of preliminarily cessation of two active tests. Many of these patients were diagnosed with a Symptom Magnification Syndrome (SMS), defined as a conscious or unconscious socially reinforced pattern of reaction where pain spreads over a growing number of regions of the body and the complaints increasingly dominate the life of the patient and his or her 
social environment. The two groups of patients studied were an SMS-group with 4 or more SMS symptoms and a control group with a maximum of one SMS symptom. All patients received function-centered treatment including strength and endurance training for three weeks. Before the treatment the SMS-group's physical capacity was significantly lower than that of the control group. The improvement of isometric and dynamic hip and back extensor strength was smaller in the SMS-group. Power, oxygen intake and maximum heart rate measured on a stationary bicycle were significantly lower in the SMS-group. These values remained unchanged in both groups. The results of this study justify the exclusion of patients with SMS from our RCT:

Chapter 9 discusses the main results of this thesis. The predictive tests have improved the selection of patients for rehabilitation. Excluding patients with two or more positive predictive tests improved the power of our RCT. The meta-analysis assisted us to choose an appropriate outcome measure for our RCT. Earlier studies had used various methods to assess time lost from work and most of them had obvious disadvantages or were not feasible for use in Switzerland. The number of days at work appeared a practical measurement of work-related outcome. The results of the RCT were somewhat unexpected because most previous studies comparing the effect of two treatments did not find a significant difference in treatment effect. The difference in work days between the FCT and PCT was independent of nationality. Patients who performed heavy work profited less from FCT.

One limitation of the research presented in this thesis is that in spite of the effect of FCT the problem of work-related disability is obviously far from resolved. Poorly educated people with heavy work find no help in our health care system because the age-related decline in physical capacity is not a disease. People who are no tonger capable of performing heavy work have to find lighter work and consequently accept a reduction of their salaries.

Future research should improve the identification of patients who benefit from various available treatments. Behavioural treatment used within physical therapy should be further studied and improved. I doubt whether the combination of active treatment with modalities such as hot packs increases outcome in patients with chronic nonspecific LBP but future studies will answer this question. High priority should be given to improve the organisation of health care, the cooperation between the involved insurances, and incentives should make return to work financially attractive for workers, employers and insurers. 


\section{Samenvatting}

Dit proefschrift gaat over de revalidatiebehandeling van patiënten met ziekteverzuim ten gevolge van aspecifieke lage rugklachten. Het primaire doel van de behandeling is de reductie van het ziekteverzuim. Fysiotherapeuten spelen daarbij een belangrijke rol, zoals ook bij de beoordeling van de fysieke conditie van de patiënten.

Slechts $15 \%$ van alle lage rugklachten zijn specifiek. Specifieke oorzaken zijn bijvoorbeeld een wervelbreuk, een vernauwing van het wervelkanaal die het ruggenmerg comprimeert, ernstige beschadigingen door rheumatoide arthritis of een kankergezwel. In zulke gevallen richt de behandeling zich grotendeels op de oorzaak van de klachten. Bij ongeveer $85 \%$ van de mensen zijn de rugklachten 'aspecifiek'. Er kunnen geen ernstige aandoeningen, zoals hierboven beschreven, vastgesteld worden. De fysiotherapeut stelt bij zijn onderzoek veelal vast dat bepaalde bewegingen pijn doen en dat de rug drukgevoelig is. De ontstaanswijze van aspecifieke lage rugklachten is vooralsnog onduidelijk. $90 \%$ van de mensen krijgt in zijn leven minstens éen keer last van lage rugklachten. Rugklachten zijn dus iets normaals. Soms is de oorzaak van de rugklachten wel specifiek, bijvoorbeeld een 'hernia' met een acute inklemming van een zenuwwortel waarbij de rug vaak plotseling 'vast zit' en de pijn kan uitstralen naar een been; hiervan is het verloop in het algemeen heel goed. Binnen een week kunnen de meeste mensen hun normale werk weer doen. In dit proefschrift gaat het om mensen met aspecifieke rugklachten waarbij de pijn niet vanzelf overgaat.

Bij acute klachten heeft pijn een waarschuwende functie. Er is meestal sprake van weefselbeschadiging en de toename van de pijn bij bellasting dient om verdere schade te voorkomen. Gedurende het weefselherstel neemt de pijn af en de patient hervat in de regel spontaan de gebruikelijke activiteiten. Soms blijft de pijn bestaan en wordt ze chronisch. De omgang met chronische pijn is veel moeilijker omdat ook chronische pijn door de patiënt vaak als alarmsignaal geinterpreteerd wordt. Het is logisch dat patienten pijn willen vermijden. Ook de behandeling door huisartsen en fysiotherapeuten is meestal gericht op pijnbestrijding. Deze behandelling is in tegenspraak met de internationale richtlijnen, die sinds 20 jaar aanbevelen om ondanks de pijn zo normal mogelijk te bewegen.

In Hoofdstuk 1 beschrijf ik de belangrijkste stappen in mijn loopbaan en leg ik wit wat de aanleiding was voor het onderzoek dat in de volgende hoofdstukken beschreven wordt.

In 1980 sloot ik mijn opleiding tot fysiotherapeut af. Sinds 1984 werk ik in een revalidatiecentrum in Valens, Zwitserland. Ik las wetenschappelijke publicaties maar mijn kennis was onvoldoende om goed van slecht onderzoek te onderscheiden. In december 1991 hoorde ik op een feest dat er in Maastricht in 1992 een tweejarige 
onderzoeksopleiding starte voor gediplomeerde fysiotherapeuten. Dit werd een belangrijke mijlpaal in mijn loopbaan! Van 1992 tot 1994 woonde ik met mijn gezin in Geulle en studeerde in Maastricht. Na mijn terugkeer in Valens hield ik me bezig met de behandeling van patienten met aspecifieke lage rugklachten. Het doel van de revalidatie was verschoven van pijnreductie naar toename van activiteit. Bij sommige patiënten resulteerde deze behandeling aanvankelijk in meer pijn. Op een dag klaagde er een patient bij Otto Knlisel, de chef-arts, over toename wan de pijn na fysiotherapie. Otto vroeg aan Peter Oesch om deze patiënt twee keer per dag met - vooral passieve manuele therapie te behandelen. Volgens Peter waren de klachten echter niet primair mechanisch. Hij wilde de patiènt daarom liever actief behandelen. Otto ging daarmee akkoord maar hij vroeg Peter om objectieve tests te zoeken om zijn beoordeling beter te kunnen funderen. Dit was de aanleiding om een test van Gordon Waddell te gaan gebruiken. Ons viel verder op, dat patiënten vaak niet in staat waren om een tweetal eenvoudige actieve tests uit te voeren, en dat ze vaak over zeer sterke pijn klaagden. Om de voorspellende waarde van deze tests te onderzoeken startten we het onderzoek dat in hoofdstuk 2 beschreven wordt. $\mathrm{Na}$ dit eerste onderzoek wilden we weten of er een verschil in effectiviteitt wan de actieve behandeling (function-centred treatment, $\mathrm{FCT}$ ) en de pijnbehandeling (pain centred treatment, PCT) bestond. De resultaten hiervan worden in hoofdstuk 4 en 5 beschreven. In het kader van de voorbereidingen bekeken we internationale studies die er op dit gebied al waren. Dit literatuuronderzoek wordt in hooldstuk 3 beschreven. Het onderzoek dat in hoofdstuk 6,7 , en 8 wordt beschreven werd gelijktijdig met de effectiviteitstudie uitgevoerd.

Hoofdstuk 2 beschrijft een cohort-onderzoek bij 99 patiënten met werkverzuim vanwege lage rugklachten met de vraag welke patiënten na de revalidatie weer aan het werk gaan. Bij alle patiënten hebben we voor de revalidatie gegevens verzameld warvan we verwachtten dat ze een prognose, ofwell een voorspelling gaven voor de werkhervatting na de revalidatie. Wat ons vooral interesseerde was, of de werkhervatting samenhing met 4 tests: de test van Waddell, de intensiteit van de pijn zoals die door de patient op een schaal van 0 tot 10 aangegeven wordt, en het voortijdig beeindigen van 2 actieve tests. Bij de "step-test" moet de patiënt gedurende 3 minuten op en vanaf een 30 centimeter hoge kist stappen. Bij de "pseudo-armkracht-test" ligt de patiënt op de rug en moel gedurende 2 minuten met vertical gestrekte armen in elke hand een gewicht van 3 kilo vasthouden. Deze tests zijn niet belastend voor rug en ammen. Verder keken we naar de samenhang tussen werkhervatting en medische gegevens zoals de diagnose en de duur van de klachten; en met persoonlijke kenmerken zoals leeftijd, opleiding, nationaliteit en het soort werk. Slechts $20 \%$ van de patiënten had ne een jaar hun werk hervat. Het bleek niet mogelijk werkhervatting betrouwbaar te voorspellen, maar $45 \%$ van de patiënten die niet meer aan het werk gingen hadden een positief resultaat bij 2 of meer van de 4 onderzochte tests. De voorspellende waarde van werkloosheid, nationaliteit en het soort werk was minder goed. Het gebruik van de 4 
tests verbetert de kosteneffectiviteit van de revalidatie. De tests zijn in tegenstelling tot het gebruik van nationaliteit objectief en niet discriminerend. Bij het effectiviteitsonderzoek dat in hoofdstuk 4 en 5 beschreven word: hebben we patienten met 2 of meer positieve tests uitgesloten. Dit verhoogde de efficientie van het onderzoek.

De 'meta-analyse' die in Hoofdstuk 3 beschreven wordt, onderzoekt de vraag of 'oefentherapie' bij patiënten met aspecifieke, niet-acute lage rugklachten invloed heeft op het ziekteverzuim. Een meta-analyse is een literatuuronderzoek dat eerdere studies samenvat. Dat is zinvol ondat vergelijkbare studies valk niet tot dezelfde conclusies komen. Ten tweede lezen geünteresseerden liever éen literatuuroverzicht dan 20 afzonderlijke studies. Meta-analysen worden ook gebruikt voor behandelrichtlijnen in de gezondlzeidszorg. We beperkten de meta-analyse tot gerandomiseerde gecontroleende studies (RCT's). In 5 databases vonden we 14 RCT's. De methodologische kwaliteit liet gedeeltelijk te wensen over en bedroeg 4 tot 8 punten op een 8 -punts schaal. Bij 12 van de 14 RCT's (79\%) werd de kwaliteit met 5 of meer punten als 'goed' beoordeeld. In een volgende stap beschreven we de studies in twee groepen: 1) 13 vergelijkingen tussen oefentherapie en de "nomale behandeling" die in de regel door de huisarts uitgevoerd wordt en waarbij vooral medicatie voorgeschreven wordt, en 2) 9 vergelijkingen tussen 2 of 3 verschillende vormen van oefentherapie. Oefentherapie reduceert in vergelijking met de normale behandeling het aantal dagen ziekteverzuim tot 1 jaar na de behandeling. Het effect is groter in studies met een betere methodologische kwaliteit. Tussen diverse soorten oefentherapie bestaat geen verschil maar het aantal onderzochte patiënten was te klein om relevante verschillen aan te tonen. Er was onvoldoende onderzoek voorhanden om de invloed op het aantal WAO-uitkeringen te beoordelen. Als laatste stap bepaalden we de grootte van het effect met een standardized effect size (ES) Het effect van de behandeling op het ziekteverzuim in het jaar na de behandeling was klein (ES -0.24). Bij patiënten met sterkere rugklachten was oefentherapie effectiever en bedroeg de ES -0.30 . Oefentherapie reduceert dus het ziekteverzuim, een belangrijke conclusie voor de fysiotherapie.

Hoofdstuk 4 en 5 beschrijven een gerandomiseerd gecontroleerd effectonderzoek (RCT) bij patiënten tussen de 20 en 55 jaar met minstens 6 weken ziekteverzuim vanwege aspecifieke lage rugklachten voorafgaand aan de revalidatie. De trial verge lijkt het aantal werkdagen gedurende een jaar na een actieve (function centered treatment, FCT) versus een pijngerichte behandeling (pain centered treatment, PCT. Patienten met een slechte prognose yoor werkhervatting ( 2 of meer positieve tests, zie Hoofdstuk 2) werden niet tot de studie toegelaten, evenmin als patiënten die onvoldoende Duits of Italiaans spraken om aan de behandeling deel te nemen. Tussen januari 2000 en mei 2003 werden 174 patiënten behandeld. Meer dan de helft van hen kwam uit het buitenland. Gegevens over werk, klachten, verwachtingen en tevredenheid werden verzameld met een vragenlijst in de moedertaal van de patiënt: Duits, Servokroatisch, 
Albainces; Turks, Italiaans, Spaans; Portugees of Frans. Een fysiotherapeute die niet in het revalidatiecentrum werkte verrichtte voor en na de behandeling de metingen bij alle patienten. Deze fysiotherapeute was "geblindeerd" dat wil zeggen dat ze niet wist welke behandeling de patienten waarbij ze de metingen utvoerde, kregen. Voor de evaluatie na 3 maanden en na een jaar stuurde een eveneens geblindeerde secretaresse meer dan 1000 vragenlijsten naar patiënten, huisartsen en werkgevers.

PCT (4 uar/dag, 6 dagen/week, 3 weken) bestond uit simulatie van werksituaties, krachttraining met apparaten en training met zwemvliezen om het uithoudingsvermogen te verbeteren. Gedurende FCT stond het doel van werkherwatting steeds centraal. De patienten werd uitgelegd dat er niets ernstigs met hun rug aan de hand was. De klachten werden verklaard door functieverlies als gevolg van het ontzien van de rug. Daarom was het belangrijkste doel van de behandeling actiever te worden, ook als daardoor aanvankelijk de pijn erger werd. Pijn diende niet als dreigende schade aan de rug geinterpreteerd te worden. De rol van de behandelaars was te vergelijken met die van een coach.

PCT (2 1/2 uur/dag, 6 dagen/week, 3 weken) bestond wit een mini-rugschoo』 en individuele actieve en passieve oefeningen voor beweeglijkheid, kracht en ontspanning. $\mathrm{Bij}$ PCT was pijnreductie het primaire doel. Het uiteindelijk doel was de hervatting van het werk. De klachten werden verklaard door de bevindingen van het klünisch en beeldgevend onderzoek zoals slijtage van de wervelkolom, stijve gewrichten en spierverhardingen. De patiënt kreeg het advies om bij een toename van de pijn de intensiteit van de oefeningen te reduceren en in het algemeen activiteiten die de pijn versterken, te vermijden.

Bij de studie verliep niet alles volgens plan. Sommige patiënten in de FCT-groep klaagden over een toename van de pijn. Bij één patiënte van de FCT-groep waren we gedwongen van het onderzoeksprotocol af te wijken ondat zij nadrukkelijk warmtepakkingen wenste; een behandelworm die in de FCT-groep niet toegestaan was. Bij een andere patiënt in de FCT-groep werd gedurende de behandeling vastgesteld dat de gewrichtskop van een heup afgestorwen was, wat een operatie noodzakelijk maakte. In overeenstemming met het "intention-to-treat"-principe werden beide patiënten in de analyse opgenomen. De tevredenheid met de behandeling was in beide groepen hetzelfde. Dat was een teken dat de patiënten in de twee behandelingen evenveel vertrouwen hadden en dat ze een eventueel door de onderzoekers verwacht voordeel van Eén van de twee onderzochte behandelingen niet bemerkt hadden. De FCT-groep had na de behandeling meer vertrouwen in de eigen fysieke prestaties, kon zwaardere lasten tillen en dragen, had meer kracht in de buik- en rugspieren en minder pijn. Het laatste was opvallend omdat er in deze groep gedurende de behandeling juist minder rekening werd gehouden met de pijn. Na een jaar was het aantal werkdagen in de FCT-groep met 118 significant groter dan in de PCT-groep met 74 werkdagen. De grootte van het 
effect was 0.35 . De pijn nam in beide groepen na de behandeling weer iets toe th het verschil was na 3 maanden niet meer significant. Het aantal werklozen en patienten die een WAO-uitkering kregen was groter in de pijngerichte groep, maar dit verschil was klein en niet significant. Het effect van de actieve behandeling was groter bij jongere patiènten die gedurende hun werk niet meer dan 10 kilo moeten tillen. Het aantal werkdagen was bij patiènten die vóor de revalidatie werkloos waren in beide groepen geringer maar het effect ofwel her verschil tussen de twee behandelingen was bij werklozen even groot als bij mensen met een baan. Ook de nationaliteit beinvloedde het aantal werkdagen, waarbij thet voordeel van de actieve behandeling bij alle nationaliteiten even groot was.

Met behulp van regressieanalyse werd onderzocht welke factoren het aantal werkdagen beïnloeden. Daarbij keken we naar demografische, fysieke, psychische en aan het werk gerelateerde factoren. 39\% van de variatie in werkdagen kon verklaard worden door het maximal gedragen gewicht, pijngedrag tijdens het onderzoek, de pijnintensiteit, werkloosheid, nationaliteit, de verwachting van de patiënt of werkhervatting mogelijk is en het maximale gewicht dat op het werk moet worden getild. Een kosteneffectiviteitsanalyse 3 jarar na de behandeling is gepland on het onderzoek af te ronden. Bij de kosten zullen de uitkeringen voor werkloosheid en WAO de grootste rol spelen.

Hoofdstuk 6 presenteert een onderzoek naar de beoordeling van de 'consistentie' van verschillende metingen binnen een functionele capaciteitsevaluatie (FCE). Een FCE dient om de werkgerelateerde fysieke capaciteit van een cliënt in kaart te brengen. Een FCE bestaat uit 23 afzonderlijke tests, bijvoorbeeld tillen, bukken, traplopen en werken boven het hoofd. Vijf FCE-tests voor het tillen werden in de effectiviteitsstudie van hoofdstuk 4 en 5 gebruikt. Een FCE dient ook vaak om de hoogte van de WAO. uitkering te bepalen. Bij de beoordeling van de fysieke capaciteit is het belangrijk dat de resultaten van de afzonderlijke FCE-tests logisch bij elkaar passen, zodat het FCEbericht op zich consistent is. Aan de hand van 13 items wordt de consistentie van de FCE-resultaten beoordeeld. Indien binnen een FCE 3 of meer inconsistenties optreden, wordt aangenomen dat de cliërnt niet de maximale prestaties toonde. Inconsistente resultaten tijdens een FCE kunnen ertoe leiden dat de invaliditeit lager beoordeeld wordt en de cliënt dientengevolge een lagere WAO-uitkering ontvangt. Het komt voor dat cliënten de beoordeling van de hoogte van de invaliditeit en de WAO-uitkering in een rechtszaak aanvechten. Het FCE-bericht en de beoordeling van de consistentie van de FCE-tests worden dan als bewijsmateriaal gebruikt. Daarom is het belangrijk om de validiteit, dat is de 'geldigheid', van de beoordeling ten aanzien van de consistentie te onderzoeken. We onderzochten retrospectief $56 \mathrm{FCE}$ 's en bepaalden de interne consistentie van de 13 items met Cronbach's Alpha. Een waarde boven de 0.6 beschouwden we als tevredenstellend. We onderzochten ook of de schaal onnodige items bevatte, wat zich uit in een slechte samenhang mel de totale score (item-total 
correlatie $<0.2$ ). Inconsistente FCE resultaten werden bij 32 van 56 cliènten gevonden. Het antal positieve iterns bedroeg gemiddeld 3/13. Drie van de 13 items waren overbodig. Cronbach"s Alpha van de 13 items was 0.71 en van de 10 items 0.74 . Deze resultaten ondersteunen de validiteit van de beoordeling van de consistentie van FCE tests en het gebruik van deze informatie voor de bepaling van de mate van invaliditeil bij do patienten en als bewijsmateriaal bij rechtszaken.

Hoofdstuk 7 onderzoekt de vraag of kennis van de resultaten van een FCE invloed theeft op de door de arts vastgestelde arbeidsgeschiktheid (AG). In de effectiviteitsstudie (Hoofdstuk 4 en 5 ) bepaalde de arts na de revalidatie de arbeidsgeschiktheid van de patienten. Bij de patiënten die een actieve behandeling ondergingen beschikte de arts over de resultaten van het FCE (FCE+). In de pijngerichte groep was dit niet het geval ( $(\mathrm{CE}-$ ). We beoordeelden de kwaliteit van de AG met een 4-punts beoordelingsschaal. Eerst keken we of de drie beoordelaars voldoende overeenstemden en bepaalden we intra-class correlaties (ICC). Daarna vergeleken we in de AG van de twee groepen de mate van de beperking van het aantal uren per dag en de zwaarte wan het werk. De overeenstemming tussen de beoordelaars was voldoende, de ICC's lagen tussen de 0.77 en 0.92. De kwaliteit van de AG's was significant beter bij de patiënten waar de arts beschikte over de informatie van het FCE. De maximale zwaarte van het werk was significant hoger in de FCE + groep. De door de arts vastgestelde beperking in de arbeidsgeschiktheid was geringer in de $\mathrm{FCE}+$ groep, dit verschil was echter niet significant $(p=0.07)$. Kennis van de resultaten van een $F C E$ verbetert de kwaliteit van de $A G$, en de vastgestelde arbeidsgeschiktheid is hoger.

Hoofdistuk 8 vergelijkt het effect van training bij twee groepen van 10 patiënten met aspecifieke chronische lage rugklachten. Patiënten die nauwelijks tot activiteit bereid waren en twee actieve tests voortijdig afbraken, werden uitgesloten van het RCT (lloofdstuk 4 en 5). Deze patiënten tonen veelal een 'Symptom Magnification Syndrome' (SMS), gedefinieerd als een bewust of onbewust sociaal versterkt reactiepatroon, waarbij de aspecifieke klachten steeds meer toenemen, zich over een steeds groter deel van het lichaam uitbreiden en steeds meer het leven van de patiënt en de sociale omgeving domineren. De patienten van de SMS-groep vertoonden 4 of meer symptomen van het 'Symptom Magnification Syndrome' terwijl de patiênten van de controlegroep maximaal I symptoom vertoonden. Alle patiënten namen gedurende 3 weken deel aan een actieve behandeling. De SMS-groep had voor de behandeling een significant slechtere fysicke capaciteit dan de controle-groep. Bij de isometrische en dynamische krachtmetingen van de spieren die de heup en de rug strekken, was de verbetering in de SMS-groep kleiner dan in de controlegroep. De verrichte arbeid, de opgenomen zutrstof en de maximale hartslag op een fietsergometer waren eveneens significant lager in de SMS-groep. Deze waarden bleven gedurende de revalidatie in beide groepen onveranderd. De resultaten van deze studie rechtvaardigen de uitsluiting van patiẻnten met SMS van het RCT. 
Hoofdstuk 9 bediscussieert de belangrijkste resultaten van dit proefschrift. De predictieve tests hebben tot een betere selectie van patienten in ons revalidatiecentrum geleid. Door het uitsluiten van patienten met twee of meer positieve predictieve tests in het RCT werd de power van de studie duidelijk verbeterd. De meta-analyse hielp ons bij de keuze van de meting van het werkverzuim in het RCT. Eerdere studies hadden het werkverzuim op verschillende manieren gemeten en de meeste methoden hadden duidelijke nadelen of waren in Zwitserland niet praktisch. Aantallen werkdagen bleken een zeer geschikte meting van het ziekteverzuim te zijn. De resultaten van het RCT waren verrassend, ondat de meeste eerdere studies die de effectiviteit van twee behandelingen vergeleken, geen significante verschillen aantoonden. Het versehil in werkdagen tussen de actieve behandeling (FCT) en de pijngerichte behandeling (PCT) was onafhankelijk van nationaliteit. Het voordeel van FCT was bij patienten die zwaar werk uitvoeren slechts gering.

Een beperking van het onderzoek dat in dit proefschrift gepresenteerd wordt, is dat ondanks de effectiveit van FCT het probleem wan arbeidsongeschiktheid nog lang niet opgelost is. Vooral voor slecht opgeleide, oudere personen die zwaar werk verrichten kan de gezondheidszorg geen oplossingen bieden. Bovendien is de leeftijdsafhankelijke afname van de fysieke conditie geen ziekte. Mensen die dit werk niet meer kunnen uitvoeren, moeten lichter werk zoeken en daarbij meestal een duidelijke reductie in sallaris accepteren.

Het is belangrijk om in de toekomst verder te onderzoeken welke patiënten baat hebben bij de verschillende behandelingen. Daarnaast moet de gedragsgeoriënteerde behandeling in het kader van de fysiotherapie verder onderzocht en ontwikkeld worden. Persoonlijk twijfel ik eraan of het zinvol is om actieve behandelingen met passieve applicaties zoals warmtepakkingen te combineren. Dit zal eveneens onderzocht moeten worden. Heel belangrijk lijkt mij de verbetering van de organisatie van de gezondheidszorg, de samenwerking tussen de verschillende verzekeringen en een systeem dat terugkeer naar het werk financieel attractief maakt voor werknemers, werkgevers en verzekeraars. 
178 


\section{Zusammenfassung}

Meine Dissertation befasst sich mit der Relhabilitation von Pattenten die arbeitsunfăhig sind wegen nicht-akuten, unspezifischen Rückenschmerzen. Das primïre Behandlungsziel ist die Reduktion der Krankheitsabsenzen. Physiotherapeuten spielen eine zentrale Rolle in der Rehabilitation dieser Patienten.

Nur 15\% aller Rückenbeschwerden haben eine spezifische Ursache wie zum Beispiel eine Wirbelfraktur, eine Einengung des Wirbelkanals mit einer Einklemmung des Rückenmarks, starke Schäden durch Rheumatoide Arthritis oder ein Tumor. In solchen Fällen richtet sich die Behandung vor allem auf die Ursache der Beschwerden. Beil etwa $85 \%$ der Patienten sind die Rückenschmerzen unspezifisch, das heisst es kann keine spezifische Ursache gefunden werden. Die physiotherapeutische Untersuchung zeigt dort schmerzhafte, eingeschränkte Bewegungen und anatomische Strukturen, die bei der Palpation schmerzhaft sind. Die Entstehung von unspezifischen, lumbalen Rückenschmerzen ist weiterhin ungeklärt. 90\% aller Menschen haben während ihrem Leben mindestens einmal lumbale Rückenschmerzen. Rückenschmerzen sind also in diesem Sinne ,normal'. Manchmal ist die Ursache der Rückenschmerzen spezifisch, zum Beispiel, wenn plötzlich eine Diskushernie auf eine Nervenwurzel drückt, wobei der Rücken oft blockiert ist und die Schmerzen in das Bein ausstrahlen können. Die Spontanheilung ist bei diesem sogenannten „Hexenschuss" übrigens sehr gut und die meisten Patienten nehmen innerhalb einer Woche ihre üblichen Tätigkeiten wieder auf. In meiner Arbeit geht es um Patienten mit unspezifischen Rückenschmerzen, wobei die Schmerzen nicht von selbst vorbei gegangen sind.

Bei akuten Beschwerden hat der Schmerz eine Warnfunktion. In der Regel ist Gewebe beschädigt und die Zunahme der Schmerzen, bei Belastung, hat zum Zweck, weitere Schädigung zu verhindern. Im Laufe der Heilung nehmen die Schmerzen ab und der Patient nimmt in der Regel, ohne medizinische Behandlung, die gewohnten Tätigkeiten wieder auf. In seltenen Fällen bleiben die Schmerzen und werden chronisch. Der Umgang mit chronischen Schmerzen ist für den Betroffenen viel schwieriger, da er diese Schmerzen oft als Alarmsignal deutet und sie darum vermeidet. Auch die Behandlung durch den Arzt und den Physiotherapeuten hat in der Regel das Ziel, die Schmerzen zu vermindern. Diese Vorgehensweise stimmt jedocls nicht mit den internationalen Leitlinien für die Behandlung überein, die seit mehr als 20 Jahre empfehlen, unabhängig von den Schmerzen, möglichst normal zu bewegen.

Das Kapitel 1 beschreibt die wichtigsten Stationen meiner Laufbahn und erklärt den Anlass der Studien, die in den folgenden Kapiteln beschrieben werden. Nacls meiner Ausbildung zum Physiotherapeuten, die ich in 1980 beendete, arbeitete ich seit $1984 \mathrm{im}$ Rehabilitationszentrum ,Klinik Valens" in der Schweiz. Ich las wissenschaftliche 
Publikationen, aber meine Kenntnisse waren unzureichend, um Studien mit einer guten und solche mit einer schlechten Qualität von einander zu unterscheiden.

Im Dezember 1991 hörte ich, dass in Maastricht im Jahre 1992 eine 2-jährige, wissenschaftliche Ausbildung für diplomierte Physiotherapeuten starten würde. Das war ein wichtiger Meilenstein in meine Laufbahn. Von 1992 bis 1994 wohnte ich mit meiner Fanilie in Geulle und studierte in Maastricht. Nach meiner Rückkehr nach Valens, beschäftigte ich mich mit der Rehabilitation von Patienten mit unspezifischen lumbalen Ruckenschmerzen. Das Ziel der Rehabilitation veränderte sich: An die Stelle von Schmerzreduktion trat immer mehr die Zunahme der Aktivität des Patienten. Bei manchen Patienten kam es im Rahmen der aktiveren Behandlung zu einer Schmerzzunahme. In solchen Situationen vertraten Arzte und Physiotherapeuten oft zwei gegensätzliche Meinungen. Die eine Meinung lautete: Die Belastung war zu stark und hat Strukturen gereizt. Diese müssen geschont und zuerst behandelt werden, zum Beispiel mit passiven, manuellen Techniken. Diese Ansicht hatte eine Reduktion der Aktivitat zur Folge. Die andere Meinung war, dass der Rücken nur durch die Aktivität wieder seine Funktion verbessern könne. Insbesondere dann, wenn der Patient chronische, unspezifische und generalisierte Symptome hatte, waren wir der Uberzeugung dass aktive Therapie indiziert war. Wir verwendeten Waddell's Test zur systematischen Beobachtung der Reaktionen eines Patienten während der Untersuchung. Uns fiel ausserdem auf, dass viele Patienten zwei aktive Tests, welche den Rücken kaum belasteten, vorzeitig beendeten und, dass sie oft über starke Schmerzen klagten. Wir untersuchten den prädiktiven Wert dieser 4 Tests für die Arbeitsfathigkeit in einer Studie, die in Kapitel 2 beschrieben wird. Anschliessend wollten wir untersuchen, ob ein Unterschied zwischen der Effektivität einer funktionsorientierten (function-centered treatment, FCT) und einer schmerzorientierten Behandlung (pain-centered treatment, PCT) besteht. Die Resultate dieser Studie werden in Kapitel 4 und 5 beschrieben. Im Rahmen der Vorbereitungen zu diesem Untersuch, vertieften wir uns in bisherige Studien zu diesem Thema. Diese Literaturstudie wird in Kapitel 3 beschrieben. Parallel zur Effektivitatsstudie fuhrten wir diverse Studien durch, die in Kapitel 6,7 und 8 beschrieben werden.

Das Kapitel 2 beschreibt eine Kohortenstudie mit 99 Patienten, die wegen lumbalen Ruckenschmerzen arbeitunfahig waren. Wir untersuchten bei diesen Patienten, wer nach einem Jahr wieder arbeitete und welche der von der Rehabilitation erfassten Daten eine Vorhersage auf die Arbeitsrilickkehr nach einem Jahr machten. Dabei interessierte uns insbesondere, ob die Rückkehr zur Arbeit mit folgenden 4 Tests zusammenhing: Einem positiven Waddell-Test, eine Schmerzintensität von 9 oder 10 auf einer Skala von 0 bis 10 und der Vorzeitige Abbruch von 2 aktiven Tests. Beim Stufentest muss der Patient während dreier Minuten eine 30 Zentimeter hohe Kiste hinauf- und hinuntersteigen. Beim Pseudo-Armkraft-Test liegt der Patient auf dem Rücken und hält mit gestreckten Armen in jede Hand ein Gewicht von 3 Kilogrammen. Diese zwei Tests sind nicht 
belastend für Arme und Rücken. Im Weiteren untersuchten wir den Zusammenhang zwischen der Rückkehr zur Arbeit, die medizinischen Faktoren wie die Dauer der Beschwerden und mït persönlichen Faktoren wie Alter, Ausbildung; Nationalität and die maximale während der Arbeit gehobene Last. Nur 20\% der Patienten nahmen nach einem Jahr die Arbeit wieder auf. Die Ruckkehr zur Arbeit konnte nicht zuverlassig worhergesagt werden, aber $45 \%$ der Patienten, die nicht wieder arbeiteten, hatten ein positives Ergebnis bei zwei der 4 untersuchten Tests. Ein geringerer Vorhersagewert hatten Arbeitslosigkeit, Nationalität und die Schwere der Arbeit. Der Einsatz der 4 untersuchten Tests zur Patientenselektion verbessert die Kosteneffektivitä der Rehabilitation. Die Tests sind im Gegensatz zur Nationalitä objektiv und nicht diskriminierend. In der Effektivitätsstudie, die in Kapitel 4 und 5 beschrieben wird, haben wir Patienten mit 2 oder mehr positive Tests ausgeschlossen. Das hat die Beweiskraft oder den Power der Studie verbessert.

Die Meta-analyse in Kapitel 3 untersucht, ob Bewegungstherapie bei Patienten mit lumballen Rückenschmerzen einen Einfluss auf die Anzahl Krankentage hat. Eine Metaanalyse ist eine Literaturstudie, die bisherige Studien zusammenfasst. Das ist sinnwoll, da vergleichbare Studien manchmal zu unterschiedlichen Schlussfolgerungen kommen und weil Interessierte lieber eine Meta-analyse, als 20 Studien lesen. Meta-analysen werden auch zur Herstellung von Leitlinien verwendet. Wir verwendeten für die Metaanalyse nur randomisierte, kontrollierte Studien (randomized controlled trial, RCT). In 5 Datenbanken fanden wir 14 RCT. Die methodologische Qualität betrug 4 bis 8 Punkte auf einer 8-Punkte Skala. Bei 12 der 14 RCT wurde die Qualităt mit 5 oder mehr Punkten als ,gut' beurteilt. In einem nächsten Schritt beschrieben wir Studien mit zwei unterschiedliche Behandlungskontraste: 1) 13 Vergleiche zwischen Bewegungstherapie und ,Usual Care", die übliche Behandlung durch den Hausarzt, der in der Regel vor allem Medikamente verschreibt, und 2) 9 Vergleiche zwischen 2 oder 3 Methoden von Bewegungstherapie. Das Ergebnis war positiv. Bewegungstherapie reduziert die Krankheitsabsenzen während dem ersten Jahr nach der Behandlung, in Vergleich zu Usual Care. Der Effekt in Studien mit einer besseren methodologischen Qualitat ist grösser. Es konnte kein Unterschied zwischen den verschiedenen Methoden von Bewegungstherapie festgestellt werden, aber die Anzahl der untersuchten Patienten war zu klein, um relevante. Unterschiede nachzuweisen. Es gab auch zu wenige Daten, um den Einfluss auf die Anzahl Invalidenrenten zu untersuchen. Als letzten Schritt bestimmten wir die Grösse vom Effekt mit standardisierten Effektstärken (ES). Der Behandlungseffekt auf die Anzahl der Krankheitstage, bis ein Jahr mach der Bewegungstherapie, war klein (ES -0.24). Bei Patienten mit stärkeren Beschwerden, war die Behandlung effektiver (ES -0.30). Bewegungstherapie reduziert bei Patienten mit lumbalen Rückenschmerzen die Anzahl Krankentage, was eine wichtige Erkenntnis für die Physiotherapie ist. 
Kapitel 4 und 5 beschreiben eine randomisierte, kontrollierte Studie (RCT) mit Patienten zwischen 20 und 55 Jahre; die vor der Rehabilitation wegen lumbalen Rulckensehmerzen wenigstens 6 Wochen arbeitsunfahig waren. Die Studie untersucht, walirend einem Jahr, die Anzahl geleisteter Arbeitstage nach einer aktiven oder schmerzorientierten Behandlung (function-centered treatment, FCT, und pain-centered treatment, PCT). Von der Teilnahme an der Studie wurden Patienten mit einer schlechten Prognose fur eine Rückkehr zur Arbeit ( 2 oder mehr positive prädiktive Tests, siehe Kapitel 2) und Patienten mit ungenügenden Deutsch- oder Italienischkenntnissen ausgeschlossen. Zwischen Januar 2000 und Mail 2003 behandelten wir 174 Patienten. Mehr als die Hälfte von ihnen stammte aus dem Ausland. Wir erfassten Daten über die Arbeit, die Beschwerden, die Erwartungen und die Zufriedenheit der Klienten mittels Fragebögen in der jeweiligen Muttersprache (Deutsch, Serbokroatisch, Albanisch, Türkisch, Italienisch, Spanisch, Portugiesisch oder Französisch). Eine Physiotherapeutin, die nicht im Rehabilitationszentrum arbeitete und nicht wusste, welche Behandlung die Patienten erhielten, untersuchte die Patienten vor und nach der Behandlung und führte alle Messungen durch. Eine ebenfalls verblindete Sekretärin erfasste bei Patienten, Hausärzten und Arbeitgebern mit über 1000 Fragebögen die Ergebnisse nach Ablauf dreier Monate und nach einem Jahr.

Die aktive Behandlung (FCT: 4 Std/Tag, 6 Tage/Woche, 3 Wochen) umfasste ein arbeitsspezifisches Training in simulierten Arbeitssituationen, ein Krafttraining an Trainingsgeräten und ein Schwimmtraining mit Flossen, um die Ausdauer zu verbessern. Während dem FCT war die Rückkehr zur Arbeit das zentrale Ziel. Den Patienten wurde erklärt, dass ihr Rücken keine ernsthaften Schäden aufwiese. Die Beschwerden wurden durch eine Abnahme der Funktionsfähigkeit in Zusammenhang mit der Schonung erklärt. Deshalb lautete das primäre Ziel der Behandlung, aktiver zu werden, auch wenn die Schmerzintensität anfänglich stärker widrde. Die Patienten sollten die Schmerzen nicht als drohende Schä́digung interpretieren. Die Rolle der Therapeuten war eher mit der Rolle eines Coaches zu vergleichen.

Die schmerzorientierte Behandlung (PCT: 2 1/2 Std.Tag, 6 Tage/Woche, 3 Wochen) umfasste eine Mini-Rückenschule und individuell ausgewählte, aktive und passive Obungen zur Verbesserung der Beweglichkeit, der Kraft und der Entspannung. Die Reduktion der Schmerzen war das primäre Ziel in der PCT-Gruppe, um schlussendlich eine Rückkehr zur Arbeit zu erreichen. Die Beschwerden wurden durch die Ergebnisse der klinischen und bildgebenden Untersuchungen wie: Abniitzung der Wirbelsäule, Einschränkungen der Beweglichkeit und schmerzhafte Muskelverhärtungen erklärt. Dem Patienten wurde empfohlen, bei einer Zunahme der Schmerzen, die Intensität einer Übung zu reduzieren und Aktivitäten, welche die Schmerzen auslösen, zu vermeiden.

Wahrend der Studie verlief nicht alles wunschgemäss. Manche Patienten in der FCTGruppe klagten iber eine Zunahme der Schmerzen. Eine Patientin der FCT-Gruppe 
insistierte darauf, Wärmepackungen zu bekommen, was genăss dem Studienprotokoll in diese Gruppe nicht erlaubt war. Bei einem anderen Patienten der FCT-Gruppe wurde während der Rehabilitation eine Huftkopfnekrose diagnostiziert und der Patient wurde zur chirurgischen Behandlung in ein Spital verlegt. In Obereinstimmung mit dem ,Intention-to-treat" Prinzip wurden beide Patienten in die Analyse aufgenommen. Die Zufriedenheit der Behandlung war in den beiden Gruppen vergleichbar, was ein Hinweis darauf war, dass die Patienten in beide Behandlungen gleich viel Vertrauen hatten und dass ein möglicherweise von dem Untersucher erwarteten Behandlungsvorteil nicht von den Patienten bemerkt worden ist. Die FCT-Gruppe hatte nach der Behandlung mehr Vertrauen in die eigene körperliche Fähigkeiten, konnte schwerere Lasten heben und tragen, hatte mehr Kraft in den Bauch- und Rückenmuskeln und weniger Schmerzen. Letzteres war erstaunlich, da in der FCT. Gruppe weniger Rücksicht auf Schmerzen genommen worden ist. Nach einem Jahr war die Anzahl Arbeitstagen in der FCT-Gruppe mit 118 signifikant höher als in der PCTGruppe mit 74 Tagen. Die Effektstärke war 0.35. In beiden Gruppen nahmen die Schmerzen nach der Behandlung wieder etwas zu und der Unterscheid war nach 3 Monaten nicht mehr signifikant. Die Anzahl arbeitsloser Patienten und die Anzahl Patienten, die nach einem Jahr eine Invalidenrente erhielten, waren etwas grösser in der PCT-Gruppe, aber dieser Unterschied war nicht signifikant. Der Effekt der aktiven Behandlung war bei jüngeren Patienten und bei Patienten, die während der Arbeit Gewichte bis 10 Kilogramm heben mussten, grösser. Die Anzahl Arbeitstage war bei arbeitslosen Patienten in beiden Gruppen geringer. Bei arbeitslosen Patienten war der Unterschied zwischen den zwei Behandlungen gleich gross wie bei Patienten mit einer Stelle. Auch die Nationalität hatte einen Einfluss auf die Anzahll Arbeitstage, wobei der Vorteil der aktiven Behandlung FCT für alle Nationalitäten gleich gross war.

Mit einer Regressionsanalyse untersuchten wir, welche Faktoren einen Einfluss aul die Anzahl Arbeitstage hatten. Wir analysierten demographische-, physische-, psychischeund arbeitsbezogene Faktoren. 39\% der Varianz in Arbeitstagen konnte durch das maximale Gewicht das getragen wurde, das Schmerzverhalten walhrend der Untersuchung, die Schmerzintensität, die Arbeitslosigkeit, die Nationalitat, die Erwartung des Patienten ob eine Rückkehr zur Arbeit möglich sei, und durch das maximale Gewicht, das bei der Arbeit gehoben werden muss, erklärt werden. Um die Studie zu wollenden, ist eine Kosteneffektivitätsanalyse drei Jahre nach der Behandlung geplant. Bei den Kosten werden die Sozialleistungen, fur Arbeitslose und Invalide, eine bedeutende Rolle spielen.

Kapitel 6 präsentiert die Resultate einer Studie über die Beurteilung der „Konsistenz" der verschiedenen Testresultate im Rahmen einer Evaluation der Funktionellen Leistungsfähigkeit (EFL). Ein EFL erfasst die arbeitsbezogene, körperliche Leistungsfähigkeit eines Klienten. Ein EFL beurteilt in 23 verschiedene Tests unter anderem das Heben, Tragen, Bücken, Treppensteügen und die Arbeit über Kopf. Im 
RCT, das in Kapitel 4 und 5 beschrieben wurde, benützten wir 5 EFL-Hebetests. Ein EFL wird won der Invalidenversicherung benutzt, um die Höhe einer Invalidenrente zu bestimnuen. Bei der Beurteilung der körperliehen Leistungsfahigkeit ist es wichtig, dass die Resultate der einzeinen EFL-Tests logisch zusammenpassen, damit der EFL-Berieht in sich konsistent ist. Die Konsistenz der EFL-Resultate wird mit 13 Items iberprüf. Bei mehr als 3 Inkonsistenzen wird angenommen, dass der Klient nicht die maximale Leistung zeigte. Inkonsistente Resultate eines EFL können dazu fuhren, dass die Invaliditat als geringer beurteilt wird und dass der Klient demzufolge eine geringere Invalidenrente erhält: Manchmal fechten Klienten die Entscheidung über den Invaliditätsgrad vor Gericht an. Der EFL-Bericht und die Beurterlung der Konsistenz der "Testresultate werden dann als Beweismaterial verwendet. Deshalb ist es wichtig, die Validităt der 13 Items zur Beurteillung der Konsistenz zu untersuchen. Wir untersuchten retrospektiv 56 EFL-Berichte und bestimmten die interne Konsistenz der 13 Items mit Cronbach's Alpha. Ein Wert über 0.6 wurde alls genulgend betrachtet. Wir untersuchten atich, ob die Skala uberflussige Items enthielt, was sich in einem schlechten Zusammenhang mit dem Totalskore äussern würde (Item-Total Korrelation < 0.2 ). Bei 32 von 56 EFL's waren die Resultate inkonsistent. Die Anzahl der Inkonsistenzen betrug durchschnittlich 3/13, Drei der 13. Items waren überflüssig. Cronbach's Alpha betrug 0.71 bei der 13-Item-Skala und 0.74 bei der 10-Item-Skala. Die Ergebnisse dieser Studie unterstützen die Validität der Beurteilung der Konsistenz der EFLTestresultate, ihre Verwendung bei der Bestimmung vom Invaliditätsgrad und ihre Bentitzung als Beweismaterial während Gerichtsverhandlungen.

Im Kapitel 7 wird untersucht welchen Einfluss die Resultate des EFL auf die vom Arzt attestierte Arbeitsfahigkeit (AF) haben. In der Effektivitätsstudie (Kapitel 4 und 5) bestimmte der Anzt nach der Rehabilitation die AF der Patienten. In der FCT-Gruppe verfugte der Arat uber die Resultate des EFL (EFL+). In der PCT-Gruppe war dies nicht der Fall (EFL-). Wir beurteilten die Qualität der AF-Atteste mit einer 4-Punkte-Skala und ewaluierten die Übereinstimmung zwischen den 3 Beurteilern mit dem Korrelationkoeffizient innerhalb der Klassen (intra-class correlation coefficient, ICC). Anschliessend verglichen wir die Einschränkung der Arbeitsfähigkeit in Bezug auf die Anzahl Stunden pro Tag und in Bezug auf die Arbeitsbelastung in den beiden Gruppen. Die Ubereinstimmung zwischen den Beurteilern war befriedigend, die ICC's lagen zwischen 0.77 und 0.92. Die Qualitäl der AF-Atteste war signifikant besser in der EFL+ Gruppe, wo der Arzt uber die Resultate der Hebetests informient worden ist. Die maximale Arbeitsbelastung war signifikant höher in der EFL+ Gruppe und die zeitliche Einschäänkung der $\mathrm{AF}^{*}$ war tiefer, wobei der letztgenannte Unterschied nicht signifikant war $(\mathrm{p}=0.07)$. Information bezunglich der Resultate der EFL-Hebetests verbessert die Qualität des AF-Attests und die AF ist höher.

Kapitel 8 vergleicht den Effekt einer aktiven Rehabilitation bei 2 Gruppen von 10 Patienten mit unspezifischen, chronischen lumbalen Rückensclumerzen. Patienten, die 
sich unfähig zeigten, ein gewisses Mass an Aktivităt zu entwickeln und 2 aktive Tests vorzeitig abbrachen, wurden von der Effektivitätsstudie, die in Kapitel 4 and 5 besprochen worden ist, ausgeschlossen. Diese Patienten zeigten vielfach ein "Symptom Magnification Syndrome' (SMS), das als ein bewusstes oder unbewusstes, sozial verstärktes Reaktionsmuster definiert wird, wobei die Schmenzen sich über ein immer grösseres Gebiet ausbreiten, und die Beschwerden zunehmend das Leben vom Patienten und von seiner sozialen Umgebung dominieren. Die 10 Patienten der SMS-Gruppe hatten 4 oder mehr SMS-Symptome, wahrend die 10 Patienten der Kontrollgruppe maximal 1 Symptom hatten. Alle Patienten wurden während dreier Wochen aktiv behandelt. Die SMS-Gruppe hatte vor der Behandlung eine signifikant schlechtere körperliche Leistungsfähigkeit als die Kontrollgruppe. Die Verbesserung der isometrischen und dynamischen Kraft der Rücken- und Huftextensoren war in der SMSGruppe geringer als in der Kontrollgruppe. Die Arbeitsleistung, die aufgenommene Sauerstoffmenge und die maximale Harzfrequenz, gemessen auf einem Fahrradergometer, waren in der SMS-Gruppe ebenfalls signifikant tiefer. Die SMSGruppe verbesserte sich nicht und der Unterschied mit der Kontrollgruppe wurde wälarend der Rehabilitation grösser. Die Resultate dieser Studie unterstützten den Ausschluss von Patienten mit SMS von der randomisierten kontrollierten Effektivitätsstudie.

Das Kapitel 9 diskutiert die wichtigsten Resultate dieser Dissertation. Die pradiktiven Tests haben die Auswahl von Patienten für die Rehabilitation in unsere Klinik verbessert. Der Ausschluss von Patienten mit positiven prädiktiven Tests verbesserte die Power und die Effizienz der Effektivitätsstudie. Die Meta-analyse erleichterte die Wahl der Methode zur Messung der Arbeitsabsenzen im RCT. Frühere Studien hatten unterschiedliche Methoden verwendet und die meisten Methoden hatten offensichtliche Nachteile oder waren in der Schweiz nicht anwendbar. Die Anzahl Arbeitstage war eine praktikable Messung. Die Ergebnisse des RCT waren erstaunlich, da die meisten bisherigen Studien, wellche zwei Behandlungen verglichen, keinen Unterscheid im Effekt nachweisen konnten. Der Effekt der aktiven Behandlung (FCT) in Bezug auf die Arbeitstage war unabhängig von der Nationalität und grösser bei Patienten mit einer leichteren Arbeit.

Die präsentierten Forschungsresultate bei Patienten mit unspezifischen chronischen lumbalen Rückenbeschwerden zeigen gewisse Einschtänkungen. Trotz der Effektivitüt der aktiven Behandlung ist das Problem der Arbeitsunfähigkeit bei weitem nicht gelöst. Insbesondere den schlechter ausgebildeten, älteren Patienten mit einer schweren Arbeut kann das Gesundheitssystem nach wie vor keine Lösung anbieten. Hinzu kommt, dass die altersbedingte Abnahme der körperlichen Leistungsfähigkeit keine Krankheit darstellt. Menschen, die ihre schwere Arbeit nicht mehr ausführen können, müssen eine leichtere Arbeit suchen und dabei eine deutliche Reduktion thres Einkommens akzeptieren. 
Es ist wichtig in den nächsten Jahren weiter zu untersuchen, bei welchen Patienten die verschiedenen Behandlungen effektiv sind. Im Weiteren muss die verhaltensorientierte Physiotherapic weiter untersucht und entwickelt werden. Ich bezweifle, ob es sinnvoll ist, aktive Behandhrigen mit passiven Massnahmen, wie Wärmepackungen, zu kombinteren. Diese Frage wird ebenfalls untersucht werden müssen. Folgende Verbesserungen schenen mir für die Arbeitsruckkehr der Patienten mit unspezifischen, chronischen lumbalen Rickenschmerzen sehr wichtig: Die Optimierung der Organisation im Gesundheitswesen, eine bessere Zusammenarbeit zwischen den verschiedenen involvierten Versicherungen und der Aufbau eines Systems, das die Wiederaufnahme der Arbeit fur die Patienten, die Arbeitgeber und die Versichenungen finanziell attraktiver macht. 


\section{Dankwoord Danke Thank you Dankwoord Danke Thank you}

Bij het schrijven van een dankwoord wordt duidelijk dat onderzoek teamwerk is. Dat moet met nadruk gezegd worden! Een eerste vereiste voor het schrijven van een proefschrift is een stabiele thuisbasis. Daarom wil ik op de eerste plaats mijn vrouw Eveline en de kinderen Sander, Nicoline en Leon bedanken voor het fijne gezinsleven ' $\mathrm{S}$ avonds, in het weekend en in de vakanties. Dat is een grote steun!

Prof. Rob de Bie, eerste promotor, jij hebt de grootste stempel op mijn ontwikkeling als onderzoeker gedrukt. Toen ik plotseling de gelegenheid had om een gerandomiseetrde gecontroleerde studie (RCT) te starten, was je meteen bereid om me te begeleiden. Tijdens jouw werkbezoek in Valens hebben we de belangrijkste aspecten van het geplande RCT besproken waarbij je je snel vertrouwd makte met de situatie in cen Zwitsers revalidatiecentrum, hoog in de bergen, waar patienten met vragenlijsten in 7 talen onderzocht zouden worden. $\mathrm{lk}$ heb ook veel. van jou kumnen leren toen we samen een boek schreven voor Thieme en verder naturulijk tijdens werkbezoeken in Maastricht en bij het gemeenschappelijk lesgeven in Zürich.

Prof. Piet van den Brandt, tweede promotor, jij hebt door kritische vragen meerdere keren mijn aandacht op belangrijke aspecten van het onderzoek gericht. Bijvoorbeeld toen je me vroeg wat voor diagnose de patiënten in mijn onderzoek precies hadden. Deze vraag was voor mij de aanleiding om de literaturur over diagnostiek bij aspecifieke lage rugklachten aandachtig te bestuderen. Toch kan ik jouw vraag helaas nog steeds niet definitief beantwoorden.

Erwin Janssen, je was de aanleiding tot de eerste mijlpaal van mijn onderzoekersloopbaan. Tyjdens een feestje maakte je me enthousiast voor de tweejarige studie in Maastricht.

Urs Gamper, du hast mich nach meiner Rickkehr aus Maastricht gefordert. Gemeinsam konnten wir nachweisen dass die von dir entwickelten Bally-Valens-NeurorehabSchuhe das Gangbild bei Patienten mit einer Hemiplegie verbesserten. Vielen Dank für das Vertrauen dass du mir entgegengebracht hast. Ich hoffe dass wir in Zukunft weitere gemeinsame Projekte vollenden können.

Lieber Peter, mein erster Paranymf, du bist mein wichtigster Berufspartner der letzten 8 Jahre. Wir teilen ein Büro, und haben dennoch zu wenig Zeit für einander. Immer wieder müssen wir Zeit suchen zusammen über Publikationen nachzudenken. Du hast die Physiotherapie und die arbeitsbezogene Rehabilitation bei Patienten mit unspezifischen Rückenschmerzen in Valens und in der Schweiz weiterentwickelt. Der zweite Meilenstein meiner Lautbahn war deine Diskussion mit Dr. Otto Knilsel. Sie initiierte die Forschung bei Patienten mit unspezifischen lumbalen Rückenschmerzen. 
Gemeinsam erhielten wir zwei Forschungspreise: in 1999 wom Deutschen Physiotherapieverband $Z$ VK und in 2005 vom Schweizerischen Physiotherapieverband.

Lieber Oto, du hast mir den dritten und grossten Meilenstein meiner Laufbahn in der Klinischen Forschung quasi in den Weg gelegt. Ich konnte den ,Stein', die randomisierte Kontrollierte Studie, nicht ausweichen und er hat mir 5 Jahre harte Arbeit beschert. Du hast mir den Auftrag gegeben mit Peter Oesch und Stefan Bachmann für das geplante RCI ein Subventionsgesuch zu schreiben das honoriert wurde.

Lieber Stefan, mein zweiter Paranymf, wir haben zusammen an die meisten Publikationen gearbeitet. Vor allem aber hast du von ärztlicher Seite das gelingen des Projektes gesichert. Du hast dafür gesorgt dass die Rekrutierung der Patienten durch die Abteillungsärzte klappte und dass sich diese am Studienprotokoll hielten. Und das ist nícht einfach denn insgesamt waren während der Studie etwa 25 Abteilungsärzte involviert.

Diese Studie wäre nicht möglich gewesen ohne die Mitarbeit vieler anderen ,Valenser'. Engagierte Physio- und Ergotherapeuten, Aerzte, Sozialarbeiter und Psychologen behandelten die Patienten im Rahmen der Studie. Mirella Russo kam während 2 1/2 Jahren zweimal pro Woche nach Valens und untersuchte die Patienten. Bruno Lori und Kevin Looser pflegten den PC und retteten verloren geglaubte Daten. Patrizia Bigger und Monika Juon schrieben über 1000 Briefe für die Nachkontrolle der behandelten Patienten. Hartelijk bedanken wil ik ook de Maastrichtse studentes Judith Dierkes, Judith Kramer en Caroline van der Wijk die hier met veel enthousiasme hun Mastersthesis geschreven hebben. Jullie hebben het onderzoek ondersteund en ik kon ook van jullie leren!

Bob Wilkinson and Ariane Knuisel, thank you very much for the corrections of my English texts! It was so valuable to know that I could always rely on your help. Conny de Zwart, je was steeds rustig en opgewekt en een grote ondersteuning bij de metaanalyse. Dat jij de lay-out van het proefschrift verzorgde heeft mij gedurende de eindsprint enorm ontlast.

Ik wil mijn vader en moeder bedanken voor de ondersteuning die ze mij altijd gegeven hebben, ook toen ik in 1976 na het VWO geen zin had om naar de universiteit te gaan. Ik kon me niet voorstellen me zo veel in studieboeken te verdiepen en koos daarom voor fysiotherapie. Jullie hebben ons ook ondersteund toen ik van deze beslissing terugkwam. We hebben samen woonruimte gezocht en van 1992 tot 1.994 woonden we in Geulle bij Maastricht.

Het spijt me voor vader dat ik pas 'op hogere leeftijd' met mijn promotieonderzoek ben begonnen. Hij heeft weliswar het begin nog meegemaakt maar is in 2003 overleden. Hij kan er tijdens mijn promotie dus helaas niet bij zijn. Lieve moeder, had jij ooit gedacht dat jouw zoon, die aanvankelijk een analfabeet leek te zijn, later zo veel zou lezen en schrijven? Hartelijk bedankt voor de correcties van de nederlandse stukjes in dit boekje! 


\section{About the author}

Jan Pieter Kool was born on May $2^{\text {nd }} 1958$ in Geldrop, The Netherlands. He completed High School in 1976 in Eindhoven. The Netherlands. In 1979 he met Eveline in Swizerland and they married in 1987. He graduated, as a Physical Therapist in, 's Hertogenbosch in 1980. After fulfilling military duty as a physiotherapist, he went to Switzerland where he worked in two hospitals before he started working in Valens Rehabilitation Centre. His focus was on the rehabilitation of patients with neurological disorders and low back pain. Between 1992 and 1994 he lived in Geulle, The Netherlands, and studied Health Sciences in Maastricht, supported by a grant from the Valens Rehabilitation Centre. After returning to Switzerland, his work consisted of patient treatment and research (both 50\%). In 1999, he and Peter Oesch won the Research Award by the German Physiotherapy Association for their publication about the rehabilitation of patients with chronic low back pain. Based on this work, he and his colleagues from the Valens Rehabilitation Centre were supported by a grant from the Swiss Federal Office of Health to conduct a randomized controlled trial., starting in 2000. He is a member of the Swiss Working Group for Ergonomics and provides continuing education for physiotherapists in Fellbach (Germany), Meersburg (Germany) and Derendingen (Switzerland). He assists Rob de Bie teaching Research Methodology in Zürich for the Physiotherapy Sciences Program, and also teaches in Bolzano (Italy) and Landquart (Switzerland) at the Physiotherapy Academy. 